\title{
THE ROLE OF CATIONIC TRYPSINOGEN AND ITS MUTATIONS IN PANCREATITIS
}

\author{
Andrea Schnúr
}

Ph.D. Thesis

Supervisor at Boston University: Miklós Sahin-Tóth, M.D., Ph.D.

Supervisors at University of Szeged: Zoltán Rakonczay Jr., M.D., Ph.D., D.Sc.

Péter Hegyi, M.D., Ph.D., D.Sc

First Department of Medicine

University of Szeged

Szeged, Hungary

2013 


\section{TABLE OF CONTENTS}

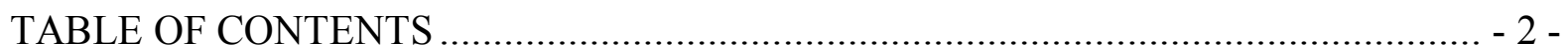

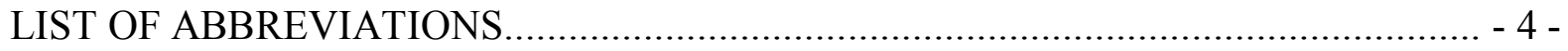

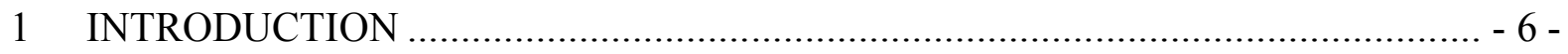

$1.1 \quad$ Chronic pancreatitis ..................................................................................... - 6 -

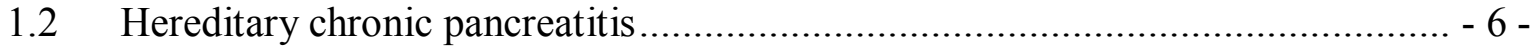

$1.3 \quad$ Human trypsinogens ............................................................................... - 7 -

$1.4 \quad$ Trypsin-central paradigm of pancreatitis .......................................................... - 8 -

$1.5 \quad$ Biochemical characterization of trypsinogens ................................................... - 9 -

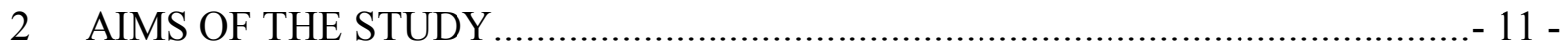

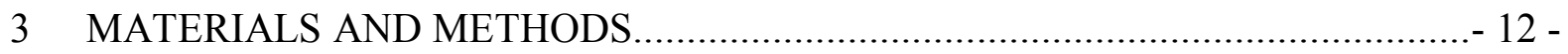

$3.1 \quad$ Nomenclature

3.2 Mutagenesis and construction of expression plasmids .......................................- 12 -

3.3 Recombinant expression and purification of human cationic trypsinogen.................. 14 -

3.3.1 Expression of human cationic trypsinogen …….........................................- 14 -

3.3.2 In vitro refolding of human cationic trypsinogen .......................................- 15 -

3.3.3 Purification of human cationic trypsinogen with ecotin affinity chromatography..- 15 -

3.4 Expression and purification of human chymotrypsin C.................................... 15 -

3.5 Active site titration of trypsin with ecotin....................................................... 16 -

3.6 Measurements of enzyme activities and kinetic parameters of trypsin ...............- 17 -

3.7 Trypsinogen autoactivation in the presence and absence of chymotrypsin C......- 17 -

3.8 Cell culture and transfection for secretion measurements .................................. 17 -

$3.9 \quad$ Trypsin activity measurement in the conditioned media .....................................- 18 -

3.10 Assay of trypsinogen content by SDS-PAGE and Western blot .......................... 18 - 
4 RESULTS $-19-$

4.1 Autoactivation of human cationic trypsinogen is $\mathrm{pH}$ dependent ..................... - 19 -

4.2 PRSS1 missense variants are exceedingly rare in the general population.......... - 21 -

4.3 Enzyme kinetic parameters of trypsin and autoactivation of trypsinogens ........ - 23 -

4.4 Autoactivation of wild-type and mutant trypsinogens in the presence of chymotrypsin $\mathrm{C}$ $-25-$

4.5 Degradation of wild type and mutant trypsinogens/trypsins by chymotrypsin C - 28 -

4.6 Secretion of PRSS1 variants from HEK 293T cells .................................. - 30 -

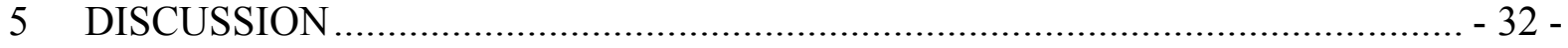

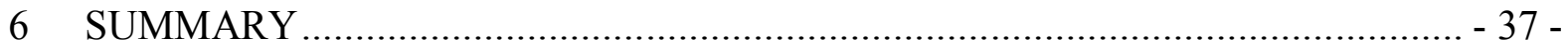

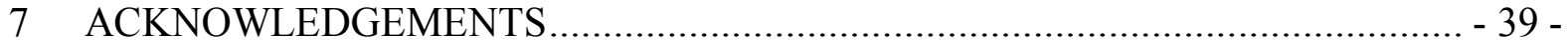

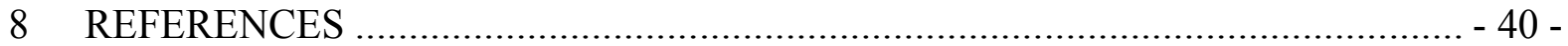




\section{LIST OF ABBREVIATIONS}

CF

CFTR

CP

CTRC

DMEM

EDTA

ER

FBS

HEK

HP

HRP

LB

$\mathrm{pH}_{\mathrm{L}}$

PAR

PBS

PCR

PRSS1

PRSS2

PRSS3

SDS

SDS-PAGE

SPINK1

TCA cystic fibrosis

cystic fibrosis transmembrane conductance regulator

chronic pancreatitis

human chymotrypsinogen $\mathrm{C}$

Dulbecco's modified Eagle's medium

ethylene diaminetetraacetic acid

Endoplasmic reticulum

fetal bovine serum

human embryonic kidney

hereditary pancreatitis

Horseradhish-peroxidase

Luria-Bertani

luminal $\mathrm{pH}$

protease activated receptor

phosphate buffer saline

polymerase chain reaction

protease serine 1 gene, human cationic trypsinogen

protease serine 2 gene, human anionic trypsinogen

protease serine 3 gene, human mesotrypsinogen

sodium dodecyl sulfate

sodium dodecyl sulfate polyacrylamide gel electrophoresis

serine protease inhibitor, Kazal type 1

trichloroacetic acid 


\section{Articles closely related to the subject of the thesis and cited in the thesis}

I. Schnúr A, Beer S, Witt H., Hegyi P., Sahin-Tóth M. Functional effects of 13 rare PRSS1 variants presumed to cause chronic pancreatitis. Gut 2013 Mar 1 (Epub ahead of print) $\mathbf{I F}_{\mathbf{2 0 1 3}}: \mathbf{1 0 . 1 1 1}$

II. Pallagi P, Venglovecz V, Rakonczay Z Jr, Borka K, Korompay A, Ozsvári B, Judák L, Sahin-Tóth M, Geisz A, Schnúr A, Maléth J, Takács T, Gray MA, Argent BE, Mayerle J, Lerch MM, Wittmann T, Hegyi P. Trypsin reduces pancreatic ductal bicarbonate secretion by inhibiting CFTR $\mathrm{Cl}^{-}$channels and luminal anion exchangers. Gastroenterology 2011; 141(6):2228-2239 IF $\mathbf{2 0 1 1}$ : 11.675

\section{Articles related to the subject of the thesis and cited in the thesis}

III.Farkas K, Yeruva S, Rakonczay Z Jr, Ludolph L, Molnár T, Nagy F, Szepes Z, Schnúr A, Wittmann T, Hubricht J, Riederer B, Venglovecz V, Lázár G, Király M, Zsembery Á, Varga G, Seidler U, Hegyi P. New therapeutic targets in ulcerative colitis: the importance of ion transporters in the human colon. Inflamm Bowel Dis 2011; 17(4):884-898. IF $_{\mathbf{2 0 1 1}}$ : $\mathbf{4 . 8 5 5}$

IV. Czepán M, Rakonczay Z Jr, Varró A, Steele I, Dimaline R, Lertkowit N, Lonovics J, Schnúr A, Biczó G, Geisz A, Lázár G, Simonka Z, Venglovecz V, Wittmann T, Hegyi P. NHE1 activity contributes to migration and is necessary for proliferation of human gastric myofibroblasts. Pflugers Arch 2012, 463(3):459-75. ). IF $_{2012}: 4.463$

Number of full publications:

Cumulative impact factor:
4 (1 first author)

31.104 


\section{INTRODUCTION}

\subsection{Chronic pancreatitis}

Chronic pancreatitis $(\mathrm{CP})$ is a long-term progressive inflammatory disease of the pancreas characterized by repeated attacks of abdominal pain and irreversible morphological changes which leads to the impairment of the exocrine as well as the endocrine component of the gland and eventually result in maldigestion and diabetes. Alcohol consumption and tobacco smoking are strongly associated with $\mathrm{CP}$ in Western countries, but other factors such as genetic variations, pancreatic duct obstruction, congenital malformations, hypertriglyceridemia, hypercalcemia, and autoimmunity also have been implicated $(1,2)$. In a minority of $\mathrm{CP}$ cases, no identifiable cause can be found and a diagnosis of idiopathic pancreatitis is made. Both basic and clinical scientists are actively investigating the pathogenic mechanisms of injury, to find new therapeutic targets to arrest this devastating illness. There is no definitive medical treatment for CP. Treatment options are limited to enzyme replacement therapy, pain relief and surgical interventions. These treatments are only capable to manage complications and provide pain relief.

\subsection{Hereditary chronic pancreatitis}

Hereditary pancreatitis (HP) is defined by the presence of a proteinase serine 1 gene PRSS1 mutation, encodes the cationic trypsinogen (genetic criterion) or by the presence of $\mathrm{CP}$ with a familial history of least two first-degree relatives or three or more second degree relatives, in two or more generations (genealogical and clinical criteria) (3). HP is an autosomal dominant disease with incomplete penetrance, characterized by early-onset recurrent attacks of acute pancreatitis and with frequent progression to CP. HP belongs to the inherited forms of pancreatitis and gives approximately $1 \%$ of all cases of pancreatitis.

The first description of a family with inherited pancreatitis in 1952 provided indication towards a possible genetic component in the etiology of CP (4). Decades later, three independent groups confirmed the co-segregation between the disease and the long arm chromosome 7 (7q35) using genetic linkage analysis (5-7). In the same year, a PRSS1 
mutation, namely c. $365 \mathrm{G}>$ A leading to a substitution of arginine by histidine in codon 122 (p.R122H), was identified as a cause of the disease (7). In the large majority of HP families, the causative PRSS1 mutation is either p.R122H ( 70\%) or p.N29I ( 20\%). Other less frequent PRSS1 mutations documented to cause pancreatitis with a family history include p.A16V, p.N29T, p.V39A, p.R116C and p.R122C (3,8-10). Interestingly, mutation p.A16V exhibits variable penetrance and was often found in sporadic cases as well $(11,12)$. Over the past decade, worldwide screening of PRSS1 broadened the mutational spectrum. More than 50 additional PRSS1 variants have been reported, the majority of which were found in patients with sporadic CP (for a complete list with references see www.pancreasgenetics.org) and often assigned by disease causing mutation despite the lack of phenotypic characterization. PRSS2 (13) andPRSS3 (14) do not contain genetic alterations that enhances the risk of CP, but a protective, loss-of-function variant in PRSS2 has been identified $(13,15)$.

\subsection{Human trypsinogens}

The pancreas is an enzyme factory. Almost all enzymes which act in the small intestine are synthetized by the pancreas. Trypsinogen is the most abundant proenzyme produced by the gland; it has a pivotal role in the digestive enzyme cascade, as it activates all zymogens to their active form. The human pancreas produces the digestive proenzyme, trypsinogen in three highly similar isoforms, encoded by the proteinase, serine - PRSS1, PRSS2 and PRSS3 genes. According to their electrophoretic mobility, the three trypsinogen isoforms commonly referred to as cationic- (PRSS1) anionic- (PRSS2) and mesotrypsinogen (PRSS3). Cationic trypsinogen makes up approximately two thirds of total trypsinogen amount in the pancreatic juice, while anionic trypsinogen represents one-third (16-18). Mesotrypsinogen is a minor species that accounts for 2 to $10 \%$ of human trypsinogens $(16,19)$. Trypsinogens are synthetized as prepro-enzymes containing a signal peptide of 15 amino-acids, followed by the 8 amino acid long propeptide, the trypsinogen activation peptide. The signal peptide is cleaved upon the entry in the endoplasmic reticulum (ER) and then the proenzymes (zymogens) are packaged into zymogen granules and are secreted into the pancreatic juice. In the small intestine the brush-border serine protease, enteropeptidase activates trypsinogen which then catalyzes the activation of all pancreatic proenzymes. 


\subsection{Trypsin-central paradigm of pancreatitis}

More than a hundred years ago, a German pathologist, Hans Chiari observed at autopsies that the pancreas "had succumbed to its own digestive properties" and coined the term, that pancreatitis is a disease of autodigestion (20). However, the molecular mechanism leading to self-digestion was unknown for a long time. Trypsin was assigned to play the key role in initiating the disease by triggering an activation cascade of the digestive zymogens in the pancreas. This pathogenic concept was supported by gain-of function mutations found in the cationic trypsinogen (10). Consistently, loss-of-function variants in serine protease inhibitor, Kazal type 1 (SPINK1) gene $(21,22)$, encoding a pancreatic trypsin inhibitor, and the trypsin-degrading enzyme chymotrypsin C (CTRC) (23) are strongly associated with idiopathic CP. On the other hand, a pathological increase in trypsin activity in the pancreas has been observed consistently in animal models of pancreatitis (24-27). How the prematurely activated trypsin could contribute to the pathogenesis of disease remains obscure.

Protective mechanisms evolved to curtail premature activation of zymogens. One of the defense mechanisms might be the hypersecretion of the bicarbonate-rich, alkaline pancreatic juice. It has been found that under certain circumstances, fluid secretion increases in the pancreas (28-30). Besides neutralizing the acidic chyme entering the duodenum from the stomach, pancreatic fluid is responsible for flushing out digestive enzymes down the ductal tree and thereby preventing their early activation. In humans, pancreatic secretions may contain up to $140 \mathrm{mM} \mathrm{NaHCO}$, which is secreted mainly via the apical $\mathrm{Cl}^{-} / \mathrm{HCO}_{3}{ }^{-}$ exchangers working in parallel with the cystic fibrosis transmembrane conductance regulator $\mathrm{Cl}^{-}$channel (CFTR) and partly via the calcium activated chloride channels $(31,32)$.

Notably, decreased pancreatic ductal fluid secretion as occurs in cystic fibrosis (CF), a genetic disease of CFTR, leads to impairment of the whole gland. Consistently, compromised ductal fluid secretion as a result of CFTR gene mutations (33-36) increases the risk of pancreatitis $(37,38)$. This hypothesis is further supported by the fact that secretin, a major mediator of pancreatic ductal fluid secretion, has been shown to have a beneficial effect on cerulein-induced acute pancreatitis (39). The pancreatic juice has an alkaline $\mathrm{pH}$, achieved by high concentration of bicarbonate secreted by the duct cells, that is considered 
important for the prevention of trypsin activation in the ductal space. It has been suggested that the fall of intraductal $\mathrm{pH}$ may increase the risk of developing pancreatitis $(38,40)$.

\subsection{Biochemical characterization of trypsinogens}

To elucidate the role of trypsin in the pathogenesis of pancreatitis and how trypsin mutations in cationic trypsinogen cause pancreatitis, comparative in vitro analysis of recombinantly expressed human trypsinogens has been performed. Pancreatic tissue and juice are not readily available in significant amounts from patients carrying PRSS1 mutations. In addition to limited availability, isolation of mutant trypsinogen from the complex protein mixture represents another technical challenge. Therefore, heterologous recombinant expression has been the method of choice to generate human wild-type and mutant trypsinogen proteins for biochemical analysis.

The mechanism of action of HP-associated mutations involves increased autoactivation of mutant trypsinogens resulting in elevated intrapancreatic trypsin activity levels (41). Recent studies uncovered that these PRSS1 mutations alter the regulation of activation and degradation of cationic trypsinogen by CTRC (42). The digestive enzyme CTRC stimulates trypsinogen activation by processing the activation peptide at the Phe18Asp19 peptide bond to a shorter form, which is easier cleaved by trypsin (43). Somewhat paradoxically, CTRC also promotes degradation of trypsinogen by cleaving the Leu81-Glu82 peptide bond in the calcium binding loop (44). This cleavage in combination with a trypsinmediated autolytic cleavage of the Arg122-Val123 peptide bond results in inactivation of trypsinogen during autoactivation and lower trypsin levels attained.

Pancreatitis-associated mutations render trypsinogen resistant to CTRC-dependent degradation and/or increase $\mathrm{N}$-terminal processing by CTRC and thereby elevate trypsin levels generated through autoactivation (42)

The unifying pathological mechanism described above does not seem to apply to some mutations that alter the number of cysteine residues in cationic trypsinogen. HPassociated mutation p.R116C was shown to induce protein misfolding with intracellular retention and degradation, which may represent an alternative disease-causing mechanism

unrelated to trypsinogen activation and trypsin activity (45). Variant p.C139S, which was reported in sporadic cases of $\mathrm{CP}$, exhibits similar properties (45). Mutation-dependent 
misfolding can elicit ER stress, which might be responsible for increased pancreatitis risk, although the mechanism remains unclear. 


\section{AIMS OF THE STUDY}

I. The secretion of the alkaline pancreatic juice is considered to prevent intraductal trypsin activation. Inhibition of fluid secretion, accompanied by a decrease in intraductal $\mathrm{pH}$, was proposed to increase the risk of developing $\mathrm{CP}$. Therefore, we investigated the effect of $\mathrm{pH}$ on the autoactivation of human cationic trypsinogen.

\section{Our specific aim was:}

- To investigate the autoactivation of human trypsinogen at different $p H$

II. Numerous rare PRSS1 mutations with unknown clinical significance were identified in subjects with idiopathic CP. Despite lack of evidence, some of these variants have been described as pancreatitis-associated. To clarify the possible pathogenic role of these mutations, our aim was to functionally characterize 13 published trypsinogen variants:

1. Our primary objective was to test whether these variants also exhibit increased activation in the presence of CTRC, as previously seen with disease-causing mutants in HP.

\section{Our specific aims were:}

- To examine the kinetic parameters of variants

- To investigate their autoactivation

- To determine the effect of the CTRC on their autoactivation

- To examine their degradation by CTRC

2. Mutation-induced changes in folding and secretion may be another disease relevant mechanism, therefore, our second objective was to assess whether mutation-induced misfolding is a more common phenotype of PRSSI variants than previously appreciated.

\section{Our specific aim was:}

- To assess cellular secretion of the mutants 


\section{MATERIALS AND METHODS}

\subsection{Nomenclature}

Nucleotide numbering reflects coding DNA numbering with +1 corresponding to the A of the ATG translation initiation codon in PRSS1. Amino acid residues are numbered starting with the initiator methionine of the primary translation product for human cationic trypsinogen. The abbreviations are in italics throughout the text when referring to genes encoding digestive zymogens.

\subsection{Mutagenesis and construction of expression plasmids}

The pTrapT7 intein-PRSS1, pcDNA3.1(-)-PRSS1and pcDNA3.1(-)-CTRC 10His expression plasmids harboring the human cationic trypsinogen gene and human chymotrypsin C gene, respectively, were constructed earlier in our laboratory $(43,44,46)$. Mutations were introduced by oligonucleotide-directed overlap-extension PCR mutagenesis using mutagenic primers listed in Table 1. Typically, the polymerase chain reaction (PCR) mixture contained $200 \mu \mathrm{M}$ dNTP, $2 \mu \mathrm{M}$ of each primer, DNA template, $0.05 \mathrm{U} / \mu \mathrm{L}$ Taq DNA polymerase (Qiagen) and in a total volume of $50 \mu \mathrm{L}$. 35 cycles of $30 \mathrm{sec}$ denaturation at 94 ${ }^{\circ} \mathrm{C}, 30 \mathrm{sec}$ annealing at $55^{\circ} \mathrm{C}$ and 1 min extension at $72{ }^{\circ} \mathrm{C}$ were performed. PCR products were analyzed by agarose gel electrophoresis and DNA sequencing.

\begin{tabular}{|c|c|}
\hline Name of the primer & Primer sequence \\
\hline \multicolumn{2}{|c|}{ For pTrapT7 constructs } \\
\hline p.P36R sense & 5'-GAA GAG AAT TCT GTT CGC TAC C-3' \\
\hline p.G83E sense & 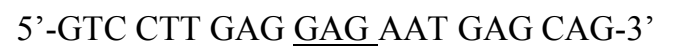 \\
\hline p.G83E antisense & 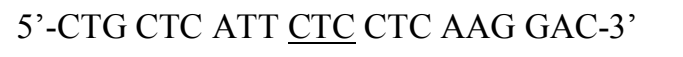 \\
\hline p.I88N sense & 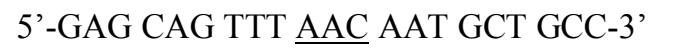 \\
\hline p.I88N antisense & 5'-GGC AGC ATT GTT AAA CTG CTC-3' \\
\hline p.K92N sense & 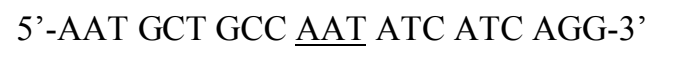 \\
\hline p.K92Nantisense & 5'-CCT GAT GAT ATT GGC AGC ATT-3' \\
\hline p.Q98K sense & 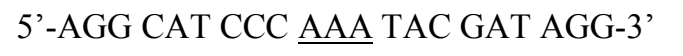 \\
\hline p.Q98K antisense & 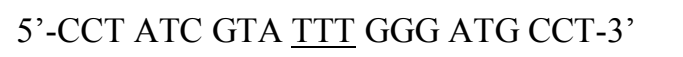 \\
\hline p.D100H sense & 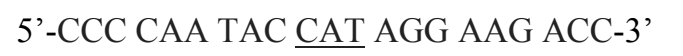 \\
\hline
\end{tabular}




\begin{tabular}{|c|c|}
\hline p.D100H antisense & 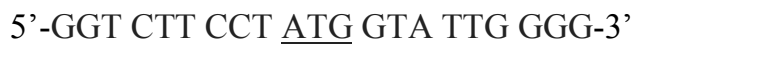 \\
\hline p.V123M sense & 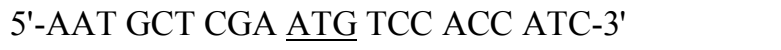 \\
\hline p.V123M antisense & 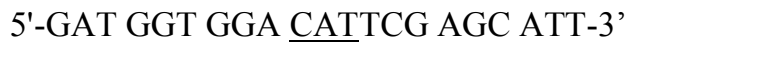 \\
\hline p.S124F & 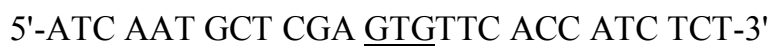 \\
\hline p.T137M sense & 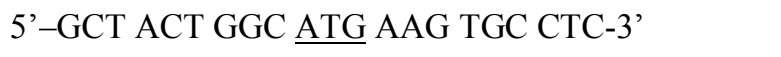 \\
\hline p.T137M antisense & 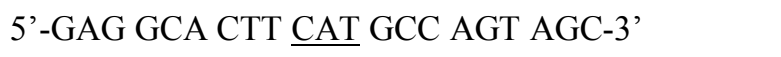 \\
\hline p.C139F sense & 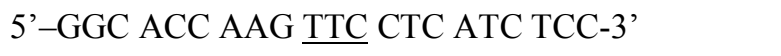 \\
\hline p.C139F antisense & 5'-GGA GAT GAG GAA CTT GGT GCC-3' \\
\hline p.K170E sense & 5'-AGC CAG GCT GAG TGT GAA GCC-3' \\
\hline p.K170E antisense & 5'-GGC TTC ACA CTC AGC CTG GCT-3' \\
\hline p.S181G sense & 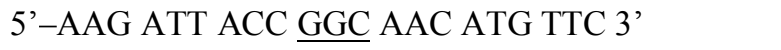 \\
\hline p.S181G antisense & 5'-GAA CAT GTT GCC GGT AAT CTT-3' \\
\hline p.G208A sense & 5'-GTC TGT AAT GCA CAG CTC CAA-3' \\
\hline p.G208A antisense & 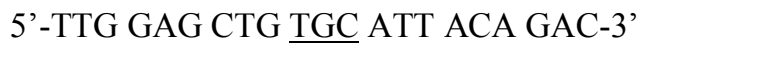 \\
\hline \multicolumn{2}{|c|}{ For pcDNA 3.1(-) constructs } \\
\hline p.P36R sense & 5'-AAT TCT GTC $\underline{\text { CGC TAC CAG GTG-3' }}$ \\
\hline p.P36R antisense & 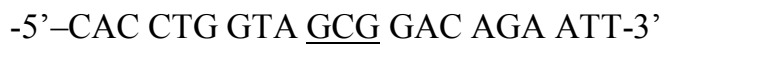 \\
\hline p.G83E & 5'-GTC CTG GAG GAG AAT GAG CAG-3' \\
\hline p.G83Eantisense & 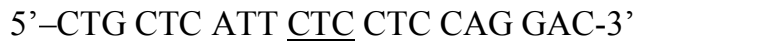 \\
\hline p.I88N sense & 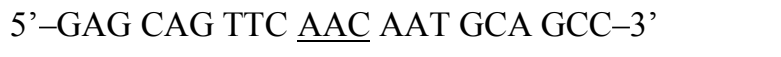 \\
\hline p.I88N antisense & 5'-GGC TGC ATT GTT GAA CTG CTC - 3' \\
\hline p.K92N & 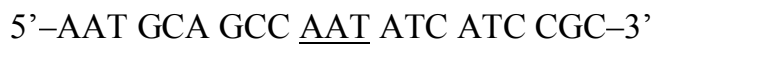 \\
\hline p.K92N antisense & 5'-GCG GAT GAT ATT GGC TGC ATT - 3' \\
\hline p.Q98K sense & 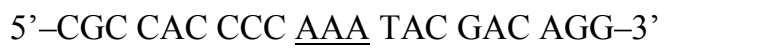 \\
\hline p.Q98K antisense & 5'-CCT GTC GTA TTT GGG GTG GCG - 3' \\
\hline p.D100H sense & 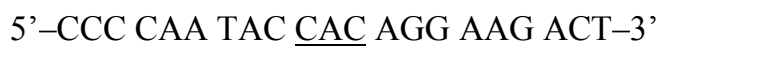 \\
\hline p.D100H antisense & 5'-AGT CTT CCT GTG GTA TTG GGG - 3' \\
\hline p.V123M sense & 5'-AAC GCC CGC ATG TCC ACC ATC-3' \\
\hline p.V123M antisense & 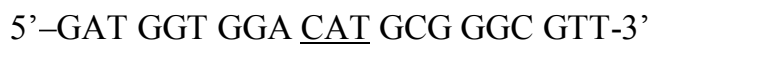 \\
\hline p.S124F sense & 5'-GCC CGC GTG TTC ACC ATC TCT-3' \\
\hline p.S124F antisense & $-5^{\prime}$-AGA GAT GGT GAA CAC GCG GGC-3' \\
\hline p.T137M sense & 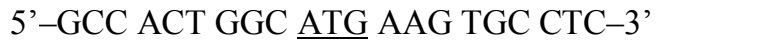 \\
\hline p.T137M antisense & 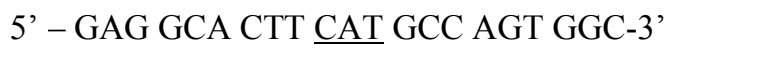 \\
\hline p.C139F sense & 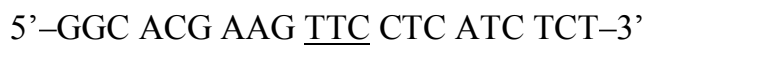 \\
\hline p.C139F antisense & 5'-AGA GAT GAG GAA CTT CGT GCC-3' \\
\hline p.K170E & Same as used for the $p$ TrapT7 construct \\
\hline
\end{tabular}



p.S181G sense

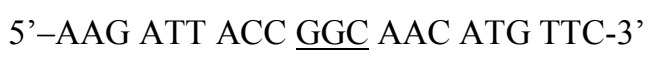
p.S181G antisense
5'-GAA CAT GTT GCC GGT AAT CTT-3'
p.G208A sense
5'-GTC TGC AAT GCA CAG CTC CAA-3'

Table 1. Primers for mutagenesis in the pTrapT7-intein-PRSS1 and pcDNA3.1(-)-PRSS1 constructs. The mutated codon is underlined. Two different primer sets were used for constructs in the pcDNA 3.1(-) and pTrapT7 expression plasmids as their DNA sequence was not identical. $p c D N A$ 3.1(-) constructs harbored the native cDNA sequence of human cationic trypsinogen, whereas in order to improve protein expression levels in E. coli, codons were optimalized in pTrapT7.

\subsection{Recombinant expression and purification of human cationic trypsinogen}

\subsubsection{Expression of human cationic trypsinogen}

Trypsinogen variants were cloned in fusion with a 154 amino acid long mini-intein. This construct was expressed in an aminopeptidase P deficient E. coli strain (LG-3) (46) as inclusion bodies. After spontaneous self-cleavage, the fusion protein gives rise to cationic trypsinogen with a homogeneous, authentic $\mathrm{N}$-terminal sequence.

Plasmids were transformed by electroporation using $0.2 \mathrm{~mm}$ electroporation cuvettes and an electroporator setting of $2.5 \mathrm{kV}$. Transformants were spread onto Luria-Bertani (LB) agar plates supplemented with $100 \mu \mathrm{g} / \mathrm{mL}$ ampicillin and $50 \mu \mathrm{g} / \mathrm{mL}$ kanamycin and incubated at $30^{\circ} \mathrm{C}$ overnight. Starter cultures were established by inoculating $10 \mathrm{~mL} \mathrm{LB}$ medium containing $100 \mu \mathrm{g} / \mathrm{mL}$ ampicillin and $50 \mu \mathrm{g} / \mathrm{mL}$ kanamycin with a streak of colonies and incubated at $30^{\circ} \mathrm{C}$ overnight with shaking. Starter cultures were then inoculated in $50 \mathrm{~mL}$ LB medium with $100 \mu \mathrm{g} / \mathrm{mL}$ ampicillin and $50 \mu \mathrm{g} / \mathrm{mL}$ kanamycin and grow until density reached an $\mathrm{OD}_{600} \mathrm{~nm}$ of 0.5 . At this point protein expression was induced by shifting the incubation temperature to $42{ }^{\circ} \mathrm{C}$ for 30 min which induced the expression of T7 RNA polymerase under the control of temperature-sensitive $\lambda$ repressor. Adding $1 \mathrm{mM}$ isopropyl-1thio- $\beta, \mathrm{D}$-galactopyranoside derepressed the lac operator which is positioned between the T7 promoter and the intein-trypsinogen fusion gene in the pTrapT7 plasmid. After induction, cultures were incubated for an additional 5 hours. Bacteria were harvested by centrifugation and inclusion bodies were isolated by sonication and centrifugation. 


\subsubsection{In vitro refolding of human cationic trypsinogen}

The inclusion body pellet was washed three times with $1 \mathrm{~mL}$ of $0.1 \mathrm{M}$ Tris- $\mathrm{HCl}(\mathrm{pH}$ 8.0) $5 \mathrm{mM}$ K-EDTA and resuspended in $500 \mu \mathrm{L}$ of $4 \mathrm{M}$ guanidine- $\mathrm{HCl} / 0.1 \mathrm{M}$ Tris- $\mathrm{HCl}, \mathrm{pH}$ 8.0., contained $30 \mathrm{mM}$ dithiothreitol and trypsinogen was solubilized at $37{ }^{\circ} \mathrm{C}$ for $30 \mathrm{~min}$. Insoluble material was removed by centrifugation and reduced trypsinogen was then diluted into $50 \mathrm{~mL}$ of refolding buffer $(0.9 \mathrm{M}$ guanidine- $\mathrm{HCl}, 0.1 \mathrm{M}$ Tris- $\mathrm{HCl}(\mathrm{pH} 8.0), 30 \mathrm{mM} \mathrm{L}-$ cysteine, $30 \mathrm{mM} \mathrm{L}$-cystine), slowly stirred under argon gas for $5 \mathrm{~min}$ at room temperature, and kept at $4{ }^{\circ} \mathrm{C}$ overnight before purification.

\subsubsection{Purification of human cationic trypsinogen with ecotin affinity chromatography}

Ecotin is a pan-serine inhibitor from $E$. coli which can bind the inactive zymogen forms of pancreatic serine proteases and this complex is stable at neutral $\mathrm{pH}$ (47). Purification of trypsinogens was carried out on a $2 \mathrm{~mL}$ ecotin column. The in vitro refolded trypsinogen solution was supplemented with $100 \mathrm{mM}$ Tris- $\mathrm{HCl}(\mathrm{pH} \mathrm{8.0)}$ and $200 \mathrm{mM} \mathrm{NaCl}$ to a final volume of $100 \mathrm{~mL}$ and the sample was loaded onto the ecotin column. After washing with $20 \mathrm{mM}$ Tris- $\mathrm{HCl}(\mathrm{pH} \mathrm{8.0)} / 0.2 \mathrm{M} \mathrm{NaCl}$, trypsinogen was eluted with $50 \mathrm{mM}$ $\mathrm{HCl}$. Protein concentration of eluted trypsinogen was calculated from the UV absorbance at $280 \mathrm{~nm}$ using the extinction coefficient $37,525 \mathrm{M}^{-1} \mathrm{~cm}^{-1}$.

\subsection{Expression and purification of human chymotrypsin C}

A deca-histidine (10His) affinity tag was engineered onto the $\mathrm{C}$ terminus of the human CTRC, and this construct was expressed in human embryonic kidney $293 \mathrm{~T}$ cells (HEK 293T). Cells were cultured in DMEM supplemented with $10 \%$ fetal bovine serum (FBS), $4 \mathrm{mM}$ glutamine, $1 \%$ penicillin in $75 \mathrm{~cm}^{2}$ flasks to $95 \%$ confluence. Transfections were carried out in a total volume of $20 \mathrm{~mL}$ DMEM using $75 \mu \mathrm{L}$ lipofectamine 2000 (Invitrogen) and $30 \mu \mathrm{g}$ plasmid harboring human CTRC-10His. After overnight incubation, cells were washed with OptiMEM and the transfection medium was replaced with $20 \mathrm{~mL}$ OptiMEM. The conditioned media were harvested after $48 \mathrm{~h}$ incubation replaced with another $20 \mathrm{~mL}$ OptiMEM and then collected again at $96 \mathrm{~h}$. Approximately $900 \mathrm{~mL}$ 
conditioned medium was used for purification. Ni-NTA Superflow Cartridge (Qiagen) equilibrated with NPI-20 buffer [50 mM NaH $2 \mathrm{PO}_{4}, 300 \mathrm{mMNaCl}, 20 \mathrm{mM}$ imidazole (pH 8.0)]. The medium was loaded onto the column at $4 \mathrm{~mL} / \mathrm{min}$ flow rate using a loading pump and the column was washed with NPI-20 buffer [50mM NaH $\mathrm{PO}_{4}, 300 \mathrm{mMNaCl}$, and 20 $\mathrm{mM}$ imidazole $(\mathrm{pH} \mathrm{8.0)]} \mathrm{until} \mathrm{the} \mathrm{absorbance} \mathrm{at} 280 \mathrm{~nm}$ returned to baseline. CTRC was eluted with NPI-250 buffer [50 $\mathrm{mM} \mathrm{NaH}_{2} \mathrm{PO}_{4}, 300 \mathrm{mMNaCl}, 250 \mathrm{mM}$ imidazole (pH 8.0)] at $2 \mathrm{~mL} / \mathrm{min}$ flow rate and $5 \mathrm{~mL}$ fractions were collected. Aliquots $(100 \mu \mathrm{L})$ of the fractions were analyzed by $15 \%$ SDS-PAGE and Coomassie blue staining and peak fractions were pooled and dialyzed for $24 \mathrm{~h}$ against two changes of 5 liters of $50 \mathrm{mM} \mathrm{NaH} 2 \mathrm{PO}_{4}(\mathrm{pH} 8.0)$ buffer containing $300 \mathrm{mM} \mathrm{NaCl}$. The dialyzed CTRC proenzyme solution was concentrated using a Vivaspin concentrator (10 kDa molecular weight cut off).

Purified CTRC zymogen was activated with $20 \mathrm{nM}$ human cationic trypsin in 100 $\mathrm{mM}$ Tris- $\mathrm{HCl}\left(\mathrm{pH} 8.0\right.$ ) and $1 \mathrm{mM} \mathrm{CaCl}_{2}$ (final concentrations) for $30 \mathrm{~min}$ at $37{ }^{\circ} \mathrm{C}$. Concentration of active CTRC was determined using active site titration with ecotin (48).

\subsection{Active site titration of trypsin with ecotin}

The concentration of trypsin for enzyme kinetic measurements was determined by active-site titration against ecotin. The concentration of the ecotin batch, which served as a universal titrant for all studies, was determined previously using titration against active sitetitrated bovine trypsin (42). Trypsin at $25 \mathrm{nM}$ estimated concentration (calculated from the ultraviolet absorbance at $280 \mathrm{~nm}$, using the theoretical extinction coefficient $37,525 \mathrm{M}^{-1} \mathrm{~cm}^{-1}$ ) was added to $0-100 \mathrm{nM}$ ecotin (two-fold serial dilution in $0.1 \mathrm{M}$ Tris- $\mathrm{HCl}(\mathrm{pH} \mathrm{8.0)}$ with 1 $\mathrm{mM} \mathrm{CaCl} 2$ ) in a total volume of $100 \mu \mathrm{L}$. After 1 hour incubation at room temperature free trypsin activity was measured as described below. Titrations were performed using protease concentrations at least 2 orders of magnitude above the $K_{D}$ values. Substrate was given in a $5 \mu \mathrm{L}$ volume so as not to perturb the equilibrium. The measured trypsin activity values were plotted as a function of the total inhibitor concentration. The equivalence point was determined by extrapolation of the linear portion of the curve to the $\mathrm{x}$ axis. This represents the inhibitor concentration equal to the trypsin concentration. 


\subsection{Measurements of enzyme activities and kinetic parameters of trypsin}

Trypsin activity was measured by adding $150 \mu \mathrm{L} 200 \mu \mathrm{M}$ N-CBZ-Gly-Pro-Arg-pnitroanilide substrate and following the release of the yellow p-nitroaniline at $405 \mathrm{~nm}$ in a SpectraMax plus384 microplate reader (Molecular Devices,Sunnyvale, CA) for 1 min. Reaction rates were calculated from fits to the initial linear portions of the curves. The trypsin substrate was dissolved in $0.1 \mathrm{M}$ Tris- $\mathrm{HCl}(\mathrm{pH} 8.0), 1 \mathrm{mM} \mathrm{CaCl}_{2}$ and $0.05 \%$ Tween20. To obtain kinetic parameters, activity measurements were performed at varying substrate concentrations $(0-180 \mu \mathrm{M})$ and initial rates were plotted as a function of substrate concentration. Kinetic parameters $\left(\mathrm{V}_{\max }, \mathrm{K}_{\mathrm{M}}\right)$ were determined from hyperbolic fits to the Michaelis-Menten equation.

\subsection{Trypsinogen autoactivation in the presence and absence of chymotrypsin C}

Trypsinogen at $1 \mu \mathrm{M}$ concentration was incubated with or without $5 \mathrm{nM}$ human CTRC and with $10 \mathrm{nM}$ cationic trypsin in $0.1 \mathrm{M}$ Tris- $\mathrm{HCl}(\mathrm{pH} 8.0), 1 \mathrm{mM} \mathrm{CaCl}_{2}$ and $0.05 \%$ Tween-20 (final concentrations) at $37^{\circ} \mathrm{C}$. At given times, $2 \mu \mathrm{L}$ aliquots were withdrawn and mixed with $48 \mu \mathrm{L}$ assay buffer containing $0.1 \mathrm{M}$ Tris- $\mathrm{HCl}(\mathrm{pH} 8.0), 1 \mathrm{mM} \mathrm{CaCl}_{2}$, and $0.05 \%$ Tween-20. Trypsin activity was measured as described above.

For autoactivation experiments at varying $\mathrm{pH}$ ranging from 6 to 8.5, a polybuffer system (100 mM MES, $100 \mathrm{mM}$ HEPES and $100 \mathrm{mM}$ Tris) was used. The $\mathrm{pH}$ of the polybuffer was adjusted to given values with $\mathrm{HCl}(\mathrm{pH} 6.0$ and 6.5) or $\mathrm{NaOH}(\mathrm{pH}$ 7.0, 7.5, 8.0 and 8.5). Reactions also contained $1 \mathrm{mM}$ or $0.1 \mathrm{mM} \mathrm{CaCl}_{2}$ and $100 \mathrm{mM} \mathrm{NaCl}$, as indicated.

\subsection{Cell culture and transfection for secretion measurements}

HEK 293 T cells were cultured in DMEM supplemented with $10 \%$ fetal bovine serum, $4 \mathrm{mM}$ glutamine and $1 \%$ penicillin/streptomycin solution in a $37{ }^{\circ} \mathrm{C}, 5 \% \mathrm{CO}_{2}$ humidified incubator. A day before transfection approximately $1.5 \times 10^{6}$ cells were seeded in a six-well tissue culture plate. Transfections were carried out using $1 \mu \mathrm{g}$ pcDNA3.1(-) plasmid harboring the wild-type or mutant trypsinogen gene and $2.5 \mu \mathrm{L}$ Lipofectamine 2000 in $2 \mathrm{~mL}$ DMEM according to the manufacturer's protocol. After overnight incubation cells were 
washed and the transfection medium was replaced with $2 \mathrm{~mL}$ OptiMEM containing $1 \mathrm{mM}$ benzamidine to inhibit autoactivation of secreted trypsinogen. After 24 hours from the media replacement, conditioned media were harvested for activity measurement and western blot analysis.

\subsection{Trypsin activity measurement in the conditioned media}

Aliquots $(50 \mu \mathrm{L})$ of conditioned media were supplemented with $5 \mu \mathrm{L} 1 \mathrm{M}$ Tris-HCl (pH:8.0) and $1 \mu \mathrm{L} 0.5 \mathrm{M} \mathrm{CaCl}_{2}$ and trypsinogens were activated by adding $1 \mu \mathrm{L} 1.4 \mu \mathrm{g} / \mathrm{mL}$ human enteropeptidase (R\&D Systems, Minneapolis, MN). After incubation for $1 \mathrm{~h}$ at $37^{\circ} \mathrm{C}$, $50 \mu \mathrm{L}$ aliquot was removed and mixed with $150 \mu \mathrm{L} 200 \mu \mathrm{M}$ N-CBZ-Gly-Pro-Arg-pnitroanilide substrate. Trypsin activity was determined as described above.

\subsection{Assay of trypsinogen content by SDS-PAGE and Western blot}

Five $\mu \mathrm{L}$ conditioned media were mixed with $20 \mu \mathrm{L}$ Laemmli sample buffer containing $100 \mathrm{mM}$ dithiothreitol, heat-denatured at $95{ }^{\circ} \mathrm{C}$ for $5 \mathrm{~min}$ and run on a $15 \%$ SDSpolyacrylamide gel. Proteins were transferred onto an Immobilon-P (Milliore Corporation, Bedford, MA, USA) membrane at $300 \mathrm{~mA}$ for 1.5 hours. The membrane was blocked with $5 \%$ milk powder in phosphate buffer saline (PBS) supplemented with $0.1 \%$ Tween-20 at $4{ }^{\circ} \mathrm{C}$ overnight. Trypsinogen was detected with a sheep polyclonal antibody (R\&D Systems, \#AF3848) used at a dilution of 1:5000 followed by Horseradhish-peroxidase (HRP)conjugated donkey polyclonal anti-sheep IgG (R\&D Systems, \#HAF016) used at 1:2000 dilution. HRP was detected using the SuperSignal West Pico Chemiluminescent Substrate (Thermo Scientific). Incubations with primary and secondary antibodies were performed at room temperature for 1 hour.

Quantitation of bands was carried out with Image Lab 3.0 software (Bio-Rad). Rectangles were drawn around each band of interest, and an identical rectangle was used in each lane for background subtraction. 


\section{RESULTS}

\subsection{Autoactivation of human cationic trypsinogen is $\mathrm{pH}$ dependent}

Etiologic factors of pancreatitis, such as bile acids $(49,50)$ or smoking $(51,52)$, can inhibit pancreatic ductal bicarbonate secretion, which leads to the acidification of the intraductal space and slows down the washout of the digestive zymogens.

To assess the effect of a decrease in intraductal $\mathrm{pH}$ on trypsinogen autoactivation, we examined the autoactivation of human cationic trypsinogen in vitro at $\mathrm{pH}$ values ranging from 6.0 to 8.5. The rate at which cationic trypsinogen autoactivates was increased when the $\mathrm{pH}$ was reduced from 8.5 to 7.0 (Figure.1A ) in the presence of $1 \mathrm{mM} \mathrm{CaCl}_{2}$ and in the absence of $\mathrm{NaCl}$. However, decreasing the $\mathrm{pH}$ from 7.0 to 6.0 had a slight effect only (Figure.1A).

To exclude that the differences observed in autoactivation were due to the different ionic strength of the buffers used, we performed the experiments in the presence of higher concentration of sodium (100mM NaCl, Figure.1B) or lower concentration of calcium $(0.1$ $\mathrm{mM} \mathrm{CaCl}_{2}$, Figure. 1C). Although the overall autoactivation rates were much slower in the presence of $100 \mathrm{mM} \mathrm{NaCl}$, the $\mathrm{pH}$ profile of autoactivation was essentially identical to that observed in the absence of added salt (Figure.1A). The $\mathrm{pH}$ dependent changes in the autoactivation of trypsinogen were still detectable when the experiments were performed using a low calcium buffer (Figure.1C). 


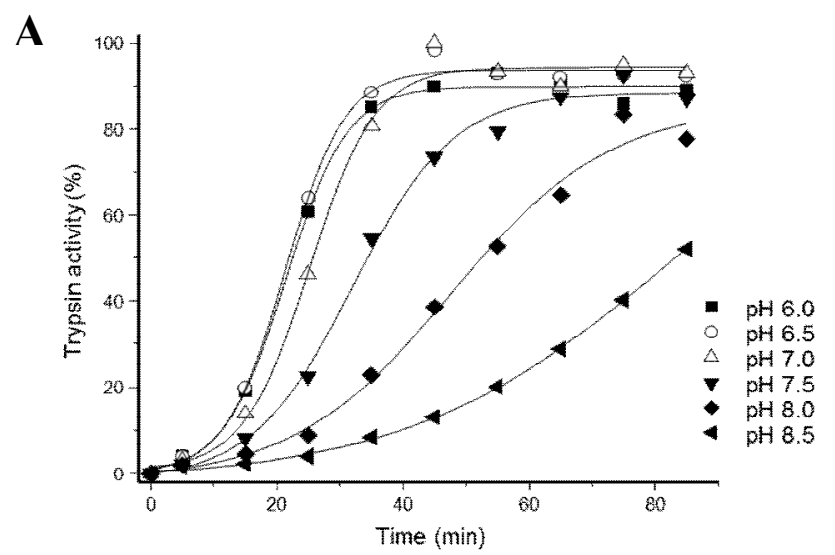

\section{$\mathbf{B}$}

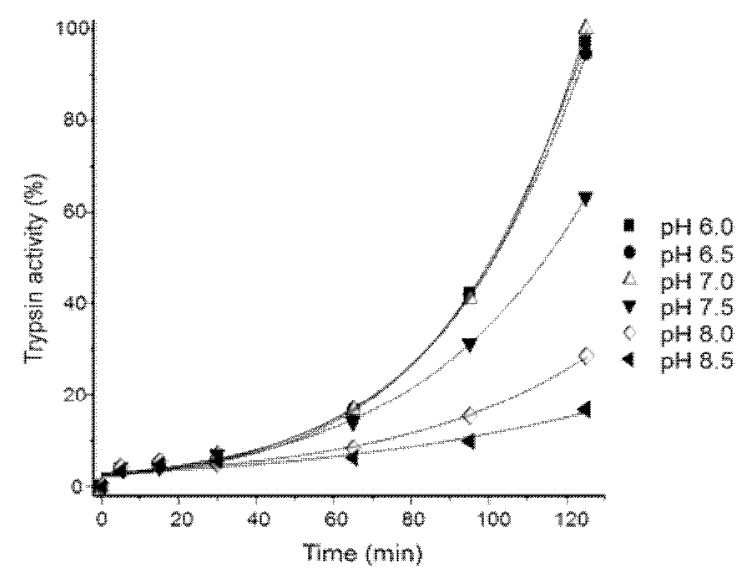

C

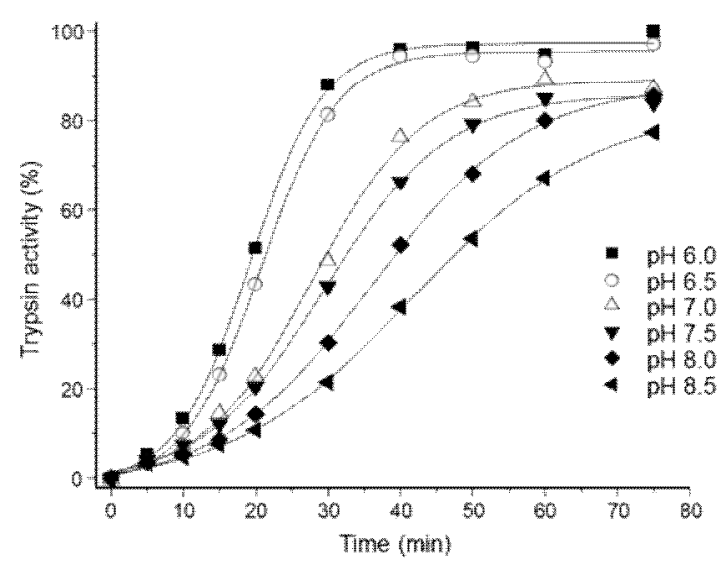

Figure 1. Autoactivation of human cationic trypsinogen at $\mathrm{pH}$ values ranging from 6.0 to 8.5 . A) Trypsinogen at $2 \mu \mathrm{M}$ concentration was incubated with $40 \mathrm{nM}$ trypsin at $37{ }^{\circ} \mathrm{C}$ in $0.1 \mathrm{M}$ Tris+HEPES+MES buffer mixture containing $1 \mathrm{mM} \mathrm{CaCl}_{2}$ in $100 \mu \mathrm{L}$ final volume. B) The same protocol was used in high $\mathrm{NaCl}$ buffer solution (the above described buffer was supplemented with $100 \mathrm{mM} \mathrm{NaCl}$ ). C) The same protocol was used in low $\left(0.1 \mathrm{mM} \mathrm{CaCl}_{2}\right) \mathrm{Ca}^{2+}$ solution. 


\subsection{PRSS1 missense variants are exceedingly rare in the general population}

We surveyed the functional properties of 13 rare PRSS1 missense mutations found in patients with sporadic CP. The 13 PRSS1 variants were found in patients with idiopathic CP without family history (Table 2). The variants were detected in the heterozygous state, with the exception of p.G208A, which was also identified in a homozygous individual. As indicated, the variants were found only in one to three cases each, therefore, the genetic information was insufficient to determine whether these variants are pathogenic or neutral. Note that variants p.T137M and p.G208A were from subjects of Asian origin, whereas all other variants were from subjects of European origin.

To get an estimate of the prevalence of missense PRSS1 variants in healthy individuals, we sequenced exon-3 of the PRSS1 gene in 1000 German subjects without any pancreatic disease. Exon-3 was selected because most of the studied variants ( 9 of 13) were found in this region. With the exception of a novel c.367G $>$ T (p.V123L) variant found in one subject, no other alterations were identified.

We consulted the NHLBI Exome Sequencing ProjectExome Variant Server (http://evs.gs.washington.edu) which lists aggregate exome-sequencing data for approximately 4300 European-American and 2200 African-American individuals. We found PRSS1 variants p.V123M and p.T137M in one European-American subject each and variant p.S181G in one African-American subject. However, interpretation of these findings is difficult, because the database also lists the disease-causing mutation p.R122C found in two European-American individuals, suggesting that the studied cohort may have contained pancreatitis patients. We also surveyed published sequencing data, which showing the absence of these 13 PRSS1 variants in 200 French (53), 82 German (54), 420 Chinese $(55,56)$ and 28 Korean (57) control subject. 


\begin{tabular}{|c|c|c|c|c|c|}
\hline Region & $\begin{array}{c}\text { Nucleotide } \\
\text { change }\end{array}$ & $\begin{array}{c}\text { Amino acid } \\
\text { change }\end{array}$ & $\begin{array}{l}\text { Carriers } \\
\text { reported } \\
\end{array}$ & $\begin{array}{c}\text { Clinical and genetic } \\
\text { information }\end{array}$ & Citations \\
\hline Exon 2 & c. $107 \mathrm{C}>\mathrm{G}$ & p.P36R & 2 & French $\mathrm{m}$ and fm, ICP & (53)\# \\
\hline \multirow[t]{12}{*}{ Exon 3} & c. $248 \mathrm{G}>\mathrm{A}$ & p.G83E & 1 & Italian, ICP & $(53) \#$ \\
\hline & c. $263 \mathrm{~T}>\mathrm{A}$ & p.I88N & 1 & $\begin{array}{l}18 \text { y white fm, CP } \\
\text { no SPINK1 or CFTR mut }\end{array}$ & $(58)$ \\
\hline & c. $276 \mathrm{G}>\mathrm{T}$ & p.K92N & 1 & Italian, ICP & (53)\# \\
\hline & c. $292 \mathrm{C}>\mathrm{A}$ & p.Q98K & 1 & $\begin{array}{l}55 \text { y French m, CP } \\
\text { no } S P I N K 1, C T R C \text { or } \\
C F T R \text { mut }\end{array}$ & $(9)^{*}$ \\
\hline & c. $298 \mathrm{G}>\mathrm{C}$ & p.D100H & 1 & German m, ICP & $(59)$ \\
\hline & c. $367 \mathrm{G}>\mathrm{A}$ & p.V123M & 1 & French fm, ICP & $(53) \#$ \\
\hline & c. $371 \mathrm{C}>\mathrm{T}$ & p.S124F & 1 & $\begin{array}{l}46 \text { y German fm, ICP } \\
\text { no } S P I N K 1, C T R C \text { or } \\
C F T R \text { mut }\end{array}$ & $(60)$ \\
\hline & c. $410 \mathrm{C}>\mathrm{T}$ & p.T137M & 3 & $\begin{array}{l}13 \text { y Asian fm, AP } \\
\text { no SPINK1 or CFTRmut }\end{array}$ & $(55)$ \\
\hline & & & & $\begin{array}{l}\text { Chinese, late onset ICP } \\
\text { no SPINKI mut }\end{array}$ & $(55)$ \\
\hline & & & & $\begin{array}{l}28 \text { y Chinese, pancreatic } \\
\text { cancer }\end{array}$ & $(56)$ \\
\hline & c. $416 \mathrm{G}>\mathrm{T}$ & p.C139F & 2 & $\begin{array}{l}14 \text { y German m, RAP } \\
\text { unaffected mother carrier }\end{array}$ & $(54)$ \\
\hline & & & & $\begin{array}{l}8 \text { y fm, CP with chronic pai } \\
\text { no SPINK } 1 \text { or } C F T R \text { mut }\end{array}$ & $(61)$ \\
\hline \multirow[t]{2}{*}{ Exon 4} & c. $508 \mathrm{~A}>\mathrm{G}$ & p.K170E & 1 & $\begin{array}{l}30 \text { y Indian m, CP } \\
\text { no } S P I N K 1, C T R C \text { or } \\
C F T R \text { mut }\end{array}$ & $(9)^{*}$ \\
\hline & c. $541 \mathrm{~A}>\mathrm{G}$ & p.S181G & 1 & $\begin{array}{l}6 \text { y Italian m, RAP } \\
\text { p.F508del CFTR } \\
\text { unaffected mother carrier }\end{array}$ & $(62)$ \\
\hline \multirow[t]{3}{*}{ Exon 5} & c. $623 \mathrm{G}>\mathrm{C}$ & p.G208A & 3 & $\begin{array}{l}12 \text { y Asian m, pancreatitis, hm } \\
\text { p.F508del and p.Q1352H } \\
\text { CFTR }\end{array}$ & $(58)$ \\
\hline & & & & $\begin{array}{l}\text { Korean child, RAP } \\
\text { no SPINK1 mut }\end{array}$ & $(57)$ \\
\hline & & & & 7 y Korean, necrotizing AP & $(57)$ \\
\hline
\end{tabular}

Table 2. Rare PRSS1 variants in pancreatitis. AP, acute pancreatitis, $\mathrm{CP}$, chronic pancreatitis; ICP, idiopathic chronic pancreatitis, RAP, recurrent acute pancreatitis; m, male; fm, female; hm, homozygous, y, year, mut, mutation. Unless indicated otherwise, mutations are heterozygous. The age indicates the time of diagnosis. *Vinciane Rebours, personal communication. \#Jian-Min Chen, personal communication. 


\subsection{Enzyme kinetic parameters of trypsin and autoactivation of trypsinogens}

First, trypsinogen variants were characterized for catalytic activity and their ability to autoactivate in the absence of CTRC. We measured catalytic activity of the activated trypsin variants with the synthetic peptide substrate $N$-CBZ-Gly-Pro-Arg-p-nitroanilide. Enzyme kinetic parameters of trypsin variants were comparable to those of wild-type cationic trypsin (Table 3). This finding is in accordance with previous observations that natural PRSS1 variants almost never affect catalytic function of trypsin.

Note that mutant p.C139F could not be purified in sufficient quantities due to misfolding, therefore it was not tested in the autoactivation and catalytic activity assays.

\begin{tabular}{cccc}
\hline & $k_{\text {cat }}\left(\mathrm{s}^{-1}\right)$ & $\mathrm{K}_{\mathrm{M}}(\mu \mathrm{M})$ & $k_{\text {cat }} / \mathrm{K}_{\mathrm{M}}\left(\mathrm{s}^{-1} \cdot \mathrm{M}^{-1}\right)$ \\
\hline wild type & 95.3 & 17.6 & 5.4 \\
p.P36R & 86.6 & 19.1 & 4.5 \\
p.G83E & 92.8 & 14.7 & 6.3 \\
p.I88N & 80.8 & 16.2 & 5.0 \\
p.K92N & 99.7 & 16.9 & 5.9 \\
p.Q98K & 95.4 & 16.3 & 5.8 \\
p.D100H & 77.6 & 15.8 & 4.9 \\
p.V123M & 90.9 & 17.4 & 5.2 \\
p.S124F & 91.6 & 16.1 & 5.7 \\
p.T137M & 102.3 & 17.1 & 6.0 \\
p.K170E & 107.8 & 14.4 & 7.5 \\
p.S181G & 103.7 & 18.4 & 5.6 \\
p.G208A & 89.7 & 17.5 & 5.1
\end{tabular}

Table 3. Kinetic parameters of wild-type and mutant human cationic trypsin on the synthetic substrate $N$ CBZ-Gly-Pro-Arg-p-nitroanilide, measured in $0.1 \mathrm{M}$ Tris- $\mathrm{HCl}$ (pH 8.0), $1 \mathrm{mM} \mathrm{CaCl}_{2}$ and $0.05 \%$ Tween 20 , at $22{ }^{\circ} \mathrm{C}$. 
A

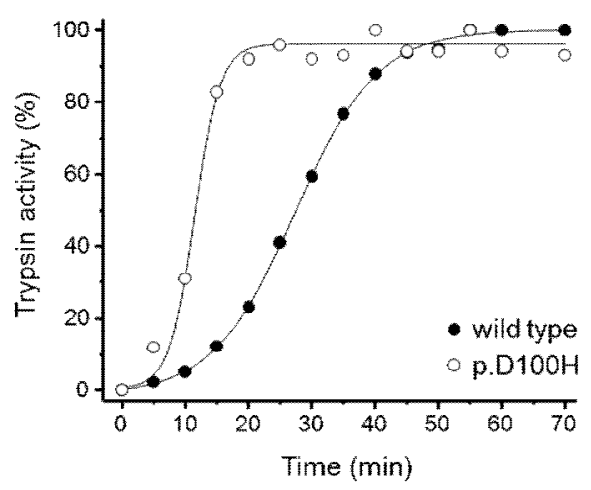

C

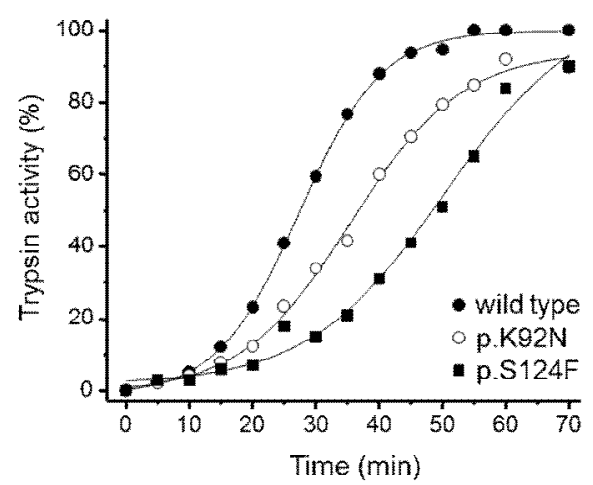

B

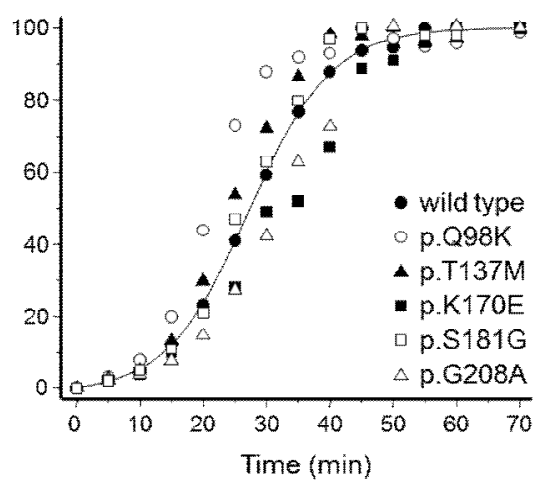

D

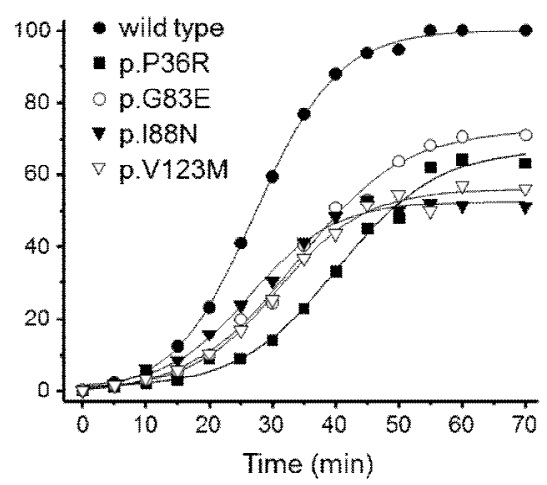

Figure 2. Autoactivation of cationic trypsinogen variants in the absence of chymotrypsin $\mathrm{C}$. Trypsinogen was incubated at $1 \mu \mathrm{M}$ concentration with $10 \mathrm{nM}$ initial trypsin in $0.1 \mathrm{M}$ Tris- $\mathrm{HCl}(\mathrm{pH} 8.0), 1 \mathrm{mM} \mathrm{CaCl}_{2}$ and $0.05 \%$ Tween-20 (final concentrations) at $37^{\circ} \mathrm{C}$. At the indicated times, $2 \mu \mathrm{L}$ aliquots were removed and trypsin activity was measured as described in Materials and Methods. Trypsin activity was expressed as percent of the maximal wild-type activity in the absence of CTRC. A) mutant with increased rate of autoactivation, B) mutants with unchanged autoactivation; C) mutants with decreased rates of autoactivation but normal final trypsin levels; D) mutants with decreased rates of autoactivation and reduced final trypsin levels.

We measured the autoactivation rates of wild type and mutants in $0.1 \mathrm{M} \mathrm{Tris} / \mathrm{HCl}(\mathrm{pH}$ $8.0)$, at $37{ }^{\circ} \mathrm{C}$, at a physiologically relevant $\mathrm{pH}(8.0)$ and $\mathrm{Ca}^{2+}$ concentration (1 mM). Only one mutant, p.D100H, exhibited increased autoactivation, which was about 2.5 -fold faster relative to wild type (Figure 2A). Five mutants (p.Q98K, p.T137M, p.K170E, p.S181G, and p.G208A) autoactivated comparable to wild-type trypsinogen (Figure 2B), while two (p.K92N and p.S124F) exhibited a decreased autoactivation rate, although they reached the 
same activity level (Figure 2C). In contrast four of the investigated mutants (p.P36R, p.G83E, p.I88N, and p.V123M) exhibited decreased rates of autoactivation with reduced final level, suggesting that these variants may become partially degraded during autoactivation (Figure 2D).

\subsection{Autoactivation of wild-type and mutant trypsinogens in the presence of chymotrypsin C}

Cationic trypsinogen and trypsin are under the regulation of CTRC. CTRC promotes proteolytic degradation of trypsinogen and trypsin (44) and also stimulates trypsinogen autoactivation. To determine the effect of CTRC on trypsinogen variants, we measured autoactivation in the presence of CTRC.

When trypsinogen at $1 \mu \mathrm{M}$ concentration was incubated with $10 \mathrm{nM}$ trypsin at $37{ }^{\circ} \mathrm{C}$, at $\mathrm{pH} 8.0$, in the presence of $1 \mathrm{mM} \mathrm{Ca}{ }^{2+}$, conversion to trypsin was essentially complete within $50 \mathrm{~min}$ (Figure 3) and final trypsin activity remained stable (black squares). As previously described (42), addition of human CTRC to this reaction (white triangles) resulted in a slightly increased rate of autoactivation with reduced final trypsin level slowly decreased over time from their peak value. In the experiments presented, wild-type cationic trypsinogen reached about 50\% activity level in the presence of CTRC, relative to trypsin levels observed in the absence of CTRC (Figure 3).

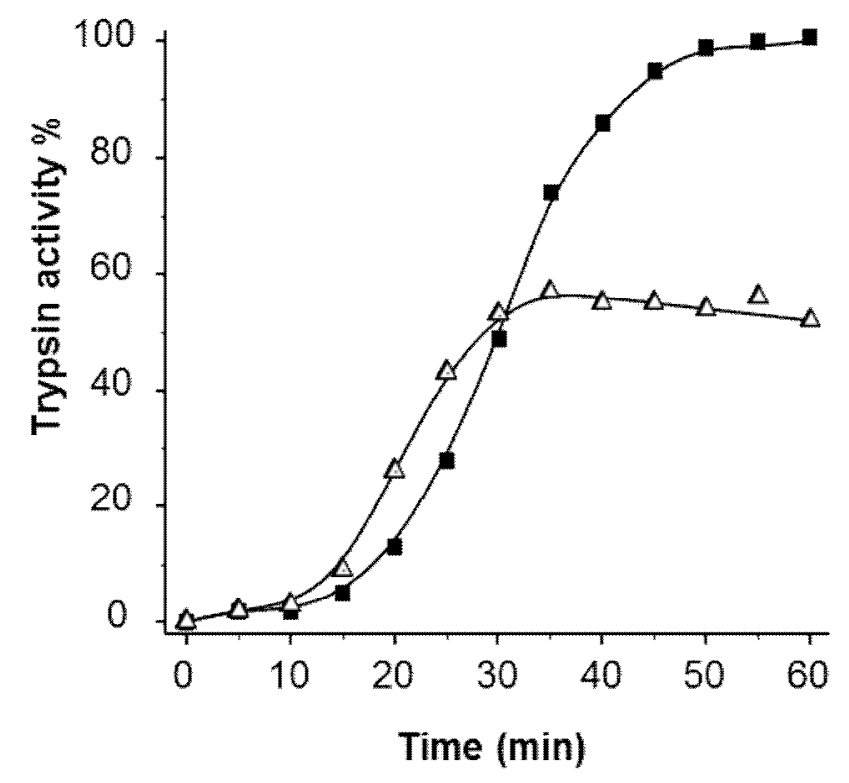

Figure 3. Activation of wild-type trypsinogen in the presence and absence of chymotrypsin $\mathrm{C}$.

Trypsinogens was incubated at $1 \mu \mathrm{M}$ concentration with $10 \mathrm{nM}$ initial trypsin in $0.1 \mathrm{M}$ Tris- $\mathrm{HCl}(\mathrm{pH} 8.0), 1 \mathrm{mM}$ $\mathrm{CaCl}_{2}$ and $0.05 \%$ Tween-20 (final concentrations) at $37{ }^{\circ} \mathrm{C}$ in the absence or presence of $5 \mathrm{nM}$ CTRC. At the indicated times, $2 \mu \mathrm{L}$ aliquots were removed and trypsin activity was measured as described in Materials and Methods. 
Under these conditions, both increases and decreases in autoactivation are readily detectable. To determine the effect of CTRC on the trypsinogen variants, we measured autoactivation in the presence of $5 \mathrm{nM}$ concentration of human CTRC.

Only one of the 12 variants tested, p.D100H exhibited increased activation in the presence of CTRC (Figure 4A). A similar phenotype was observed with this mutant when autoactivation was performed in the absence of CTRC (see above), indicating that the mutation increases autoactivation independent of CTRC. Consistent with this interpretation, degradation of p.D100H mutant trypsinogen and trypsin by CTRC was unchanged (not shown). Six mutants (p.K92N, p.Q98K, p.T137M, p.K170E, p.S181G, and p.G208A) autoactivated in the presence of CTRC in a manner that was comparable to wild type (Figure 4B). Surprisingly, however, five mutants (p.P36R, p.G83E, p.I88N, p.V123M and p.S124F) reached markedly reduced trypsin activity levels during autoactivation, suggesting increased susceptibility to CTRC-dependent degradation (Figure 4C). This notion was confirmed by direct degradation experiments which demonstrated that these five mutants were degraded by CTRC at increased rates (Figure 5). 


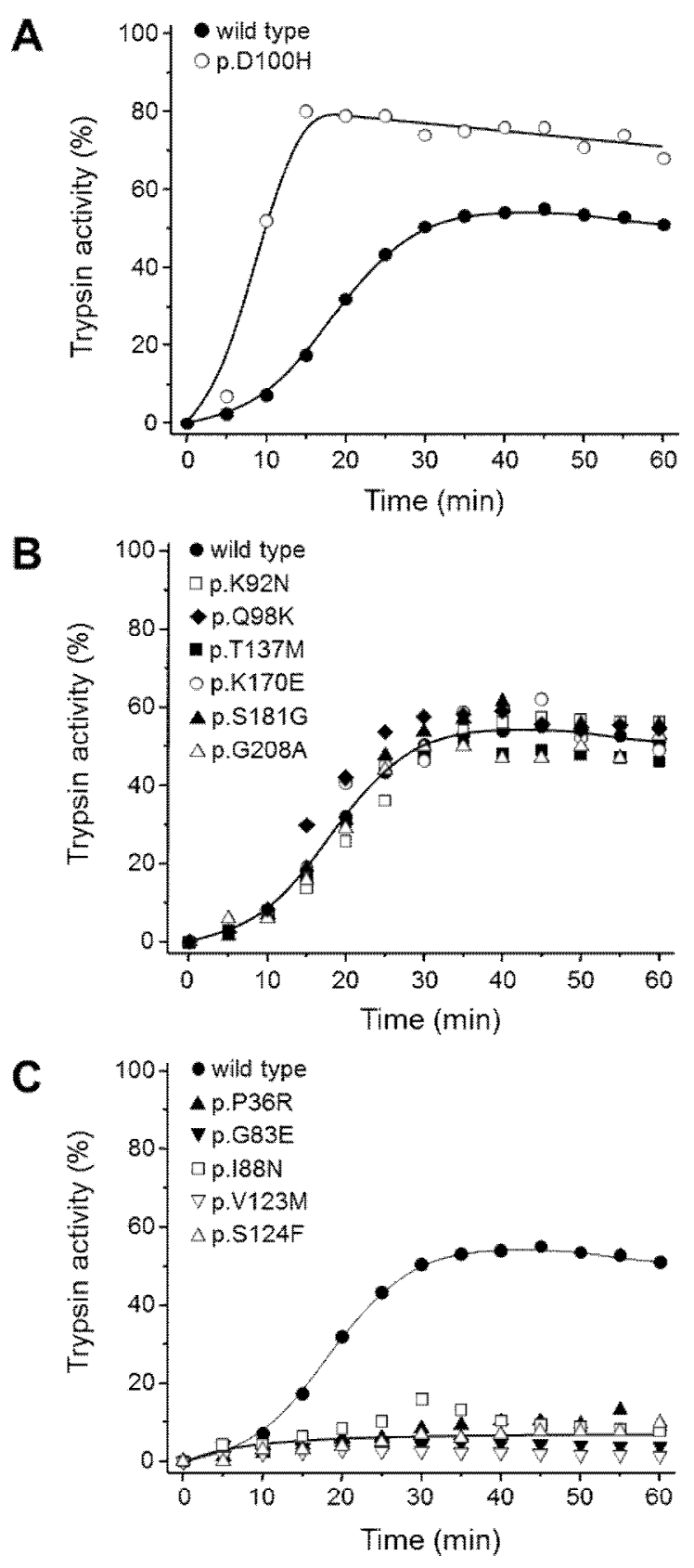

Figure 4. Autoactivation of cationic trypsinogen in the presence of CTRC:Trypsinogens were incubated at 1 $\mu \mathrm{M}$ concentration with $10 \mathrm{nM}$ initial trypsin in $0.1 \mathrm{M}$ Tris- $\mathrm{HCl}(\mathrm{pH} 8.0), 1 \mathrm{mM} \mathrm{CaCl}_{2}$ and $0.05 \%$ Tween-20 (final concentrations) at $37{ }^{\circ} \mathrm{C}$ in the presence of CTRC at $5 \mathrm{nM}$ concentrations. At the indicated times, $2 \mu \mathrm{L}$ aliquots were removed and trypsin activity was measured as described in Materials and Methods. Trypsin activity was expressed as percent of the maximal wild type activity in the absence of CTRC. Panel A) mutant with increased rate of autoactivation, B) mutants with unchanged autoactivation; C) mutants with decreased rates of autoactivation but normal final trypsin levels; D) mutants with decreased rates of autoactivation and reduced final trypsin levels. 


\subsection{Degradation of wild type and mutant trypsinogens/trypsins by chymotrypsin C}

Five mutants (p.P36R, p.G83E, p.I88N, p.V123M and p.S124F) reached markedly reduced trypsin activity levels during autoactivation in the presence of CTRC, suggesting increased susceptibility to CTRC-dependent degradation (Figure 4C). We performed direct degradation experiments to confirm this notion. First we tested degradation of trypsin by CTRC (Figure 5). Figure 4 and 5 demonstrate that indeed these five mutants exhibited an increased trypsin (Figure 5) as well as trypsinogen (Figure 6) degradation by CTRC.

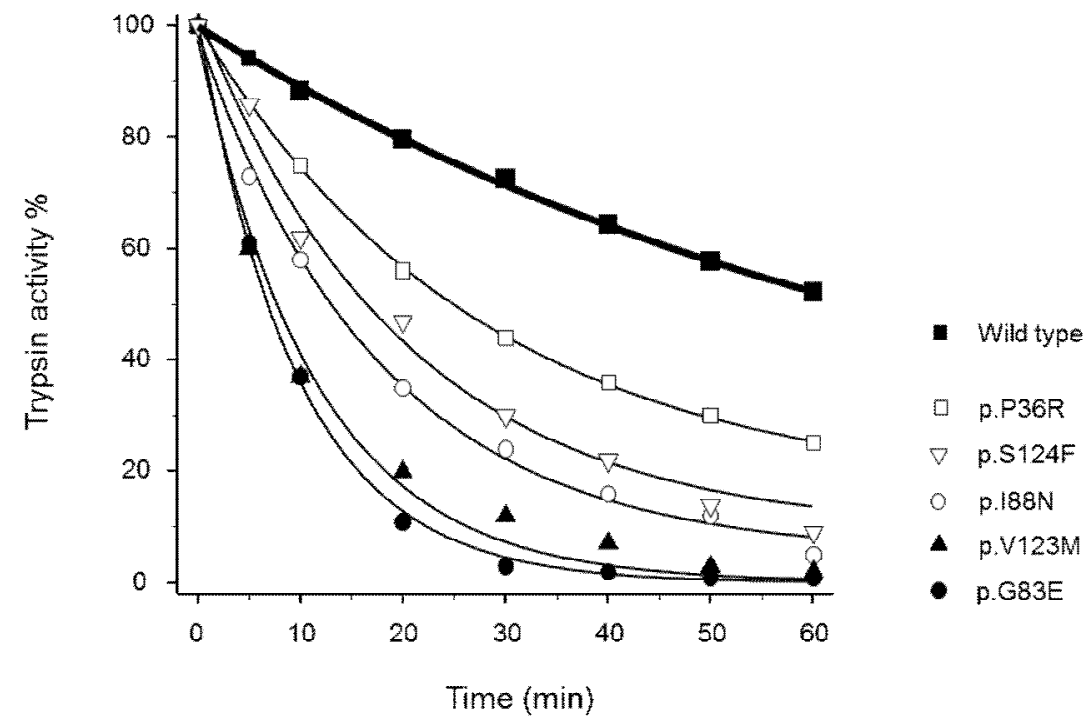

Figure 5. Degradation of cationic trypsins by chymotrypsin $\mathbf{C}$ : Wildtype and mutant trypsinogens were activated at $1 \mu \mathrm{M}$ concentration with enterokinase for $30 \mathrm{~min}$ at $37{ }^{\circ} \mathrm{C}$ in the presence of $1 \mathrm{mM} \mathrm{Ca}$ at $\mathrm{pH} 8.0$. Degradation of trypsins was then followed after adding human CTRC at $25 \mathrm{nM}$ concentration. 

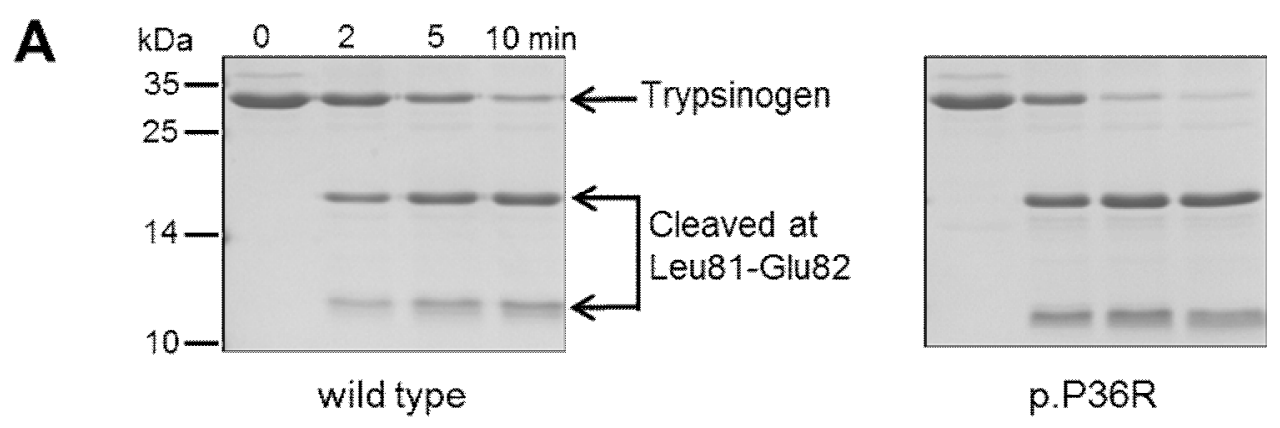

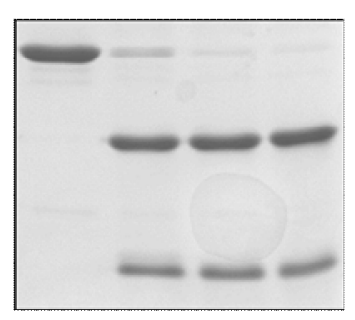

p.G83E

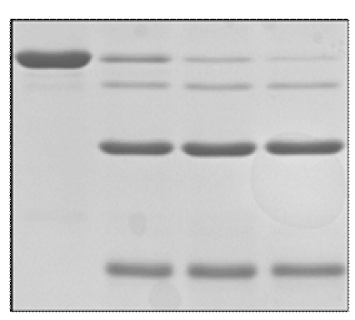

p. $188 \mathrm{~N}$

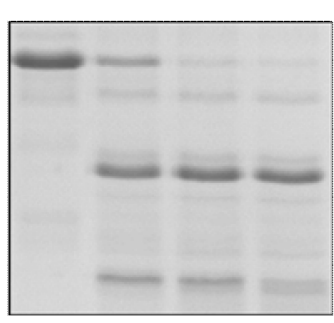

p.V123M

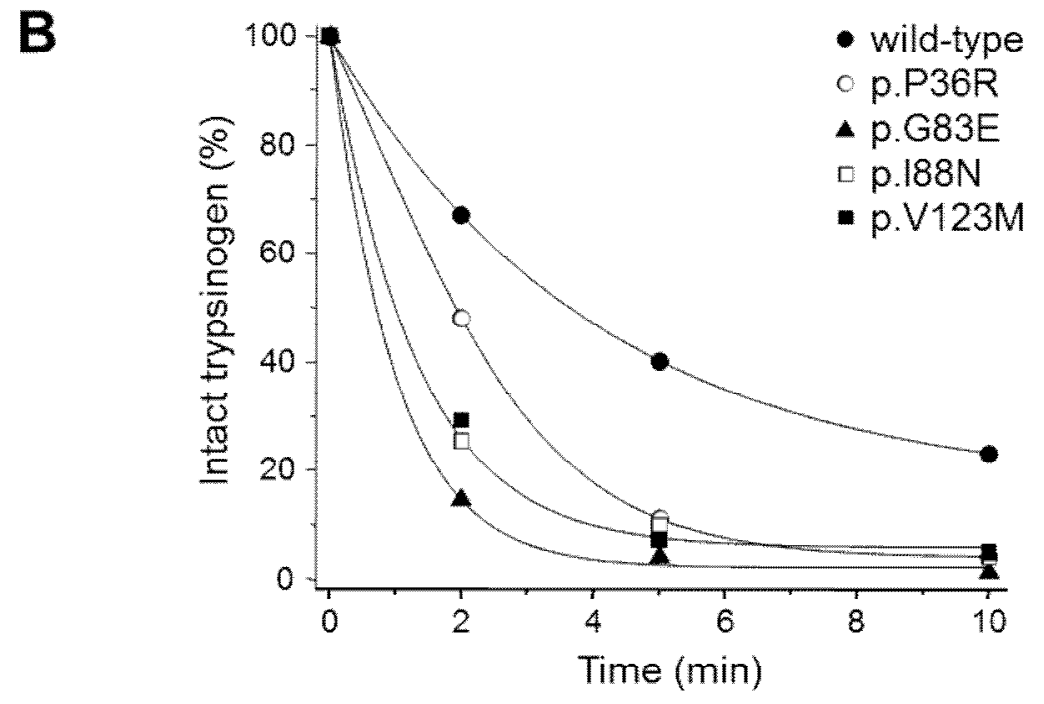

Figure 6. Degradation of cationic trypsinogen variants by chymotrypsin C. Trypsinogens at $2 \mu \mathrm{M}$ concentration were incubated with $25 \mathrm{nM}$ CTRC in $0.1 \mathrm{M}$ Tris- $\mathrm{HCl}(\mathrm{pH} 8.0)$ (final concentrations) at $37^{\circ} \mathrm{C}$. At the indicated times, the reactions were precipitated with $10 \%$ trichloroacetic acid (final concentration) and analyzed by SDS-PAGE and Coomassie blue staining. Representative gels of two experiments are shown. The graph indicates densitometric evaluation of the intensity of the trypsinogen bands. Average of two experiments was plotted with error bars omitted for clarity. The errors were within $12 \%$ of the mean. 


\subsection{Secretion of PRSS1 variants from HEK 293T cells}

To identify trypsinogen variants defective in folding, we evaluated their secretion from transiently transfectedHEK293T cells. We evaluated their secretion using SDSPAGE,western blot analysis and trypsin activity measurements after activation with enteropeptidase from the conditioned media.

Six of 13 mutants tested (p.P36R, p.G83E, p.Q98K, p.V123M, p.T137M, and p.S181G) showed trypsinogen secretion close to wild-type levels( 70-120\%) (Figure 7, black bars). Severe secretion defects ( $20 \%$ of wild type) were observed with mutants p.D100H and p.C139F. Moderate reduction in secretion ( $40-50 \%$ of wild type) was noted in case of three mutants (p.K92N, p.S124F and p.G208A). Two mutants (p.I88N and p.K170E) showed increased secretion levels, $170 \%$ and $140 \%$ of wild type, respectively. Although increased secretion of variant p.I88N may represent a gain of function, the rapid degradation of this variant by CTRC (see above) would cancel out this effect and result in a loss-of-function phenotype. The higher secretion of mutant p.I88 $\mathrm{N}$ was due to the appearance of a second trypsinogen band which represents an aberrantly glycosylated trypsinogen form (Figure 7A, 7B). This band is also observed in a much fainter form with all other trypsinogen variants and may be an artifact of the heterologous cell line used.

For the majority of the variants, the trypsin activity levels in the conditioned medium correlated well with the protein levels secreted (Figure 7B, gray bars). Four variants (p.P36R, p.G83E, p.K92N, and p.C139F) had considerably lower enzyme activity relative to their protein levels. Variant p.C139F may be misfolded and catalytically defective, which explains its lower activity. The other three variants exhibited normal catalytic activity in enzymatic tests (see above); suggesting that degradation or incomplete activation may underlie their lower activity. 
A

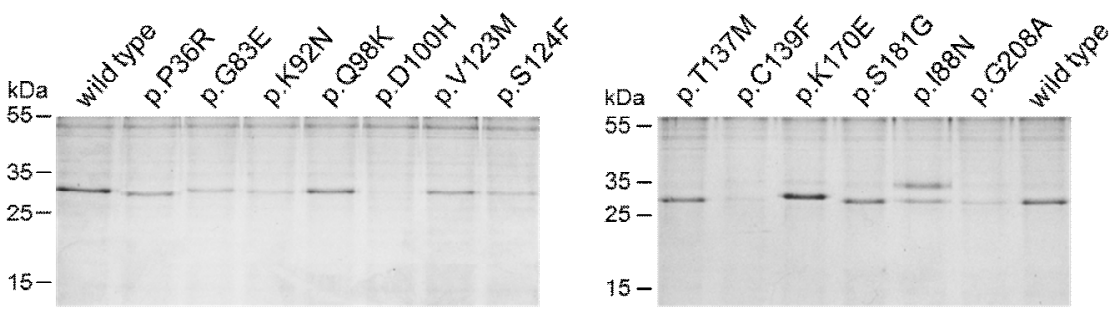

B

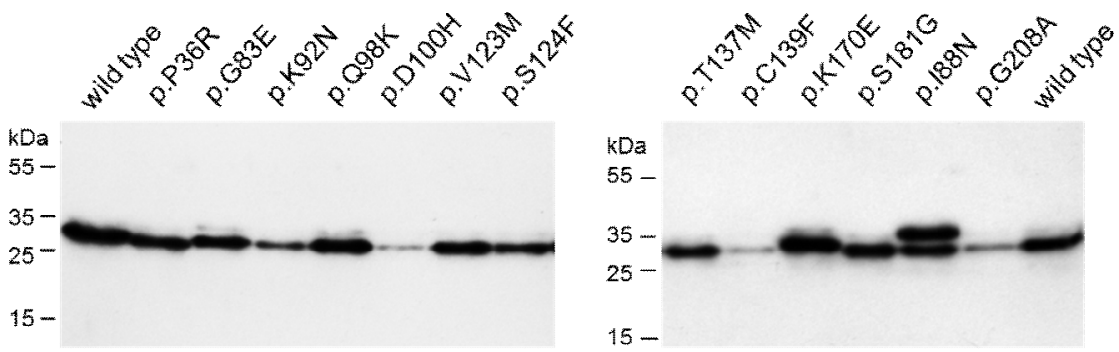

C

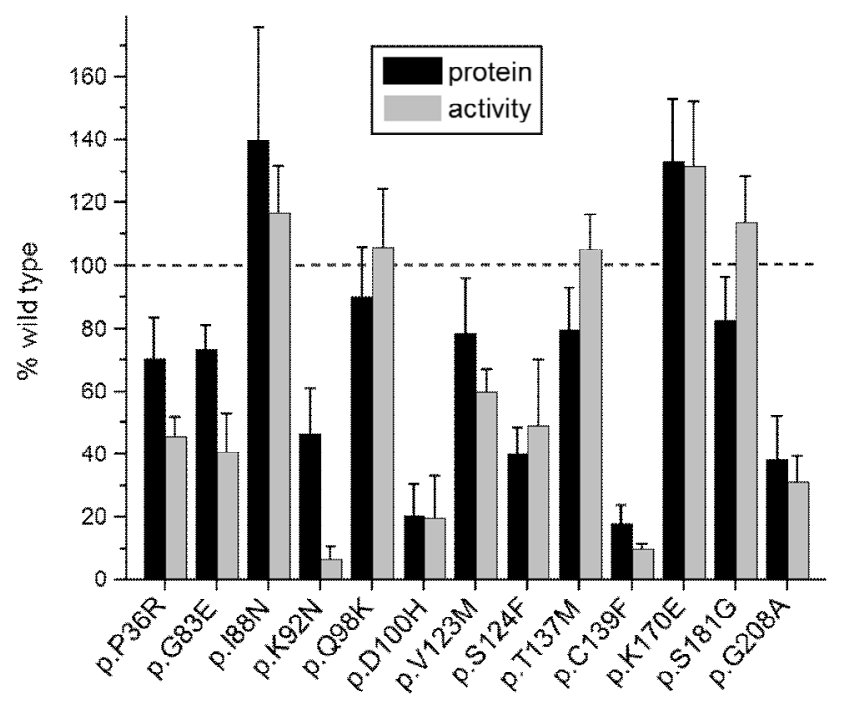

Figure 7. Secretion of wild-type and mutant trypsinogens from transfected HEK 293T. Cells were transiently transfected and conditioned media were collected after $24 \mathrm{~h}$. Trypsinogen protein levels were qualitatively analyzed on Coomassie Blue stained SDS-polyacrylamide gels (A) and then quantitatively determined by Western blots (B) and densitometry (C, black bars). Trypsin activity was measured after fully activation with enteropeptidase (C, gray bars). See in Materials and Methods section for details. Representative gels and blots of four independent experiments are shown. Average of four experiments with SD was plotted. Trypsinogen protein and trypsin activity levels were expressed as percent of wildtype values. 


\section{DISCUSSION}

A growing body of evidence supports the hypothesis that elevated intrapancreatic trypsin activity is highly significant in the pathogenesis of pancreatitis. However, the mechanism how activated trypsin acts still remains sketchy. There are protective mechanisms, such as the continuous ductal fluid secretion, responsible for the arrest of early trypsin activation. Impairment of bicarbonate secretion leads to the increase in the transit time of zymogens down the ductal tree and also decreases luminal $\mathrm{pH}\left(\mathrm{pH}_{\mathrm{L}}\right) \mathrm{pH}_{\mathrm{L}}$ can be elevated from 7.2 to 8.5 by stimulation with secretin or forskolin and this effect is strictly dependent on the presence of bicarbonate (63-65). Also, inhibition of ductal bicarbonate secretion with the anion-transport inhibitor $\mathrm{H}_{2}$ DIDS can decrease the $\mathrm{pH}_{\mathrm{L}}$ to below 8.0 (64). In light of these results, we tested whether trypsinogen autoactivation was affected by $\mathrm{pH}$ over the range 6.0 to 8.5 . Autoactivation of trypsinogen was relatively slow at $\mathrm{pH} 8.5$, but decreasing the $\mathrm{pH}$ from 8.5 to 7 stimulated autoactivation. These results suggest that under physiological conditions bicarbonate secretion by pancreatic ductal epithelial cells is not only important for elevating the $\mathrm{pH}$ in the duodenum, but also for keeping digestive enzymes in an inactive state. On the other hand, our results indicate that not only the increased time but the decreased $\mathrm{pH}_{\mathrm{L}}$ will contribute to the early trypsin activation. Prematurely activated trypsin in the ductal tree inhibits bicarbonate transport (66) leading to a vicious cycle generating a further decrease in $\mathrm{pH}_{\mathrm{L}}$ and enhanced trypsinogen activation, which will favour development of pancreatitis.

We investigated the functional properties of 13 rare PRSS1 variants detected in patients with CP. The clinical significance of such variants has been a contentious issue because their very low frequency did not allow statistical determination of genetic association with the disease phenotype (8). Segregation with pancreatitis within families could not be observed either, because these variants were found in cases with no family history. Nonetheless, investigators have often assigned clinical relevance to novel PRSS1 variants found in subjects with $\mathrm{CP}$, purely on the basis of a mistaken analogy with true disease-causing mutations. In a recent publication, we cautioned against this practice by demonstrating that the p.A121T variant had no functional effect on cationic trypsinogen even though it lies next to the amino-acid affected by the p.R122H causative mutation(8). In this 
work, we used functional analysis as a tool to identify phenotypic similarities between rare variants and well-characterized known disease-causing PRSS1 mutations. The common biochemical phenotype of PRSS1 mutations associated with HP is the generation of greatly increased trypsin levels during autoactivation in the presence of CTRC (42). This phenomenon is due to increased sensitivity of trypsinogen mutants to CTRC-mediated stimulation of autoactivation and/or resistance to CTRC-dependent trypsinogen degradation (Figure 8). Simply put, if a rare variant exhibits similar properties as HP associated mutations, then this variant is very likely pathogenic (Table 4). Conversely, phenotypically neutral variants are likely to be clinically irrelevant (Table 4).

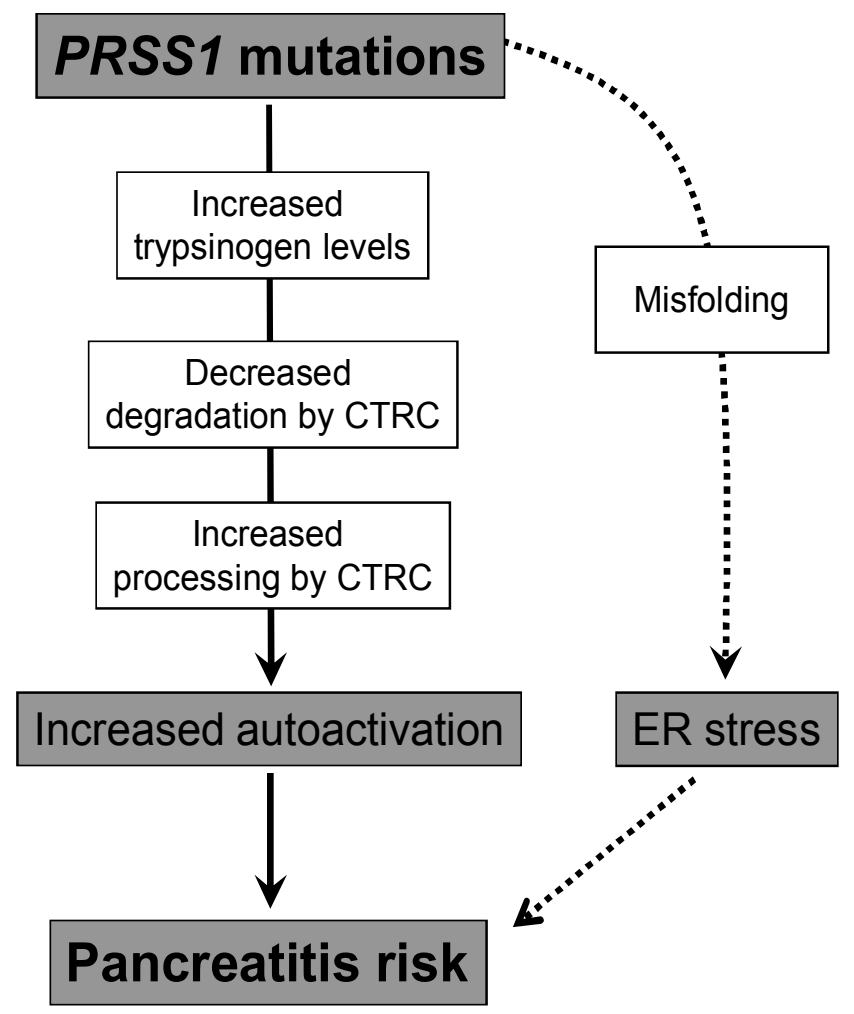

Figure 8. Pathological pathways associated with PRSS1 mutations in hereditary and sporadic chronic pancreatitis. Mutations in PRSS1 can increase autoactivation of cationic trypsinogen by different mechanism: increased trypsinogen expression or secretion; inhibition of chymotrypsin $\mathrm{C}$ (CTRC)-dependent trypsinogen degradation, stimulation of N-terminal processing of the trypsinogen activation peptide by CTRC; and direct stimulation of autoactivation. Alternatively PRSS1 mutations can cause misfolding and endoplasmic reticulum stress reticulum stress. See text for further details 
Unexpectedly, we observed that only one (p.D100H) of 13 mutants had a gain-offunction phenotype, which might contribute to the development of pancreatitis. However, this variant also exhibits a severe secretion defect and is therefore less likely to reach significant intrapancreatic trypsin activity. Contrariwise, half of the trypsinogen variants showed an increased propensity to CTRC degradation, resulting in lower trypsin levels during autoactivation relative to wild-type trypsinogen. This biochemical phenotype is inconsistent with the trypsin-dependent model of HP and suggests that these variants are not pathogenic (Table 4).This loss of function is particularly surprising for the mutant p.V123M, which is located next to the autolytic site Arg122, and was previously postulated to increase trypsin stability $(53,67)$. This similar to mutant p.A121T, which has also been classified as HP associated mutation without functional analysis $(67,68)$. However, uncertainties in the classification of cationic trypsinogen variants as disease associated mutations were already highlighted by Szmola et al. That study demonstrated that p.A121T variant is functionally innocuous and shows no association with HP (8).

ER-stress is proposed to represent a different pathomechanism leading to pancreatitis (69) (Figure 8). Mutation-induced protein misfolding can cause ER-stress, especially if the protein is made in huge amounts, as it is the case of digestive enzymes in the pancreatic acinar cells. Misfolding and ER-stress can be assumed in vivo if the mutation exhibits a secretion defect in certain cell culture models $(45,70,71)$. Furthermore, it can be hypothesized that the threshold of pathological ER-stress correlates with the abundance of each protein made. As cationic trypsinogen is the most abundant protease secreted from the pancreatic acinar cell, misfolding might have a significant impact. Although, most mutants investigated in this study did not cause a pancreatitis-associated gain-of-function phenotype, secretion defect, likely caused by mutation-induced misfolding, was observed in the present study for variants p.D100H and p.C139F and, to a smaller extent, variants p.K92N, p.S124F and p.G208A, suggesting that these variants are pathogenic (Table 4).

Increased secretion of mutant trypsinogens may result in higher trypsinogen levels in the pancreatic juice with consequently increased risk for autoactivation (Figure 8). Copy number mutations in trypsinogen genes may exert their pathogenic effect via this mechanism $(72,73)$. Conversely, decreased trypsinogen expression due to the c. $1-408 \mathrm{C}>\mathrm{T}$ 


\begin{tabular}{|c|c|c|c|}
\hline Region & Nucleotide change & Amino acid change & Relevant phenotype \\
\hline \multicolumn{4}{|c|}{ Pathogenic variants, strong } \\
\hline Exon 3 & c. $298 \mathrm{G}>\mathrm{C}$ & p.D100H & severe secretion defect \\
\hline Exon 3 & c. $416 \mathrm{G}>\mathrm{T}$ & p.C139F & severe secretion defect \\
\hline \multicolumn{4}{|c|}{ Pathogenic variants, mild } \\
\hline Exon 3 & c. $276 \mathrm{G}>\mathrm{T}$ & p.K92N & moderate secretion defect \\
\hline Exon 3 & c. $371 \mathrm{C}>\mathrm{T}$ & p.S124F & moderate secretion defect \\
\hline Exon 4 & c. $508 \mathrm{~A}>\mathrm{G}$ & p.K170E & moderate secretion increase \\
\hline Exon 5 & c. $623 \mathrm{G}>\mathrm{C}$ & p.G208A & moderate secretion defect \\
\hline \multicolumn{4}{|c|}{ Non-pathogenic variants, functionally neutral } \\
\hline Exon 3 & c. $292 \mathrm{C}>\mathrm{A}$ & p.Q98K & none \\
\hline Exon 3 & c. $410 \mathrm{C}>\mathrm{T}$ & p.T137M & none \\
\hline Exon 4 & c. $541 \mathrm{~A}>\mathrm{G}$ & p.S181G & none \\
\hline \multicolumn{4}{|c|}{ Non-pathogenic variants, loss of function } \\
\hline Exon 2 & c. $107 \mathrm{C}>\mathrm{G}$ & p.P36R & degradation by CTRC \\
\hline Exon 3 & c. $248 \mathrm{G}>\mathrm{A}$ & p.G83E & degradation by CTRC \\
\hline Exon 3 & c. $263 \mathrm{~T}>\mathrm{A}$ & p.I88N & degradation by CTRC \\
\hline Exon 3 & c. $367 \mathrm{G}>\mathrm{A}$ & p.V123M & degradation by CTRC \\
\hline
\end{tabular}

Table 4. Clinical relevance of PRSS1 variants classified on the basis of functional phenotype.

polymorphism in the $5^{\prime}$ region is associated with decreased pancreatitis risk (74). In this study, we observed slightly increased secretion with two mutants, p.I88N and p.K170E. While the rapid degradation of mutant p.I88N by CTRC would counteract the effect of higher trypsinogen concentrations, the phenotype of mutant p.K170E may indicate a true gain of function with potentially elevated risk of pancreatitis (Table 4). Finally, three trypsinogen variants (p.Q98K, p.T137M and p.S181G) proved functionally neutral in this study, indicating that PRSS1variants of no clinical significance may be incidental findings when subjects with CP are screened for underlying genetic defects (Table 4).

Taken together, our experimental results indicate that most of the investigated rare PRSS1 variants do not phenocopy the disease causing HP-associated PRSS1 mutations 
(p.R122H, p.R122C, p.N29I.). Instead, loss-of-function characteristics related to increased degradation or reduced secretion were observed mostly. Variants with decreased secretion may increase pancreatitis risk through an alternative pathological pathway related to mutation-induced misfolding and consequent ER stress.

Considerable research effort has been made to identify the underlying mechanism leading to the development of CP. However, aspects of CP inflammation still need to be elucidated, including the mechanisms that turn acute inflammation into a chronic, destructive process which may eventually lead to pancreatic cancer. In the last decades increasing number of studies have been published concerning the important role of ion transport mechanisms in the development of inflammatory disorders (75-78). Supressed transporter activites, resulting in decreased ductal fluid secretion is associated with development of pancreatitis $(49,66)$. These data suggest that the impairment of ion transport mechanisms might be a universal component for inflammatory diseases, such as pancreatitis and inflammatory bowel diseases. In the light of this view, we looked further ion transport mechanisms in different cell types of the gastrointestinal tract as it might imply novel mechanism to consider in the inflammation process. Our group found that in patients with ulcerative colitis the sodium hidrogen exchanger isoform 1 (NHE1), which has been shown to promote immun response (79) upregulated, whereas both sodium and chloride absorption is damaged, which may play a role in the pathogenesis of diarrhea in colitis (80). The same transporter (NHE1) was found to have a great impact on the cell function (migration and proliferation) of gastric myofibroblasts (81), contributors of the tumour genesis (82). The insight in other pathomechanistic processes, like inflammatory bowel diseases or cancer genesis might provide us new points to focus in the research of pancreatitis. 


\section{SUMMARY}

Introduction: Pancreatitis is caused by the premature activation of trypsinogen, followed by the activation of other digestive zymogenes. To prevent early activation, defensive mechanisms have evolved, such as the hypersecretion of pancreatic fluid during pancreatitis. Suppressed fluid secretion accompanied by the fall of intraductal $\mathrm{pH}$ found to have a deleterious effect on the whole gland. Hereditary CP is caused by mutations in human cationic trypsinogen (PRSS1) which lead to elevated intrapancreatic trypsin activity by altering the chymotrypsin $\mathrm{C}(\mathrm{CTRC})$-dependent regulation of trypsinogen activation and degradation. To date, a large number of rare PRSS1 mutations have been found and reported in patients with pancreatitis. Despite lack of evidence, some of these variants have been described as pancreatitis-associated merely on the analogy of the disease-causing mutation. The aims of this work were to understand the effect of decreased intraductal $\mathrm{pH}$ on autoactivation of wild-type cationic trypsinogen and to establish possible clinical relevance of published rare PRSS1 mutations on the basis of their phenotypic characteristics. Design: We investigated the autoactivation of wild-type trypsinogen at different $\mathrm{pH}$ and performed functional analysis of 13 published PRSS1 variants with respect to autoactivation in the presence of CTRC and cellular secretion. To estimate PRSS1 variant frequency in healthy controls, we sequenced exon-3 in 1000 German subjects without pancreatic disease. Results: The autoactivation of human wild-type trypsinogen was increased when the $\mathrm{pH}$ was reduced from 8.5 to 7.0. However, decreasing the $\mathrm{pH}$ from 7.0 to 6.0 had a slight effect only. Only one mutation (p.D100H) increased trypsinogen autoactivation, but this gain on function was offset by marked reduction in secretion. Surprisingly, seven mutants showed a loss-offunction phenotype, which was related to increased degradation by CTRC (p.P36R, p.G83E, p.I88N, p.V123M, p.S124F) or to markedly reduced secretion (p.C139F, p.D100H). In addition, moderately decreased secretion was observed with three mutants (p.K92N, p.S124F, p.G208A). One mutant showed slightly increased secretion and three mutants had no phenotypic alterations when compared to wild-type trypsinogen. DNA sequencing of exon-3 in healthy controls identified a novel p.V123L variant in one subject but no other variants. Conclusions: Increased autoactivation of cationic trypsinogen at decreased $\mathrm{pH}$ indicates that not only impaired washout but also decreased intraductal $\mathrm{pH}$ will contribute to 
early trypsin activation, when fluid secretion is suppressed. Rare cationic trypsinogen variants found in subjects with sporadic $\mathrm{CP}$ do not exhibit a gain of function typical of hereditary pancreatitis. Instead, decreased secretion or increased degradation by CTRC is observed frequently. Impaired secretion is likely due to misfolding which may represent an alternative mechanism for pancreatitis risk unrelated to trypsin activity. These results emphasize that classification of novel PRSS1 variants should be based on functional evidence. 


\section{ACKNOWLEDGEMENTS}

I would like to express my sincere appreciation to my supervisors at the University of Szeged, professor Péter Hegyi and associate professor Zoltán Rakonczay Jr. for the continuous support and guidance during my Ph.D. and undergraduate studies. To witness how they have built up a successful and continuously growing research group has been one of the best learning experiences of my budding career.

I owe a debt of gratitude to my supervisor at Boston University, professor Miklós Sahin-Tóth, who is the true embodiment of a mentor. I am deeply grateful for introducing me the fascinating field of protease biochemistry, for the continuous encouragement, constructive criticism and prompt responses to all my queries.

I wish to thank professors János Lonovics and Tibor Wittmann, past and present chairs of the First Department of Medicine, University of Szeged, for the possibility to pursue my $\mathrm{Ph}$.D. studies in their department.

I wish to thank my colleagues at Boston University, Dr. Sebastian Beer, Dr. András Szabó, Andrea Geisz, Dr. Melinda Bence and Vera Sahin-Tóth for teaching me the research techniques in biochemistry, for the numerous stimulating scientific discussions and for providing a cheerful environment.

I owe warm thanks to all of my colleagues at the University of Szeged for all the emotional support, their kindness and for having had the opportunity to work with them.

This work was supported by the National Development Agency grants (TÁMOP-4.2.2.A11/1/KONV-2012-0035, TÁMOP-4.2.2.A-11/1/KONV-2012-0073, TÁMOP-4.2.211/1/KONV-2012-0052) by NIH grants (R01DK058088, R01DK082412, R01DK082412-S2, R01DK095753) and a scholarship from the Rosztoczy Foundation.

My deepest gratitude goes to my dear father who taught me the value of hard work and education and supported me in every possible way. I dedicate this thesis to him. 


\section{REFERENCES}

1. Ahmed SA, Wray C, Rilo HLR, Choe KA, Gelrud A, Howington JA, et al. Chronic pancreatitis: recent advances and ongoing challenges. Curr Probl Surg. 2006 ;43(3):127-238.

2. Etemad B, Whitcomb DC. Chronic pancreatitis: diagnosis, classification, and new genetic developments. Gastroenterology. 2001;120(3):682-707.

3. Howes N, Lerch MM, Greenhalf W, Stocken DD, Ellis I, Simon P, et al. Clinical and genetic characteristics of hereditary pancreatitis in Europe. Clin. Gastroenterol. Hepatol. 2004;2(3):252-61.

4. Comfort MW, Steinberg AG. Pedigree of a family with hereditary chronic relapsing pancreatitis. Gastroenterology. 1952;21(1):54-63.

5. Le Bodic L, Schnee M, Georgelin T, Soulard F, Ferec C, Bignon JD, et al. An exceptional genealogy for hereditary chronic pancreatitis. Dig. Dis. Sci. 1996 ;41(7):1504-10.

6. Pandya A, Blanton SH, Landa B, Javaheri R, Melvin E, Nance WE, et al. Linkage studies in a large kindred with hereditary pancreatitis confirms mapping of the gene to a 16-cM region on 7q. Genomics. 1996;38(2):227-30.

7. Whitcomb DC, Gorry MC, Preston RA, Furey W, Sossenheimer MJ, Ulrich CD, et al. Hereditary pancreatitis is caused by a mutation in the cationic trypsinogen gene. Nat. Genet. 1996;14(2):141-5.

8. Szmola R, Sahin-Tóth M. Uncertainties in the classification of human cationic trypsinogen (PRSS1) variants as hereditary pancreatitis-associated mutations. J. Med. Genet. 2010;47(5):348-50.

9. Rebours V, Boutron-Ruault M-C, Schnee M, Férec C, Le Maréchal C, Hentic O, et al. The natural history of hereditary pancreatitis: a national series. Gut. 2009;58(1):97-103.

10. Teich N, Rosendahl J, Tóth M, Mössner J, Sahin-Tóth M. Mutations of human cationic trypsinogen (PRSS1) and chronic pancreatitis. Hum. Mutat. 2006;27(8):721-30.

11. Grocock CJ, Rebours V, Delhaye MN, Andrén-Sandberg A, Weiss FU, Mountford R, et al. The variable phenotype of the p.A16V mutation of cationic trypsinogen (PRSS1) in pancreatitis families. Gut. 2010;59(3):357-63.

12. Witt H, Luck W, Becker M. A signal peptide cleavage site mutation in the cationic trypsinogen gene is strongly associated with chronic pancreatitis. Gastroenterology. 1999;117(1):7-10. 
13. Witt H, Sahin-Tóth M, Landt O, Chen J-M, Kähne T, Drenth JP, et al. A degradationsensitive anionic trypsinogen (PRSS2) variant protects against chronic pancreatitis. Nat. Genet. 2006;38(6):668-73.

14. Rosendahl J, Teich N, Kovacs P, Szmola R, Blüher M, Gress TM, et al. Complete analysis of the human mesotrypsinogen gene (PRSS3) in patients with chronic pancreatitis. Pancreatology. 2010;10(2-3):243-9.

15. Kume K, Masamune A, Takagi Y, Kikuta K, Watanabe T, Satoh K, et al. A loss-offunction p.G191R variant in the anionic trypsinogen (PRSS2) gene in Japanese patients with pancreatic disorders. Gut. 2009;58(6):820-4.

16. Guy O, Lombardo D, Bartelt DC, Amic J, Figarella C. Two human trypsinogens. Purification, molecular properties, and N-terminal sequences. Biochemistry. 1978;17(9):1669-75.

17. Rinderknecht H, Renner IG, Carmack C. Trypsinogen variants in pancreatic juice of healthy volunteers, chronic alcoholics, and patients with pancreatitis and cancer of the pancreas. Gut. 1979;20(10):886-91.

18. Rinderknecht H, Stace NH, Renner IG. Effects of chronic alcohol abuse on exocrine pancreatic secretion in man. Dig. Dis. Sci. 1985;30(1):65-71.

19. Rinderknecht H, Renner IG, Abramson SB, Carmack C. Mesotrypsin: a new inhibitorresistant protease from a zymogen in human pancreatic tissue and fluid. Gastroenterology. 1984;86(4):681-92.

20. Chiari H. Über selbstverdauung des menschlichen pancreas. Zeitschrift für Heilkunde. 1896;(17):69-96.

21. Pfützer RH, Barmada MM, Brunskill AP, Finch R, Hart PS, Neoptolemos J, et al. SPINK1/PSTI polymorphisms act as disease modifiers in familial and idiopathic chronic pancreatitis. Gastroenterology. 2000;119(3):615-23.

22. Witt H, Luck W, Hennies HC, Classen M, Kage A, Lass U, et al. Mutations in the gene encoding the serine protease inhibitor, Kazal type 1 are associated with chronic pancreatitis. Nat. Genet. 2000;25(2):213-6.

23. Rosendahl J, Witt H, Szmola R, Bhatia E, Ozsvári B, Landt O, et al. Chymotrypsin C (CTRC) variants that diminish activity or secretion are associated with chronic pancreatitis. Nat. Genet. 2008;40(1):78-82.

24. Saluja AK, Lerch MM, Phillips PA, Dudeja V. Why does pancreatic overstimulation cause pancreatitis? Annu. Rev. Physiol. 2007;69:249-69.

25. Lerch MM, Gorelick FS. Early trypsinogen activation in acute pancreatitis. Med. Clin. North Am. 2000;84(3):549-563 
26. Hofbauer B, Saluja AK, Lerch MM, Bhagat L, Bhatia M, Lee HS, et al. Intra-acinar cell activation of trypsinogen during caerulein-induced pancreatitis in rats. Am. J. Physiol. 1998;275(2 Pt 1):G352-362.

27. Thrower EC, Gorelick FS, Husain SZ. Molecular and cellular mechanisms of pancreatic injury. Curr. Opin. Gastroenterol. 2010;26(5):484-9.

28. Czakó L, Yamamoto M, Otsuki M. Pancreatic fluid hypersecretion in rats after acute pancreatitis. Dig. Dis. Sci. 1997;42(2):265-72.

29. Yamamoto A, Ishiguro H, Ko SBH, Suzuki A, Wang Y, Hamada H, et al. Ethanol induces fluid hypersecretion from guinea-pig pancreatic duct cells. J Physiol. 2003;551(3):917-26.

30. Yamamoto M, Shirohara H, Otsuki M. CCK-, secretin-, and cholinergic-independent pancreatic fluid hypersecretion in protease inhibitor-treated rats. Am. J. Physiol. 1998 ;274(2 Pt 1):G406-412.

31. Ishiguro H, Steward MC, Sohma Y, Kubota T, Kitagawa M, Kondo T, et al. Membrane potential and bicarbonate secretion in isolated interlobular ducts from guinea-pig pancreas. J. Gen. Physiol. 2002;120(5):617-28.

32. Sohma Y, Gray MA, Imai Y, Argent BE. HCO3- transport in a mathematical model of the pancreatic ductal epithelium. J. Membr. Biol. 2000;176(1):77-100.

33. Weiss FU, Simon P, Bogdanova N, Shcheynikov N, Muallem S, Lerch MM. Functional characterisation of the CFTR mutations M348V and A1087P from patients with pancreatitis suggests functional interaction between CFTR monomers. Gut. 2009;58(5):733-4.

34. Chen J-M, Férec C. Genetics and pathogenesis of chronic pancreatitis: the 2012 update. Clin Res Hepatol Gastroenterol. 2012;36(4):334-40.

35. LaRusch J, Whitcomb DC. Genetics of pancreatitis. Curr. Opin. Gastroenterol. 2011 ;27(5):467-74.

36. Schneider A, Larusch J, Sun X, Aloe A, Lamb J, Hawes R, et al. Combined bicarbonate conductance-impairing variants in CFTR and SPINK1 variants are associated with chronic pancreatitis in patients without cystic fibrosis. Gastroenterology. 2011 ;140(1):162-71.

37. Cavestro GM, Zuppardo RA, Bertolini S, Sereni G, Frulloni L, Okolicsanyi S, et al. Connections between genetics and clinical data: Role of MCP-1, CFTR, and SPINK-1 in the setting of acute, acute recurrent, and chronic pancreatitis. Am. J. Gastroenterol. 2010;105(1):199-206. 
38. Hegyi P, Rakonczay Z. Insufficiency of electrolyte and fluid secretion by pancreatic ductal cells leads to increased patient risk for pancreatitis. Am. J. Gastroenterol. 2010 ;105(9):2119-20.

39. Renner IG, Wisner JR Jr, Rinderknecht H. Protective effects of exogenous secretin on ceruletide-induced acute pancreatitis in the rat. J. Clin. Invest. 1983;72(3):1081-92.

40. Hegyi P, Pandol S, Venglovecz V, Rakonczay Z Jr. The acinar-ductal tango in the pathogenesis of acute pancreatitis. Gut. 2011;60(4):544-52.

41. Sahin-Tóth M, Tóth M. Gain-of-function mutations associated with hereditary pancreatitis enhance autoactivation of human cationic trypsinogen. Biochem. Biophys. Res. Commun. 2000;278(2):286-9.

42. Szabó A, Sahin-Tóth M. Increased Activation of Hereditary Pancreatitis-associated Human Cationic Trypsinogen Mutants in Presence of Chymotrypsin C. J. Biol. Chem. 2012;287(24):20701-10.

43. Nemoda Z, Sahin-Tóth M. Chymotrypsin C (caldecrin) stimulates autoactivation of human cationic trypsinogen. J. Biol. Chem. 2006;281(17):11879-86.

44. Szmola R, Sahin-Tóth M. Chymotrypsin C (caldecrin) promotes degradation of human cationic trypsin: identity with Rinderknecht's enzyme Y. Proc. Natl. Acad. Sci. U.S.A. 2007;104(27):11227-32.

45. Kereszturi E, Szmola R, Kukor Z, Simon P, Weiss FU, Lerch MM, et al. Hereditary pancreatitis caused by mutation-induced misfolding of human cationic trypsinogen: a novel disease mechanism. Hum. Mutat. 2009;30(4):575-82.

46. Király O, Guan L, Sahin-Tóth M. Expression of recombinant proteins with uniform Ntermini. Methods Mol. Biol. 2011;705:175-94.

47. Lengyel Z, Pál G, Sahin-Tóth M. Affinity purification of recombinant trypsinogen using immobilized ecotin. Protein Expr. Purif. 1998;12(2):291-4.

48. Szabó A, Héja D, Szakács D, Zboray K, Kékesi KA, Radisky ES, et al. High affinity small protein inhibitors of human chymotrypsin C (CTRC) selected by phage display reveal unusual preference for P4' acidic residues. J. Biol. Chem. 2011;286(25):2253545.

49. Venglovecz V, Rakonczay Z Jr, Ozsvári B, Takács T, Lonovics J, Varró A, et al. Effects of bile acids on pancreatic ductal bicarbonate secretion in guinea pig. Gut. 2008 ;57(8):1102-12.

50. Maléth J, Venglovecz V, Rázga Z, Tiszlavicz L, Rakonczay Z Jr, Hegyi P. Nonconjugated chenodeoxycholate induces severe mitochondrial damage and inhibits bicarbonate transport in pancreatic duct cells. Gut. 2011;60(1):136-8. 
51. Bynum TE, Solomon TE, Johnson LR, Jacobson ED. Inhibition of pancreatic secretion in man by cigarette smoking. Gut. 1972;13(5):361-5.

52. Kadiyala V, Lee LS, Banks PA, Suleiman S, Paulo JA, Wang W, et al. Cigarette smoking impairs pancreatic duct cell bicarbonate secretion. JOP. 2013;14(1):31-8.

53. Chen JM, Piepoli Bis A, Le Bodic L, Ruszniewski P, Robaszkiewicz M, Deprez PH, et al. Mutational screening of the cationic trypsinogen gene in a large cohort of subjects with idiopathic chronic pancreatitis. Clin. Genet. 2001;59(3):189-93.

54. Teich N, Bauer N, Mössner J, Keim V. Mutational screening of patients with nonalcoholic chronic pancreatitis: identification of further trypsinogen variants. Am. J. Gastroenterol. 2002;97(2):341-6.

55. Chang Y-T, Wei S-C, L P-C, Tien Y-W, Jan I-S, Su Y-N, et al. Association and differential role of PRSS1 and SPINK1 mutation in early-onset and late-onset idiopathic chronic pancreatitis in Chinese subjects. Gut. 2009;58(6):885.

56. Zeng K, Liu Q, Lin J, Lin X, Zhuang Z, Gao F, et al. Novel mutations of PRSS1 gene in patients with pancreatic cancer among Han population. Chin. Med. J. 2011;124(13):2065-7.

57. Lee YJ, Kim KM, Choi JH, Lee BH, Kim G-H, Yoo H-W. High incidence of PRSS1 and SPINK1 mutations in Korean children with acute recurrent and chronic pancreatitis. J. Pediatr. Gastroenterol. Nutr. 2011;52(4):478-81.

58. Keiles S, Kammesheidt A. Identification of CFTR, PRSS1, and SPINK1 mutations in 381 patients with pancreatitis. Pancreas. 2006;33(3):221-7.

59. Tautermann G, Ruebsamen H, Beck M, Dertinger S, Drexel H, Lohse P. R116C mutation of cationic trypsinogen in a Turkish family with recurrent pancreatitis illustrates genetic microheterogeneity of hereditary pancreatitis. Digestion. 2001;64(4):226-32.

60. Rosendahl J, Landt O, Bernadova J, Kovacs P, Teich N, Bödeker H, et al. CFTR, SPINK1, CTRC and PRSS1 variants in chronic pancreatitis: is the role of mutated CFTR overestimated? Gut [Internet]. 2012 [epub ahead of print];

61. Sultan M, Werlin S, Venkatasubramani N. Genetic prevalence and characteristics in children with recurrent pancreatitis. J. Pediatr. Gastroenterol. Nutr. 2012;54(5):645-50.

62. Corleto VD, Gambardella S, Gullotta F, D'Apice MR, Piciucchi M, Galli E, et al. New PRSS1 and common CFTR mutations in a child with acute recurrent pancreatitis, could be considered an "Hereditary" form of pancreatitis ? BMC Gastroenterol. 2010;10:119.

63. Ishiguro H, Steward MC, Wilson RW, Case RM. Bicarbonate secretion in interlobular ducts from guinea-pig pancreas. J. Physiol. (Lond.). 1996;495 ( Pt 1):179-91. 
64. Ishiguro H, Naruse S, Steward MC, Kitagawa M, Ko SB, Hayakawa T, et al. Fluid secretion in interlobular ducts isolated from guinea-pig pancreas. J. Physiol. (Lond.). 1998;511 ( Pt 2):407-22.

65. Ishiguro H, Naruse S, Kitagawa M, Hayakawa T, Case RM, Steward MC. Luminal ATP stimulates fluid and HCO3- secretion in guinea-pig pancreatic duct. J. Physiol. (Lond.). 1999;519 Pt 2:551-8.

66. Pallagi P, Venglovecz V, Rakonczay Z Jr, Borka K, Korompay A, Ozsvári B, et al. Trypsin reduces pancreatic ductal bicarbonate secretion by inhibiting CFTR $\mathrm{Cl}^{-}$ channels and luminal anion exchangers. Gastroenterology. 2011;141(6):2228-2239.e6.

67. Felderbauer P, Schnekenburger J, Lebert R, Bulut K, Parry M, Meister T, et al. A novel A121T mutation in human cationic trypsinogen associated with hereditary pancreatitis: functional data indicating a loss-of-function mutation influencing the R122 trypsin cleavage site. J. Med. Genet. 2008 Aug;45(8):507-12.

68. Liu Q, Gao F, Ou Q, Zhuang Z, Lin S, Yang B, et al. Novel mutation and polymorphism of PRSS1 gene in the Chinese patients with hereditary pancreatitis and chronic pancreatitis. Chin. Med. J. 2008;121(2):108-11.

69. Kubisch CH, Logsdon CD. Endoplasmic reticulum stress and the pancreatic acinar cell. Expert Rev Gastroenterol Hepatol. 2008;2(2):249-60.

70. Szmola R, Sahin-Tóth M. Pancreatitis-associated chymotrypsinogen C (CTRC) mutant elicits endoplasmic reticulum stress in pancreatic acinar cells. Gut. 2010;59(3):365-72.

71. Beer S, Zhou J, Szabó A, Keiles S, Chandak GR, Witt H, et al. Comprehensive functional analysis of chymotrypsin $\mathrm{C}$ (CTRC) variants reveals distinct loss-of-function mechanisms associated with pancreatitis risk. Gut. 2012;

72. Chen JM, Masson E, Le Maréchal C, Férec C. Copy number variations in chronic pancreatitis. Cytogenet. Genome Res. 2008;123(1-4):102-7.

73. Le Maréchal C, Masson E, Chen J-M, Morel F, Ruszniewski P, Levy P, et al. Hereditary pancreatitis caused by triplication of the trypsinogen locus. Nat. Genet. 2006 ;38(12):1372-4.

74. Whitcomb DC, LaRusch J, Krasinskas AM, Klei L, Smith JP, Brand RE, et al. Common genetic variants in the CLDN2 and PRSS1-PRSS2 loci alter risk for alcohol-related and sporadic pancreatitis. Nat. Genet. 2012;44(12):1349-54.

75. Németh ZH, Mabley JG, Deitch EA, Szabó C, Haskó G. Inhibition of the $\mathrm{Na}(+) / \mathrm{H}(+)$ antiporter suppresses IL-12 p40 production by mouse macrophages. Biochim. Biophys. Acta. 2001; 20;1539(3):233-42. 
76. Németh ZH, Deitch EA, Szabó C, Mabley JG, Pacher P, Fekete Z, et al. Na+/H+ exchanger blockade inhibits enterocyte inflammatory response and protects against colitis. Am. J. Physiol. Gastrointest. Liver Physiol. 2002;283(1):G122-132.

77. Rolfe MW, Kunkel SL, Rowens B, Standiford TJ, Cragoe EJ Jr, Strieter RM. Suppression of human alveolar macrophage-derived cytokines by amiloride. Am. J. Respir. Cell Mol. Biol. 1992;6(6):576-82.

78. Shi Y, Kim D, Caldwell M, Sun D. The role of $\mathrm{Na}(+) / \mathrm{h}(+)$ exchanger isoform 1 in inflammatory responses: maintaining $\mathrm{H}(+)$ homeostasis of immune cells. Adv. Exp. Med. Biol. 2013;961:411-8.

79. De Vito P. The sodium/hydrogen exchanger: a possible mediator of immunity. Cell. Immunol. 2006;240(2):69-85.

80. Farkas K, Yeruva S, Rakonczay Z Jr, Ludolph L, Molnár T, Nagy F, et al. New therapeutic targets in ulcerative colitis: the importance of ion transporters in the human colon. Inflamm. Bowel Dis. 2011;17(4):884-98.

81. Czepán M, Rakonczay Z Jr, Varró A, Steele I, Dimaline R, Lertkowit N, et al. NHE1 activity contributes to migration and is necessary for proliferation of human gastric myofibroblasts. Pflugers Arch. 2012;463(3):459-75.

82. Desmoulière A, Guyot C, Gabbiani G. The stroma reaction myofibroblast: a key player in the control of tumor cell behavior. Int. J. Dev. Biol. 2004;48(5-6):509-17. 
Articles closely related to the subject of the thesis and cited in the thesis 


$$
\text { I. }
$$


ORIGINAL ARTICLE

\title{
Functional effects of 13 rare PRSS1 variants presumed to cause chronic pancreatitis
}

\author{
Andrea Schnúr, ${ }^{1,2}$ Sebastian Beer, ${ }^{1}$ Heiko Witt, ${ }^{3,4}$ Péter Hegyi, ${ }^{2}$ Miklós Sahin-Tóth ${ }^{1}$
}

- Additional material is published online only. To view please visit the journal online (http://dx.doi.org/10.1136/ gutjnl-2012-304331)

${ }^{1}$ Department of Molecular and Cell Biology, Henry

M. Goldman School of Dental Medicine, Boston University, Boston, Massachusetts, USA

${ }^{2}$ First Department of Medicine, University of Szeged, Szeged, Hungary

${ }^{3}$ Else Kröner-Fresenius-Zentrum für Ernährungsmedizin (EKFZ) \& Zentralinstitut für Ernährungsund Lebensmittelforschung (ZIEL), Technische Universität München (TUM), Freising,

Germany

${ }^{4}$ Department of Pediatrics, Klinikum rechts der Isar (MRI), Technische Universität München (TUM), Munich, Germany

Correspondence to Dr Miklós Sahin-Tóth, Department of Molecular and Cell Biology, Henry

M. Goldman School of Dental Medicine, Boston University, 72 East Concord Street,

Evans-433; Boston,

MA 02118, USA miklos@bu.edu

Received 13 December 2012 Revised 3 February 2013 Accepted 5 February 2013

To cite: Schnúr $A$, Beer $S$ Witt $H$, et al. Gut Published Online First: [please include Day Month Year] doi:10.1136/gutjnl-2012 304331

\section{ABSTRACT}

Objective Hereditary pancreatitis is caused by mutations in human cationic trypsinogen (PRSS1) which lead to increased autoactivation by altering chymotrypsin C (CTRC)-dependent trypsinogen activation and degradation. Exceptions are some cysteine mutations which cause misfolding, intracellular retention and endoplasmic reticulum stress. Clinical relevance of many PRSS1 variants found in patients with sporadic chronic pancreatitis is unknown but often assumed by analogy with known disease-causing mutations. Functional comparison of PRSS1 variants found in sporadic and hereditary cases is needed to resolve this dilemma. Design Here, we investigated the functional phenotype of 13 published PRSS1 variants with respect to autoactivation in the presence of CTRC and cellular secretion.

Results Only mutation p.D100H increased trypsinogen autoactivation, but this gain in function was offset by a marked reduction in secretion. Five mutants (p.P36R, p.G83E, p.I88N, p.V123M, p.S124F) showed decreased autoactivation due to increased degradation by CTRC. Five mutants exhibited strongly (p.D100H, p.C139F) or moderately (p.K92N, p.S124F, p.G208A) reduced secretion, whereas mutant p.K170E showed slightly increased secretion. Mutant p.I88N was also secreted to higher levels but was rapidly degraded by CTRC. Finally, three mutants (p.Q98K, p.T137M, p.S181G) had no phenotypic alterations relative to wild-type trypsinogen. Conclusions Rare PRSS1 variants found in sporadic chronic pancreatitis do not stimulate autoactivation but may cause increased degradation, impaired secretion or no functional change. Variants with reduced secretion are likely pathogenic due to mutation-induced misfolding and consequent endoplasmic reticulum stress.

\section{INTRODUCTION}

Hereditary pancreatitis is an autosomal dominant disorder caused by mutations in the serine protease 1 (PRSS1) gene that codes for cationic trypsinogen. ${ }^{1}$ Causative mutations are p.R122H ( 65\%), p.N29I $(\sim 25 \%)$ and less frequently p.A16V, p.D22G, p.K23R， p.K23_I24insIDK， p.N29T， p.V39A, p.R116C and p.R $122 C .{ }^{1-5}$ To date, 21 additional rare missense PRSS1 variants have been reported, the majority of which were found in patients with sporadic chronic pancreatitis with no family history ${ }^{5}$ (http://www.pancreasgenetics.org). The mechanism of action of hereditary pancreatitis-associated mutations involves increased autoactivation of mutant trypsinogens resulting in elevated intrapancreatic trypsin activity levels ${ }^{6}$ (figure 1). Recent studies uncovered that PRSS1 mutations alter the regulation

\section{Significance of this study}

What is already known on this subject?

- Hereditary pancreatitis is caused by mutations in human cationic trypsinogen (PRSS1) that increase autoactivation.

- Some pathogenic PRSS1 variants misfold, suffer intracellular retention and cause endoplasmic reticulum stress.

- Clinical relevance of rare PRSS1 variants found in subjects with sporadic chronic pancreatitis is uncertain but frequently assumed.

What are the new findings?

- Rare PRSS1 variants found in sporadic chronic pancreatitis do not increase trypsinogen activation.

- Rather, they cause increased degradation, loss of secretion or no functional change.

- Reduced secretion is indicative of misfolding that may increase pancreatitis risk through endoplasmic reticulum stress.

How might it impact on clinical practice in the foreseeable future?

- Functional classification of PRSS1 variants found in patients with chronic pancreatitis is required for determination of clinical relevance.

of activation and degradation of cationic trypsinogen by chymotrypsin C (CTRC). The digestive enzyme CTRC stimulates trypsinogen activation by processing the activation peptide to a shorter form, which is easier cleaved by trypsin. ${ }^{7}$ Somewhat paradoxically, CTRC also promotes degradation of trypsinogen by cleaving the calcium binding loop. ${ }^{6} 8$ This cleavage in combination with a trypsinmediated autolytic cleavage results in inactivation of trypsinogen during autoactivation and lower trypsin levels attained. Pancreatitis-associated mutations render trypsinogen resistant to CTRC-dependent degradation and/or increase $\mathrm{N}$-terminal processing by CTRC and thereby elevate trypsin levels generated through autoactivation ${ }^{6}$ (figure 1 ).

The unifying pathological mechanism described above does not seem to apply to some mutations that alter the number of cysteine residues in cationic trypsinogen. Hereditary pancreatitisassociated mutation p.R116C was shown to induce protein misfolding with intracellular retention and degradation, which may represent an alternative 


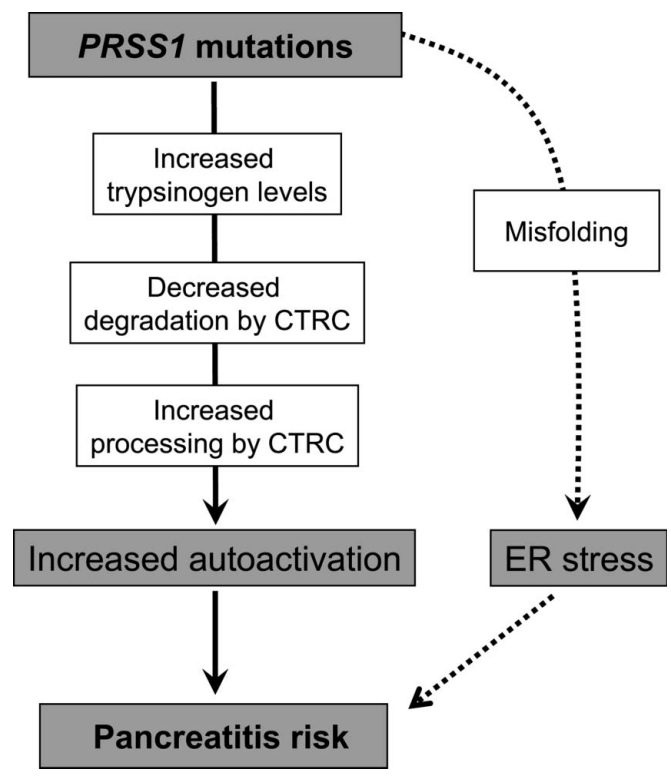

Figure 1 Pathological pathways associated with PRSS1 mutations in hereditary and sporadic chronic pancreatitis. Mutations in PRSS1 can increase autoactivation of cationic trypsinogen by different mechanisms: increased trypsinogen expression or secretion; inhibition of chymotrypsin C (CTRC)-dependent trypsinogen degradation, stimulation of $\mathrm{N}$-terminal processing of the trypsinogen activation peptide by CTRC; and direct stimulation of autoactivation. Alternatively, PRSS1 mutations can cause misfolding and endoplasmic reticulum (ER) stress. See text for further details.

disease-causing mechanism unrelated to trypsinogen activation and trypsin activity. ${ }^{9}$ Mutation p.C139S, which was reported in sporadic cases of chronic pancreatitis, exhibits similar properties. ${ }^{9}$ Mutation-dependent misfolding can elicit endoplasmic reticulum (ER) stress, which might be responsible for increased pancreatitis risk, although the mechanism remains unclear (figure 1).

In the present study, we surveyed the functional properties of 13 rare missense PRSS1 variants found in patients with sporadic chronic pancreatitis. Our primary objective was to test whether these variants also exhibit increased activation in the presence of CTRC as previously seen with disease-causing mutants in hereditary pancreatitis. A second objective of the study was to assess cellular secretion of the mutants to determine whether mutation-induced changes in folding and secretion may be a more common phenotype of PRSS1 variants than previously appreciated.

\section{EXPERIMENTAL PROCEDURES \\ Nomenclature}

Amino acid residues in human cationic trypsinogen (serine protease $1, P R S S 1)$ are numbered starting with the initiator methionine of the primary translation product in accordance with the recommendations of the Human Genome Variation Society.

\section{Plasmid construction and mutagenesis}

The pTrapT7 intein-PRSS1, pcDNA3.1(-) PRSS1 and pcDNA3.1(-) CTRC 10His expression plasmids were constructed previously. $^{7} 8{ }^{10}$ Missense mutations were introduced by overlap extension PCR mutagenesis, cloned into the expression plasmids and verified by DNA sequencing.
Expression and purification of trypsinogen

Wild-type and mutant trypsinogens were expressed in the aminopeptidase P deficient LG-3 Escherichia coli strain as fusions with a self-splicing mini-intein, as described in. ${ }^{10}{ }^{11}$ This expression system was developed to produce recombinant trypsinogen with uniform, authentic $\mathrm{N}$-termini. Isolation of cytoplasmic inclusion bodies, in vitro refolding and purification with ecotin affinity chromatography were carried out according to published protocols. ${ }^{10} 11$ Mutant p.C139F could not be purified by this method, as it misfolded during in vitro refolding. Concentrations of trypsinogen preparations were calculated from their ultraviolet absorbance at $280 \mathrm{~nm}$ using the extinction coefficient $37525 \mathrm{M}^{-1} \mathrm{~cm}^{-1}$.

\section{Cell culture and transfection}

Human embryonic kidney 293T (HEK 293T) cells were cultured and transfected as described previously. ${ }^{12}$ Transfections were performed using $1 \mu \mathrm{g}$ expression plasmid and $2.5 \mu \mathrm{l}$ Lipofectamine 2000 (Invitrogen, Carlsbad, California, USA) in $2 \mathrm{ml}$ Dulbecco's Modified Eagle Medium. After overnight incubation, cells were washed and the transfection medium was replaced with $2 \mathrm{ml}$ OPTI-MEM I Reduced Serum Medium (Invitrogen) containing $1 \mathrm{mM}$ benzamidine (final concentration) to inhibit autoactivation of secreted trypsinogen. Conditioned media were harvested $24 \mathrm{~h}$ after addition of OPTI-MEM.

\section{Expression and purification of human CTRC}

Large-scale expression of human CTRC in HEK 293T cells and purification from the conditioned medium using nickel-affinity chromatography were performed as reported previously. ${ }^{6}$ CTRC was activated with human cationic trypsin and active CTRC concentrations were determined by active site titration with ecotin, as described. ${ }^{13}$

\section{Trypsinogen autoactivation in the presence of CTRC}

Trypsinogen at $1 \mu \mathrm{M}$ concentration was incubated with $5 \mathrm{nM}$ human CTRC and $10 \mathrm{nM}$ cationic trypsin in $0.1 \mathrm{M}$ Tris- $\mathrm{HCl}$ ( $\mathrm{pH} 8.0$ ), $1 \mathrm{mM} \mathrm{CaCl} 2$ and $0.05 \%$ Tween-20 (final concentrations) at $37^{\circ} \mathrm{C}$. At given times, $2 \mu \mathrm{l}$ aliquots were withdrawn and mixed with $48 \mu \mathrm{l}$ assay buffer containing $0.1 \mathrm{M}$ Tris- $\mathrm{HCl}(\mathrm{pH}$ 8.0), $1 \mathrm{mM} \mathrm{CaCl}$ and $0.05 \%$ Tween-20. Trypsin activity was measured by adding $150 \mu \mathrm{l} 200 \mu \mathrm{M}$ N-CBZ-Gly-ProArg-p-nitroanilide substrate and following the release of the yellow p-nitroanilin at $405 \mathrm{~nm}$ in a SpectraMax plus384 microplate reader (Molecular Devices, Sunnyvale, California, USA) for $1 \mathrm{~min}$. Reaction rates were calculated from fits to the initial linear portions of the curves. The trypsin substrate was dissolved in $0.1 \mathrm{M}$ Tris- $\mathrm{HCl}$ ( $\mathrm{pH} 8.0$ ), $1 \mathrm{mM} \mathrm{CaCl}_{2}$ and $0.05 \%$ Tween-20.

\section{Measurement of trypsin activity in conditioned media}

Aliquots $(50 \mu \mathrm{l})$ of conditioned media were supplemented with $5 \mu \mathrm{l} 1 \mathrm{M}$ Tris- $\mathrm{HCl}(\mathrm{pH} 8.0)$ and $1 \mu \mathrm{l} 0.5 \mathrm{M} \mathrm{CaCl}_{2}$ and trypsinogens were activated by adding $1 \mu \mathrm{l} 1.4 \mu \mathrm{g} / \mathrm{ml}$ human enteropeptidase (R\&D Systems, Minneapolis, Minnesota, USA). After incubation for $1 \mathrm{~h}$ at $37^{\circ} \mathrm{C}$, a $50 \mu \mathrm{l}$ aliqout was removed and mixed with $150 \mu \mathrm{l} 200 \mu \mathrm{M}$ N-CBZ-Gly-Pro-Arg-p-nitroanilide substrate. Activity was determined as described above.

\section{Sodium dodecyl sulfate-polyacrylamide (SDS-PAGE) and} western blotting

Conditioned media $(200 \mu \mathrm{l})$ was precipitated with $10 \%$ trichloroacetic acid (final concentration), resuspended in $20 \mu \mathrm{l}$ Laemmli sample buffer containing $100 \mathrm{mM}$ dithiothreitol, 
heat-denatured at $95^{\circ} \mathrm{C}$ for $5 \mathrm{~min}$ and run on $15 \%$ SDS-polyacrylamide gels. The gels were stained with Coomassie Blue R-250. For western blotting, $5 \mu \mathrm{l}$ conditioned media were directly mixed with sample buffer and electrophoresed as described above. Proteins were transferred onto an Immobilon-P membrane (Millipore Corporation, Bedford, Massachusetts, USA) at $300 \mathrm{~mA}$ for $1.5 \mathrm{~h}$. The membrane was blocked with $5 \%$ milk powder dissolved in phosphate-buffered saline supplemented with $0.1 \%$ Tween- 20 (final concentration), at $4^{\circ} \mathrm{C}$ overnight. Trypsinogen was detected with a sheep polyclonal antibody (R\&D Systems, \#AF3848) used at a dilution of 1:5000 followed by horse-radish peroxidase (HRP)-conjugated donkey polyclonal antisheep IgG (R\&D Systems, \#HAF016) used at 1:2000 dilution. Incubations with primary and secondary antibodies were performed at room temperature for $1 \mathrm{~h}$ each. HRP was detected using the SuperSignal West Pico Chemiluminescent Substrate (Thermo Scientific). Quantitation of bands was carried out with the Image Lab 3.0 (Bio-Rad) software.

\section{RESULTS}

PRSS1 variants found in subjects with sporadic chronic pancreatitis

We studied here 13 missense PRSS1 variants found in patients with idiopathic chronic pancreatitis or recurrent acute pancreatitis with no family history (table 1 ). The variants were detected in the heterozygous state, with the exception of p.G208A, which was also identified in a homozygous individual. As indicated, the variants were found only in one to three cases each; therefore, the genetic information was insufficient to determine whether these variants are pathogenic or neutral. Unaffected carrier parent was reported in two cases, for variant p.C139F and p.S181G. Note that variants p.T137M, p.K170E and p.G208A were from subjects of Asian origin, whereas all other variants were from subjects of European origin.

To determine whether these 13 variants are prevalent in the general population, we consulted the NHLBI Exome Sequencing Project Exome Variant Server (http://evs.gs.washington.edu) which lists aggregate exome-sequencing data for approximately 4300 European-American and 2200 African-American individuals. We found PRSS1 variants p.V123M and p.T137M in one European-American subject each and variant p.S181G in one African-American subject. However, interpretation of these findings is difficult, because the database also lists the disease-causing mutation p.R122C found in two European-American individuals, suggesting that the studied cohort may have contained pancreatitis patients. Therefore, we sequenced exon-3 of the PRSS1 gene in 1000 German subjects without any pancreatic disease. Exon-3 was selected because most of the studied variants (nine of 13) were in this region. With the exception of a novel c.367G $>$ T (p.V123L) variant found in one subject, no other alterations were identified.

Table 1 Rare PRSS1 variants in pancreatitis

\begin{tabular}{|c|c|c|c|c|c|}
\hline Region & Nucleotide change & Amino acid change & Carriers reported & Clinical and genetic information & Citations \\
\hline Exon 2 & c. $107 C>G$ & p.P36R & 2 & French $\mathrm{m}$ and $\mathrm{fm}, \mathrm{ICP}$ & $14 *$ \\
\hline Exon 3 & c. $248 \mathrm{G}>\mathrm{A}$ & p.G83E & 1 & Italian, ICP & $14 *$ \\
\hline Exon 3 & c. $263 \mathrm{~T}>\mathrm{A}$ & p. $188 \mathrm{~N}$ & 1 & $\begin{array}{l}18 \text { years white } \mathrm{fm}, \mathrm{CP} \\
\text { No SPINK1 or CFTR mut }\end{array}$ & 23 \\
\hline Exon 3 & c. $276 \mathrm{G}>\mathrm{T}$ & p.K92N & 1 & Italian, ICP & $14 *$ \\
\hline Exon 3 & c. $292 C>A$ & p.Q98K & 1 & $\begin{array}{l}55 \text { years French } \mathrm{m}, \mathrm{CP} \\
\text { No SPINK1, CTRC or CFTR mut }\end{array}$ & ${ }^{4}+$ \\
\hline Exon 3 & c. $298 \mathrm{G}>\mathrm{C}$ & p.D100H & 1 & German m, ICP & 24 \\
\hline Exon 3 & c. $367 \mathrm{G}>\mathrm{A}$ & p.V123M & 1 & French $\mathrm{fm}, \mathrm{ICP}$ & $14 *$ \\
\hline Exon 3 & c. $371 C>T$ & p.S124F & 1 & $\begin{array}{l}46 \text { years German fm, ICP } \\
\text { No SPINK1, CTRC or CFTR mut }\end{array}$ & 25 \\
\hline \multirow[t]{3}{*}{ Exon 3} & c. $410 C>T$ & p.T137M & 3 & $\begin{array}{l}13 \text { years Asian fm, AP } \\
\text { No SPINK1 or CFTR mut }\end{array}$ & 23 \\
\hline & & & & $\begin{array}{l}\text { Chinese, late onset ICP } \\
\text { No SPINK1 mut }\end{array}$ & 16 \\
\hline & & & & $\begin{array}{l}28 \text { years Chinese, pancreatic cancer } \\
\text { Also carried p.T135A PRSS1 }\end{array}$ & 17 \\
\hline \multirow[t]{2}{*}{ Exon 3} & c. $416 \mathrm{G}>\mathrm{T}$ & p.C139F & 2 & $\begin{array}{l}14 \text { years German m, RAP } \\
\text { Unaffected mother carrier }\end{array}$ & 15 \\
\hline & & & & $\begin{array}{l}8 \text { years } \mathrm{fm}, \mathrm{CP} \text { with chronic pain } \\
\text { No SPINK1 or CFTR mut }\end{array}$ & 26 \\
\hline Exon 4 & c. $508 \mathrm{~A}>\mathrm{G}$ & p.K170E & 1 & $\begin{array}{l}30 \text { years Indian } \mathrm{m}, \mathrm{CP} \\
\text { No SPINK1, CTRC or CFTR mut }\end{array}$ & ${ }^{4}+$ \\
\hline Exon 4 & c. $541 \mathrm{~A}>\mathrm{G}$ & p.S181G & 1 & $\begin{array}{l}6 \text { years Italian m, RAP } \\
\text { p.F508del CFTR } \\
\text { Unaffected mother carrier }\end{array}$ & 27 \\
\hline \multirow[t]{3}{*}{ Exon 5} & c. $623 \mathrm{G}>\mathrm{C}$ & p.G208A & 3 & $\begin{array}{l}12 \text { years Asian m, pancreatitis, hm } \\
\text { p.F508del and p.Q1352H CFTR }\end{array}$ & 23 \\
\hline & & & & $\begin{array}{l}\text { Korean child, RAP } \\
\text { No SPINK1 mut }\end{array}$ & 18 \\
\hline & & & & 7 years Korean, necrotising AP & 18 \\
\hline
\end{tabular}


This observation is in agreement with published sequencing data showing the absence of these 13 PRSS1 variants in 200 French, ${ }^{14}$ 82 German, ${ }^{15} 420$ Chinese $^{16} 17$ and 28 Korean ${ }^{18}$ control subjects. We conclude that the 13 PRSS1 variants presumed to cause chronic pancreatitis (table 1) are not generally found in a healthy population.

\section{Autoactivation and catalytic activity of PRSS1 variants}

First, trypsinogen variants were characterised for their ability to autoactivate in the absence of CTRC. When measured at $\mathrm{pH} 8.0$, in $1 \mathrm{mM} \mathrm{Ca}^{2+}$, only one mutant, p.D100H, exhibited increased autoactivation, which was about 2.5 -fold faster than wild type (see online supplementary figure S1A). Five mutants (p.Q98K, p.T137M, p.K170E, p.S181G and p.G208A) autoactivated as well as wild-type cationic trypsinogen (see online supplementary figure S1B). Mutants p.K92N and p.S124F autoactivated at a decreased rate but reached essentially the same final trypsin levels as wild-type trypsinogen (see online supplementary figure S1C). In contrast, four mutants exhibited decreased rates of autoactivation (p.P36R, p.G83E, p.I88N and p.V123M) with reduced final trypsin levels, suggesting that these mutants may become partially degraded during autoactivation (see online supplementary figure S1D).

Catalytic activity of the activated trypsin variants was measured with the synthetic peptide substrate N-CBZ-Gly-Pro-Argp-nitroanilide. As shown in online supplementary table S1, enzyme kinetic parameters of trypsin variants were comparable with those of wild-type cationic trypsin. This finding is consistent with previous observations that natural PRSS1 variants almost never affect catalytic function of trypsin.

Note that mutant p.C139F could not be purified in sufficient quantities due to misfolding; therefore, it was not tested in the autoactivation and catalytic activity assays.

\section{Autoactivation of PRSS1 variants in the presence of CTRC}

To determine the effect of CTRC on the trypsinogen variants, we measured autoactivation in the presence of $5 \mathrm{nM}$ human CTRC. This low CTRC concentration slightly stimulates the rate of autoactivation but causes a reduction in final active trypsin levels due to trypsinogen degradation during activation. ${ }^{6}$ In the experiments presented, wild-type cationic trypsinogen reached about $50 \%$ activity in the presence of CTRC, relative to trypsin activity observed in the absence of CTRC (not shown, also see figure $\left.1 \mathrm{~A} \mathrm{in}{ }^{6}\right)$. Under these conditions, both increases and decreases in autoactivation are readily detectable.

Only one of the 12 variants tested, p.D100H, exhibited increased activation in the presence of CTRC (figure 2A). A similar phenotype was observed with this mutant when autoactivation was performed in the absence of CTRC (see above), indicating that the mutation increases autoactivation independent of CTRC. Consistent with this interpretation, degradation of p.D100H mutant trypsinogen and trypsin by CTRC was unchanged (not shown). Six mutants (p.K92N, p.Q98K, p.T137M, p.K170E, p.S181G and p.G208A) autoactivated in the presence of CTRC in a manner that was comparable with wild type (figure 2B). Surprisingly, however, five mutants (p.P36R, p.G83E, p.I88N, p.V123M and p.S124F) reached markedly reduced trypsin activity levels during autoactivation, suggesting increased susceptibility to CTRC-dependent degradation (figure 2C). This notion was confirmed by direct degradation experiments which demonstrated that these five
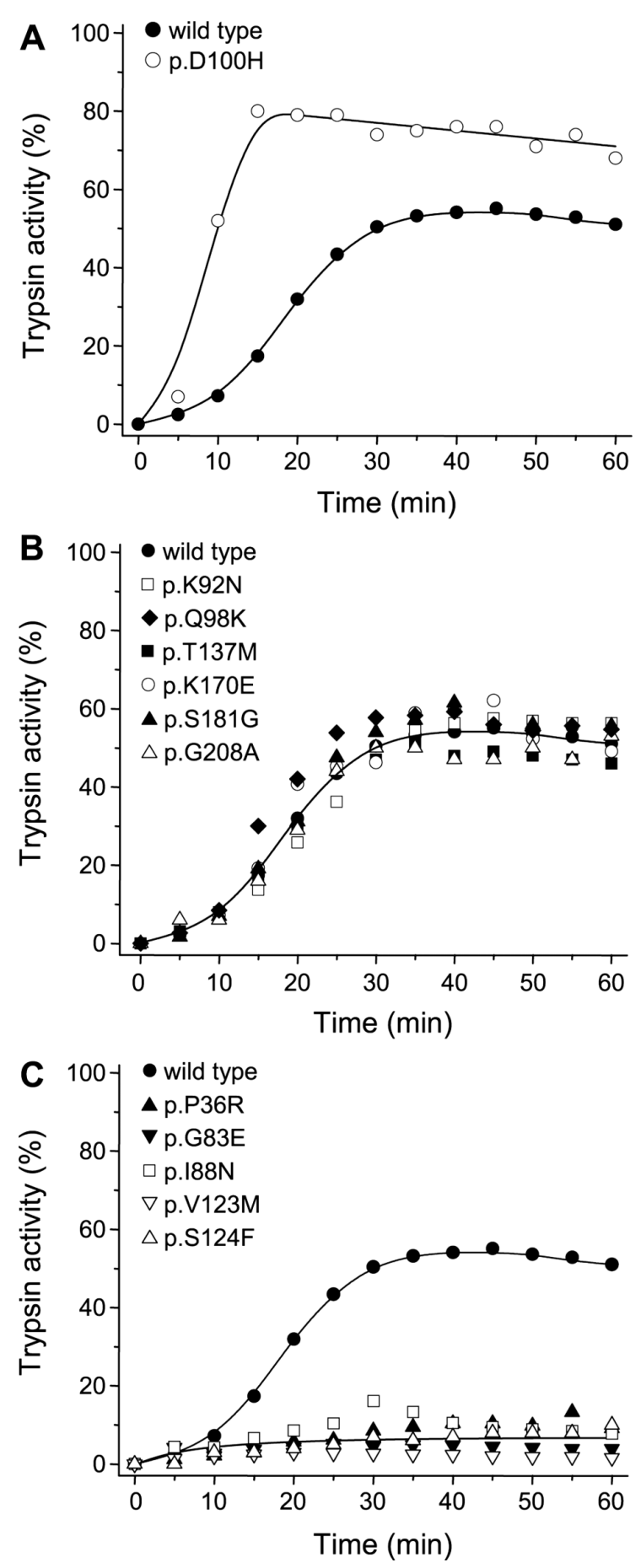

Figure 2 Autoactivation of cationic trypsinogen variants in the presence of chymotrypsin C (CTRC). Trypsinogen was incubated at $1 \mu \mathrm{M}$ concentration with $5 \mathrm{nM}$ CTRC and $10 \mathrm{nM}$ initial trypsin in $0.1 \mathrm{M}$ Tris- $\mathrm{HCl}$ (pH 8.0), $1 \mathrm{mM} \mathrm{CaCl}$ and $0.05 \%$ Tween-20 (final concentrations) at $37^{\circ} \mathrm{C}$. At the indicated times, $2 \mu \mathrm{l}$ aliquots were removed and trypsin activity was measured as described in Experimental procedures section. Trypsin activity was expressed as per cent of the maximal wild-type activity in the absence of CTRC. (A) Mutant with increased autoactivation. (B) Mutants with unchanged autoactivation. (C) Mutants with decreased autoactivation. 
mutants were degraded by CTRC at increased rates (see online supplementary figure S2).

\section{Secretion of PRSS1 variants from HEK 293T cells}

To identify trypsinogen variants defective in folding, we evaluated their secretion from transfected cells to the conditioned medium using SDS-PAGE with Coomassie Blue staining, western blot analysis and trypsin activity measurements after activation with enteropeptidase. The use of HEK 293T cells for cellular secretion studies is a compromise, as efficient transfection of pancreatic acinar cells is not feasible. Despite its constitutive secretion, this cell line remains a good model to study ER related disturbances such as misfolding, retention and degradation of secretory proteins.
Six of 13 mutants tested (p.P36R, p.G83E, p.Q98K, p.V123M, p.T137M and p.S181G) showed trypsinogen secretion close to wild-type levels $(\sim 70 \%-85 \%)$ (figure $3 \mathrm{~A}-\mathrm{C}$, black bars). Severe secretion defects ( $20 \%$ of wild type) were observed with mutants p.D100H and p.C139F. Moderate reduction in secretion ( $40 \%-50 \%$ of wild type) was noted with three mutants (p.K92N, p.S124F and p.G208A). Two mutants (p.I88N and p.K170E) showed increased secretion levels, $140 \%$ and $130 \%$ of wild type, respectively. The higher secretion of mutant p.I88 N was due to the appearance of a second trypsinogen band which represents an aberrantly glycosylated trypsinogen form (figure 3A,B). This band was also observed in a much fainter form with wild-type trypsinogen and all other variants and may be an artefact of the heterologous cell line used.
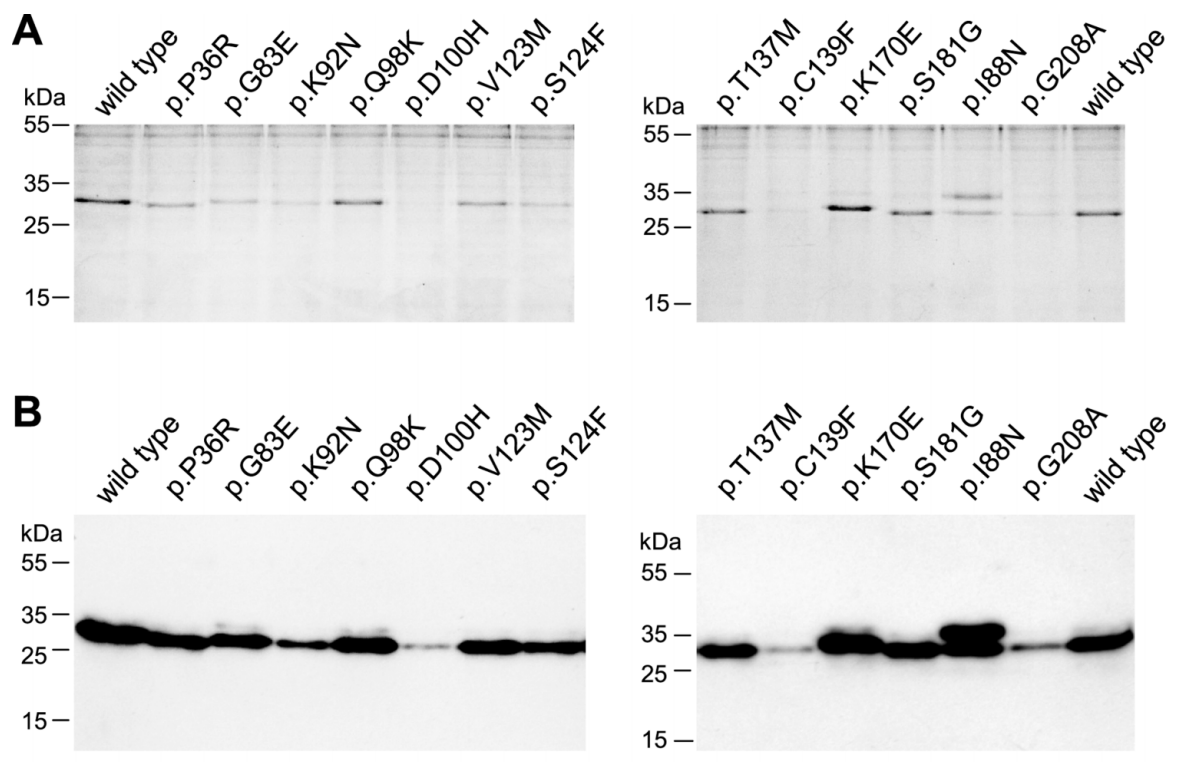

C

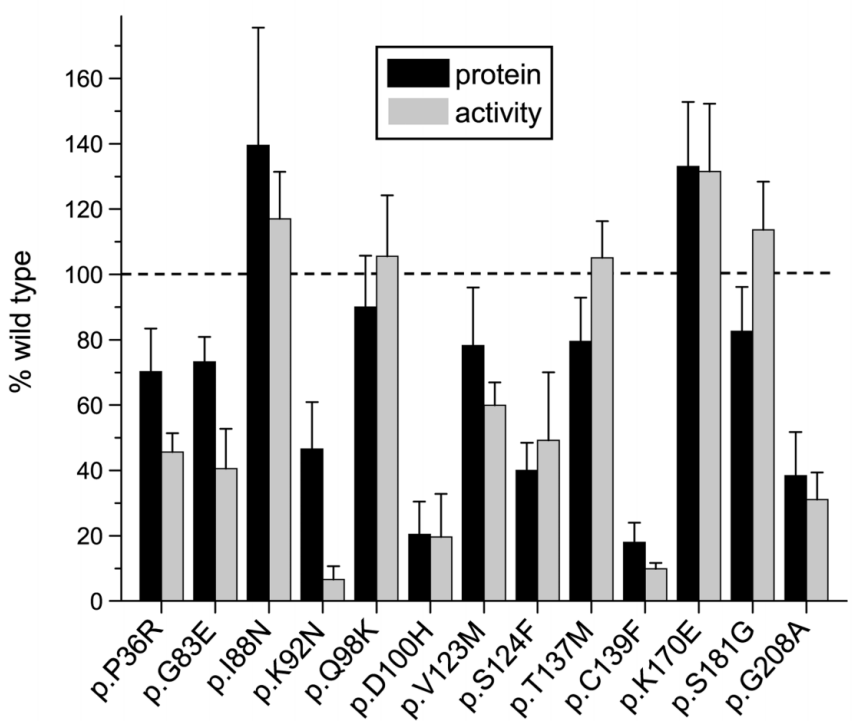

Figure 3 Secretion of cationic trypsinogen variants from HEK 293T cells. Cells were transiently transfected and conditioned media were collected after $24 \mathrm{~h}$. Trypsinogen protein levels were qualitatively analysed on Coomassie Blue stained SDS-polyacrylamide gels (A) and then quantitatively determined by western blots (B) and densitometry ( $C$, black bars). Trypsin activity was measured after activation with enteropeptidase (C, grey bars). See Experimental procedures section for details. Representative gels and blots of four independent experiments are shown. Average of four experiments with SD was plotted. Trypsinogen protein and trypsin activity levels were expressed as per cent of wild-type values. 
Although increased secretion of variant p.I88N may represent a gain of function, the rapid degradation of this variant by CTRC (see above) would cancel out this effect and result in a loss-of-function phenotype. On the other hand, it seems probable that the slightly more efficient secretion of mutant p.K170E may confer an increased risk for pancreatitis.

For the majority of the variants, trypsin activity levels in the conditioned medium correlated well with the protein levels secreted (figure 3C, grey bars). Four variants (p.P36R, p.G83E, p.K92N and p.C139F) had considerably lower enzyme activity relative to their protein levels. Variant p.C139F may be misfolded and catalytically defective, which explains its lower activity, whereas mutants p.P36R and p.G83E suffer some degradation during activation, as seen in the autoactivation experiments in online supplementary figure S1D. The lower activity of mutant p.K92N is unexplained and may be related to increased sensitivity to some inhibitory component in the cell culture medium, because when this mutant was purified either from $E$ coli or from the conditioned medium of transfected HEK 293T cells, wild-type trypsin activity levels were reached after activation with enteropeptidase.

\section{DISCUSSION}

In this study, we investigated the functional properties of 13 rare PRSS1 variants detected in patients with sporadic chronic pancreatitis. The common biochemical phenotype of PRSS1 mutations associated with hereditary pancreatitis is the generation of greatly increased trypsin levels during autoactivation in the presence of CTRC. ${ }^{6}$ This phenomenon is due to increased sensitivity of trypsinogen mutants to CTRC-mediated stimulation of autoactivation and/or resistance to CTRC-dependent trypsinogen degradation (figure 1). Unexpectedly, only one of the investigated 13 mutants exhibited a similar phenotype when autoactivation was tested in the presence of CTRC. Mutant p.D100H autoactivated at a faster rate and reached higher trypsin levels than wild-type trypsinogen; however, this was independent of CTRC as the same phenotype was observed in its absence. More importantly, further studies, discussed below, demonstrated that mutant p.D100H was poorly secreted, which would completely negate any increased propensity for autoactivation and result in diminished trypsin levels upon activation.

Five mutants were degraded by CTRC at an increased rate resulting in lower trypsin levels during autoactivation, relative to wild-type trypsinogen. This biochemical phenotype is inconsistent with the trypsin-dependent model of hereditary pancreatitis and suggests that these variants are not pathogenic (table 2). Previous studies found that PRSS1 mutations p.R116C and p.C139S resulted in reduced trypsinogen secretion. ${ }^{9}$ These mutations alter the number of Cys residues and thus may interfere with correct disulfide formation during folding, which results in intracellular retention and degradation. A similar secretion defect, likely caused by mutation-induced misfolding, was observed in the present study for variants p.D100H and p.C139F and, to a smaller extent, variants p.K92N, p.S124F and p.G208A, suggesting that these variants are pathogenic (table 2). Trypsinogen misfolding underlying the reduced secretion may elicit ER stress and thereby increase the risk for pancreatitis, as previously shown for mutants p.R116C and p.C139S 9 (figure 1). Secretion defect and ER stress was also observed for a subset of CTRC mutants associated with chronic pancreatitis. ${ }^{12} 19$ Increased secretion of mutant trypsinogens may result in higher trypsinogen levels in the pancreatic juice with consequently increased risk for autoactivation (figure 1). Copy number mutations in trypsinogen genes may exert their
Table 2 Clinical relevance of PRSS1 variants classified on the basis of functional phenotype

\begin{tabular}{|c|c|c|c|}
\hline Region & $\begin{array}{l}\text { Nucleotide } \\
\text { change }\end{array}$ & $\begin{array}{l}\text { Amino acid } \\
\text { change }\end{array}$ & Relevant phenotype \\
\hline \multicolumn{4}{|c|}{ Pathogenic variants, strong } \\
\hline Exon 3 & c. $298 \mathrm{G}>\mathrm{C}$ & p.D100H & Severe secretion defect \\
\hline Exon 3 & c. $416 \mathrm{G}>\mathrm{T}$ & p.C139F & Severe secretion defect \\
\hline \multicolumn{4}{|c|}{ Pathogenic variants, mild } \\
\hline Exon 3 & $c .276 \mathrm{G}>\mathrm{T}$ & p.K92N & Moderate secretion defect \\
\hline Exon 3 & c. $371 \mathrm{C}>\mathrm{T}$ & p.S124F & Moderate secretion defect \\
\hline Exon 4 & c. $508 \mathrm{~A}>\mathrm{G}$ & p.K170E & Moderate secretion increase \\
\hline Exon 5 & c. $623 \mathrm{G}>\mathrm{C}$ & p.G208A & Moderate secretion defect \\
\hline \multicolumn{4}{|c|}{ Non-pathogenic variants, functionally neutral } \\
\hline Exon 3 & c. $292 C>A$ & p.Q98K & None \\
\hline Exon 3 & c. $410 \mathrm{C}>\mathrm{T}$ & p.T137M & None \\
\hline Exon 4 & c. $541 \mathrm{~A}>\mathrm{G}$ & p.S181G & None \\
\hline \multicolumn{4}{|c|}{ Non-pathogenic variants, loss of function } \\
\hline Exon 2 & c. $107 C>G$ & p.P36R & Degradation by CTRC \\
\hline Exon 3 & c. $248 \mathrm{G}>\mathrm{A}$ & p.G83E & Degradation by CTRC \\
\hline Exon 3 & c. $263 \mathrm{~T}>\mathrm{A}$ & p. $188 \mathrm{~N}$ & Degradation by CTRC \\
\hline Exon 3 & c. $367 \mathrm{G}>\mathrm{A}$ & p.V123M & Degradation by CTRC \\
\hline
\end{tabular}

pathogenic effect via this mechanism. ${ }^{20} 21$ Conversely, decreased trypsinogen expression due to the c.1-408C $>\mathrm{T}$ polymorphism in the $5^{\prime}$ region is associated with decreased pancreatitis risk. ${ }^{22}$ In this study, we observed slightly increased secretion with two mutants, p.I $88 \mathrm{~N}$ and p.K170E. While the rapid degradation of mutant p.I88 $\mathrm{N}$ by CTRC would counteract the effect of higher trypsinogen concentrations, the phenotype of mutant p.K170E may indicate a true gain of function with potentially elevated risk of pancreatitis (table 2). Finally, three trypsinogen variants (p.Q98K, p.T137M and p.S181G) proved functionally neutral in this study, indicating that PRSS1 variants of no clinical significance may be incidental findings when subjects with chronic pancreatitis are screened for underlying genetic defects (table 2).

In summary, functional analysis of 13 PRSS1 variants found in patients with chronic pancreatitis demonstrated that these rare PRSS1 variants do not phenocopy the disease-causing hereditary pancreatitis-associated PRSS1 mutations. Instead, increased degradation or reduced secretion was observed mostly. Variants with decreased secretion may increase pancreatitis risk through an alternative pathological pathway related to mutation-induced misfolding rather than trypsin activity.

Acknowledgements These studies were supported by NIH grants R01DK058088, R01DK082412, R01DK082412-S2 and R01DK095753 (to MS-T). AS was also supported by a fellowship from the Rosztoczy Foundation in Boston and AS and PH were supported by the TÁMOP-4.2.2/B-10/1-2010-0012 grant in Szeged. The authors thank Vinciane Rebours (Beaujon Hospital, Clichy, France) and Jian-Min Chen (Université de Bretagne Occidentale, Brest, France) for providing unpublished information.

Contributors The study was designed by AS, PH and MS-T. The experiments were performed by AS, SB and HW. The manuscript was written by AS, SB, PH and MS-T. Competing interests None.

Provenance and peer review Not commissioned; externally peer reviewed.

\section{REFERENCES}

1 Whitcomb DC, Gorry MC, Preston RA, et al. Hereditary pancreatitis is caused by a mutation in the cationic trypsinogen gene. Nat Genet 1996;14:141-5.

2 Howes N, Lerch MM, Greenhalf W, et al. Clinical and genetic characteristics of hereditary pancreatitis in Europe. Clin Gastroenterol Hepatol 2004;2:252-61. 
3 Teich $\mathrm{N}$, Rosendahl J, Tóth $\mathrm{M}$, et al. Mutations of human cationic trypsinogen (PRSS1) and chronic pancreatitis. Hum Mutat 2006;27:721-30.

4 Rebours V, Boutron-Ruault MC, Schnee M, et al. The natural history of hereditary pancreatitis: a national series. Gut 2009:58:97-103.

5 Szmola R, Sahin-Tóth M. Uncertainties in the classification of human cationic trypsinogen (PRSS1) variants as hereditary pancreatitis-associated mutations. J Med Genet 2010;47:348-50.

6 Szabó A Sahin-Tóth M. Increased activation of hereditary pancreatitis-associated human cationic trypsinogen mutants in presence of chymotrypsin C. J Biol Chem 2012;287:20701-10

7 Nemoda Z, Sahin-Tóth M. Chymotrypsin C (caldecrin) stimulates autoactivation of human cationic trypsinogen. J Biol Chem 2006:281:11879-86.

8 Szmola R, Sahin-Tóth M. Chymotrypsin C (caldecrin) promotes degradation of human cationic trypsin: identity with Rinderknecht's enzyme Y. Proc Natl Acad Sci USA 2007;104:11227-32.

9 Kereszturi E, Szmola R, Kukor Z, et al. Hereditary pancreatitis caused by mutation-induced misfolding of human cationic trypsinogen: a novel disease mechanism. Hum Mutat 2009;30:575-82.

10 Király 0 , Guan L, Szepessy E, et al. Expression of human cationic trypsinogen with an authentic $\mathrm{N}$ terminus using intein-mediated splicing in aminopeptidase $\mathrm{P}$ deficient Escherichia coli. Protein Expr Purif 2006;48:104-11.

11 Király O, Guan L, Sahin-Tóth M. Expression of recombinant proteins with uniform N-termini. Methods Mol Biol 2011;705:175-94.

12 Beer S, Zhou J, Szabó A, et al. Comprehensive functional analysis of chymotrypsin C (CTRC) variants reveals distinct loss-of-function mechanisms associated with pancreatitis risk. Gut Published Online First: 1 September 2012. doi:10.1136/gutjnl2012-303090

13 Szabó A, Héja D, Szakács D, et al. High affinity small protein inhibitors of human chymotrypsin C (CTRC) selected by phage display reveal unusual preference for $\mathrm{P4}^{\prime}$ acidic residues. J Biol Chem 2011;286:22535-45.

14 Chen JM, Bis A Piepoli, Le Bodic L, et al. Mutational screening of the cationic trypsinogen gene in a large cohort of subjects with idiopathic chronic pancreatitis. Clin Genet 2001;59:189-93.
15 Teich N, Bauer N, Mössner J, et al. Mutational screening of patients with nonalcoholic chronic pancreatitis: identification of further trypsinogen variants. Am J Gastroenterol 2002;97:341-6.

16 Chang YT, Wei SCm L P-C, et al. Association and differential role of PRSS1 and SPINK1 mutation in early-onset and late-onset idiopathic chronic pancreatitis in Chinese subjects. Gut 2009;58:885.

17 Zeng K, Liu QC, Lin JH, et al. Novel mutations of PRSS1 gene in patients with pancreatic cancer among Han population. Chin Med J (Engl) 2011:124:2065-7.

18 Lee YJ, Kim KM, Choi JH, et al. High incidence of PRSS1 and SPINK1 mutations in Korean children with acute recurrent and chronic pancreatitis. J Pediatr Gastroenterol Nutr 2011;52:478-81.

19 Szmola R, Sahin-Tóth M. Pancreatitis-associated chymotrypsinogen C (CTRC) mutant elicits endoplasmic reticulum stress in pancreatic acinar cells. Gut 2010;59:365-72.

20 Le Maréchal C, Masson E, Chen JM, et al. Hereditary pancreatitis caused by triplication of the trypsinogen locus. Nat Genet 2006;38:1372-4.

21 Masson E, Le Maréchal C, Chandak GR, et al. Trypsinogen copy number mutations in patients with idiopathic chronic pancreatitis. Clin Gastroenterol Hepatol 2008;6:82-8.

22 Whitcomb DC, Larusch J, Krasinskas AM, et al. Common genetic variants in the CLDN2 and PRSS1-PRSS2 loci alter risk for alcohol-related and sporadic pancreatitis. Nat Genet 2012:44:1349-54.

23 Keiles S, Kammesheidt A. Identification of CFTR, PRSS1, and SPINK1 mutations in 381 patients with pancreatitis. Pancreas 2006;33:221-7.

24 Tautermann G, Ruebsamen $\mathrm{H}$, Beck M, et al. R116C mutation of cationic trypsinogen in a Turkish family with recurrent pancreatitis illustrates genetic microheterogeneity of hereditary pancreatitis. Digestion 2001;64:226-32.

25 Rosendahl J, Landt O, Bernadova J, et al. CFTR, SPINK1, CTRC and PRSS1 variants in chronic pancreatitis: is the role of mutated CFTR overestimated? Gut Published Online First: 17 March 2012. doi:10.1136/gutinl-2011-300645

26 Sultan M, Werlin S, Venkatasubramani N. Genetic prevalence and characteristics in children with recurrent pancreatitis. J Pediatr Gastroenterol Nutr 2012;54:645-50.

27 Corleto VD, Gambardella S, Gullotta F, et al. New PRSS1 and common CFTR mutations in a child with acute recurrent pancreatitis, could be considered an "Hereditary" form of pancreatitis? BMC Gastroenterol 2010;10:119. 


\title{
GUT Functional effects of 13 rare PRSS1 variants presumed to cause chronic pancreatitis
}

Andrea Schnúr, Sebastian Beer, Heiko Witt, et al.

Gut published online March 1, 2013

doi: 10.1136/gutjnl-2012-304331

Updated information and services can be found at:

http://gut.bmj.com/content/early/2013/02/28/gutjnl-2012-304331.full.html

\section{These include:}

\section{Data Supplement "Supplementary Data" http://gut.bmj.com/content/suppl/2013/02/27/gutjnl-2012-304331.DC1.html \\ References This article cites 25 articles, 8 of which can be accessed free at: http://gut.bmj.com/content/early/2013/02/28/gutjnl-2012-304331.full.html\#ref-list-1 \\ $\mathbf{P}<\mathbf{P} \quad$ Published online March 1, 2013 in advance of the print journal.}

Email alerting Receive free email alerts when new articles cite this article. Sign up in service the box at the top right corner of the online article.

Topic Articles on similar topics can be found in the following collections

Collections

Pancreas and biliary tract (1751 articles)

Pancreatitis (464 articles)

\begin{abstract}
Advance online articles have been peer reviewed, accepted for publication, edited and typeset, but have not not yet appeared in the paper journal. Advance online articles are citable and establish publication priority; they are indexed by PubMed from initial publication. Citations to Advance online articles must include the digital object identifier (DOIs) and date of initial publication.
\end{abstract}

\section{To request permissions go to:}

http://group.bmj.com/group/rights-licensing/permissions

To order reprints go to:

http://journals.bmj.com/cgi/reprintform

To subscribe to BMJ go to:

http://group.bmj.com/subscribe/ 
Downloaded from gut.bmj.com on April 29, 2013 - Published by group.bmj.com

Notes

Advance online articles have been peer reviewed, accepted for publication, edited and typeset, but have not not yet appeared in the paper journal. Advance online articles are citable and establish publication priority; they are indexed by PubMed from initial publication. Citations to Advance online articles must include the digital object identifier (DOIs) and date of initial publication.

To request permissions go to:

http://group.bmj.com/group/rights-licensing/permissions

To order reprints go to:

http://journals.bmj.com/cgi/reprintform

To subscribe to BMJ go to:

http://group.bmj.com/subscribe/ 


\title{
SUPPLEMENTARY MATERIAL
}

\section{Functional effects of 13 rare $P R S S 1$ variants presumed to cause chronic pancreatitis}

\author{
Andrea Schnúr ${ }^{1,2}$, Sebastian Beer ${ }^{1}$, Heiko Witt ${ }^{3,4}$, Péter Hegyi ${ }^{2}$, Miklós Sahin-Tóth ${ }^{1}$ * \\ ${ }^{1}$ Department of Molecular and Cell Biology, Henry M. Goldman School of Dental Medicine, \\ Boston University, Boston, MA 02118; ${ }^{2}$ First Department of Medicine, University of Szeged, \\ Szeged, Hungary; ${ }^{3}$ Else Kröner-Fresenius-Zentrum für Ernährungsmedizin (EKFZ) \& \\ Zentralinstitut für Ernährungs- und Lebensmittelforschung (ZIEL), Technische Universität \\ München (TUM), 85350 Freising, Germany; ${ }^{4}$ Department of Pediatrics, Klinikum rechts der Isar \\ (MRI), Technische Universität München (TUM), 80804 Munich, Germany
}


Supplementary Table S1. Kinetic parameters of wild-type and mutant human cationic trypsin on the synthetic substrate $\mathrm{N}$-CBZ-Gly-Pro-Arg-p-nitroanilide, measured in $0.1 \mathrm{M}$ Tris- $\mathrm{HCl}(\mathrm{pH}$ $8.0), 1 \mathrm{mM} \mathrm{CaCl}_{2}$ and $0.05 \%$ Tween 20 , at $22{ }^{\circ} \mathrm{C}$.

\begin{tabular}{|l|c|c|c|}
\hline & $k_{\text {cat }}\left(\mathrm{s}^{-1}\right)$ & $\mathrm{K}_{\mathrm{M}}(\mu \mathrm{M})$ & $k_{\text {cat }} / \mathrm{K}_{\mathrm{M}}\left(\mathrm{s}^{-1} \cdot \mathrm{M}^{-1}\right)$ \\
\hline wild type & 95.3 & 17.6 & 5.4 \\
\hline p.P36R & 86.6 & 19.1 & 4.5 \\
\hline p.G83E & 92.8 & 14.7 & 6.3 \\
\hline p.I88N & 80.8 & 16.2 & 5.0 \\
\hline p.K92N & 99.7 & 16.9 & 5.9 \\
\hline p.Q98K & 95.4 & 16.3 & 5.8 \\
\hline p.D100H & 77.6 & 15.8 & 4.9 \\
\hline p.V123M & 90.9 & 17.4 & 5.2 \\
\hline p.S124F & 91.6 & 16.1 & 5.7 \\
\hline p.T137M & 102.3 & 17.1 & 6.0 \\
\hline p.K170E & 107.8 & 14.4 & 7.5 \\
\hline p.S181G & 103.7 & 18.4 & 5.6 \\
\hline p.G208A & 89.7 & 17.5 & 5.1 \\
\hline
\end{tabular}


A

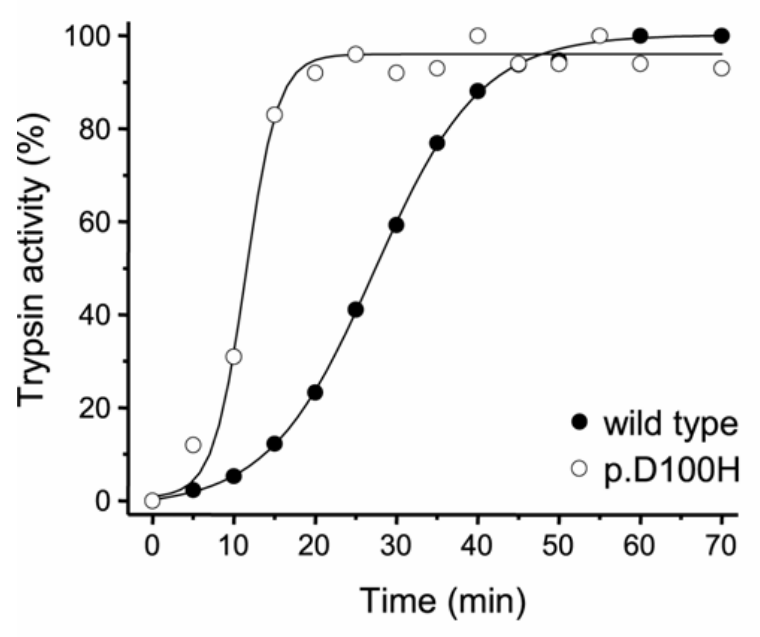

C

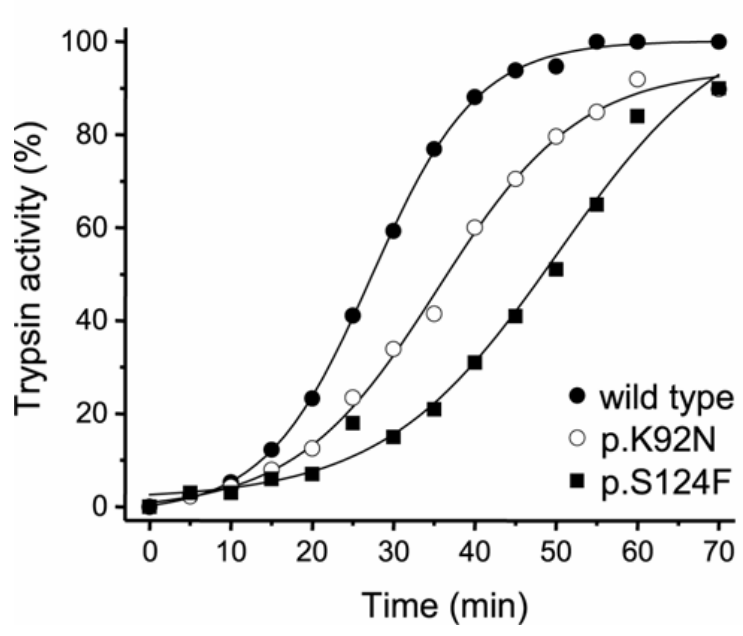

B

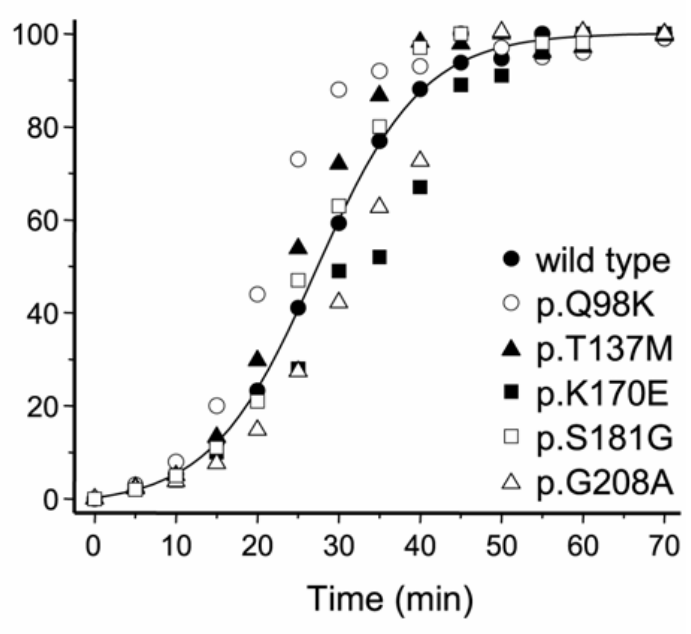

D

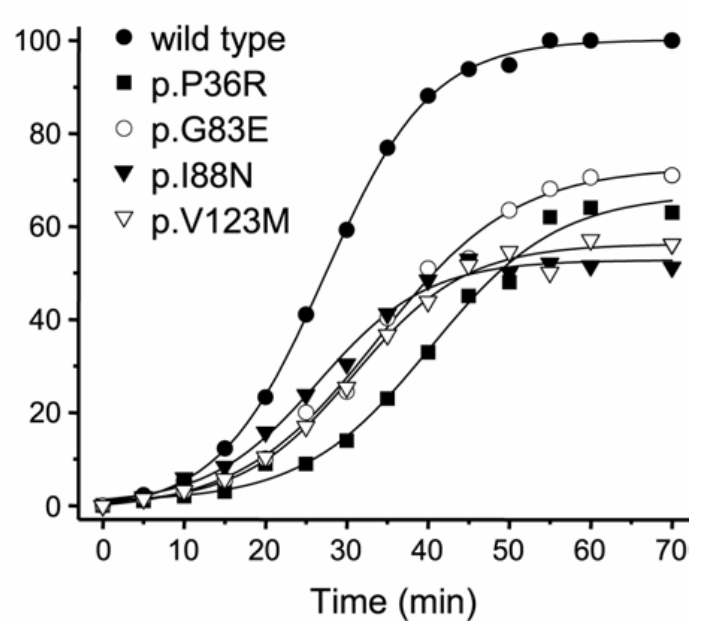

Supplementary Figure S1. Autoactivation of cationic trypsinogen variants in the absence of chymotrypsin $\mathrm{C}(\mathrm{CTRC})$. Trypsinogen $(1 \mu \mathrm{M})$ was incubated with $10 \mathrm{nM}$ initial trypsin in $0.1 \mathrm{M}$ Tris- $\mathrm{HCl}(\mathrm{pH} 8.0), 1 \mathrm{mM} \mathrm{CaCl}_{2}$ and $0.05 \%$ Tween-20 (final concentrations) at $37^{\circ} \mathrm{C}$. At the indicated times, $2 \mu \mathrm{L}$ aliquots were removed and trypsin activity was measured as described in Experimental Procedures. Trypsin activity was expressed as percent of the maximal wild-type activity. A, mutant with increased rate of autoactivation, B, mutants with unchanged autoactivation; $\mathbf{C}$, mutants with decreased rates of autoactivation but normal final trypsin levels; D, mutants with decreased rates of autoactivation and reduced final trypsin levels. 

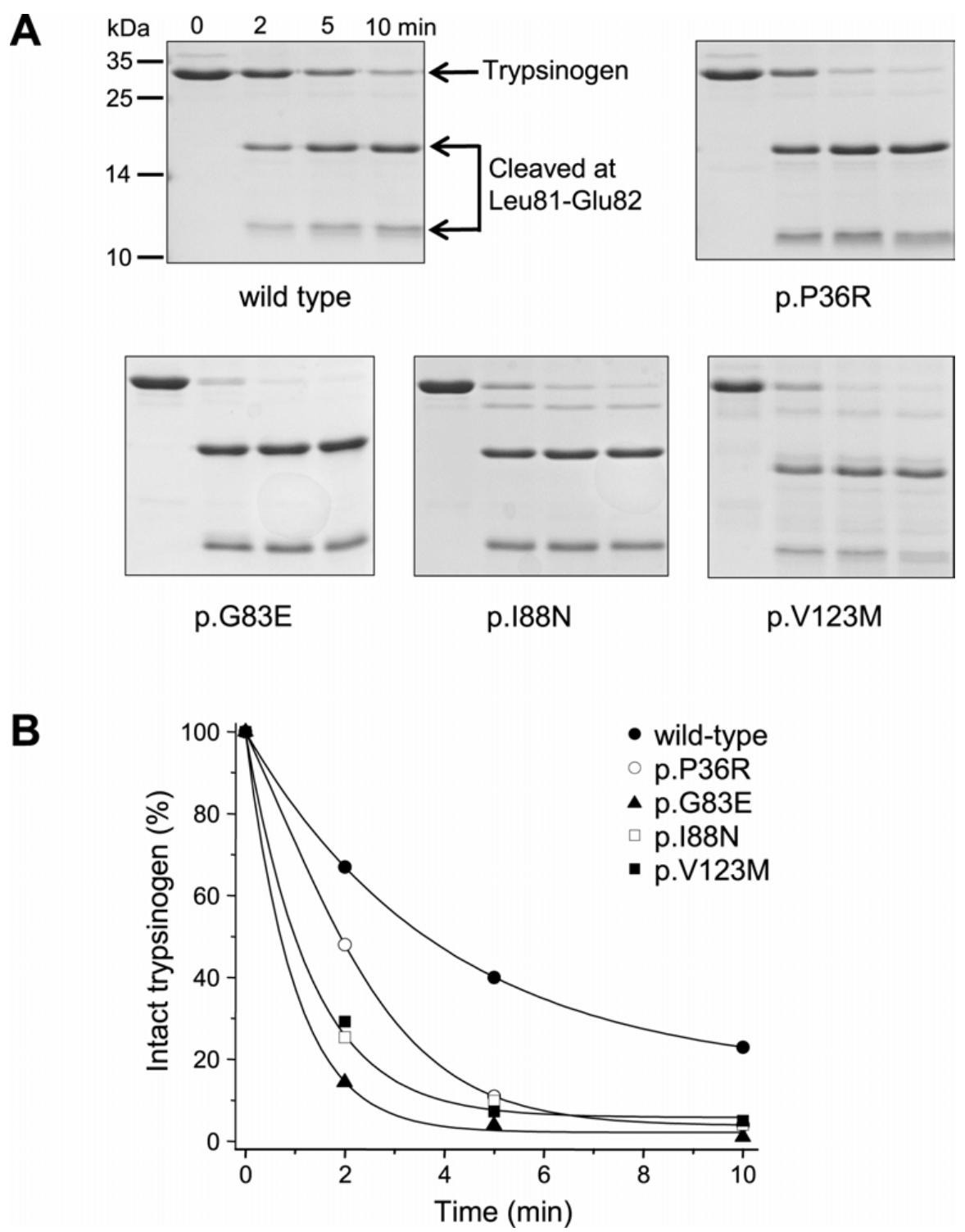

Supplementary Figure S2. Degradation of cationic trypsinogen variants by chymotrypsin C (CTRC). Trypsinogens at $2 \mu \mathrm{M}$ concentration were incubated with $25 \mathrm{nM}$ CTRC in $0.1 \mathrm{M}$ Tris$\mathrm{HCl}\left(\mathrm{pH} \mathrm{8.0)}\right.$ (final concentrations) at $37^{\circ} \mathrm{C}$. At the indicated times, reactions were precipitated with 10\% trichloroacetic acid (final concentration) and analyzed by SDS-PAGE, and Coomassie blue staining. Representative gels of two experiments are shown. The graph indicates densitometric evaluation of the intensity of the trypsinogen bands. Average of two experiments was plotted with error bars omitted for clarity. The error was within $12 \%$ of the mean. 
II. 


\title{
Trypsin Reduces Pancreatic Ductal Bicarbonate Secretion by Inhibiting CFTR $\mathrm{Cl}^{-}$Channels and Luminal Anion Exchangers
}

\author{
PETRA PALLAGI, * VIKTÓRIA VENGLOVECZ, ${ }^{\ddagger}$ ZOLTÁN RAKONCZAY Jr, * KATALIN BORKA, ${ }^{\S}$ ANNA KOROMPAY, \\ BÉLA ÓZSVÁRI, ${ }^{\star}$ LINDA JUDÁK, ${ }^{*}$ MIKLÓS SAHIN-TÓTH,, ANDREA GEISZ, ${ }^{*, \|}$ ANDREA SCHNÚR,, ,\| JÓZSEF MALÉTH, * \\ TAMÁS TAKÁCS, ${ }^{*}$ MIKE A. GRAY," BARRY E. ARGENT," JULIA MAYERLE," MARKUS M. LERCH, ${ }^{*}$ TIBOR WITTMANN, ${ }^{*}$ \\ and PÉTER HEGYI*
}

${ }^{*}$ First Department of Medicine and ${ }^{\ddagger}$ Department of Pharmacology, University of Szeged, Szeged, Hungary; \$2nd Department of Pathology, Semmelweis University, Budapest, Hungary; "Department of Molecular and Cell Biology, Henry M. Goldman School of Dental Medicine, Boston University, Boston, Massachusetts; "Institute for Cell \& Molecular Biosciences, Newcastle University, Newcastle upon Tyne, England; and \#Department of Medicine A, Greifswald University Hospital, Greifswald, Germany

BACKGROUND \& AIMS: The effects of trypsin on pancreatic ductal epithelial cells (PDECs) vary among species and depend on the localization of proteinase-activated receptor 2 (PAR-2). We compared PAR-2 localization in human and guinea-pig PDECs, and used isolated guinea pig ducts to study the effects of trypsin and a PAR-2 agonist on bicarbonate secretion. METHODS: PAR-2 localization was analyzed by immunohistochemistry in guinea pig and human pancreatic tissue samples (from 15 patients with chronic pancreatitis and 15 without pancreatic disease). Functionally, guinea pig PDECs were studied by microperfusion of isolated ducts, measurements of intracellular $\mathrm{pH}$ and intracellular $\mathrm{Ca}^{2+}$ concentration, and patch clamp analysis. The effect of $\mathrm{pH}$ on trypsinogen autoactivation was assessed using recombinant human cationic trypsinogen. RESULTS: PAR-2 localized to the apical membrane of human and guinea pig PDECs. Trypsin increased intracellular $\mathrm{Ca}^{2+}$ concentration and intracellular $\mathrm{pH}$ and inhibited secretion of bicarbonate by the luminal anion exchanger and the cystic fibrosis transmembrane conductance regulator (CFTR) $\mathrm{Cl}^{-}$channel. Autoactivation of human cationic trypsinogen accelerated when the $\mathrm{pH}$ was reduced from 8.5 to 6.0. PAR-2 expression was strongly down-regulated, at transcriptional and protein levels, in the ducts of patients with chronic pancreatitis, consistent with increased activity of intraductal trypsin. Importantly, in PAR-2 knockout mice, the effects of trypsin were markedly reduced. CONCLUSIONS: Trypsin reduces pancreatic ductal bicarbonate secretion via PAR-2-dependent inhibition of the apical anion exchanger and the CFTR $\mathrm{Cl}^{-}$channel. This could contribute to the development of chronic pancreatitis by decreasing luminal $\mathrm{pH}$ and promoting premature activation of trypsinogen in the pancreatic ducts.

Keywords: Acinar Cells; Ductal Epithelium; Animal Model; Pancreatic Enzymes.

rypsinogen is the most abundant digestive protease
in the pancreas. Under physiologic conditions, trypsinogen is synthesized and secreted by acinar cells, transferred to the duodenum via the pancreatic ducts, and then activated by enteropeptidase in the small intestine. ${ }^{1}$ There is substantial evidence that early intra-acinar ${ }^{2,3}$ or luminal ${ }^{4,5}$ activation of trypsinogen to trypsin is a key and common event in the development of acute and chronic pancreatitis. Importantly, almost all forms of acute pancreatitis are due to autodigestion of the gland by pancreatic enzymes. ${ }^{6}$

Several studies have shown that trypsin stimulates enzyme secretion from acinar cells via proteinase-activated receptor 2 (PAR-2), 7,8 whereas the effect of trypsin on pancreatic ductal epithelial cells (PDECs) is somewhat controversial. Trypsin activates ion channels in dog $\mathrm{PDECs}^{9}$ and stimulates bicarbonate secretion in the CAPAN-1 human pancreatic adenocarcinoma cell line, ${ }^{10}$ whereas it dose-dependently inhibits bicarbonate efflux from bovine PDECs. ${ }^{11}$ The effect of trypsin differs not only among species, but also with respect to the localization of PAR-2. When PAR-2 is localized to the basolateral membrane and activated by trypsin, the result is stimulation of bicarbonate secretion., ${ }^{9,10}$ In contrast, when the receptor is localized to the luminal membrane, the effect is inhibition. ${ }^{11}$ Interestingly, there are no data available concerning the effects of trypsin on guinea pig PDECs which, in terms of bicarbonate secretion, are an excellent model of human PDECs. ${ }^{12}$

The human pancreatic ductal epithelium secretes an alkaline fluid that may contain up to $140 \mathrm{mmol} / \mathrm{L}$ $\mathrm{NaHCO}_{3} \cdot{ }^{12,13}$ The first step in $\mathrm{HCO}_{3}{ }^{-}$secretion is the accumulation of $\mathrm{HCO}_{3}{ }^{-}$inside the cell, which is driven by basolateral $\mathrm{Na}^{+} / \mathrm{HCO}_{3}{ }^{-}$cotransporters, $\mathrm{Na}^{+} / \mathrm{H}^{+}$exchangers, and $\mathrm{H}^{+}$-adenosine triphosphatases. ${ }^{12,13}$ Only 2 transporters have been identified on the apical membrane of

\footnotetext{
Abbreviations used in this paper: BAPTA-AM, 1,2-bis(o-aminophenoxy)ethane- $N, N, N^{\prime}, N^{\prime}$-tetraacetic acid; CFTR, cystic fibrosis transmembrane conductance regulator $\mathrm{Cl}^{-}$channel; CFTRinh-172, CFTR inhibitor172; $\left[\mathrm{Ca}^{2+}\right]_{\mathrm{i}}$, intracellular $\mathrm{Ca}^{2+}$ concentration; $\mathrm{H}_{2}$ DIDS, dihydro-4,4'diisothiocyanostilbene-2,2' -disulfonic acid; PAR-2, proteinase-activated receptor-2; PAR-2-AP, PAR-2 activating peptide; PAR-2-ANT, PAR-2 antagonist; PDEC, pancreatic ductal epithelial cell; $\mathrm{pH}_{\mathrm{i}}$, intracellular $\mathrm{pH}$; $\mathrm{pH}_{\mathrm{L}}$, luminal $\mathrm{pH}$; $\mathrm{SBTI}$, soybean trypsin inhibitor; SLC26, solute carrier family 26 .
}

(C) 2012 by the AGA Institute

0016-5085/\$36.00

doi:10.1053/j.gastro.2011.08.039 
cells in the proximal ducts that are the major sites of $\mathrm{HCO}_{3}{ }^{-}$secretion: cystic fibrosis transmembrane conductance regulator (CFTR) and the solute carrier family 26 (SLC26) anion exchangers. ${ }^{12,13}$ How these transporters act in concert to produce a high $\mathrm{HCO}_{3}{ }^{-}$secretion is controversial. ${ }^{14}$ Most likely, $\mathrm{HCO}_{3}{ }^{-}$is secreted through the anion exchanger until the luminal concentration reaches about $70 \mathrm{mmol} / \mathrm{L}$, after which the additional $\mathrm{HCO}_{3}{ }^{-}$ required to raise the luminal concentration to 140 $\mathrm{mmol} / \mathrm{L}$ is transported via CFTR. ${ }^{15,16}$

The role of PAR-2 in experimental acute pancreatitis is also controversial and highly dependent on the model of pancreatitis studied. PAR-2 was found to be protective in secretagogue-induced pancreatitis in mice e,17-19 $^{7}$ and rats. ${ }^{20}$ However, PAR-2 is clearly harmful when pancreatitis is evoked by the clinically more relevant luminal administration of bile salts in mice. ${ }^{17}$

In this study, we show for the first time that (1) PAR-2 is localized to the apical membrane of the human proximal PDECs, (2) the localization of PAR-2 in the guinea pig pancreas is identical to that in the human gland, (3) trypsin markedly reduces bicarbonate efflux through a dihydro-4, $4^{\prime}$-diisothiocyanostilbene- $2,2^{\prime}$-disulfonic acid $\left(\mathrm{H}_{2} \mathrm{DIDS}\right)$-sensitive apical SLC26 anion exchanger and strongly inhibits CFTR, (4) a decrease in $\mathrm{pH}$ within the ductal lumen will strongly accelerate the autoactivation of trypsinogen, and (5) trypsin down-regulates PAR-2 expression at both transcriptional and protein levels in PDECs of patients with chronic pancreatitis.

\section{Materials and Methods}

A brief outline of the materials and methods is given in the following text. For further details, please see Supplementary Materials and Methods.

\section{Solutions}

The compositions of the solutions used for microfluorimetry are shown in Table 1.

\section{Isolation of Pancreatic Ducts and Individual Ductal Cells}

Small intralobular proximal ducts and individual ductal cells were isolated from guinea pigs or PAR-2 wild-type (PAR-

Table 1. Composition of Solutions for Microfluorimetry Studies

\begin{tabular}{lrrrr}
\hline & $\begin{array}{c}\text { Standard } \\
\mathrm{HEPES}\end{array}$ & $\begin{array}{c}\text { Standard } \\
\mathrm{HCO}_{3}{ }^{-}\end{array}$ & $\begin{array}{c}\mathrm{Cl}^{-} \text {-free } \\
\mathrm{HCO}_{3}{ }^{-}\end{array}$ & $\begin{array}{c}\mathrm{Ca}^{2+} \text {-free } \\
\mathrm{HEPES}\end{array}$ \\
\hline $\mathrm{NaCl}$ & 130 & 115 & & 132 \\
$\mathrm{KCl}$ & 5 & 5 & & 5 \\
$\mathrm{MgCl}_{2}$ & 1 & 1 & & 1 \\
$\mathrm{CaCl}_{2}$ & 1 & 1 & & 10 \\
Sodium HEPES $_{\text {Glucose }}$ & 10 & & & 10 \\
NaHCO & 10 & 10 & 10 & \\
Sodium gluconate & & 25 & 25 & \\
Magnesium gluconate & & & 115 & \\
Calcium gluconate & & & 1 & \\
Potassium sulfate & & & 6 & \\
\hline
\end{tabular}

NOTE. Values are concentrations in $\mathrm{mmol} / \mathrm{L}$.
$2^{+/+}$) and knockout (PAR-2 $2^{-/}$) mice with a C57BL6 background by microdissection as described previously. ${ }^{21}$

\section{Measurement of Intracellular $\mathrm{pH}$ and $\mathrm{Ca}^{2+}$ Concentration}

Intracellular $\mathrm{pH}\left(\mathrm{pH}_{\mathrm{i}}\right)$ and calcium concentration $\left(\left[\mathrm{Ca}^{2+}\right]_{\mathrm{i}}\right)$ were estimated by microfluorimetry using the $\mathrm{pH}-$ and $\mathrm{Ca}^{2+}$-sensitive fluorescent dyes 2,7-bis-(2-carboxyethyl)-5-(and-6-)carboxyfluorescein, acetoxymethyl ester (BCECF-AM) and 2-(6-(bis(carboxymethyl)amino)-5-(2-(2-(bis(carboxymethyl)amino)-5-methylphenoxy)ethoxy)-2-benzofuranyl)-5-oxazolecarboxylic acetoxymethyl ester (FURA 2-AM), respectively.

\section{Microperfusion of Intact Pancreatic Ducts}

The luminal perfusion of the cultured ducts was performed as described previously. ${ }^{22}$

\section{Electrophysiology}

CFTR $\mathrm{Cl}^{-}$channel activity was investigated by whole cell patch clamp recordings on guinea pig single pancreatic ductal cells.

\section{Measuring Autoactivation of Trypsinogen}

Autoactivation of human cationic trypsinogen was determined in vitro at $\mathrm{pH}$ values ranging from 6.0 to 8.5. Experimental details are described in Supplementary Materials and Methods.

\section{Immunobistochemistry}

Five guinea pig, 2 PAR-2 $2^{+/+}, 2$ PAR-2 ${ }^{-/-}$, and 30 human pancreata were studied to analyze the expression pattern of PAR-2 protein. Relative optical densitometry was used to quantify the protein changes in the histologic sections. Patients' data and the full methods are described in Supplementary Supplementary Materials and Methods.

\section{Real-Time Reverse-Transcription Polymerase Chain Reaction}

RNA was isolated from 30 human pancreata. Following reverse transcription, messenger RNA (mRNA) expression of PAR-2 and $\beta$-actin was determined by real-time polymerase chain reaction analysis.

\section{Results}

\section{Expression of PAR-2 in Guinea Pig and Human Pancreata}

PAR-2 was highly expressed in the luminal membrane of small intralobular and interlobular ducts (Figure $1 A$ [i]; cuboidal epithelial cells forming the proximal pancreatic ducts) but was almost undetectable in the larger interlobular ducts (Figure $1 A$ [ii]; columnar epithelial cells forming the distal pancreatic ducts). The localization of PAR-2 in the human pancreas was identical to that in the guinea pig gland (Figure $1 A$ [iv-vi]). Measurements of relative optical density confirmed the significant differences between the expression of PAR- 2 in small intralobular and interlobular ducts and the larger interlobular ducts in both species (Figure 1C). 
A

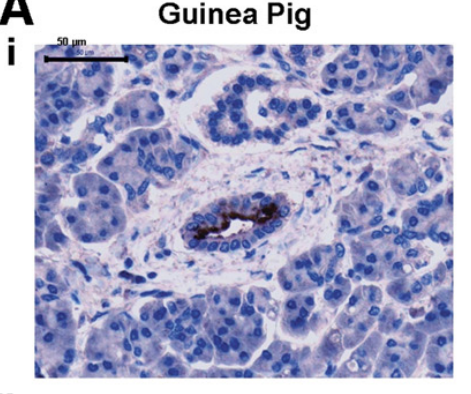

ii

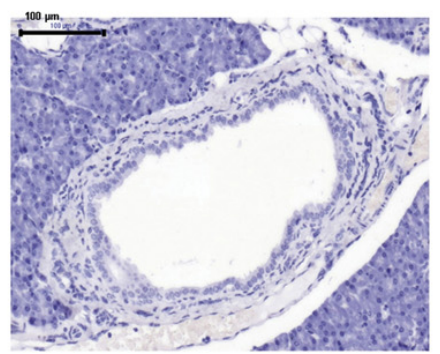

iii

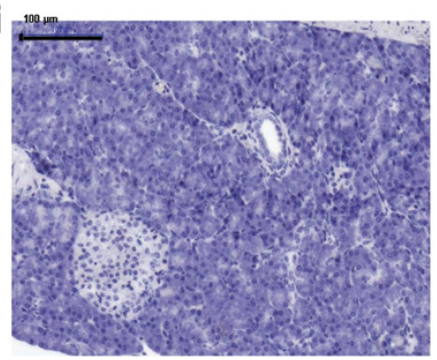

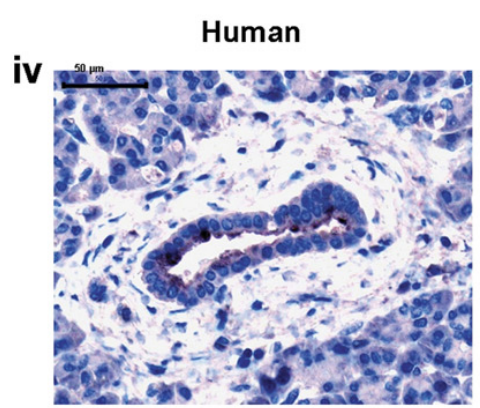

V

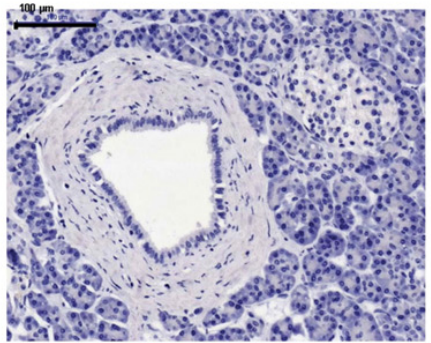

vi

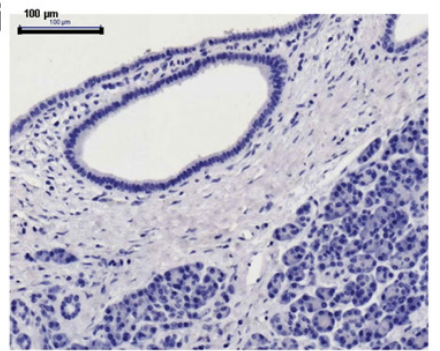

B

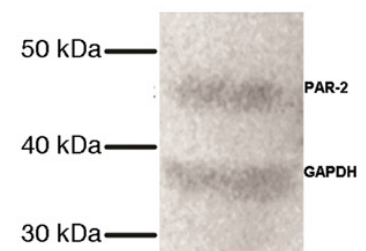

C

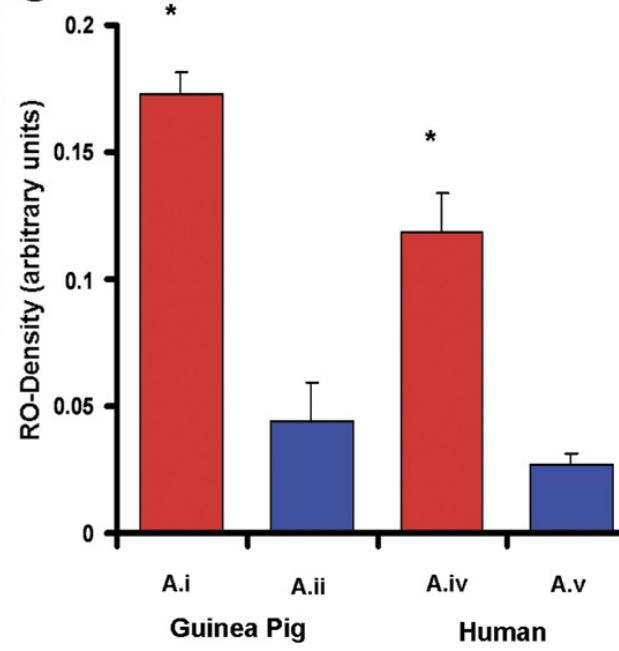

Figure 1. Localization of PAR-2 on human and guinea pig pancreatic ducts. Light micrographs of (A [i-iii]) guinea pig and (A [iv-vi]) human pancreas are shown. (i) PAR-2 is localized to the luminal membrane of PDECs in small intralobular and interlobular ducts (original magnification 400X). (ii) Large interlobular ducts do not express PAR-2 (original magnification 200×). (iii) No primary antiserum (original magnification $200 \times$ ). (iv and v) Sections from human pancreas exhibit a similar localization of PAR-2 compared with the guinea pig gland (original magnification 400X and $200 \times$ ). (vi) No primary antiserum (original magnification 200X). (B) Western blot analysis was used to determine the specificity of the PAR-2 antibody. Polyclonal anti-PAR-2 showed a single 44-kilodalton band. (C) Quantitative measurement of relative optical densities (RO-Density) of small intralobular and interlobular $\operatorname{ducts}\left(\right.$ A.i,iv), and large interlobular ducts (A.ii, v) is shown. $n=12 .{ }^{*} P<.05$ vs A.ii or A.v, respectively. Scale bar $=50 \mu \mathrm{m}$ for $A$ (i, iv) and $100 \mu \mathrm{m}$ for $A$ (ii and iii) and $A$ ( $v$ and vi).

\section{Luminal Administration of PAR-2-AP and Trypsin Induces Dose-Dependent $\left[\mathrm{Ca}^{2+}\right]_{i}$ Signals}

Because PAR-2 expression was detected only on the luminal membrane of intralobular duct cells, we used the microperfusion technique to see whether these receptors can be activated by PAR-2 agonists. First, the experiments were performed at $\mathrm{pH} 7.4$ to understand the effects of trypsin and PAR-2 under quasi-physiologic conditions (Figure 2). The fluorescent images in Figure $2 \mathrm{~A}$ clearly show that luminal administration of PAR-2 activating peptide (PAR-2-AP) increased $\left[\mathrm{Ca}^{2+}\right]_{\mathrm{i}}$ in perfused pancreatic ducts. The $\left[\mathrm{Ca}^{2+}\right]_{i}$ response was dose dependent and consisted of a peak in $\left[\mathrm{Ca}^{2+}\right]_{\mathrm{i}}$ that decayed in the continued presence of the agonist, possibly reflecting PAR-2 inactivation or depletion of intracellular $\mathrm{Ca}^{2+}$ stores (Figure $2 B$ ). Pretreatment of PDECs with $10 \mu \mathrm{mol} / \mathrm{L}$ PAR-2 antagonist (PAR-2-ANT) for 10 minutes completely blocked the effects of $10 \mu \mathrm{mol} / \mathrm{L}$ PAR-2-AP on $\left[\mathrm{Ca}^{2+}\right]_{\mathrm{i}}$
(Figure $2 A$ and $C$ ). Removal of extracellular $\mathrm{Ca}^{2+}$ had no effect on the increase in $\left[\mathrm{Ca}^{2+}\right]_{\mathrm{i}}$ evoked by luminal administration of $10 \mu \mathrm{mol} / \mathrm{L}$ PAR-2-AP; however, preloading ducts with the calcium chelator 1,2-bis(o-aminophenoxy)ethane- $N, N, N^{\prime}, N^{\prime}$-tetraacetic acid (BAPTA-AM) at 40 $\mu \mathrm{mol} / \mathrm{L}$ totally blocked the response (Figure $2 A$ and $C$ ).

Trypsin also induced a dose-dependent elevation in $\left[\mathrm{Ca}^{2+}\right]_{\mathrm{i}}$ similar to that evoked by PAR-2-AP (Figure $2 E$ and $F)$. Addition of $5 \mu \mathrm{mol} / \mathrm{L}$ soybean trypsin inhibitor (SBTI), $10 \mu \mathrm{mol} / \mathrm{L}$ PAR-2-ANT, and $40 \mu \mathrm{mol} / \mathrm{L}$ BAPTA-AM totally blocked the increase in $\left[\mathrm{Ca}^{2+}\right]_{\mathrm{i}}$ (Figure $2 D$ and $F$ ). These data show that trypsin activates PAR-2 on the luminal membrane of the duct cell, which leads to release of $\mathrm{Ca}^{2+}$ from intracellular stores and an elevation of $\left[\mathrm{Ca}^{2+}\right]_{\mathrm{i}}$.

Because the $\mathrm{pH}$ of pancreatic juice can vary between approximately 6.8 and $8.0,23,24$ we also evaluated the effects of trypsin and PAR-2-AP on $\left[\mathrm{Ca}^{2+}\right]_{\mathrm{i}}$ at these $\mathrm{pH}$ values (Supplementary Figures 1 and 2, respectively). The 
A

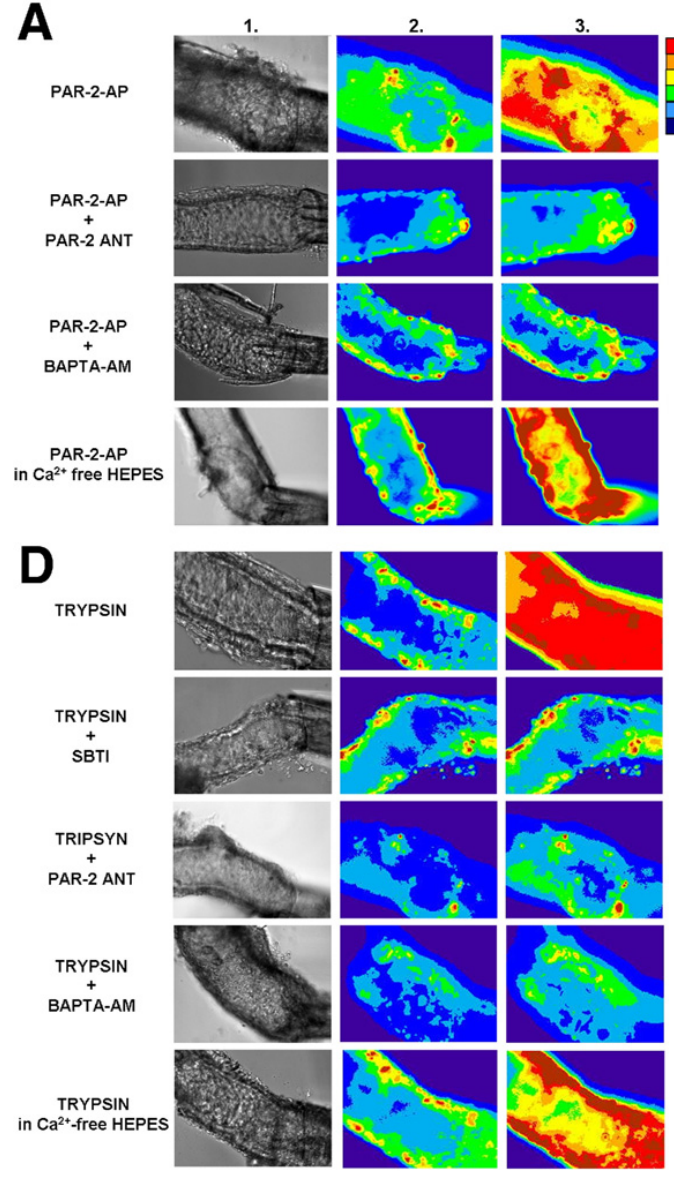

B

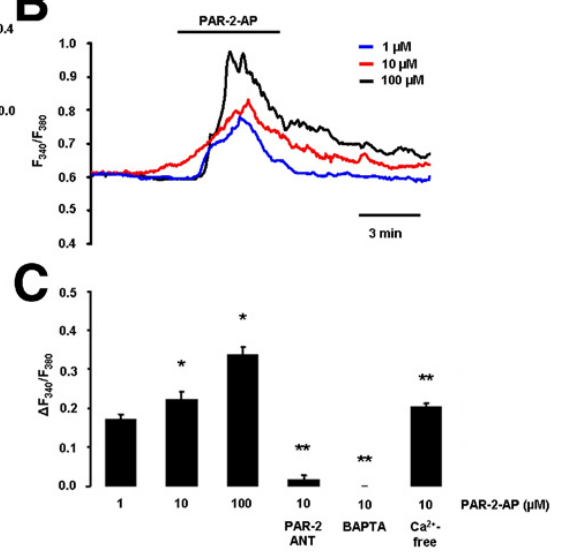

$\mathbf{E}$

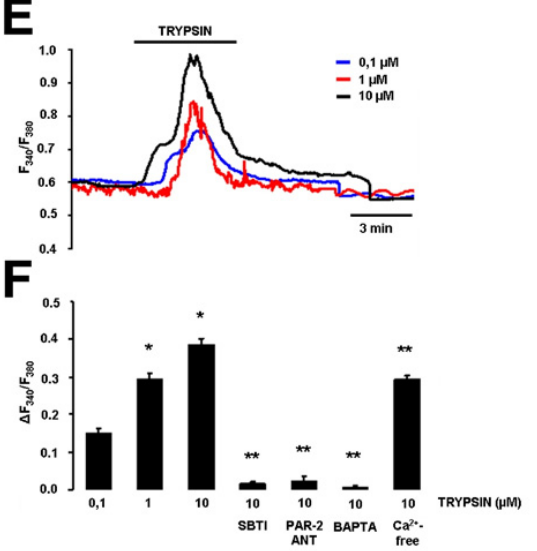

Figure 2. Effects of PAR-2-AP and trypsin on $\left[\mathrm{Ca}^{2+}\right]_{\mathrm{i}}$ in microperfused guinea pig pancreatic ducts at $\mathrm{pH}$ 7.4. (A) Light (1) and fluorescent ratio images (2 and 3) of microperfused pancreatic ducts showing the effects of luminal administration of $10 \mu \mathrm{mol} / \mathrm{L}$ PAR-2-AP, $10 \mu \mathrm{mol} / \mathrm{L}$ PAR-2-ANT, or $40 \mu \mathrm{mol} / \mathrm{L}$ BAPTA-AM on $\left[\mathrm{Ca}^{2+}\right]$. Images were taken before (1 and 2) and after (3) exposure of the ducts to PAR-2-AP or trypsin. (B and C) Representative experimental traces and summary data of the changes in $\left[\mathrm{Ca}^{2+}{ }_{\mathrm{i}}\right.$. $(D)$ The same protocol was used to evaluate the effects of trypsin. Addition of $5 \mu \mathrm{mol} / \mathrm{L}$ SBTI was used to inhibit trypsin activity. ( $E$ and $F$ ) Representative experimental traces and summary data of the changes in $\left[\mathrm{Ca}^{2+}{ }_{\text {]. }} \mathrm{n}=5\right.$ for all groups. ${ }^{*} \mathrm{P}<.05 \mathrm{vs} 1 \mu \mathrm{mol} / \mathrm{L}$ PAR-2-AP or $0.1 \mu \mathrm{mol} / \mathrm{L}$ trypsin, respectively. ${ }^{* *} \mathrm{P}<.001 \mathrm{vs} 10 \mu \mathrm{mol} / \mathrm{L}$ PAR-2-AP or $10 \mu \mathrm{mol} / \mathrm{L}$ trypsin, respectively.

elevations of $\left[\mathrm{Ca}^{2+}\right]_{\mathrm{i}}$ at $\mathrm{pH} 6.8$ and 8.0 were generally very similar to the changes observed at $\mathrm{pH}$ 7.4. However, the increases in $\left[\mathrm{Ca}^{2+}\right]_{\mathrm{i}}$ evoked by $1 \mu \mathrm{mol} / \mathrm{L}$ PAR-2-AP and 0.1 $\mu \mathrm{mol} / \mathrm{L}$ trypsin were significantly lower at $\mathrm{pH} 6.8$ compared with either pH 7.4 or 8.0 (Supplementary Figure 3).

\section{Luminal Exposure to PAR-2-AP and Trypsin Evokes Intracellular Alkalosis in PDECs}

Figure 3 shows $\mathrm{pH}_{\mathrm{i}}$ recordings from microperfused pancreatic ducts. Luminal application of the CFTR inhibitor (CFTRinh) $172(10 \mu \mathrm{mol} / \mathrm{L})$ and the anion exchanger inhibitor $\mathrm{H}_{2}$ DIDS $(500 \mu \mathrm{mol} / \mathrm{L})$ induced intracellular alkalization in PDECs (Figure $3 A[i]$ ). These data indicate that when bicarbonate efflux across the luminal membrane of PDECs (ie, bicarbonate secretion) is blocked, elevation of duct cell $\mathrm{pH}_{\mathrm{i}}$ occurs, presumably because the basolateral transporters continue to move bicarbonate ions into the duct cell. Note also that the increase in $\mathrm{pH}_{\mathrm{i}}$ evoked by the inhibitors is not sustained and begins to reverse before the inhibitors are withdrawn (Figure $3 A$ [i]), which might be explained by the regulation of $\mathrm{pH}_{\mathrm{i}}$ by basolateral acid/base transporters.

Both luminal PAR-2-AP and trypsin induced a dose-dependent elevation of $\mathrm{pH}_{\mathrm{i}}$ (Figure $3 A$ [ii and iii]), suggesting that activation of PAR-2 inhibits bicarbonate efflux across the apical membrane of the duct cell. Preincubation of PDECs with either $10 \mu \mathrm{mol} / \mathrm{L}$ PAR-2-ANT or $5 \mu \mathrm{mol} / \mathrm{L}$ SBTI or $40 \mu \mathrm{mol} / \mathrm{L}$ BAPTA-AM for 30 minutes totally blocked the effect of trypsin on $\mathrm{pH}_{\mathrm{i}}$ (Figure $3 \mathrm{~A}$ [iv]). The inhibitory effect of the calcium chelator BAPTA-AM suggests that the actions of trypsin and PAR-2-AP on $\mathrm{pH}_{\mathrm{i}}$ are mediated by the increase in $\left[\mathrm{Ca}^{2+}\right]_{\mathrm{i}}$ that they evoke (Figure 2). Therefore, in this case, the transient nature of the $\mathrm{pH}_{\mathrm{i}}$ response may reflect the transient effect that PAR-2 activators have on $\left[\mathrm{Ca}^{2+}\right]_{\mathrm{i}}$ (Figure $2 B$ and $E$ ), as well as $\mathrm{pH}_{\mathrm{i}}$ regulation by basolateral acid/base transporters.

Next we tested the effects of trypsin on $\mathrm{pH}_{\mathrm{i}}$ in $\mathrm{Cl}^{-}$-free conditions and during pharmacologic inhibition of the 
A
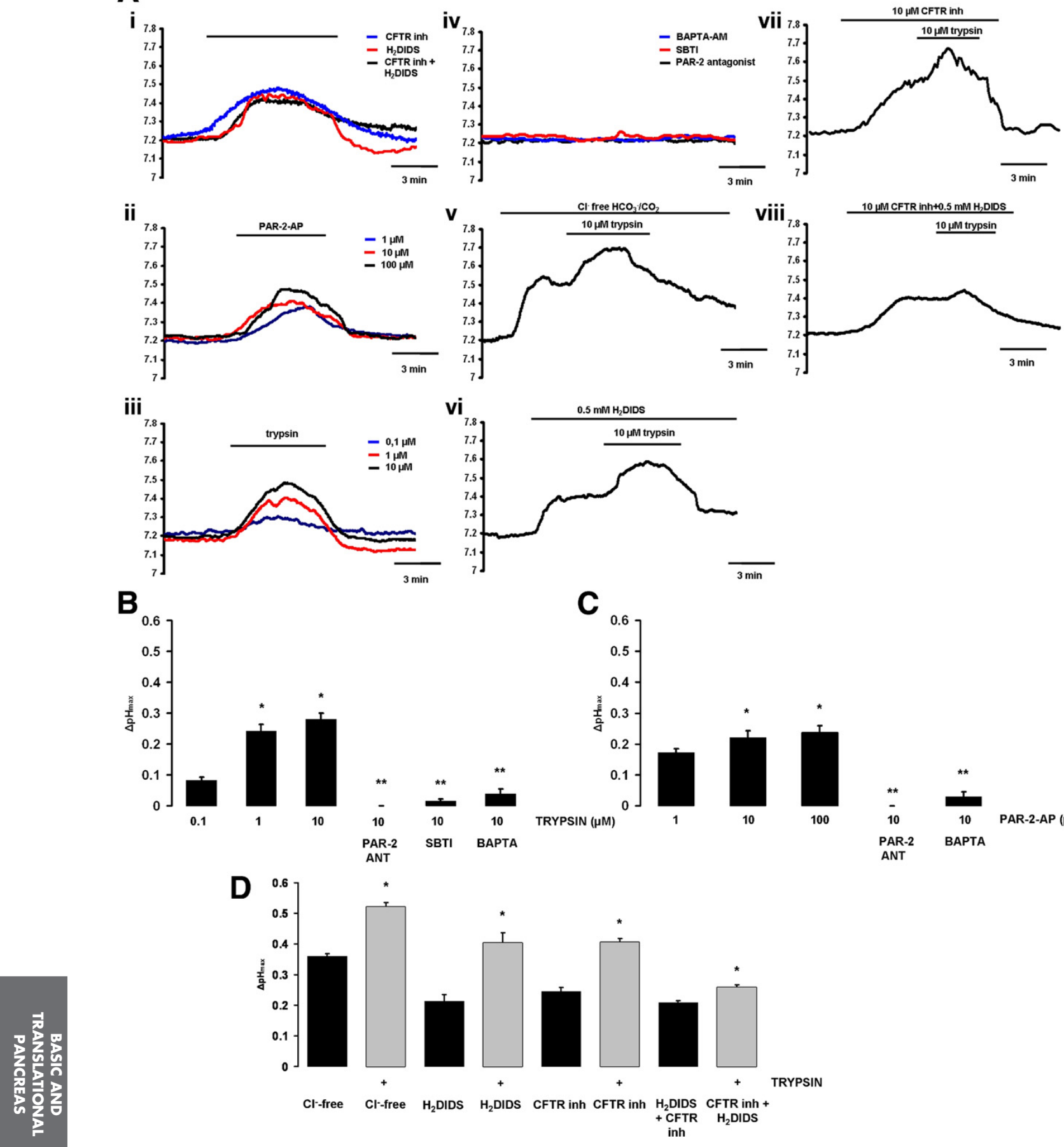

Figure 3. Effects of PAR-2-AP and trypsin on $\mathrm{pH}_{\mathrm{i}}$ in microperfused guinea pig pancreatic ducts. $(A)$ Representative $\mathrm{pH}_{\mathrm{i}}$ traces showing the effects of luminal administration of different agents in microperfused pancreatic ducts. (i) A total of $10 \mu \mathrm{mol} / \mathrm{L} \mathrm{CFTRinh}-172$ and/or $500 \mu \mathrm{mol} / \mathrm{L} \mathrm{H}_{2} \mathrm{DIDS}$ caused alkalization of $\mathrm{pH}_{\mathrm{i}}$. (ii) PAR-2-AP and (iii) trypsin induced a dose-dependent $\mathrm{pH}_{\mathrm{i}}$ elevation. (iv) Preincubation of ductal cells with $10 \mu \mathrm{mol} / \mathrm{L}$ PAR-2-ANT or $5 \mu \mathrm{mol} / \mathrm{L}$ SBTI or $40 \mu \mathrm{mol} / \mathrm{L}$ BAPTA-AM totally blocked the alkalization caused by $10 \mu \mathrm{mol} / \mathrm{L}$ trypsin. (v) Removal of luminal Cl- or (vi) administration of $\mathrm{H}_{2}$ DIDS $(500 \mu \mathrm{mol} / \mathrm{L})$ decreased, but did not totally abolish, the effects of $10 \mu \mathrm{mol} / \mathrm{L}$ trypsin on $\mathrm{pH}$. (vii) Pretreatment with 10 $\mu \mathrm{mol} / \mathrm{L}$ CFTRinh-172 also decreased the effects of trypsin (10 $\mu \mathrm{mol} / \mathrm{L}$ ) on $\mathrm{pH}_{\mathrm{i}}$. (viii) Simultaneous administration of $\mathrm{H}_{2} \mathrm{DIDS}$ and CFTRinh-172 strongly inhibited the effect of $10 \mu \mathrm{mol} / \mathrm{L}$ trypsin. $\left(B\right.$ and $C$ ) Summary of the effects of PAR-2-AP and trypsin on changes in $\mathrm{pH}_{\mathrm{i}} . \Delta \mathrm{pH}$ max was calculated from the experiments shown in $A$. (D) Effects of $\mathrm{Cl}^{-}$-free conditions. $\mathrm{Cl}^{-}$-free conditions, $\mathrm{H}_{2} \mathrm{DIDS}$, CFTRinh-172, and a combination of the inhibitors all induced an intracellular alkalosis. Trypsin further increased the alkalinization of $\mathrm{pH}_{\mathrm{i}}$, although the effect was markedly reduced when both $\mathrm{H}_{2} \mathrm{DIDS}$ and CFTRinh-172 were present. $\mathrm{n}=4-5$ for all groups. $(B){ }^{*} P<.05$ vs $0.1 \mu \mathrm{mol} / \mathrm{L}$ trypsin; ${ }^{* *} P<.001 \mathrm{vs} 10 \mu \mathrm{mol} / \mathrm{L}$ trypsin. $(C){ }^{*} P<.05$ vs $0.1 \mu \mathrm{mol} / \mathrm{L}$ PAR-2-AP; ${ }^{* *} P<.001$ vs $10 \mu \mathrm{mol} / \mathrm{L}$ PAR-2-AP. (D) ${ }^{*} P<.05$ vs the respective filled column. 
luminal anion exchangers and/or CFTR (Figure $3 A[\mathrm{v}-$ viii]). Luminal $\mathrm{Cl}^{-}$-free conditions increased the $\mathrm{pH}_{\mathrm{i}}$ of PDECs, presumably by driving $\mathrm{HCO}_{3}{ }^{-}$influx on the apical anion exchangers (Figure $3 A[\mathrm{v}])$. Note that luminal administration of trypsin further elevated $\mathrm{pH}_{\mathrm{i}}$ in $\mathrm{Cl}^{-}$-free conditions (Figure $3 A[\mathrm{v}]$ ) and also in the presence of $\mathrm{H}_{2}$ DIDS (Figure $3 A$ [vi]) and CFTRinh-172 (Figure $3 A$ [vii]). However, pretreatment of ducts with a combination of $\mathrm{H}_{2}$ DIDS and CFTRinh-172 markedly reduced the effect of trypsin on $\mathrm{pH}_{\mathrm{i}}$ (Figure $3 A$ [viii]).

Figure $3 B-D$ is a summary of the $\mathrm{pH}_{\mathrm{i}}$ experiments. Trypsin (Figure $3 B$ ) and PAR-2-AP (Figure $3 C$ ) both induced statistically significant, dose-dependent increases in $\mathrm{pH}_{\mathrm{i}}$ and these effects were blocked by PAR-2-ANT, SBTI, and BAPTA-AM. Exposure of the ducts to luminal $\mathrm{Cl}^{-}$free conditions, $\mathrm{H}_{2}$ DIDS, CFTRinh-172, or a combination of the inhibitors also induced an intracellular alkalosis (Figure $3 D$ ). Also shown in Figure $3 D$ is the additional, statistically significant increase in $\mathrm{pH}_{\mathrm{i}}$ caused by trypsin in ducts exposed to $\mathrm{Cl}^{-}$-free conditions and the individual inhibitors. However, when ducts were exposed to both CFTRinh-172 and $\mathrm{H}_{2}$ DIDS simultaneously, the effect of trypsin on $\mathrm{pH}_{\mathrm{i}}$ was markedly reduced, although it remained statistically significant (Figure $3 D$ ). We interpret these results as indicating that trypsin inhibits both $\mathrm{Cl}^{-}$-dependent (ie, anion exchanger mediated; revealed when CFTR is blocked by CFTRinh-172) and $\mathrm{Cl}^{-}$-independent (ie, CFTR mediated; revealed in $\mathrm{Cl}^{-}$-free conditions and when the luminal exchangers are blocked by $\mathrm{H}_{2}$ DIDS) bicarbonate secretory mechanisms in PDECs. Reduced bicarbonate secretion will lead to a decrease in intraductal $\mathrm{pH}$.

\section{Trypsin and PAR-2-AP Inbibit CFTR}

Exposure of guinea pig PDECs to $5 \mu \mathrm{mol} / \mathrm{L}$ forskolin, which elevates intracellular adenosine $3^{\prime} 5^{\prime}$-cyclic monophosphate levels, increased basal whole cell currents (Figure $4 A-D$ [i]) from $8.9 \pm 2.3$ to $91.2 \pm 13.5 \mathrm{pA} / \mathrm{pF}$ (Figure $4 A-D$ [ii]) at $+60 \mathrm{mV}$ in $78 \%$ of cells $(38 / 49)$. The forskolin-activated currents were time- and voltage-independent, with a near linear I/V relationship and a reversal potential of $-5.15 \pm 1.12 \mathrm{mV}$ (Figure $4 A-D$ [iv]). These biophysical characteristics indicate that the currents are carried by CFTR.

Exposure of PDECs to $10 \mu \mathrm{mol} / \mathrm{L}$ trypsin did not affect the basal currents; however, administration of either 10 $\mu \mathrm{mol} / \mathrm{L}$ PAR-2-AP (Figure $4 A$ [iii]) or $10 \mu \mathrm{mol} / \mathrm{L}$ trypsin (Figure $4 B$ [iii]) inhibited forskolin-stimulated CFTR currents by $51.7 \% \pm 10.5 \%$ and $57.4 \% \pm 4.0 \%$, respectively. In both cases, the inhibition was voltage independent and irreversible. Pretreatment with either SBTI $(10 \mu \mathrm{mol} / \mathrm{L}$; Figure $4 C$ [iii]) or PAR-2-ANT (10 $\mu \mathrm{mol} / \mathrm{L}$; Figure $4 D$ [iii] $)$ completely prevented the inhibitory effect of trypsin on the forskolin-stimulated CFTR currents. Figure $4 E$ is a summary of these data, which suggest that trypsin inhibits CFTR $\mathrm{Cl}^{-}$currents by activation of PAR-2.

\section{Autoactivation of Trypsinogen Is $p H$ Dependent}

Trypsinogen can undergo autocatalytic activation during which trace amounts of trypsin are generated, which, in turn, can further activate trypsinogen in a selfamplifying reaction. Human trypsinogens are particularly prone to autoactivation, and mutations that facilitate autoactivation are associated with hereditary pancreatitis. To assess the effect of a decrease in intraductal $\mathrm{pH}$ (caused by reduced bicarbonate secretion) on trypsinogen activation, we measured autoactivation of human cationic trypsinogen in vitro at $\mathrm{pH}$ values ranging from 6.0 to 8.5 using a mixture of various buffers. As shown in Figure $5 \mathrm{~A}$, the rate at which cationic trypsinogen autoactivates was markedly increased as the $\mathrm{pH}$ was reduced from 8.5 to 7.0 when the buffer solution contained $1 \mathrm{mmol} / \mathrm{L} \mathrm{CaCl}_{2}$ and no $\mathrm{NaCl}$. However, a further reduction in $\mathrm{pH}$, from 7.0 to 6.0, had little effect (Figure $5 A[i]$ ).

To rule out that the differences observed in autoactivation were due to the different ionic strengths of the buffers used, we repeated the experiments in the presence of a higher concentration of sodium $(100 \mathrm{mmol} / \mathrm{L} \mathrm{NaCl}$, Figure $5 A$ [ii]) or lower concentration of calcium (0.1 $\mathrm{mmol} / \mathrm{L} \mathrm{CaCl}_{2}$, Figure $5 \mathrm{~A}$ [iii]). Although the overall autoactivation rates were much slower in the presence of $\mathrm{NaCl}$, the $\mathrm{pH}$ profile of autoactivation was essentially identical to that observed in the absence of added salt (Figure $5 A$ [ii]). Also, pH-dependent changes in the autoactivation of trypsinogen were still detectable when the experiments were performed using a low calcium buffer (Figure $5 A$ [iii]).

\section{PAR-2 Is Down-regulated in Patients With Chronic Pancreatitis}

It has been documented that there is activated trypsin in the pancreatic ductal lumen in chronic pancreatitis in humans. ${ }^{25-28}$ If trypsin activity is elevated in the duct lumen, PAR-2 down-regulation should occur, which could be due to either (1) changes in PAR-2 mRNA transcription and/or (2) receptor internalization and translocation to the cytoplasm. Our data show a marked reduction in membranous PAR-2 protein level but no significant changes in cytoplasmic PAR-2 protein in chronic pancreatitis (Figure $5 B[i-i v]$ and $C$ ). Furthermore, PAR-2 mRNA expression was markedly reduced in chronic pancreatitis (Figure $5 D$ ), suggesting that reduced PAR-2 mRNA transcription may cause PAR-2 down-regulation in chronic pancreatitis.

\section{Luminal Exposure to R122H Mutant Cationic Trypsin Induces Elevation of $\left[\mathrm{Ca}^{2+}\right]_{i}$ and Evokes Alkalosis in PDECs}

It has been shown that mutations in cationic trypsinogen increase the risk of chronic pancreatitis, most likely because of the enhanced autoactivation exhibited by the mutant trypsinogens. ${ }^{29}$ Here we tested whether the commonest mutation in cationic trypsin, $\mathrm{R} 122 \mathrm{H}$, affected the ability of the protease to interact with PAR-2. 
A

PAR2-AP

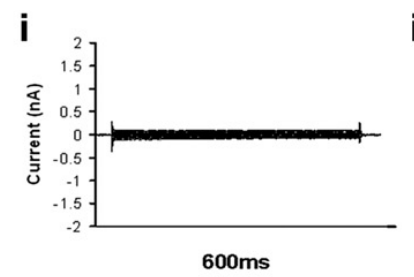

B

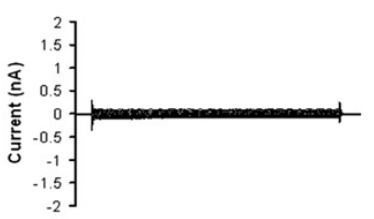

C

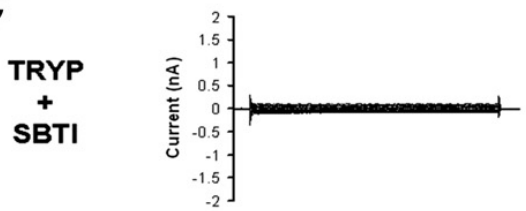

ii

D

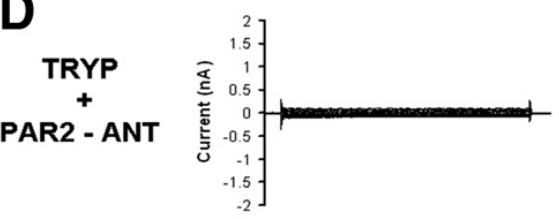

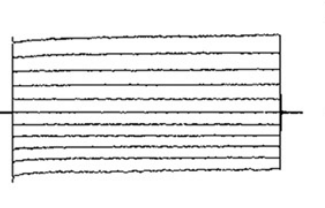
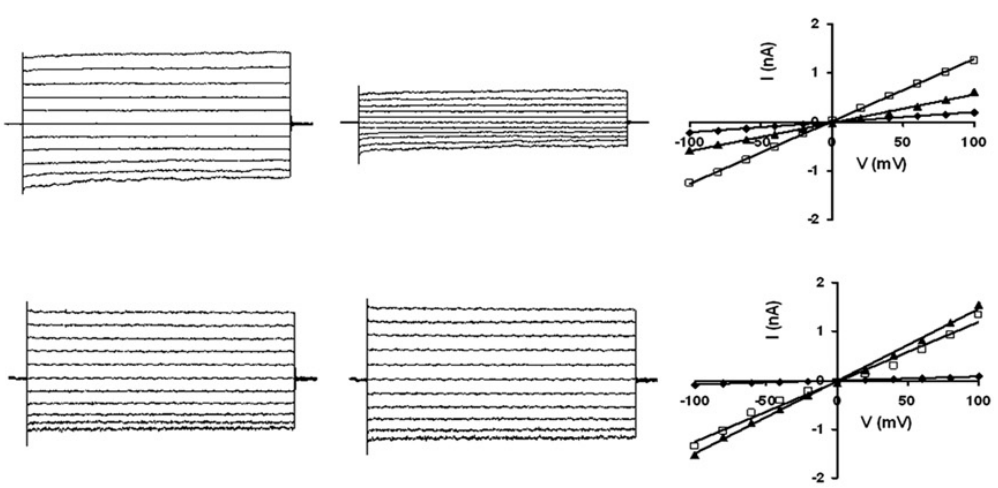

iii
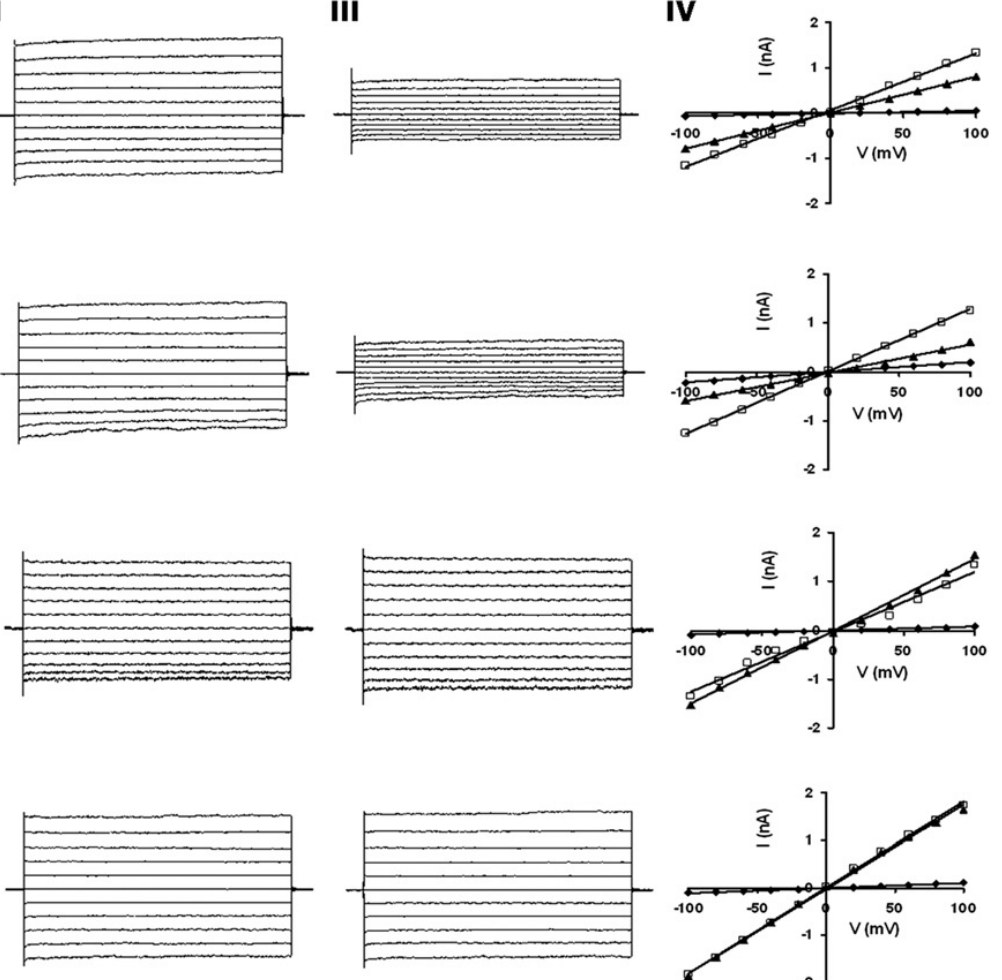
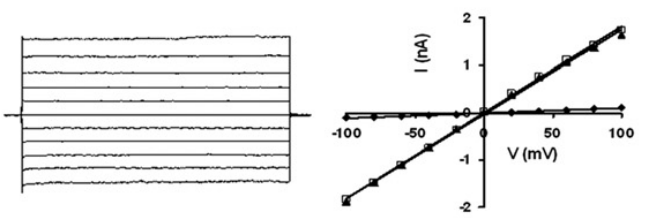

E

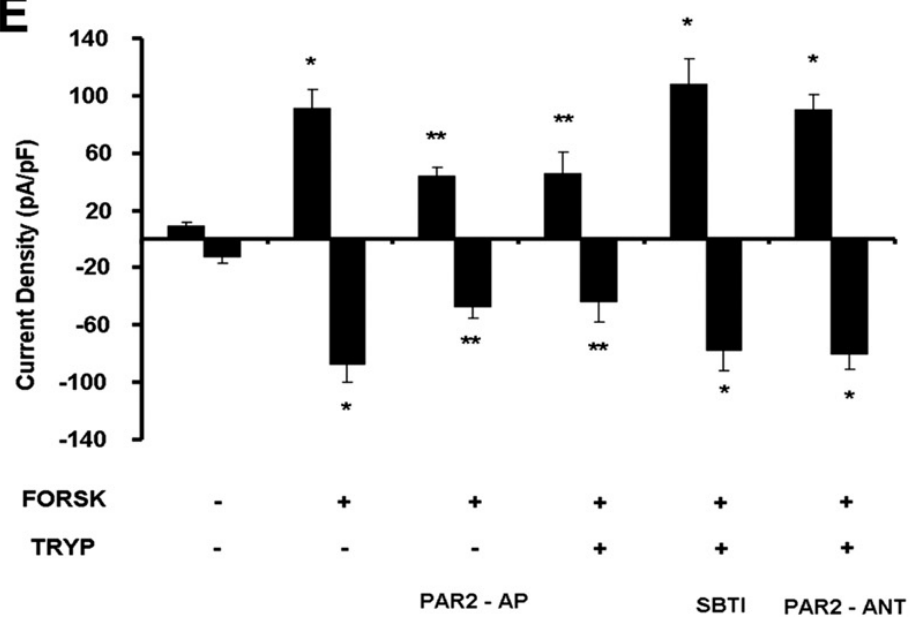

Figure 4. Effects of trypsin and PAR-2-AP on CFTR $\mathrm{Cl}^{-}$currents of guinea pig pancreatic duct cells. Representative fast whole cell current recordings from PDECs. (A-D) (i) Unstimulated currents, (ii) currents after stimulation with $5 \mu \mathrm{mol} / \mathrm{L}$ forskolin, and (iii) currents following 3-minute exposure to (A) $10 \mu \mathrm{mol} / \mathrm{L}$ PAR-2-AP, (B) $10 \mu \mathrm{mol} / \mathrm{L}$ trypsin, (C) $10 \mu \mathrm{mol} / \mathrm{L}$ trypsin/5 $\mu \mathrm{mol} / \mathrm{L}$ SBTI, and (D) $10 \mu \mathrm{mol} / \mathrm{L}$ trypsin/10 $\mu \mathrm{mol} / \mathrm{L}$ PAR-2-ANT. (iv) I/V relationships. Diamonds represent unstimulated currents, squares represent forskolin-stimulated currents, and triangles represent forskolinstimulated currents in the presence of the tested agents (see previous text). (E) Summary of the current density (pA/pF) data obtained from $A-D$ measured at $\mathrm{E}_{\text {rev }} \pm 60 \mathrm{mV}$. Exposing PDECs to either PAR-2-AP or trypsin blocked the forskolin-stimulated CFTR $\mathrm{Cl}^{-} \mathrm{currents}$, while administration of SBTI or PAR-2-ANT prevented the inhibitory effect of trypsin. $\mathrm{n}=6$ for all groups. ${ }^{\star} P<.05$ vs the unstimulated cells, ${ }^{\star \star} P<.05$ vs forskolin. FORSK, forskolin; TRYP, trypsin.

Figure $6 A$ and $B$ shows that $1 \mu \mathrm{m}$ of $\mathrm{R} 122 \mathrm{H}$ human cationic trypsin causes comparable changes in $\mathrm{pH}_{\mathrm{i}}$ and $\left[\mathrm{Ca}^{2+}\right]_{\mathrm{i}}$ to $0.4 \mu \mathrm{mol} / \mathrm{L}$ wild-type bovine trypsin, suggesting that a trypsin-mediated inhibition of bicarbonate secretion could play a role in the pathogenesis of hereditary as well as chronic pancreatitis.

\section{Activation of PAR-2 Is Diminished in PAR $-2^{-/-}$Mice}

Finally, we investigated the effects of both PAR2-AP and trypsin on PDECs isolated from PAR- $2^{+/+}$and PAR- $2^{-/-}$mice (Figure $6 C-E$ ). First we confirmed using 
A

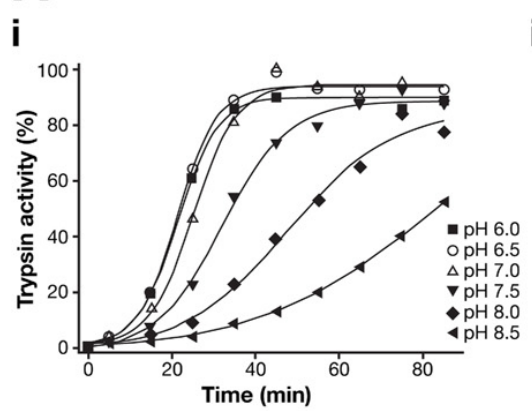

TRYPSIN ACTIVATION PROFILE

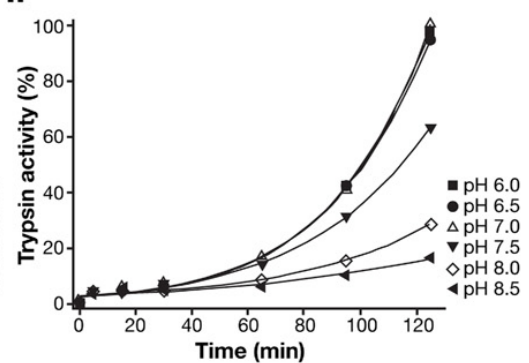

iii

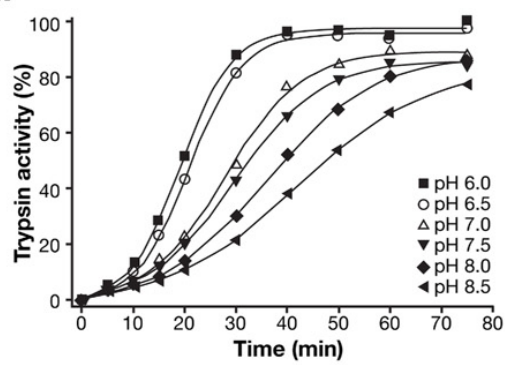

B

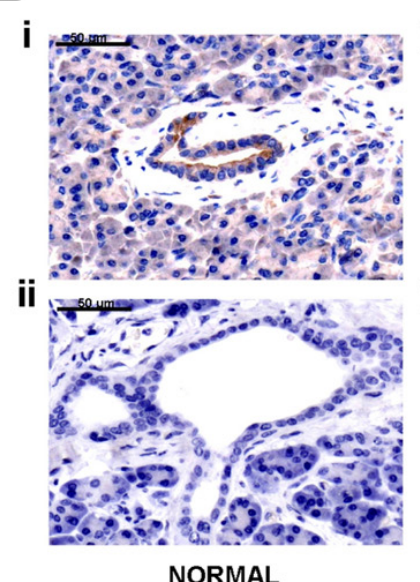

IMMUNOHISTOCHEMISTRY

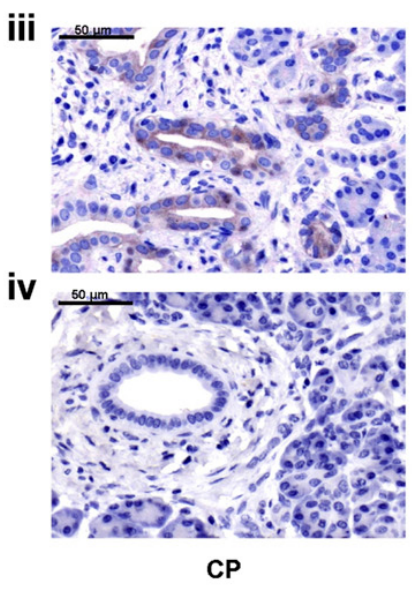

DENSITOMETRY AND PCR

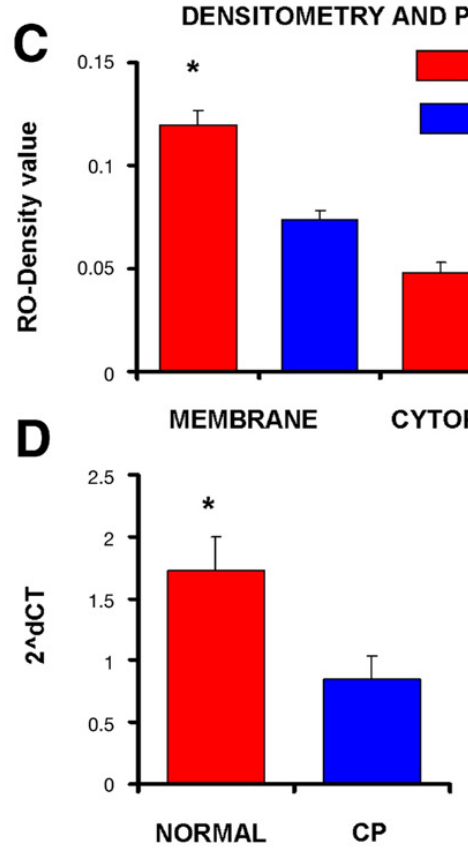

Figure 5. The effects of $\mathrm{pH}$ on trypsinogen activation and analyses of PAR-2 expression in human pancreatic samples. The autoactivation of human cationic trypsinogen was determined in vitro at $\mathrm{pH}$ values ranging from 6.0 to 8.5. (A) (i) Trypsinogen at $2 \mu \mathrm{mol} / \mathrm{L}$ concentration was incubated with $40 \mathrm{nmol} / \mathrm{L}$ trypsin at $37^{\circ} \mathrm{C}$ in $0.1 \mathrm{~mol} / \mathrm{L}$ Tris + HEPES + 2-( $\mathrm{N}$-morpholino)ethanesulfonic acid2-( $N$-morpholino)ethanesulfonic acid buffer mixture containing $1 \mathrm{mmol} / \mathrm{L} \mathrm{CaCl}$. (ii) The same protocol was used in high $(100 \mathrm{mmol} / \mathrm{L}) \mathrm{NaCl}$ buffer solution. Autoactivation of cationic trypsinogen significantly increased as the $\mathrm{pH}$ was reduced from 8.5 to 6.0. (iii) The same protocol was used in low $(0.1 \mathrm{mmol} / \mathrm{L}) \mathrm{Ca}^{2+}$-buffered solution buffer solution. (B) (i-iv) PAR-2 expression. (i) Representative section of normal human pancreas. (ii) No primary antiserum. (iii) Representative section of human pancreas from a patient with chronic pancreatitis (CP). (iv) No primary antiserum. (C) Relative optical density. $\mathrm{n}=15 .{ }^{*} P<.05$ vs $\mathrm{CP}$ membrane. (D) Real-time reverse-transcription polymerase chain reaction analysis of PAR-2 mRNA expression of human pancreas. Data are given in $2^{\wedge} \mathrm{dCT} . \mathrm{n}=15 .{ }^{*} \mathrm{P}<.05$ vs $\mathrm{CP}$.

immunohistochemistry that PAR $-2^{+/+}$mice do, whereas PAR-2 ${ }^{-/}$mice do not, express PAR-2 in their PDECs (Figure 6C [i and iii]). Accordingly, our functional data clearly show that the $\mathrm{pH}_{\mathrm{i}}$ and $\left[\mathrm{Ca}^{2+}\right]_{\mathrm{i}}$ responses to luminal administration of either trypsin or PAR-2-AP were markedly diminished in PAR-2 $2^{-/-}$PDECs (Figure $6 D$ and $E$ ).

\section{Discussion}

The human pancreatic ductal epithelium secretes 1 to $2 \mathrm{~L}$ of alkaline fluid every 24 hours that may contain up to $140 \mathrm{mmol} / \mathrm{L} \mathrm{NaHCO}{ }_{3} \cdot{ }^{1213}$ The physiologic function of this alkaline secretion is to wash digestive enzymes down the ductal tree and into the duodenum and to neutralize acidic chyme entering the duodenum from the stomach. There are important lines of evidence supporting the idea that pancreatic ducts play a role in the pathogenesis of pancreatitis: (1) ductal fluid and bicarbonate secretion are compromised in acute and chronic pancreatitis, ${ }^{30,31}$ (2) one of the main end points of chronic pancreatitis is the destruction of the ductal system, ${ }^{32,33}$ (3) mutations in CFTR may increase the risk of pancreatitis, ${ }^{30,31,34-36}$ and (4) etiologic factors for pancreatitis, such as bile acids or ethanol in high concentration, inhibit pancreatic ductal bicarbonate secretion. ${ }^{37-39}$ Despite the previously men- 
R122H TRYPSIN

A

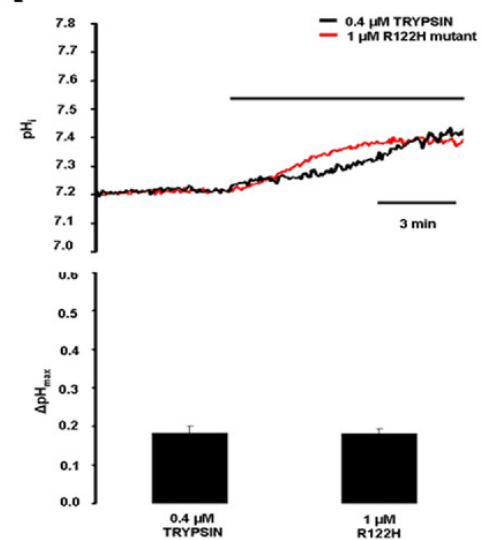

C

PAR-2 $^{\text {+/+ }}$
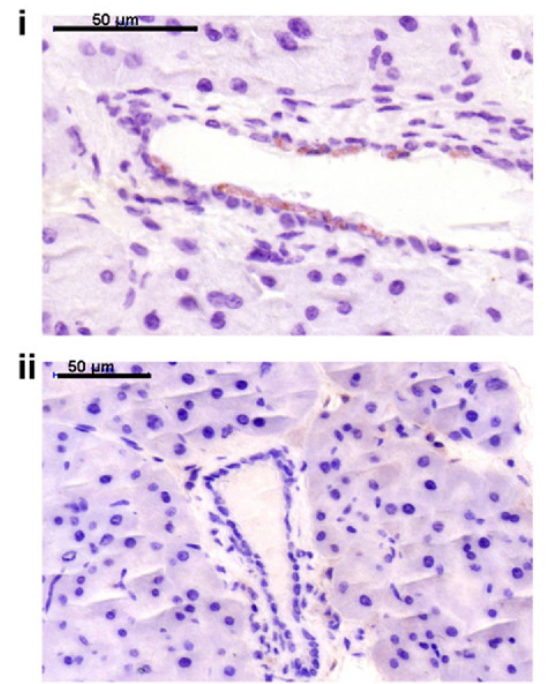

\section{B}

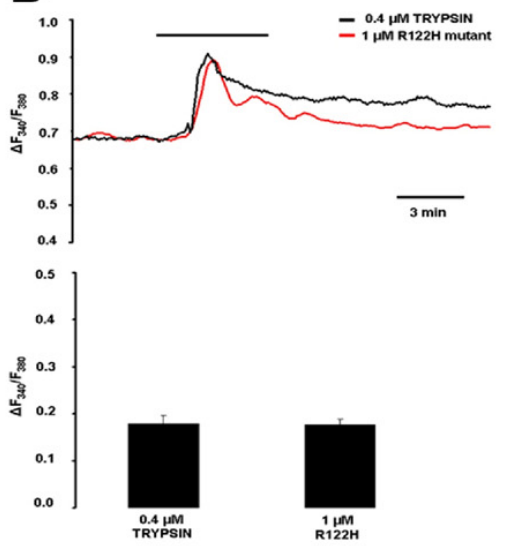

PAR-2-1-
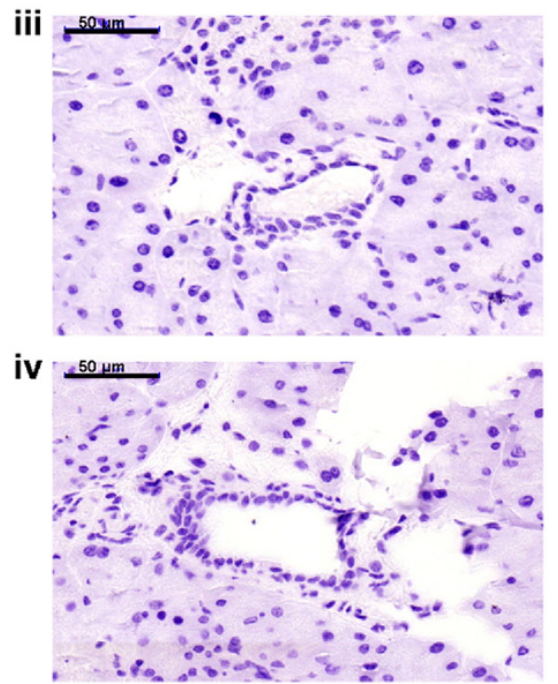

D

$\mathbf{E}$
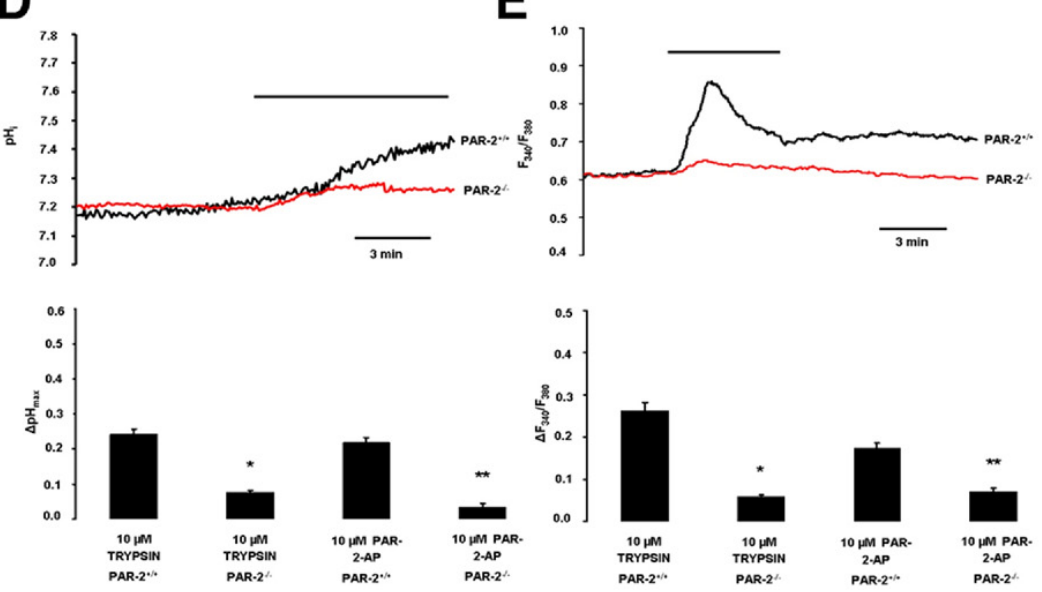

Figure 6. Experiments using $\mathrm{R} 122 \mathrm{H}$ human mutant cationic trypsin and PAR-2 ${ }^{-1-}$ mice. Representative $(A) \mathrm{pH}_{\mathrm{i}}$ and $(B)\left[\mathrm{Ca}^{2+}\right]_{\mathrm{i}}$ measurements using luminal administration of normal and $\mathrm{R} 122 \mathrm{H}$ mutant cationic trypsin in microperfused guinea pig pancreatic ducts. $n=5$ for all experiments. (C) (i-iv) PAR-2expressing cells were visualized by immunohistochemistry as described in Figure 1. (i) Representative section of the pancreas removed from PAR-2 $2^{+/+}$mice. (ii) Section without primary antiserum. (iii) Pancreas removed from PAR-2 ${ }^{-/-}$mice. (iv) Section without primary antiserum. $(D) \mathrm{pH}_{\mathrm{i}}$ and $(E)\left[\mathrm{Ca}^{2+}\right]_{\mathrm{i}}$ measurements using luminal administration of trypsin in microperfused pancreatic ducts isolated from PAR-2 knockout (red curve) and PAR-2 wild-type mice (black curve). $\mathrm{n}=$ 5 for all experiments. ${ }^{*} P<.05$ vs $10 \mu \mathrm{mol} / \mathrm{L}$ trypsin PAR $-2^{+/+},{ }^{* *} \mathrm{P}<.05$ vs $10 \mu \mathrm{mol} / \mathrm{L}$ PAR-2-AP PAR- $2^{+/+}$. tioned data, the role of PDECs in the development of pancreatitis has received relatively little attention. ${ }^{40}$

There are important species differences regarding the localization of PAR-2 in pancreatic ducts and in the effect of its activation on bicarbonate secretion. For example, CAPAN-1 cells ${ }^{10}$ and dog PDECs ${ }^{9}$ express PAR-2 only on the basolateral membrane, whereas bovine PDECs express PAR-2 on the luminal membrane. ${ }^{11}$ Therefore, one of our 
first aims was to determine which animal model best mimics human PAR-2 expression and thus would be the best for studying the effects of trypsin on PDEC function. Our results showed that in the human pancreas PAR-2 is localized to the luminal membrane of small proximal pancreatic ducts, which are probably the major site of bicarbonate and fluid secretion. Because CAPAN-1 cells and dog PDECs express PAR-2 only on the basolateral membrane, they do not mimic the human situation. Rats or mice are also not good models for the human gland because they secrete only 70 to $80 \mathrm{mmol} / \mathrm{L}$ bicarbonate. ${ }^{41,42}$ However, the guinea pig pancreas secretes $\sim 140$ $\mathrm{mmol} / \mathrm{L}$ bicarbonate, as does the human gland, and the regulation of bicarbonate secretion is similar in both species. ${ }^{41,42}$ Because PAR-2 expression in the guinea pig pancreas was localized to the luminal membrane of duct cells, we performed our experiments on isolated guinea pig ducts.

First we characterized the effects of PAR-2 activation by trypsin and PAR-2-AP on PDECs. Previously, it has been shown that activation of the G protein-coupled PAR-2 by proteinases requires proteolytic cleavage of the receptor, which is followed by an elevation of $\left[\mathrm{Ca}^{2+}\right]_{\mathrm{i}} \cdot{ }^{43-45}$ As expected, luminal trypsin and PAR2-AP caused a dose-dependent elevation of $\left[\mathrm{Ca}^{2+}\right]_{i}$ in guinea pig ducts. Importantly, the trypsin inhibitor SBTI, PAR-2-ANT, and the intracellular calcium chelator BAPTA-AM all completely blocked the elevation of $\left[\mathrm{Ca}^{2+}\right]_{i}$, whereas removal of extracellular $\mathrm{Ca}^{2+}$ had no effect. Acidosis ( $\mathrm{pH}$ 6.8) also slightly reduced the changes in $\left[\mathrm{Ca}^{2+}\right]_{\mathrm{i}}$ evoked by trypsin, most probably due to reduced cleavage activity of trypsin at an acidic $\mathrm{pH}$. Next we characterized the effects of PAR-2 activation on $\mathrm{pH}_{\mathrm{i}}$. Luminal application of trypsin and PAR-2-AP both caused a dose-dependent intracellular alkalosis in PDECs. This alkalosis is most likely explained either by a reduction in the rate of bicarbonate efflux (ie, secretion) across the apical membrane of PDECs or by an increase in the rate of bicarbonate influx at the basolateral side of the cell. We favor the former explanation because luminal application of the anion exchange inhibitor $\mathrm{H}_{2}$ DIDS or the CFTR inhibitor CFTRinh-172 produced a similar intracellular alkalization. ${ }^{22,46}$ Thus, PAR-2 activation inhibits bicarbonate secretion in PDECs by inhibiting SLC26 anion exchangers and CFTR $\mathrm{Cl}^{-}$channels expressed on the apical membrane of the duct cell. In similarity with the $\left[\mathrm{Ca}^{2+}\right]_{\mathrm{i}}$ signals, the effect of PAR-2 activation on $\mathrm{PH}_{\mathrm{i}}$ was blocked by SBTI, PAR-2-ANT, and BAPTA-AM, with the action of BAPTA-AM suggesting that the inhibition of bicarbonate secretion follows from the increase in $\left[\mathrm{Ca}^{2+}\right]_{\mathrm{i}}$. Interestingly, an elevation of $\left[\mathrm{Ca}^{2+}\right]_{\mathrm{i}}$ is crucial for both stimulatory (eg, acetylcholine, ${ }^{13}$ low concentrations of bile acids, ${ }^{39}$ and ethanol ${ }^{38}$ ) and inhibitory pathways (eg, basolateral adenosine triphosphate, arginine vasopressin, and high concentrations of ethanol) that control bicarbonate secretion by PDECs. Such marked differences in the outcome of $\left[\mathrm{Ca}^{2+}\right]_{\mathrm{i}}$ signals in PDECs probably reflect differences in the source of $\mathrm{Ca}^{2+}$ and/or in the intracellular compartmentalization of
$\left[\mathrm{Ca}^{2+}\right]_{\mathrm{i}}$ signals generated by different secretory agonists and antagonists.

Remarkably, trypsin was still able to evoke an elevation of $\mathrm{pH}_{\mathrm{i}}$ when $\mathrm{Cl}^{-}$was removed from the duct lumen and when PDECs were pretreated with $\mathrm{H}_{2}$ DIDS, conditions that should inhibit bicarbonate efflux on the exchanger. These results suggested the involvement of CFTR, the only other known bicarbonate efflux pathway on the apical membrane, in the inhibitory effect of trypsin. This hypothesis was confirmed by patch clamp experiments in which trypsin decreased CFTR whole cell currents in isolated guinea pig PDECs by $50 \%$ to $60 \%$. Finally, the fact that the trypsin-induced alkalinization was completely blocked by a combination of CFTRinh-172 and $\mathrm{H}_{2}$ DIDS confirms the involvement of both CFTR and SLC26 anion exchangers. Our conclusion from these $\mathrm{pH}_{\mathrm{i}}$ and patch clamp data is that PAR-2 activation inhibits both the SLC26 anion exchanger (probably SLC26A6 [PAT-1] ${ }^{47}$ because SLC26A3 [DRA] is only weakly inhibited by disulfonic stilbenes ${ }^{47,48}$ ) and CFTR $\mathrm{Cl}^{-}$channels expressed on the apical membrane of the duct cell.

The $\mathrm{pH}$ of pancreatic juice (and therefore the luminal $\mathrm{pH}\left[\mathrm{pH}_{\mathrm{L}}\right]$ in the duct) can vary between approximately 6.8 and 8.0. It has recently been shown that protons coreleased during exocytosis cause significant acidosis (up to 1 $\mathrm{pH}$ unit) in the lumen of the acini. ${ }^{23}$ However, Ishiguro et $\mathrm{al}^{49}$ have clearly shown that the $\mathrm{pH}_{\mathrm{L}}$ in pancreatic ducts is dependent on the level of bicarbonate secretion. $\mathrm{pH}_{\mathrm{L}}$ can be elevated from 7.2 to 8.5 by stimulation with secretin or forskolin, and this effect was strictly dependent on the presence of bicarbonate. ${ }^{24,49,50}$ Also, inhibition of ductal bicarbonate secretion with $\mathrm{H}_{2}$ DIDS can decrease the $\mathrm{pH}_{\mathrm{L}}$ to less than 8.0.49 In view of these results, we tested whether trypsinogen autoactivation was affected by $\mathrm{pH}$ over the range of 6.0 to 8.5 . Autoactivation of trypsinogen was relatively slow at $\mathrm{pH} 8.5$, but decreasing the $\mathrm{pH}$ from 8.5 to 7 progressively stimulated autoactivation. These results suggest that under physiologic conditions bicarbonate secretion by PDECs is not only important for elevating the $\mathrm{pH}$ in the duodenum, but also for keeping pancreatic enzymes in an inactive state in the ductal system of the gland.

Receptor down-regulation is a phenomenon that occurs in the continued presence of an agonist and leads to a reduction in the sensitivity of the cell to the agonist. Potentially, there are 2 mechanisms that could underlie receptor down-regulation of PAR-2: (1) after proteolytic activation, the PAR- 2 is internalized by a clathrin-mediated mechanism and then targeted to lysosomes ${ }^{45}$ and (2) if trypsin is present for a longer time in the lumen, PAR-2 may be down-regulated at the transcriptional level. In this study, we provide evidence that the second mechanism, transcriptional down-regulation, explains the reduced expression of PAR-2 seen in chronic pancreatitis.

Conflicting data can be found in the literature concerning the role of PAR-2 in acute pancreatitis. Singh et $\mathrm{al}^{7}$ showed that in secretagogue-induced experimental pancreatitis, PAR-2 deletion is associated with a more severe 
pancreatitis. Although Laukkarinen et al $^{17}$ confirmed these results in cerulein-induced pancreatitis, they also clearly showed that in taurocholate-induced pancreatitis, PAR-2 deletion markedly reduced the severity of the disease. There is no evidence to suggest that clinical pancreatitis is evoked by supramaximal secretagogue stimulation; however, the taurocholate-induced pancreatitis model may mimic the clinical situation. Therefore, Laukkarinen et al ${ }^{17}$ speculated that PAR-2 activation promotes the worsening of clinical pancreatitis and our data are consistent with that hypothesis.

Besides the clear pathophysiologic role of the trypsin/PAR-2 interaction in chronic pancreatitis, there is still a debate as to why PAR-2 are localized to the luminal membrane of PDEC in small ducts close to the acinar cells. What could the physiologic role of this PAR-2 be? A number of agents have been shown to have dual effects on PDECs at different concentrations. For example, bile acids in low concentrations stimulate but in high concentrations inhibit bicarbonate secretion. ${ }^{39}$ The same applies to ethanol. ${ }^{38}$ Under physiologic conditions, trypsin inhibitors are coreleased from acinar cells with trypsinogen and should block the activity of any trypsin that is generated spontaneously. Therefore, only very small amounts of active trypsin, if any, will be present in the duct lumen under normal conditions. However, there remains a possibility that very small amounts of active trypsin (ie, concentrations less than $0.1 \mu \mathrm{mol} / \mathrm{L}$ that would not cause an elevation of $\left[\mathrm{Ca}^{2+}\right]_{\mathrm{i}}$ or change in $\mathrm{pH}$ ) could bind to PAR-2 on the luminal membrane of the ducts and augment other stimulatory mechanisms so as to enhance flushing of digestive enzymes down the ductal tree.

In conclusion, we suggest for the first time that one of the physiologic roles of bicarbonate secretion by PDECs is to curtail trypsinogen autoactivation within the pancreatic ductal system. However, if trypsin is present in the duct lumen (as may occur during the early stages of pancreatitis due to leakage from acinar cells), PAR-2 on the duct cell will be activated, leading to $\mathrm{Ca}^{2+}$ release from intracellular stores and an increase in cytosolic $\mathrm{Ca}^{2+}$ concentration. This causes inhibition of the luminal anion exchangers and CFTR $\mathrm{Cl}^{-}$channels, reducing bicarbonate secretion by the duct cell. The decrease in bicarbonate secretion will increase the transit time of zymogens down the duct tree and decrease $\mathrm{pH}_{\mathrm{L}}$, both of which will promote the autoactivation of trypsinogen. The trypsin so formed will further inhibit bicarbonate transport, leading to a vicious cycle generating further decreases in $\mathrm{pH}_{\mathrm{L}}$ and enhanced trypsinogen activation, which will favor development of the pancreatitis (Supplementary Figure 4). Finally, the $\mathrm{R} 122 \mathrm{H}$ mutant cationic trypsin also elevated $\left[\mathrm{Ca}^{2+}\right]_{\mathrm{i}}$ and $\mathrm{pH}_{\mathrm{i}}$ in duct cells, suggesting that this mechanism may be particularly important in hereditary pancreatitis in which the mutant trypsinogens more readily autoactivate. $^{29}$

\section{Supplementary Material}

Note: To access the supplementary material accompanying this article, visit the online version of Gastroenterology at www.gastrojournal.org, and at doi: 10.1053/j.gastro.2011.08.039.

\section{References}

1. Petersen $\mathrm{OH}$. Physiology of acinar cell secretion. In: Hans Beger, Andrew Warshaw, Markus Büchler, et al, eds. The pancreas. 2nd ed. Malden, MA: Blackwell Publishing, 2008:71-77.

2. Lerch MM, Gorelick FS. Early trypsinogen activation in acute pancreatitis. Med Clin North Am 2000;84:549-563.

3. Thrower EC, Gorelick FS, Husain SZ. Molecular and cellular mechanisms of pancreatic injury. Curr Opin Gastroenterol 2010;84:549-563.

4. Geokas MC, Rinderknecht H. Free proteolytic enzymes in pancreatic juice of patients with acute pancreatitis. Am J Dig Dis 1974;19:591598.

5. Renner IG, Rinderknecht H, Douglas AP. Profiles of pure pancreatic secretions in patients with acute pancreatitis: the possible role of proteolytic enzymes in pathogenesis. Gastroenterology 1978;75:10901098.

6. Withcomb D, Beger H. Definitions of pancreatic diseases and their complications. In: Hans Beger, Andrew Warshaw, Markus Büchler et al, eds. The pancreas. 2nd ed. Malden, MA: Blackwell Publishing, 2008:1-6.

7. Singh VP, Bhagat L, Navina S, et al. Protease-activated receptor-2 protects against pancreatitis by stimulating exocrine secretion. Gut 2007;56:958-964.

8. Kawabata A, Kuroda R, Nishida M, et al. Protease-activated receptor-2 (PAR-2) in the pancreas and parotid gland:Immunolocalization and involvement of nitric oxide in the evoked amylase secretion. Life Sci 2002;71:2435-2446.

9. Nguyen TD, Moody MW, Steinhoff M, et al. Trypsin activates pancreatic duct epithelial cell ion channels through proteinase activated receptor-2. J Clin Invest 1999;103:261-269.

10. Namkung W, Lee JA, Ahn W, et al. $\mathrm{Ca}^{2+}$ activates cystic fibrosis transmembrane conductance regulator- and $\mathrm{Cl}$-dependent $\mathrm{HCO}_{3}{ }^{-}$transport in pancreatic duct cells. J Biol Chem 2003;278:200-207.

11. Alvarez C, Regan JP, Merianos D, et al. Protease-activated receptor- 2 regulates bicarbonate secretion by pancreatic duct cells in vitro. Surgery 2004;136:669-676.

12. Lee M, Muallem S. Physiology of duct cell secretion. In: Hans Beger, Andrew Warshaw, Markus Büchler, et al, eds. The pancreas. 2nd ed. Malden, MA: Blackwell Publishing, 2008:78-90.

13. Argent BE. Cell physiology of pancreatic ducts. In: Johnson LR, ed. Physiology of the gastrointestinal tract. Volume 2. 4th ed. San Diego, CA: Elsevier, 2006:1376-1396.

14. Hegyi P, Rakonczay Z Jr, Farkas K, et al. Controversies in the role of SLC26 anion exchangers in pancreatic ductal bicarbonate secretion. Pancreas 2008;37:232-234.

15. Ishiguro H, Steward MC, Sohma $Y$, et al. Membrane potential and bicarbonate secretion in isolated interlobular ducts from guineapig pancreas. J Gen Physiol 2002;120:617-628.

16. Sohma $\mathrm{Y}$, Gray $\mathrm{MA}$, Imai $\mathrm{Y}$, et al. $\mathrm{HCO}_{3}{ }^{-}$transport in a mathematical model of the pancreatic ductal epithelium. J Membr Biol 2000;176:77-100.

17. Laukkarinen JM, Weiss ER, van Acker GJ, et al. Protease-activated receptor-2 exerts contrasting model-specific effects on acute experimental pancreatitis. J Biol Chem 2008;283:20703-20712.

18. Kawabata A, Matsunami M, Tsutsumi M, et al. Suppression of pancreatitis-related allodynia/hyperalgesia by proteinase-activated receptor-2 in mice. Br J Pharmacol 2006;148:54-60.

19. Sharma A, Tao X, Gopal A, et al. Protection against acute pancreatitis by activation of protease-activated receptor-2. Am J Physiol Gastrointest Liver Physiol 2005;288:G388-G395. 
20. Namkung W, Han W, Luo X, et al. Protease-activated receptor 2 exerts local protection and mediates some systemic complications in acute pancreatitis. Gastroenterology 2004;126:1844-1859.

21. Argent BE, Arkle S, Cullen MJ, et al. Morphological, biochemical and secretory studies on rat pancreatic ducts maintained in tissue culture. Q J Exp Physiol 1986;71:633-648.

22. Hegyi P, Rakonczay Z Jr, Tiszlavicz L, et al. Protein kinase $C$ mediates the inhibitory effect of substance $\mathrm{P}$ on $\mathrm{HCO}_{3}{ }^{-}$secretion from guinea pig pancreatic ducts. Am J Physiol Cell Physiol 2005; 288:C1030-C1041.

23. Behrendorff N, Floetenmeyer M, Schwiening C, et al. Protons released during pancreatic acinar cell secretion acidify the lumen and contribute to pancreatitis in mice. Gastroenterology 2010; 139:1711-1720.

24. Ishiguro H, Steward MC, Wilson RW, et al. Bicarbonate secretion in interlobular ducts from guinea-pig pancreas. J Physiol 1996;495:179191.

25. Kukor Z, Mayerle J, Kruger B, et al. Presence of cathepsin B in the human pancreatic secretory pathway and its role in trypsinogen activation during hereditary pancreatitis. J Biol Chem 2002;277:2138921396.

26. Tympner F, Rosch W. Viscosity and trypsin activity of pure pancreatic juice in chronic pancreatitis. Acta Hepatogastroenterol (Stuttg) 1978;25:73-76.

27. Fedail SS, Harvey RF, Salmon PR, et al. Trypsin and lactoferrin levels in pure pancreatic juice in patients with pancreatic disease. Gut 1979;20:983-986.

28. Tympner F. Selectively aspirated pure pancreatic secretion. Viscosity, trypsin activity, protein concentration and lactoferrin content of pancreatic juice in chronic pancreatitis. Hepatogastroenterology 1981;28:169-172.

29. Sahin-Tóth M, Tóth M. Gain-of-function mutations associated with hereditary pancreatitis enhance autoactivation of human cationic trypsinogen. Biochem Biophys Res Commun 2000;278:286-289.

30. Cavestro GM, Zuppardo RA, Bertolini S, et al. Connections between genetics and clinical data:Role of MCP-1, CFTR, and SPINK-1 in the setting of acute, acute recurrent, and chronic pancreatitis. Am J Gastroenterol 2010;105:199-206.

31. Hegyi P, Rakonczay Z. Insufficiency of electrolyte and fluid secretion by pancreatic ductal cells lead to increase patients risk to pancreatitis. Am J Gastroenterol 2010;105:2119-2120.

32. Kloppel G, Luttges J, Sipos B, et al. Autoimmune pancreatitis: pathological findings. Jop 2005;6:97-101.

33. Ectors N, Maillet B, Aerts R, et al. Non-alcoholic duct destructive chronic pancreatitis. Gut 1997:41:263-268.

34. Hegyi P, Pandol S, Venglovecz V, et al. The acinar-ductal tango in the pathogenesis of acute pancreatitis. Gut 2011;60:544-552.

35. Nousia-Arvanitakis S. Cystic fibrosis and the pancreas: recent scientific advances. J Clin Gastroenterol 1999;29:138-142.

36. Weiss FU, Simon P, Bogdanova N, et al. Functional characterisation of the CFTR mutations M348V and A1087P from patients with pancreatitis suggests functional interaction between CFTR monomers. Gut 2009;58:733-734.

37. Maleth J, Venglovecz V, Rázga Z, et al. The non-conjugated chenodeoxycholate induces severe mitochondrial damage and inhibits bicarbonate transport in pancreatic duct cells. Gut 2011;60:136-138.
38. Yamamoto A, Ishiguro $\mathrm{H}$, Ko SB, et al. Ethanol induces fluid hypersecretion from guinea-pig pancreatic duct cells. J Physiol 2003:551:917-926.

39. Venglovecz V, Rakonczay Z Jr, Ozsvari B, et al. Effects of bile acids on pancreatic ductal bicarbonate secretion in guinea pig. Gut 2008;57:1102-1112

40. Lee MG, Muallem S. Pancreatitis: the neglected duct. Gut 2008; 57:1037-1039.

41. Padfield PJ, Garner A, Case RM. Patterns of pancreatic secretion in the anaesthetised guinea pig following stimulation with secretin, cholecystokinin octapeptide, or bombesin. Pancreas 1989;4:204-209.

42. Steward MC, Ishiguro $\mathrm{H}$, Case RM. Mechanisms of bicarbonate secretion in the pancreatic duct. Annu Rev Physiol 2005;67:377-409.

43. Vergnolle N. Review article: proteinase-activated receptors-nove signals for gastrointestinal pathophysiology. Aliment Pharmacol Ther 2000;14:257-266.

44. Bohm SK, Khitin LM, Grady EF, et al. Mechanisms of desensitization and resensitization of proteinase-activated receptor-2. J Biol Chem 1996;271:22003-22016.

45. Hoxie JA, Ahuja M, Belmonte $\mathrm{E}$, et al. Internalization and recycling of activated thrombin receptors. J Biol Chem 1993;268:13756-13763.

46. Stewart AK, Yamamoto A, Nakakuki M, et al. Functional coupling of apical $\mathrm{Cl}^{-} / \mathrm{HCO}_{3}{ }^{-}$exchange with CFTR in stimulated $\mathrm{HCO}_{3}$ secretion by guinea pig interlobular pancreatic duct. Am J Physio Gastrointest Liver Physiol 2009;296:G1307-G1317.

47. Ko SB, Shcheynikov N, Choi JY, et al. A molecular mechanism for aberrant CFTR-dependent $\mathrm{HCO}_{3}$ transport in cystic fibrosis. EMBO J 2002;21:5662-5672.

48. Chernova MN, Jiang L, Shmukler BE, et al. Acute regulation of the SLC26A3 congenital chloride diarrhoea anion exchanger (DRA) expressed in Xenopus oocytes. J Physiol 2003;549:3-19.

49. Ishiguro H, Naruse S, Steward MC, et al. Fluid secretion in interlobular ducts isolated from guinea-pig pancreas. J Physiol 1998; 511:407-422.

50. Ishiguro $\mathrm{H}$, Naruse $\mathrm{S}$, Kitagawa $\mathrm{M}$, et al. Luminal ATP stimulates fluid and $\mathrm{HCO}_{3}{ }^{-}$secretion in guinea-pig pancreatic duct. J Physiol 1999;519:551-558.

Received October 26, 2010. Accepted August 5, 2011.

\section{Reprint requests}

Address requests for reprints to: Péter Hegyi, MD, PhD, DSc, First Department of Medicine, University of Szeged, Faculty of Medicine, Korányi fasor 8-10, H-6720, Szeged, Hungary. e-mail: hegyi.peter@ med.u-szeged.hu; fax: (36) 62 545-185.

\section{Conflicts of interest}

The authors disclose no conflicts.

\section{Funding}

Supported by grants from the Hungarian Scientific Research Fund to

V.V., Z.R., and P.H. (PD78087, K78311, and NNF 78851), Bolyai postdoctoral fellowships to P.H. and Z.R. (00334/08/5, 00174/10/5) awarded by the Hungarian Academy of Sciences, a European Pancreatic Club travel grant, National Office for Research and Technology grants (TÁMOP-4.2.2-08/1/2008-0002 and 0013, TÁMOP 4.2.1.B-09/1/KONV), National Institutes of Health grant DK058088 (to M.S.-T.), and scholarships from the Rosztoczy Foundation (to A.G. and A.S.).

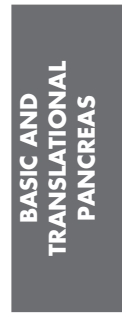




\section{Supplementary Materials and Methods Ethics}

All experiments were conducted in compliance with the Guide for the Care and Use of Laboratory Animals (USA NIH publication No 85-23, revised 1985). Animal experiments were approved by the Regional Ethical Board at the University of Szeged, Hungary.

\section{Solutions and Chemicals}

HEPES-buffered solutions were gassed with $100 \%$ $\mathrm{O}_{2}$, and their $\mathrm{pH}$ was set to 7.4 with $\mathrm{HCl}$ at $37^{\circ} \mathrm{C}$. $\mathrm{HCO}_{3}{ }^{-}$buffered solutions were gassed with $95 \% \mathrm{O}_{2} / 5 \% \mathrm{CO}_{2}$ to set $\mathrm{pH}$ to 7.4 at $37^{\circ} \mathrm{C}$. For patch clamp studies, the standard extracellular solution contained (in mmol/L): $145 \mathrm{NaCl}$, $4.5 \mathrm{KCl}, 2 \mathrm{CaCl}_{2}, 1 \mathrm{MgCl}_{2}, 10$ HEPES, and 5 glucose $(\mathrm{pH}$ 7.4 adjusted with $\mathrm{NaOH}$ ). The osmolarity of the extracellular solution was $300 \mathrm{mOsm} / \mathrm{L}$. The standard pipette solution for the patch clamp experiments contained (in $\mathrm{mmol} / \mathrm{L}): 120 \mathrm{CsCl}, 2 \mathrm{MgCl}_{2}, 0.2$ ethylene glycol-bis( $\beta$ aminoethyl ether)- $N, N, N^{\prime}, N^{\prime}$-tetraacetic acid (EGTA), 10 HEPES, and $1 \mathrm{Na}_{2} \mathrm{ATP}$ (pH 7.2 adjusted with $\mathrm{NaOH}$ ). Chromatographically pure collagenase was purchased from Worthington (Lakewood, NJ). 2,7-Bis-(2-carboxyethyl)-5-(and-6-)carboxyfluorescein, acetoxymethyl ester (BCECF-AM), 2-(6-(bis(carboxymethyl)amino)-5-(2-(2(bis(carboxymethyl)amino)-5-methylphenoxy)ethoxy)-2benzofuranyl)-5-oxazolecarboxylic acetoxymethyl ester (FURA 2-AM), dihydro-4,4'-diisothiocyanostilbene2,2'-disulfonic acid ( $\mathrm{H}_{2} \mathrm{DIDS}$ ), and 1,2-bis(o-aminophenoxy)ethane- $N, N, N^{\prime}, N^{\prime}$-tetraacetic acid (BAPTAAM) were from Invitrogen (Carlsbad, CA). PAR-2-ANT (H-Phe-Ser-Leu-Leu-Arg-Tyr- $\left.\mathrm{NH}_{2}\right)$ and PAR-2-AP (HSer-Leu-Ile-Gly-Arg-Leu-amid trifluoroacetate salt) were from Peptides International (Louisville, KY). Forskolin were from Tocris (Ellisville, MO). Rabbit PAR-2 polyclonal antibody was purchased from Santa Cruz Biotechnology (Heidelberg, Germany). All other chemicals were obtained from Sigma-Aldrich (Budapest, Hungary).

\section{Isolation of Pancreatic Ducts and Individual Ductal Cells}

Male guinea pigs weighing between 150 and $250 \mathrm{~g}$ or mice (PAR-2 $2^{+/}$and PAR-2 $2^{-/}$) weighing between 18 and $21 \mathrm{~g}$ were humanely killed by cervical dislocation, the pancreas was removed, and small intralobular proximal ducts were isolated by microdissection as described previously. ${ }^{1}$ PAR-2 $2^{-/-}$mice (B6.Cg-F2rl1 ${ }^{\mathrm{tm} 1 \mathrm{Mslb} / \mathrm{J}}$ ) were previously generated by Schmidlin et $\mathrm{al}^{1}$ and a kind gift from Ashok Saluja. ${ }^{2}$ Isolated ducts were then cultured overnight in a $37^{\circ} \mathrm{C}$ incubator gassed with $5 \% \mathrm{CO}_{2} / 95 \%$ air. ${ }^{3}$

To obtain single pancreatic ductal cells, cultured ducts were incubated for 50 minutes at $37^{\circ} \mathrm{C}$ in $50 \mathrm{U} / \mathrm{mL}$ elastase dissolved in storage solution (Dulbecco's modified Eagle medium containing 3\% [wt/vol] bovine serum albumin $[\mathrm{pH} 7.4$ with $\mathrm{NaOH}]$ ). Then the ducts were transferred to a $\mathrm{Ca}^{2+} / \mathrm{Mg}^{2+}$-free HEPES-buffered solution and incubated for a further 10 minutes at $37^{\circ} \mathrm{C}$. After the incubation, the ducts were transferred to a coverslip and teased apart using stainless steel needles. The individual ductal cells were used for experiments within 3 to 4 hours after isolation.

\section{Measurement of $\mathrm{pH}_{i}$ and $\mathrm{Ca}^{2+}$ Concentration}

Ducts were bathed in standard HEPES solution and loaded with BCECF-AM $(2 \mu \mathrm{mol} / \mathrm{L})$ or FURA 2-AM $(5 \mu \mathrm{mol} / \mathrm{L})$ for 30 to 60 minutes at room temperature.

Ducts were then transferred to a perfusion chamber mounted on an IX71 inverted microscope (Olympus, Budapest, Hungary) and perfused continuously with solutions at $37^{\circ} \mathrm{C}$ both from the luminal and basolateral side at a rate of 10 to $30 \mu \mathrm{L} / \mathrm{min}$ and 4 to $5 \mathrm{~mL} / \mathrm{min}$, respectively. Four to 5 small areas (region of interests) of 5 to 10 cells in each intact duct were excited with light at a given wavelength. Excitation of BCECF was at 495 and $440 \mathrm{~nm}$, with emitted light monitored at $535 \mathrm{~nm}$. Excitation of FURA-2 was at 380 and $340 \mathrm{~nm}$, with emitted light monitored at $510 \mathrm{~nm}$. The fluorescence emissions were captured by a charge-coupled device camera and digitized by a Cell imaging system (Olympus, Budapest, Hungary). Ratio images were collected at 1-second intervals. In situ calibration of $\mathrm{pH}_{\mathrm{i}}$ measured with BCECF was performed using the high $\mathrm{K}^{+}$-nigericin technique., ${ }^{4,5}$

\section{Electrophysiology}

Guinea pig PDECs were isolated by an enzymatic microdissection procedure as described previously. Using a glass pipette, a few drops of cell suspension were placed within a perfusion chamber mounted on the stage of an inverted microscope (TMS; Nikon, Tokyo, Japan). The ductal cells were allowed to settle and attach to the bottom of the chamber for at least 30 minutes before the perfusion was started.

Patch clamp micropipettes were fabricated from borosilicate glass capillaries (Clark, Reading, England) by using a P-97 Flaming/Brown micropipette puller (Sutter Co, Novato, CA). These pipettes had resistances between 1.5 and $2.5 \mathrm{M} \Omega$. Membrane currents were recorded with an Axopatch 1D amplifier (Axon Instruments, Union City, CA) using the whole cell configuration of the patch clamp technique at $37^{\circ} \mathrm{C}$. After establishing a high-resistance seal (1-10 G $\Omega$ ) by gentle suction, the cell membrane beneath the tip of the pipette was disrupted by suction or by application of short electrical pulses. The series resistance was typically 4 to $8 \mathrm{M} \Omega$ before compensation $(50 \%-80 \%$, depending on the voltage protocol). Current-voltage $(\mathrm{I} / \mathrm{V})$ relationships were obtained by holding $\mathrm{V}_{\mathrm{m}}$ at $0 \mathrm{mV}$ and clamping to $\pm 100 \mathrm{mV}$ in $20-\mathrm{mV}$ increments. Membrane currents were digitized by using a $333-\mathrm{kHz}$ analog-to-digital converter (Digidata 1200; Axon Instruments) under software control (pClamp 6; 
Axon Instruments). Analyses were performed by using pClamp 6 software after low-pass filtering at $1 \mathrm{kHz}$.

\section{Expression and Purification of Human Trypsinogens}

Wild-type and $\mathrm{R} 122 \mathrm{H}$ mutant human cationic trypsinogen was expressed in Escherichia coli and purified by ecotin-affinity chromatography as reported previously. ${ }^{6}$

\section{Measuring Autoactivation of Trypsinogen}

Autoactivation of trypsinogen was measured at 2 $\mu \mathrm{mol} / \mathrm{L}$ concentration at $37^{\circ} \mathrm{C}$ in a polybuffer system (American Bioanalytical Inc, Natick, MA) containing 100 $\mathrm{mmol} / \mathrm{L} \quad 2-(N$-morpholino)ethanesulfonic acid, 100 $\mathrm{mmol} / \mathrm{L}$ HEPES, and $100 \mathrm{mmol} / \mathrm{L}$ Tris in $100 \mu \mathrm{L}$ final volume. The $\mathrm{pH}$ of the Polybuffer was adjusted to given values with $\mathrm{HCl}(\mathrm{pH} 6.0$ and 6.5) or $\mathrm{NaOH}(\mathrm{pH} 7.0,7.5$, 8.0, and 8.5). Reactions also contained $1 \mathrm{mmol} / \mathrm{L}$ or 0.1 $\mathrm{mmol} / \mathrm{L} \mathrm{CaCl}$ and $100 \mathrm{mmol} / \mathrm{L} \mathrm{NaCl}$, as indicated. At given times, $2-\mu \mathrm{L}$ aliquots were removed and trypsin activity was determined using the N-CBZ-Gly-Pro-Arg-pnitroanilide substrate at $150 \mu \mathrm{mol} / \mathrm{L}$ final concentration.

\section{Immunohistochemistry}

Pancreatic tissue from 5 guinea pigs, 15 patient samples without pancreatic disease near neuroendocrine tumors (average age, 59.5; female/male, 7:8), and 15 patients (average age, 56.6; female/male, 4:11) who had chronic pancreatitis ( 13 alcohol, 2 gallstone) were investigated. The human samples were obtained with the permission of the Regional Ethical Committee of Semmelweis University (\#172/2003).

The pancreatic tissues were fixed in $10 \%$ neutral buffered formalin for 24 hours, followed by paraffin embedding, and were then cut and stained with H\&E to establish the diagnosis. Paraffin-embedded, 3 - to 4- $\mu$ m-thick sections were used for immunohistochemistry to detect PAR-2 expression. The slides were treated for 30 minutes with target retrieval solution (Dako, Glostrup, Denmark) in a microwave oven, followed by incubation with the primary rabbit polyclonal antibody (Santa Cruz Biotechnology Inc, Heidelberg, Germany) in 1:100 dilution overnight at $4^{\circ} \mathrm{C}$. Signal detection was achieved by using ImPRESS reagent with secondary anti-rabbit immunoglobulin G antibody (20 minutes) (Vector Laboratories, Burlingame, CA). Diaminobenzidine was used to visualize immune complexes, and nuclear counterstaining was performed with hematoxylin. For negative controls, the appropriate antibody was omitted and either the antibody diluent alone or isotype-matched immunoglobulin $\mathrm{G}$ serum was used. The negative controls exhibited no signal. Normal skin epithelial cells were used as positive controls to confirm correct immunohistochemical staining for PAR-2 (results not shown).

The immunohistochemical reactions were digitalized with a Mirax MIDI slide scanner (3DHistech Ltd, Buda- pest, Hungary). Relative optical (RO) density was calculated using ImageJ program (National Institutes of Health, Bethesda, MD). Pixel values (PV) were normalized to erythrocyte density $\left(\mathrm{PV}_{\text {Norm }}=\mathrm{PV}_{\text {Measured }}-\mathrm{PV}_{\text {Erythrocyte }}\right)$ in all sections. RO-Density value was calculated from the RO-Density $=\log _{10}\left(255 / \mathrm{PV}_{\text {Norm }}\right)$ equation, assuming that the brightest value in the image equals 255 .

Western blot analysis was used to determine the specificity of the PAR-2 antibody. Proteins were extracted from fresh-frozen guinea pig $(\mathrm{n}=3)$ and human $(\mathrm{n}=3)$ pancreatic tissue stored at $-80^{\circ} \mathrm{C}$. Isolation was performed by using lysis buffer $(20 \mathrm{mmol} / \mathrm{L}$ Tris, $\mathrm{pH} 7.5,150$ $\mathrm{mmol} / \mathrm{L} \mathrm{NaCl}, 2 \mathrm{mmol} / \mathrm{L}$ EDTA, 1\% Triton X-100 containing protease inhibitor complex [Sigma Aldrich Co, Budapest, Hungary]). Samples (50 mg) were homogenized, followed by centrifugation at $13,200 \mathrm{rpm}$ at $4^{\circ} \mathrm{C}$ for 5 minutes. Measurements of protein concentration were performed using Bradford analysis. ${ }^{7}$ A total of $30 \mu \mathrm{g}$ of protein samples were loaded in each lane, run on $10 \%$ sodium dodecyl sulfate/polyacrylamide electrophoresis at $200 \mathrm{~V}$ for 35 minutes, and then transferred to nitrocellulose membranes at $100 \mathrm{~V}, 4^{\circ} \mathrm{C}$, for 75 minutes. For aspecific protein blocking, nonfat dry milk (5\%, phosphate-buffered saline) was used for 30 minutes. Blots were incubated with polyclonal PAR-2 rabbit antibody (1:300; Santa Cruz Biotechnology Inc, Heidelberg, Germany) and anti-GAPDH antibody (1:5000; AbDSerotec, Kidlington, England) at $4{ }^{\circ} \mathrm{C}$ overnight. After washing in $0.1 \%$ Tris, the secondary antibodies as anti-mouse GAPDH (1:2000; AbDSerotec, Düsseldorf, Germany) and horseradish peroxidase-conjugated anti-rabbit antibody (1:2000, Dako Cytomation, Ghostrup, Denmark) were applied at room temperature for 90 minutes. Following 3 series of washings in Tris-buffered saline with Tween 20, signals were visualized by enhanced chemiluminescent detection.

\section{Real-Time Reverse-Transcription Polymerase Chain Reaction}

RNA extraction. Fifteen formalin-fixed, paraffinembedded normal pancreatic tissue samples and 15 samples of chronic pancreatitis tissue were selected for realtime reverse-transcription polymerase chain reaction analysis. Total RNA was isolated from five 5- to $10-\mu \mathrm{m}$ macrodissected sections (connective tissue excluded) using RNeasy FFPE Kit (Qiagen, Hilden, Germany) in accordance with the manufacturer's instructions. RNA concentrations were obtained using a NanoDrop Spectrophotometer ND1000 (Thermo Fisher Scientific Inc, Waltham, MA).

Reverse transcription of RNA. Complementary DNA samples were prepared from $1 \mu \mathrm{g}$ total RNA using a High Capacity RNA-to-cDNA Kit (Applied Biosystems, Carlsbad, CA) as specified by the manufacturer.

Primer design. Gene-specific primers were designed by AlleleID 6.01 primer design software (Premier Biosoft International, Palo Alto, CA) for real-time reverse- 
transcription polymerase chain reaction. Isoform specificity and primer sizes were checked by BioEdit biological sequence alignment editor software (Tom Hall Ibis Therapeutics, Carlsbad, CA). Primer specificity was checked by BiSearch software (Hungarian Academy of Sciences, Institute of Enzymology, Budapest, Hungary). Primer specific amplification degree $\left(58^{\circ} \mathrm{C}\right)$ was optimized by gradient polymerase chain reaction. The used primer sequences are shown in Supplementary Table 1.

Reverse-transcription polymerase chain reaction. Real-time reverse-transcription polymerase chain reaction analysis was performed using SYBR Green technology on an ABI Prism 7000 Sequence Detection System (Applied Biosystems, Foster City, CA), according to the manufacturer's instructions. $\beta$-actin was used as the internal control gene. Primer-specific amplification was controlled by $2 \%$ agarose gel electrophoresis, as well as by melting temperature analysis. The final $20 \mu \mathrm{L}$ reaction mixture contained Power SYBR Green PCR Master Mix (Applied Biosystems), $10 \mathrm{pmol} / \mathrm{L}$ of forward and reverse primers, and $100 \mathrm{ng}$ complementary DNA as template. Amplification conditions were as follows: incubation at $95^{\circ} \mathrm{C}$ for 10 minutes, followed by 45 cycles at $95^{\circ} \mathrm{C}$ for 15 seconds, $60^{\circ} \mathrm{C}$ for 60 seconds, and $72^{\circ} \mathrm{C}$ for 15 seconds, with subsequent melting analysis, heating to $95^{\circ} \mathrm{C}$ for 20 seconds, cooling to $45^{\circ} \mathrm{C}$ for 10 seconds, and then reheating to $95^{\circ} \mathrm{C}$.

\section{Statistical Analysis}

Data are expressed as means \pm SEM. Significant difference between groups was determined by analysis of variance. Statistical analysis of the immunohistochemical data was performed using the Mann-Whitney $U$ test. Probability values of $P<.05$ were accepted as being significant.

\section{Supplementary References}

1. Schmidlin F, Amadesi S, Dabbagh K, et al. Protease-activated receptor 2 mediates eosinophil infiltration and hyperreactivity in allergic inflammation of the airway. J Immunol 2002;169:53155321.

2. Singh VP, Bhagat L, Navina S, et al. Protease-activated receptor-2 protects against pancreatitis by stimulating exocrine secretion. Gut 2007;56:958-964.

3. Argent BE, Arkle S, Cullen MJ, et al. Morphological, biochemical and secretory studies on rat pancreatic ducts maintained in tissue culture. Q J Exp Physiol 1986;71:633-648.

4. Hegyi P, Rakonczay Z Jr, Gray MA, et al. Measurement of intracellular $\mathrm{pH}$ in pancreatic duct cells: a new method for calibrating the fluorescence data. Pancreas 2004;28:427-434.

5. Thomas JA, Buchsbaum RN, Zimniak A, et al. Intracellular pH measurements in Ehrlich ascites tumor cells utilizing spectroscopic probes generated in situ. Biochemistry 1979;18:22102218.

6. Sahin-Tóth M, Tóth M. Gain-of-function mutations associated with hereditary pancreatitis enhance autoactivation of human cationic trypsinogen. Biochem Biophys Res Commun 2000;278:286-289.

7. Bradford MM. A rapid and sensitive method for the quantitation of microgram quantities of protein utilizing the principle of protein-dye binding. Anal Biochem 1976;72:248-254. 
Articles related to the subject of the thesis and cited in the thesis 
III. 


\title{
New Therapeutic Targets in Ulcerative Colitis: The Importance of Ion Transporters in the Human Colon
}

\author{
Klaudia Farkas, MD, ${ }^{*}$ Sunil Yeruva, MSc, PhD, ${ }^{+}$Zoltán Rakonczay, Jr, MD, PhD, ${ }^{*}$ Lisa Ludolph, MSc, ${ }^{+}$ \\ Tamás Molnár, MD, PhD, ${ }^{*}$ Ferenc Nagy, MD, PhD, Zoltán Szepes, MD, PhD, ${ }^{*}$ Andrea Schnúr, MSc, ${ }^{*}$ \\ Tibor Wittmann, MD, PhD, ${ }^{*}$ Jessica Hubricht, MD, ${ }^{+}$Brigitte Riederer, MSc, PhD, ${ }^{+}$ \\ Viktória Venglovecz, MSc, PhD, ${ }^{\neq}$György Lázár, MD, PhD, Marianna Király, MSc, ${ }^{\text {" }}$ \\ Ákos Zsembery, MD, PhD, Gábor Varga, MSc, PhD, DSc, Ursula Seidler, XX, and Péter Hegyi, MD, PhD*
}

Background: The absorption of water and ions (especially $\mathrm{Na}^{+}$ and $\mathrm{Cl}^{-}$) is an important function of colonic epithelial cells in both physiological and pathophysiological conditions. Despite the comprehensive animal studies, there are only scarce available data on the ion transporter activities of the normal and inflamed human colon.

Methods: In this study, 128 healthy controls and 69 patients suffering from ulcerative colitis (UC) were involved. We investigated the expressional and functional characteristics of the $\mathrm{Na}^{+} / \mathrm{H}^{+}$exchangers (NHE) 1-3, the epithelial sodium channel (ENaC), and the SLC26A3 $\mathrm{Cl}^{-} / \mathrm{HCO}_{3}^{-}$exchanger downregulated in adenoma (DRA) in primary colonic crypts isolated from human biopsy and surgical samples using microfluorometry, patch clamp, and real-time reverse-transcription polymerase chain reaction (RT-PCR) techniques.

Results: Data collected from colonic crypts showed that the activities of electroneutral (via NHE3) and the electrogenic $\mathrm{Na}^{+}$ absorption (via $\mathrm{ENaC}$ ) are in inverse ratio to each other in the proximal and distal colon. We found no significant differences in the activity of NHE2 in different segments of the colon. Surface

Received for publication June 16, 2010; Accepted June 22, 2010.

From the *First Department of Medicine, University of Szeged, Szeged, Hungary, ${ }^{\dagger}$ Department of Gastroenterology, Hepatology and Endocrinology, Hannover Medical School, Hannover, Germany, ${ }^{\ddagger}$ Department of Pharmacology and Pharmacotherapy, University of Szeged, Szeged, Hungary, ${ }^{\S}$ Department of Surgery, University of Szeged, Szeged, Hungary, "Department of Oral Biology, Semmelweis University, Budapest, Hungary, "Institute of Human Physiology and Clinical Experimental Research, Semmelweis University, Budapest, Hungary.

Supported by OTKA (CK 80136, NNF 78851, K79189), by NKTH (TÁMOP-4.2.2-08/1/2008-0002 and 0013), by MTA (Bolyai BO/00334/ $08 / 5$ and $\mathrm{BO} / 00174 / 10 / 5)$, by grants from the Deutsche Forschungsgemeinschaft DFG Se 460/13-4 and SFB621-C9 (to U.S.), and by a stipend of the HBRS "matching program" which was financed in equal parts by the DAAD and Abbot GmbH, Wiesbaden, Germany (to L.L.).

The first two authors contributed equally.

Reprints: Péter Hegyi, First Department of Medicine, University of Szeged, H-6720, Korányi fasor 8-10, Szeged, Hungary (e-mail: hep@ in1st.szote.u-szeged.hu)

Copyright $\odot 2010$ Crohn's \& Colitis Foundation of America, Inc.

DOI 10.1002/ibd.21432

Published online 18 August 2010 in Wiley Online Library (wileyonlinelibrary.com). cell $\mathrm{Cl}^{-} / \mathrm{HCO}_{3}^{-}$exchange is more active in the distal part of the colon. Importantly, both sodium and chloride absorptions are damaged in UC, whereas NHE1, which has been shown to promote immune response, is upregulated by 6 -fold.

Conclusions: These results open up new therapeutic targets in UC.

(Inflamm Bowel Dis 2011;17:884-898)

Key Words: ulcerative colitis, therapeutic targets, ion transporters

U lcerative colitis (UC), a form of inflammatory bowel disease (IBD), is a chronic, idiopathic inflammatory disorder of the colorectum. Although the medical treatment of IBD has advanced rapidly, complete remission cannot be achieved in most of the complicated cases. ${ }^{1}$ Therefore, studies focusing on the pathophysiology of the disease that highlight new therapeutic targets are crucially important. In the last decades more and more animal studies have been published concerning the role of ion transport mechanisms in intestinal epithelial cells (colonic crypts) in the pathogenesis of UC. ${ }^{2-4}$ Although Teleky et $\mathrm{al}^{5}$ investigated the regulation of intracellular $\mathrm{pH}\left(\mathrm{pH}_{\mathrm{i}}\right)$ in freshly isolated human colonocytes, a comprehensive functional characterization of ion transporters of human colonic crypts is still missing.

The ion transporters on the apical and basolateral plasma membranes of polarized colonic epithelial cells determine the selectivity of the cells for the vectorial transport of specific ions. Under physiological conditions, the mammalian colon absorbs $\mathrm{Na}^{+}, \mathrm{Cl}^{-}$, and water and secretes $\mathrm{K}^{+}$and $\mathrm{HCO}_{3}^{-}{ }^{6}{ }^{6}$ Human colonic electroneutral sodium absorption is probably mediated via parallel activity of $\mathrm{Na}^{+} / \mathrm{H}^{+}$exchangers (NHE) 2 and 3 and $\mathrm{Cl}^{-} / \mathrm{HCO}_{3}^{-}$exchangers in the proximal and distal colon, ${ }^{6,7}$ whereas electrogenic sodium uptake is mediated by the epithelial sodium channel $(\mathrm{ENaC})$. Animal studies suggested that colonic sodium chloride absorption (including electroneutral $\mathrm{Na}^{+} / \mathrm{H}^{+}$exchange, $\mathrm{Cl}^{-} / \mathrm{HCO}_{3}^{-}$ exchange, and the electrogenic sodium uptake) differs significantly in the proximal and distal segments of the large 
intestine. ${ }^{8-11}$ A limited number of human studies also showed segmental heterogeneity of these transporters in the colon. ${ }^{12,13}$ Concerning the anion exchange mechanisms in the large intestine, recent studies revealed that $\mathrm{Cl}^{-}$-dependent $\mathrm{HCO}_{3}^{-}$ secretion and the mucosal surface $\mathrm{pH}$ is higher in the distal than in the proximal colon in mouse. ${ }^{14}$ These data also suggest that $\mathrm{pH}_{\mathrm{i}}$ regulation and the functional activities of the acidbase transporters are different in the proximal and distal colon. A recent study in rodent colon demonstrated strong segmental differences in Slc26a3 (downregulated in adenoma (DRA)) expression, $\mathrm{a} \mathrm{Cl}^{-} / \mathrm{HCO}_{3}^{-}$exchanger expressed in the luminal membrane, towards the distal colon. ${ }^{11}$

In $\mathrm{UC}, \mathrm{Cl}^{-}$uptake by the colon is significantly reduced. ${ }^{15}$ It has been described that there is a higher level of $\mathrm{Cl}^{-}$in the colon of patients with UC compared to controls, suggesting that the normal luminal to mucosal exchange of $\mathrm{Cl}^{-}$for bicarbonate is damaged. ${ }^{16}$ Excess bacterial fatty acids have been implicated as the cause of acidic stools, especially in infant diarrhea. ${ }^{17}$ However, it has been shown that the failure of bicarbonate secretion rather than excessive bacterial fermentation is the cause of decreased luminal $\mathrm{pH}$ of the colon with UC. ${ }^{15}$ Not only anion exchange, but also sodium uptake is altered in UC. NHE3 and $\mathrm{Na}^{+} / \mathrm{H}^{+}$exchanger regulatory factor (NHERF) protein expression have been described to be downregulated in IBD patients and in a mouse colitis model. ${ }^{16}$ Notably, NHE3-deficient mice spontaneously develop colitis restricted to the distal colonic mucosa, suggesting a key role of NHE3 in UC. ${ }^{3}$ In addition, UC is also associated with substantial decreases in the expression of the electrogenic $\mathrm{ENaC}$ beta and gamma subunits. ${ }^{19}$

The regulation of NHE1 on the basolateral membrane behaves opposite to the apical NHE3 in UC. NHE1 was shown to be upregulated in mouse colitis. ${ }^{2}$ Supporting this observation, NHE1 is rapidly activated in response to a variety of inflammatory signals, such as interleukin-1 (IL-1), ${ }^{20}$ tumor necrosis factor alpha (TNF- $\alpha),{ }^{21}$ interferon gamma, ${ }^{22}$ and lipopolysaccharide. ${ }^{21,24}$ Furthermore, functional NHE1 activity is required for both maximal nuclear factor-kappa $\mathrm{B}$ activation and IL-8 production in colonic epithelial cells. ${ }^{2}$ The regulation of intestinal inflammation by NHE is also operational in vivo, because NHE inhibition dramatically attenuates disease activity in the mouse dextran sulfate model of IBD. ${ }^{2}$ In this study we characterized the segmental differences of ion transport mechanisms (NHE1-3, DRA, ENaC) in human colonic epithelial cells for the first time; in addition, we also highlight crucial differences between the activities of these transporters in $\mathrm{UC}$ that may open up new therapeutic approaches.

\section{MATERIALS AND METHODS}

\section{Humans Involved in the Study}

Humans were divided into two groups. In all, 69 IBD patients with active distal UC and 128 age- and sex-matched healthy controls with normal colonoscopic findings were enrolled in the study. Informed consent was obtained prior to endoscopy or surgery. Protocols of the study were approved by the regional ethical committees (both at the University of Szeged, Szeged, Hungary, and Hannover Medical School, Hannover, Germany). Six colonic biopsies were obtained from each patient undergoing colonoscopy at the First Department of Medicine or surgery at the Department of Surgery, University of Szeged, and 2-3 biopsies from each patient in addition to those needed for histological examination at the Department of Gastroenterology, Hannover Medical School.

In control patients neither macroscopic (by endoscopy) nor microscopic (by histology) evaluation showed any signs of inflammation in the colon. Patients with normal endoscopic findings were examined because of colorectal cancer screening or different abdominal complaints. IBD patients did not receive any steroid therapy.

All of the UC patients complained of diarrhea with or without hematochezia. The diagnosis of UC was made based on the colonoscopic findings that showed erythema and friability of the mucosa, confluent superficial ulceration, and a decreased vascular pattern. Histological examination was performed in every case showing inflammatory cell infiltration in the mucosa, cryptitis, and/or crypt abscess. Patients having only mild or moderate UC with no steroid therapy were involved in the study. Please note that we also wanted to include patients with severe colitis as well; however, only a small number of strongly damaged colonic crypts could be isolated from the biopsy samples, which were unsuitable for functional experiments.

\section{Isolation of Colonic Crypts}

Colonic crypts were isolated from six biopsy specimens obtained from colonoscopy or surgical samples of control and IBD patients. Samples were collected from four different segments of the colon (cecum, transverse colon, sigmoid colon or rectum). However, only one segment of the colon was investigated in each patient. The tissue samples were placed immediately in ice-cold $\mathrm{NaHCO}_{3}$ containing Hank's balanced salt solution (HBSS) and transferred to the laboratory. The samples were washed three times with HBSS and cut into small pieces with a razor blade and incubated in $1 \mathrm{mM}$ dithiothreitol (DTT) in HBSS for 15 minutes followed by $2 \times 30$ minutes enzymatic digestion with $0.38 \mathrm{mg} / \mathrm{mL}$ collagenase $\mathrm{A}$ at $37^{\circ} \mathrm{C}$ and continuously gassed with $5 \% \mathrm{CO}_{2} / 95 \% \mathrm{O}_{2}$. The small fragments were mixed with a Pasteur pipette, the large fragments were allowed to settle down to the bottom of the flask under gravity for 35-40 seconds, and the supernatant removed and viewed under a Nikon stereo microscope (Jencons-PLS, Grinstead, UK). The crypts (200-300 crypts/ 


\begin{tabular}{|c|c|c|c|c|c|c|}
\hline & Standard HEPES & High-K ${ }^{+}$HEPES & $\mathrm{NH}_{4}^{+}$in HEPES & $\mathrm{Na}^{+}$-free HEPES & Standard $\mathrm{HCO}_{3}^{-}$ & $\mathrm{Cl}^{-}$-free $\mathrm{HCO}_{3}^{-}$ \\
\hline $\mathrm{NaCl}$ & 130 & 5 & 110 & & 115 & \\
\hline $\mathrm{KCl}$ & 5 & 130 & 5 & 5 & 5 & \\
\hline $\mathrm{MgCl}_{2}$ & 1 & 1 & 1 & 1 & 1 & \\
\hline $\mathrm{CaCl}_{2}$ & 1 & 1 & 1 & 1 & 1 & \\
\hline Na-HEPES & 10 & 10 & 10 & & & \\
\hline Glucose & 10 & 10 & 10 & 10 & 10 & 10 \\
\hline $\mathrm{NaHCO}_{3}$ & & & & & 25 & 25 \\
\hline $\mathrm{NH}_{4} \mathrm{Cl}$ & & & 20 & & & \\
\hline HEPES & & & & 10 & & \\
\hline NMDG-Cl & & & & 140 & & \\
\hline Na-gluconate & & & & & & 115 \\
\hline Mg-gluconate & & & & & & 1 \\
\hline Ca-gluconate & & & & & & 6 \\
\hline $\mathrm{K}_{2}$-sulfate & & & & & & 2.5 \\
\hline
\end{tabular}

isolation) were aspirated into a micropipette and transferred to a Petri dish. For intracellular $\mathrm{pH}\left(\mathrm{pH}_{\mathrm{i}}\right)$ measurements the crypts were kept in a storage solution for 3 hours at $4^{\circ} \mathrm{C}$ before the experiments. However, for patch clamp experiments the crypts were incubated on 24-mm coverslips in culture solution for 24 hours at $37^{\circ} \mathrm{C}$ with $5 \% \mathrm{CO}_{2}$.

The culture solution contained Dulbecco's Modified Eagle's Medium (DMEM), 10\% fetal bovine serum (FBS; Sigma-Aldrich, Budapest, Hungary), $2 \mathrm{mM}$ L-glutamine, $100 \mathrm{U} / \mathrm{mL}$ penicillin, and $100 \mu \mathrm{g}$ streptomycin.

\section{Materials and Solutions for the Experiments}

General laboratory chemicals were obtained from Sigma-Aldrich. Collagenase A was obtained from Roche Diagnostic (Mannheim, Germany), nigericin from Fluka Biochemic (Munich, Germany). Nigericin was dissolved in absolute ethanol. HOE-642 (4-isopropyl-3-methylsulphonylbenzoyl-guanidin methanesulphonate) was kindly provided by Sanofi Aventis (Frankfurt, Germany) and was dissolved in dimethyl sulfoxide (DMSO).

BCECF-AM (2',7'-biscarboxyethyl-5(6)-carboxyfluorescein-acetoxymethylester) was obtained from Invitrogen (Eugene, OR); cell and tissue adhesive from Becton Dickinson Bioscience (Cell Tak, Bedford, MA). BCECF-AM was dissolved in DMSO.

\section{$\mathrm{pH}_{\mathrm{i}}$ Measurements}

The compositions of the solutions used are shown in Table 1. HEPES-buffered solutions were gassed with $100 \%$ $\mathrm{O}_{2}$ and their $\mathrm{pH}$ was set to 7.4 with $\mathrm{NaOH}$ or $\mathrm{HCl}$ at $37^{\circ} \mathrm{C}$. $\begin{array}{llll}\mathrm{HCO}_{3}^{-} \text {-buffered solutions were gassed with } 95 \% & \mathrm{O}_{2} / 5 \%\end{array}$ $\mathrm{CO}_{2}$ to set the $\mathrm{pH}$ to 7.4 at $37^{\circ} \mathrm{C}$.
Colonic crypts were attached with Cell Tak to a glass 24-mm diameter coverslips 3 hours after isolation and placed in a perfusion chamber mounted on the stage of an inverted fluorescent microscope linked to a cell imaging system (Olympus, Budapest, Hungary). Colonic crypts were bathed in standard HEPES solution at $37^{\circ} \mathrm{C}$ and loaded with the $\mathrm{pH}$-sensitive fluorescent dye BCECF-AM for 20-30 minutes. Crypts were continuously perfused with solutions at a rate of $4-5 \mathrm{~mL} / \mathrm{min}$. Three different areas (base, medium, surface) in each crypt were excited with light at wavelengths of $495 \mathrm{~nm}$ and $440 \mathrm{~nm}$ and the 495/440 fluorescence emission ratio was measured at $535 \mathrm{~nm}^{24,25}$ In situ calibration of the fluorescence signal was performed using the high $\mathrm{K}^{+}$nigericin technique.

\section{Measurement of NHE Activities}

The crypts were acid-loaded by exposure to a 5-minute pulse of $20 \mathrm{mM} \mathrm{NH}_{4} \mathrm{Cl}$ in HEPES solution followed by a 10 -minute exposure of $\mathrm{Na}^{+}$-free HEPES solution. Due to the blocked acid/base transporters (neither sodium nor bicarbonate was present in the solution), the $\mathrm{pH}_{\mathrm{i}}$ was set to a stable acidic level. NHE activity was switched on by readdition of extracellular sodium and the activity of $\mathrm{NHE}$ was determined by measuring the initial rate of $\mathrm{pH}_{\mathrm{i}}$ recovery over the first 60 seconds ( 60 data points). The activities of the different NHE isoforms were extracted using the isoform selective NHE inhibitor HOE-642. One $\mu \mathrm{M}$ HOE-642 inhibits NHE1, whereas $50 \mu \mathrm{M}$ HOE-642 inhibits both NHE1 and 2 but not NHE3. ${ }^{26,27}$ Although there are nine different NHE isoforms in mammalian digestive tract, ${ }^{28}$ only NHE1-3 are localized to the membrane of the cells. ${ }^{29}$ 
Therefore, the activities (A) of NHE isoforms can be calculated from the recoveries (R) as follows:

$$
\begin{aligned}
& A_{\mathrm{NHE} 1}=\mathrm{R}_{0 \mu \mathrm{M} \mathrm{HOE}-642}-R_{1 \mu \mathrm{M} \mathrm{HOE}-642} \\
& A_{\mathrm{NHE} 2}=R_{1 \mu \mathrm{M} \mathrm{HOE}-642}-R_{50 \mu \mathrm{MHOE}-642} \\
& A_{\mathrm{NHE} 3}=R_{50 \mu \mathrm{M} \mathrm{HOE}-642}
\end{aligned}
$$

\section{Measurement of $\mathrm{Cl}^{-} / \mathrm{HCO}_{3}^{-}$Exchange Activity}

The $\mathrm{Cl}^{-} / \mathrm{HCO}_{3}^{-}$exchange activity of the cells was determined using the $\mathrm{Cl}^{-}$withdrawal technique. Briefly, removing $\mathrm{Cl}^{-}$from the standard $\mathrm{HCO}_{3}^{-} / \mathrm{CO}_{2}$ buffered solution causes alkalization due to the reverse activity of the $\mathrm{Cl}^{-} / \mathrm{HCO}_{3}^{-}$exchanger. The activity of the exchanger was determined by measuring the initial rate of alkalization over the first 30 seconds (30 data points).

\section{Measurement of ENaC Activity}

Voltage-clamp recordings were performed using the patch-clamp technique in whole-cell configuration at room temperature with an Axopatch 200B amplifier (Axon Instruments, Union City, CA). Micropipettes were fabricated by a P-97 Flaming/Brown type micropipette puller (Sutter Instrument, Novato, CA) from GC120F-10 glass capillary tubes (Harvard Apparatus, Holliston, MA) and had resistances of 5-10 M $\Omega$ when filled with pipette solution. Capacitative currents were compensated with analog compensation. Linear leak currents were not compensated. Series resistance was $\approx 8-15 \mathrm{M} \Omega$, and series resistance compensation $(70 \%-80 \%)$ was used in whole-cell recordings if the current exceeded $1 \mathrm{nA}$. Currents were filtered at $2 \mathrm{kHz}$ (four-pole Bessel filter) and sampled at $5 \mathrm{kHz}$. Pulse generation, data acquisition, and analysis were performed using pClamp 6.03 software (Axon Instruments). The pipette solution contained (in $\mathrm{mM}$ ): $95 \mathrm{~K}$-gluconate, $5 \mathrm{Na}$-gluconate, 2 Mg-ATP, 10 HEPES, 2 EGTA-Na, $0.2 \mathrm{MgCl}_{2}$, $40 \mathrm{CsOH}$, and $20 \mathrm{TEA}-\mathrm{OH}$, with $\mathrm{pH}$ adjusted to 7.2 using gluconic acid. Our standard bath solution contained (in $\mathrm{mM}$ ): 140 Na-gluconate, $5 \mathrm{~K}$-gluconate, $1 \mathrm{CaCl}_{2}, 5 \mathrm{BaCl}_{2}$, $1 \mathrm{MgCl}_{2}, 10$ HEPES, and 5 glucose, with $\mathrm{pH}$ adjusted to 7.4 using Tris, supplemented when appropriate with $50 \mu \mathrm{g} /$ $\mathrm{mL}$ trypsin or $10 \mu \mathrm{M}$ amiloride (final concentrations). In some experiments, $\mathrm{Na}^{+}$was substituted with N-methyl-dglucamine $\left(\mathrm{NMDG}^{+}\right)$in the extracellular solution. Inward currents (downward current deflections) are defined as negative currents, i.e., movement of positive charge from the extracellular side to the cytoplasmic side. Starting from a $V_{\text {hold }}$ of $-50 \mathrm{mV}$, voltage step protocols were performed intermittently using consecutive $300-\mathrm{ms}$ step changes to potentials ranging from -100 up to $+100 \mathrm{mV}$ in $20-\mathrm{mV}$ increments. The average current values reached during the last $100 \mathrm{~ms}$ of the voltage steps were used for the $I-V$ plots.

\begin{tabular}{lc}
\hline \multicolumn{2}{l}{ TABLE 2. Primer sequences for PCR experiments. } \\
\hline Gene \\
\hline NHE1 For & Sequence \\
NHE1 Rev & 5'-TGAGGAGCTGAAGGGCAAAG-3' \\
NHE2 For & 5'-CCTTGCTCCGCATCATGAT-3' \\
NHE2 Rev & 5'-CTTCCACTTCAACCTCCCGAT-3' \\
NHE3 For & 5'-GCTGCTATTGCCATCTGCAA-3' \\
NHE3 Rev & 5'-AGAAGCGGAGAAACAGCAG-3' \\
DRA For & 5'-TGGTGACACTAGCCAGGAAC-3' \\
DRA Rev & 5'-AGCACAGGAGGCAAAACACAG-3' \\
Villin For & 5'-GACTTTTGTAGAGGCGCCAGG-3' \\
Villin Rev & 5'-CTATGCCAACACCAAGAGAC-3' \\
& 5'-CCCAGACATCTAGTAGGAACAC-3' \\
\hline
\end{tabular}

The changes in current amplitudes are expressed as changes in current densities $(\mathrm{pA} / \mathrm{pF})$.

\section{RNA Isolation and Real-time Reverse-transcription Polymerase Chain Reaction (RT-PCR)}

The biopsy samples were collected in RNA later (Sigma-Aldrich, Steinheim, Germany) solution. RNA was isolated from the biopsies using Nucleo spin kit (Machery and Nagel, Düren, Germany) as recommended by the manufacturer. The RNA of each sample was tested for intactness, and only such samples were used in which no RNA breakdown was documented. One $\mu \mathrm{g}$ of RNA was reversetranscribed using MMLV superscript III reverse transcriptase (Invitrogen, Karlsruhe, Germany). Real-time PCR was performed using SYBR Green PCR mastermix (Applied Biosystems, Darmstadt, Germany) exactly as previously described. ${ }^{30}$ Primer sequences are given in Table 2.

\section{Statistical Analysis}

Values are means \pm SE. Statistical analyses were performed using unpaired Student's $t$-test or analysis of variance (ANOVA) as appropriate. $P \leq 0.05$ was accepted as significant. $N=10-15$ colonic crypts isolated from 4-6 patients. For the quantitative mRNA results, the number of biopsies used for the experiments is indicated in the figure legends.

\section{RESULTS}

\section{Determination of the Resting $\mathrm{pH}_{\mathrm{i}}$ of Human Colonic Crypts in Different Parts of the Colon}

In the first series of experiments, our aim was to determine the resting $\mathrm{pH}_{\mathrm{i}}$ of human colonic crypts (Fig. 1A,B). We used the classical linear model ${ }^{24,25}$ to determine the resting $\mathrm{pH}_{\mathrm{i}}$, which proved to be significantly higher in the middle versus the surface or the base of the crypts (Fig. 1C) in all parts of the colon. Importantly, the resting $\mathrm{pH}_{\mathrm{i}}$ was significantly higher in the distal versus proximal part of the colon (Fig. 1D). 


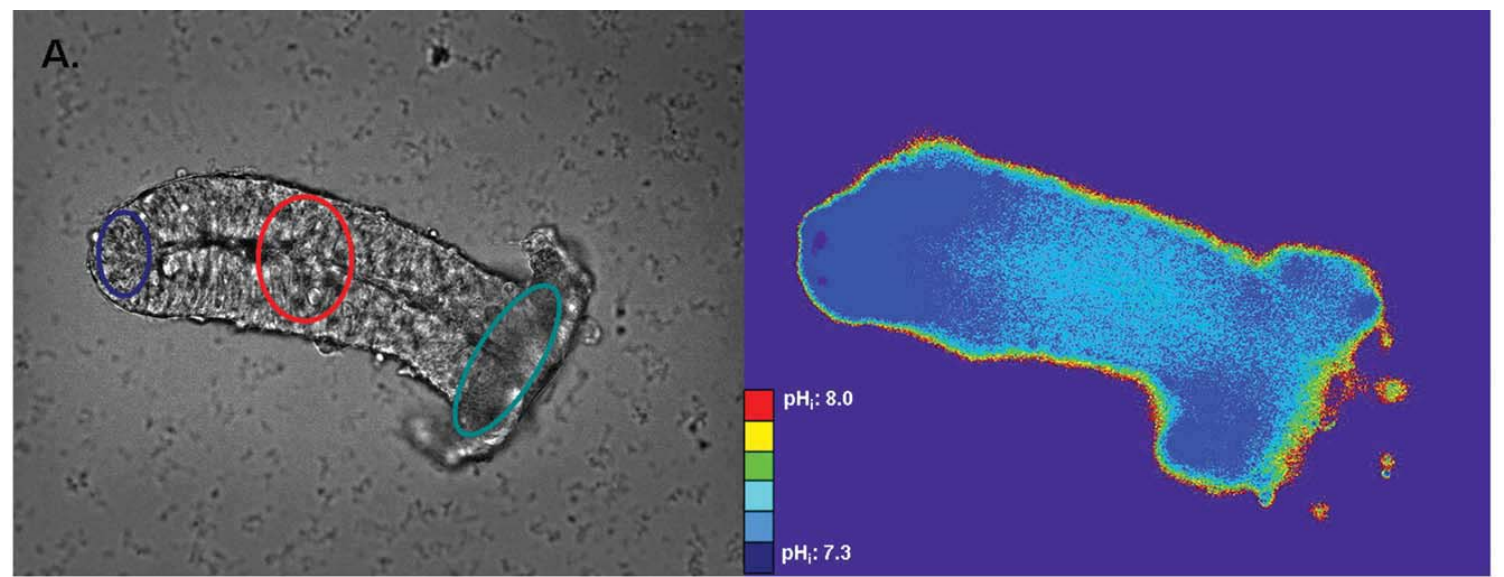

B.

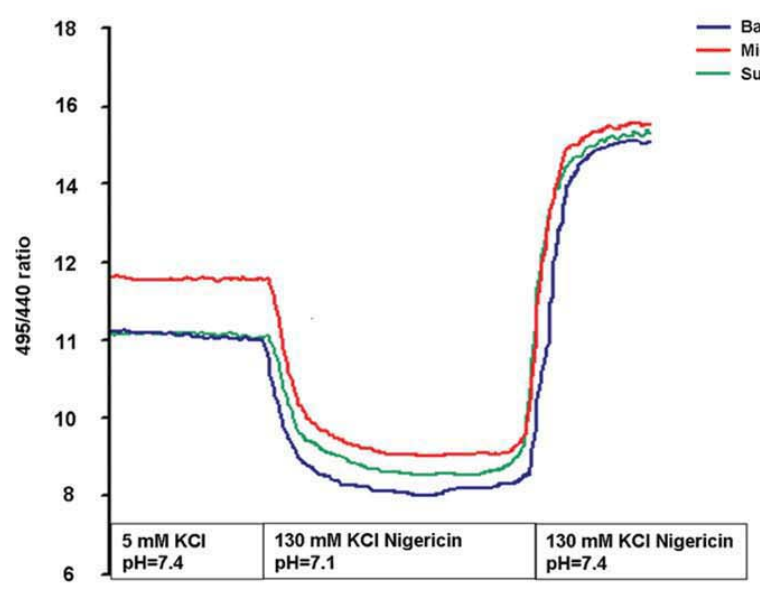

C.

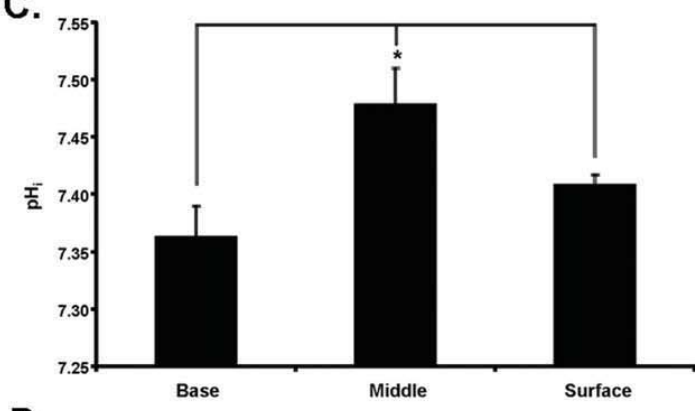

D.

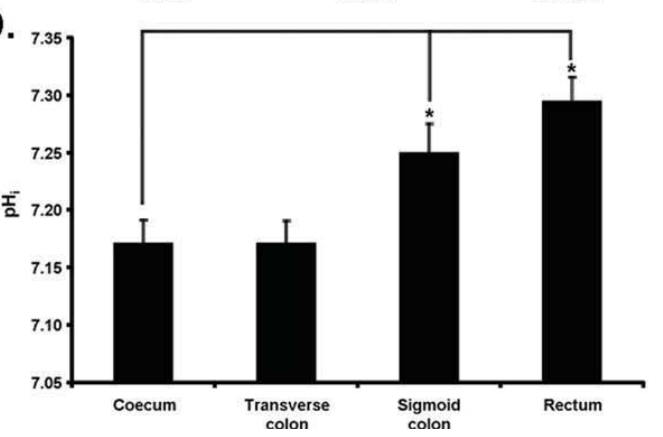

FIGURE 1. Resting $\mathrm{pH}_{\mathrm{i}}$ of colonic epithelial cells. (A) Light and fluorescence microscopy. Isolated colonic crypts were fixed on a coverglass. Three areas (ROls) of each crypt were excited with light at wavelengths of $495 \mathrm{~nm}$ and $440 \mathrm{~nm}$ and the $495 /$ 440 fluorescence emission ratio was measured at $535 \mathrm{~nm}$. (B) Crypts were exposed to nigericin/high $\mathrm{K}^{+}$HEPES solutions of $\mathrm{pH} 7.1$ and 7.4. Resting $\mathrm{pH}_{\mathrm{i}}$ was calculated by linear regression analysis. Bar charts show the summary of resting $\mathrm{pH}_{\mathrm{i}}$ in different parts of the (C) crypts and (D) the colon. Significantly higher resting $\mathrm{pH}_{\mathrm{i}}$ was measured in the middle part of the crypts. Significantly higher resting $\mathrm{pH}_{\mathrm{i}}$ was detected in the distal versus the proximal part of the normal colon. $n=19$ colonic crypts isolated from seven patients. Data are presented as means \pm SEM. *Significant difference $(P<0.05)$ versus the respective groups. [Color figure can be viewed in the online issue, which is available at wileyonlinelibrary.com.]

\section{Activities and Expression of NHE Isoforms in Different Parts of the Normal Colon}

Since the NHEs play a key role in the regulation of $\mathrm{pH}_{\mathrm{i}}$, we investigated the activity of different NHE isoforms in the normal human colon. Removal of $\mathrm{Na}^{+}$from the standard HEPES solution caused a rapid decrease in the $\mathrm{pH}_{\mathrm{i}}$, while adding back $\mathrm{Na}^{+}$led to a complete $\mathrm{pH}_{\mathrm{i}}$ recovery, confirming the presence of a $\mathrm{Na}^{+}$-dependent $\mathrm{H}^{+}$ efflux in the epithelial cells of the colonic crypts (data not shown). The $\mathrm{NH}_{4} \mathrm{Cl}$ pulse technique was used to measure the activity of NHE isoforms. Exposure of colonic crypts to $20 \mathrm{mM} \mathrm{NH} \mathrm{NH}_{4} \mathrm{Cl}$ induced an immediate rise in 

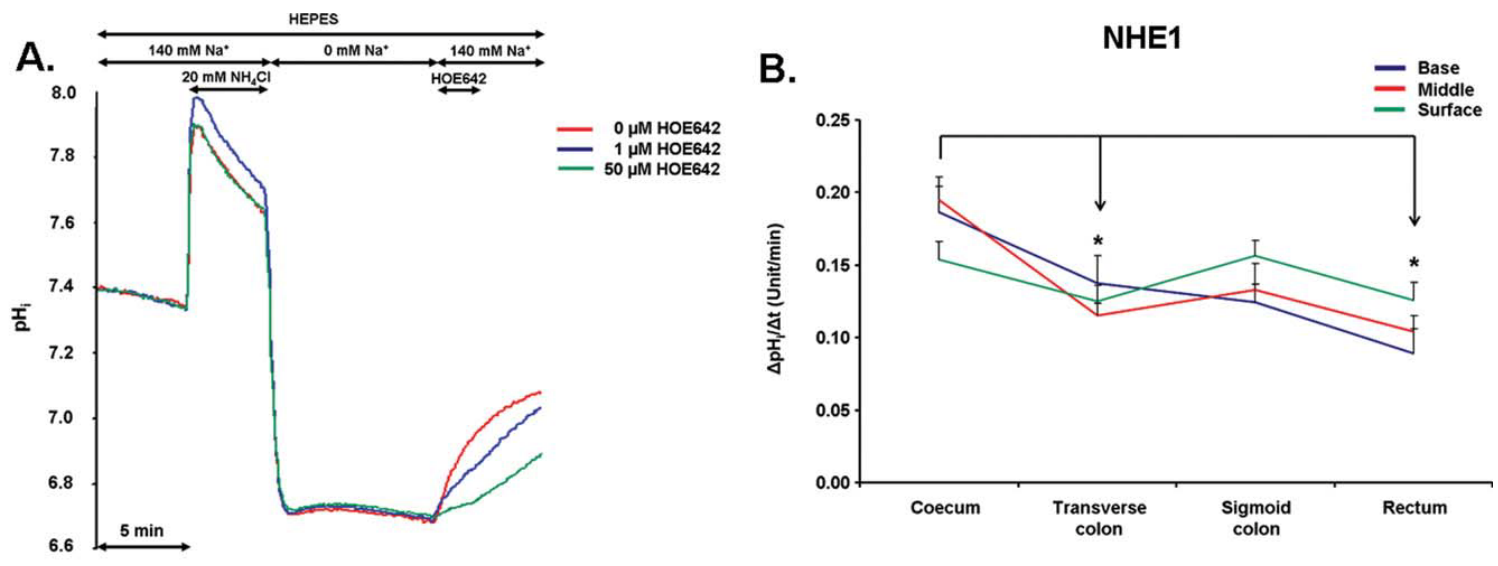

C.

NHE2

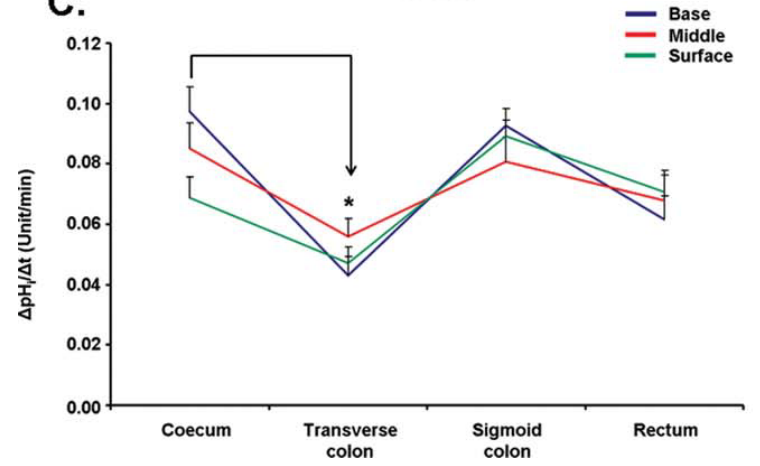

D.

NHE3

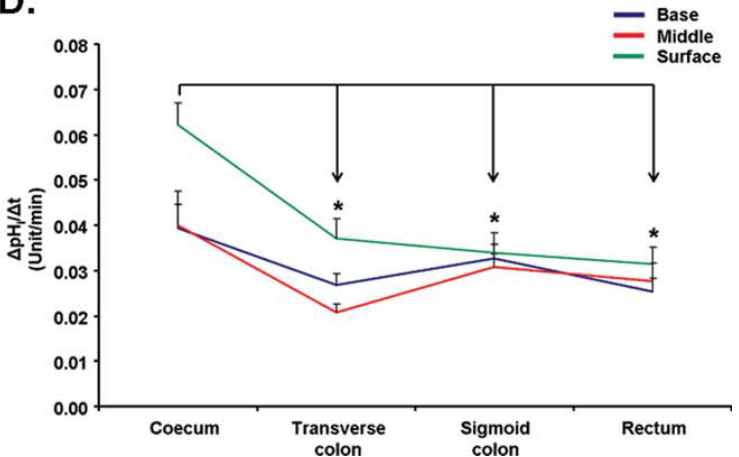

FIGURE 2. Determination of the $\mathrm{Na}^{+} / \mathrm{H}^{+}$exchange activity in colonic epithelial cells. (A) Representative $\mathrm{pH}_{\mathrm{i}}$ trace. The crypts were acid loaded by an exposure to a 5-minute pulse of $20 \mathrm{mM} \mathrm{NH}_{4} \mathrm{Cl}$ followed by a 10-minute exposure of $\mathrm{Na}^{+}$-free $\mathrm{HEPES}$ solution. The activities of the different NHE isoforms were measured by the isoform selective NHE inhibitor HOE-642. One $\mu \mathrm{M}$ HOE-642 inhibits the activity of NHE1, whereas $50 \mu \mathrm{M}$ HOE-642 inhibits the activity of NHE2 and 3 . The line charts (B-D) show that the activities of NHE1 and 3 were significantly higher in the proximal versus the distal part of the colon. NHE3 activity proved to be the highest at the surface of the isolated colonic crypts. $n=26$ colonic crypts isolated from 13 patients. Data are presented as means \pm SEM. *Significant difference $(P<0.05)$ versus the respective groups. [Color figure can be viewed in the online issue, which is available at wileyonlinelibrary.com.]

$\mathrm{pH}_{\mathrm{i}}$ because of the rapid entry of the lipophilic base, $\mathrm{NH}_{3}$ into the cell. After the removal of $\mathrm{NH}_{4} \mathrm{Cl}, \mathrm{pH}_{\mathrm{i}}$ rapidly decreased (Fig. 2A). This acidification is caused by the dissociation of intracellular $\mathrm{NH}_{4}^{+}$to $\mathrm{H}^{+}$and $\mathrm{NH}_{3}$, followed by the diffusion of $\mathrm{NH}_{3}$ out of the cell. After this acidification, $\mathrm{pH}_{\mathrm{i}}$ starts to recover due to activation of $\mathrm{pH}_{\mathrm{i}}$ regulatory mechanisms. In the absence of extracellular $\mathrm{HCO}_{3}^{-}$in the solution and due to the low activity of $\mathrm{H}^{+}$efflux mechanisms from the cells, the recovery from acidosis (in the presence of $\mathrm{Na}^{+}$) reflects the activity of NHE. Cariporide (HOE-642), the well-known isoform-specific NHE inhibitor, ${ }^{31}$ was used to test the activities of NHE1, NHE2, and NHE3, as previously validated in murine colonic crypts of NHE knockout mice. ${ }^{26,27}$ The activities of NHE1 and 3 isoforms showed a decreasing pattern from the proximal to the distal part of the colon, whereas the activity of NHE2 did not change significantly (Fig. 2B-D). The activities of all examined NHE isoforms could be detected in the different parts of the colonic crypts (surface, middle, base). Importantly, in the proximal colon NHE3 activity was significantly higher in the surface of the crypt (Fig. 2D).

Next, we were interested in whether the alterations of NHE1, NHE2, and NHE3 activities are associated with the changes of mRNA levels of these transporters. RT-PCR analyses revealed that mRNA expression of NHE3 was clearly decreased in the distal part of the colon in relation to villin, an epithelial marker (Fig. 3C), $\beta$-actin, and $\beta 2$ microglobulin, which are nonepithelial markers (data not shown). However, there were no significant differences between the NHE1 and 2 mRNA levels in the different segments of the colon (Fig. 3A,B). 
A.

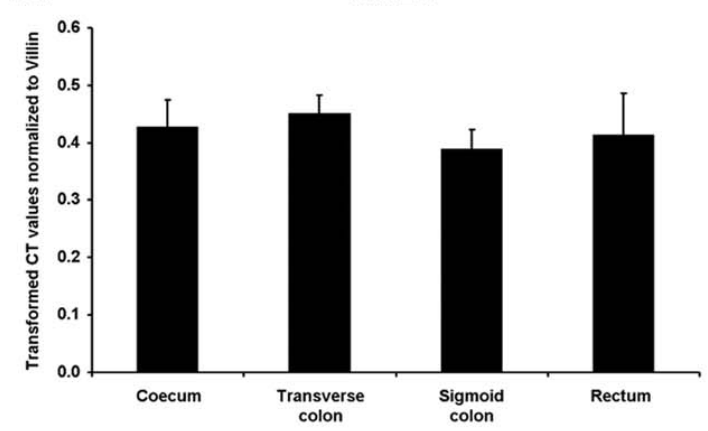

C.

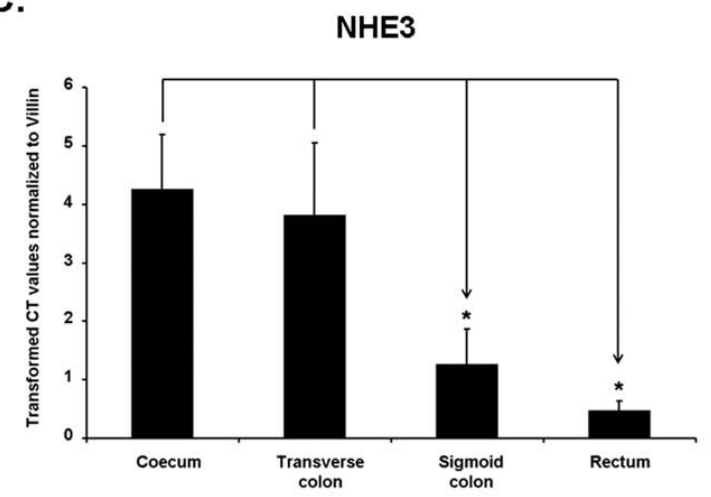

B.

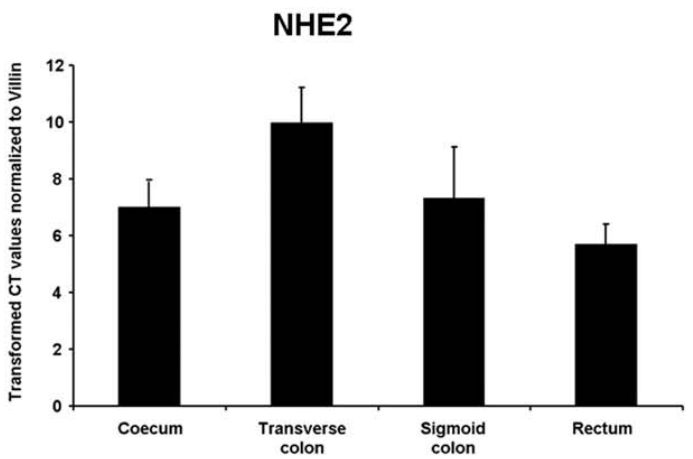

D.

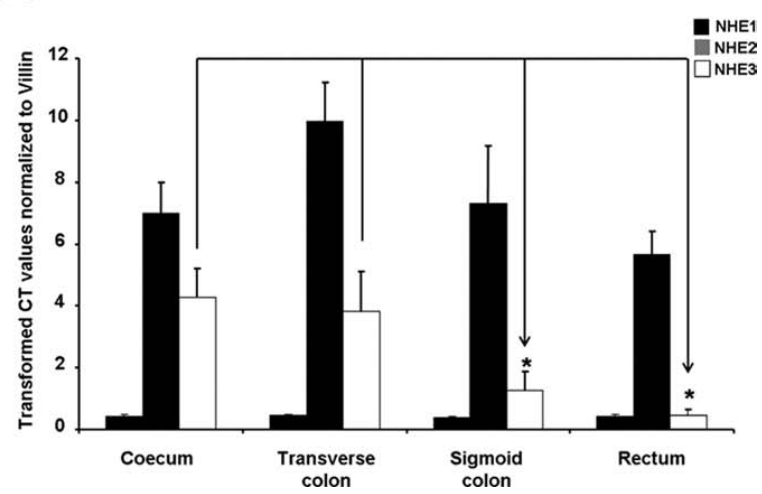

FIGURE 3. mRNA expression of NHE 1, 2, and 3 in the noninflamed human biopsies collected from cecum to rectum. RNA was isolated from human biopsies and real-time PCRs were conducted as mentioned in Materials and Methods. (A) NHE1, (B) NHE2, and (C) NHE3 mRNA expression levels were normalized against villin (an epithelial marker). (D) An overview of all three genes normalized against villin shows the differential expression of these genes from cecum to rectum. For each region, RNA was isolated from several biopsies of 3-5 controls. Data are presented as means \pm SEM. *Significant difference $(P<0.05)$ between the different parts of the colon. CT: The cycle number at the threshold level of log-based fluorescence.

\section{Differences in Functional $\mathrm{Na}^{+}$Channel Activity Along the Large Intestine}

In order to compare the $\mathrm{Na}^{+}$channel activity in different parts of the large intestine, we isolated colonocytes from the cecum, transverse colon, and sigmoid colon/rectum of individuals without UC. Colonic crypts were seeded on glass coverslips covered by Matrigel, where they preserved the original crypt structures and attached in a perpendicular orientation (Fig. 4A). There is recent evidence that proteases contribute to $\mathrm{ENaC}$ regulation by cleaving specific sites in the extracellular loops of the $\alpha$ - and $\gamma$-subunits but not the $\beta$ subunit. ${ }^{32}$ Several studies indicate that trypsin activates $\mathrm{ENaC}$ by interacting with its $\alpha$ and/or $\gamma$ subunits. ${ }^{33,34}$ This interaction could alter the binding of amiloride to $\mathrm{ENaC}$, decreasing the potency of the inhibitor. ${ }^{35}$ Thus, trypsin was chosen to stimulate $\mathrm{Na}^{+}$channel activity. Figure 4B,C shows that inward currents were activated by trypsin $(50 \mu \mathrm{g} / \mathrm{mL})$ in colonocytes isolated from sigmoid colon/rectum. These effects were abolished when extracellular $\mathrm{Na}^{+}$was replaced with NMDG (Fig. 4D). On the other hand, trypsin remained ineffective if cells were perfused with $\mathrm{NMDG}^{+}$-rich external solution. Readministration of $\mathrm{Na}^{+}$to the bath solution restored the stimulatory effects of trypsin (data not shown). In our hands, amiloride $(10 \mu \mathrm{M})$ inhibited trypsin-induced activation of the inward currents in only two cells out of 10 experiments. In contrast to colonic crypts isolated from sigmoid colon/rectum, trypsin did not cause significant activation of inward currents in cells derived from the cecum or transverse colon (Fig. 4E; Table 3). Following trypsin administration, the reversal potential shifted towards more positive values in cells isolated from both sigmoid colon/rectum and transverse colon, suggesting the activation of inward $\mathrm{Na}^{+}$current (Fig. 4F).

\section{$\mathrm{Cl}^{-} / \mathrm{HCO}_{3}^{-}$Exchange Activities in Different Parts of the Normal Colon}

To test the activity of the $\mathrm{Cl}^{-} / \mathrm{HCO}_{3}^{-}$exchange (AE) mechanisms of colonic crypts we utilized the $\mathrm{Cl}^{-}$removal 

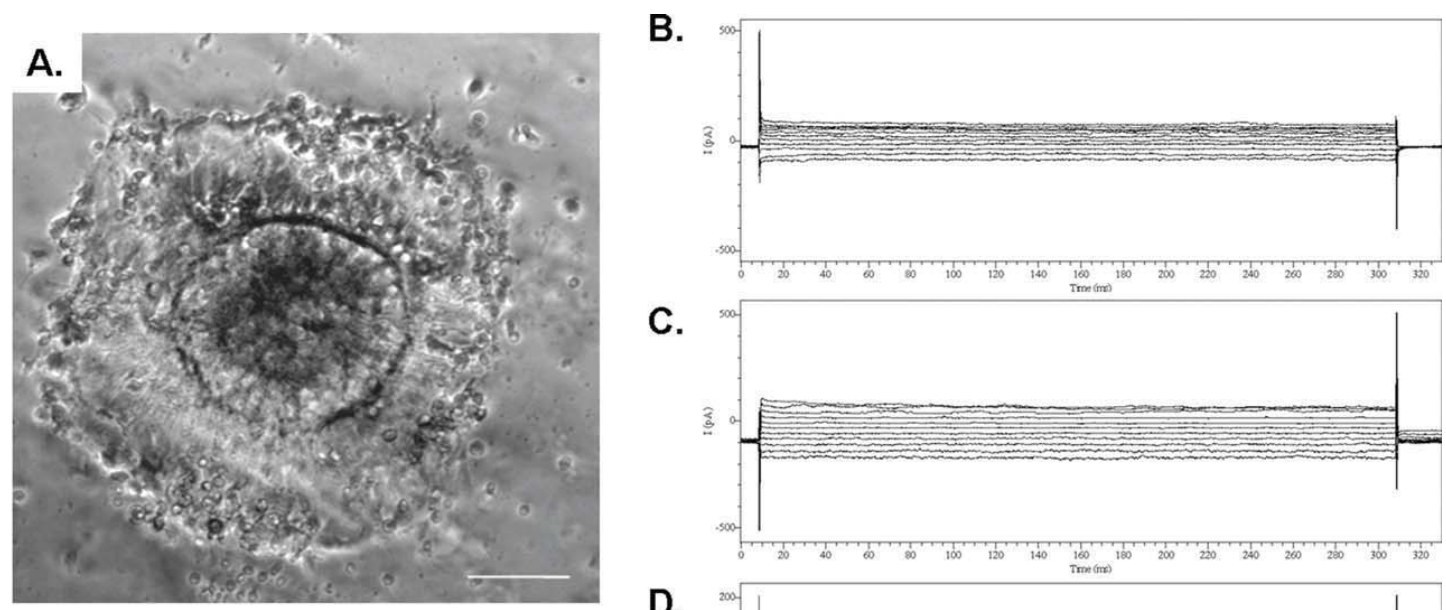

C.
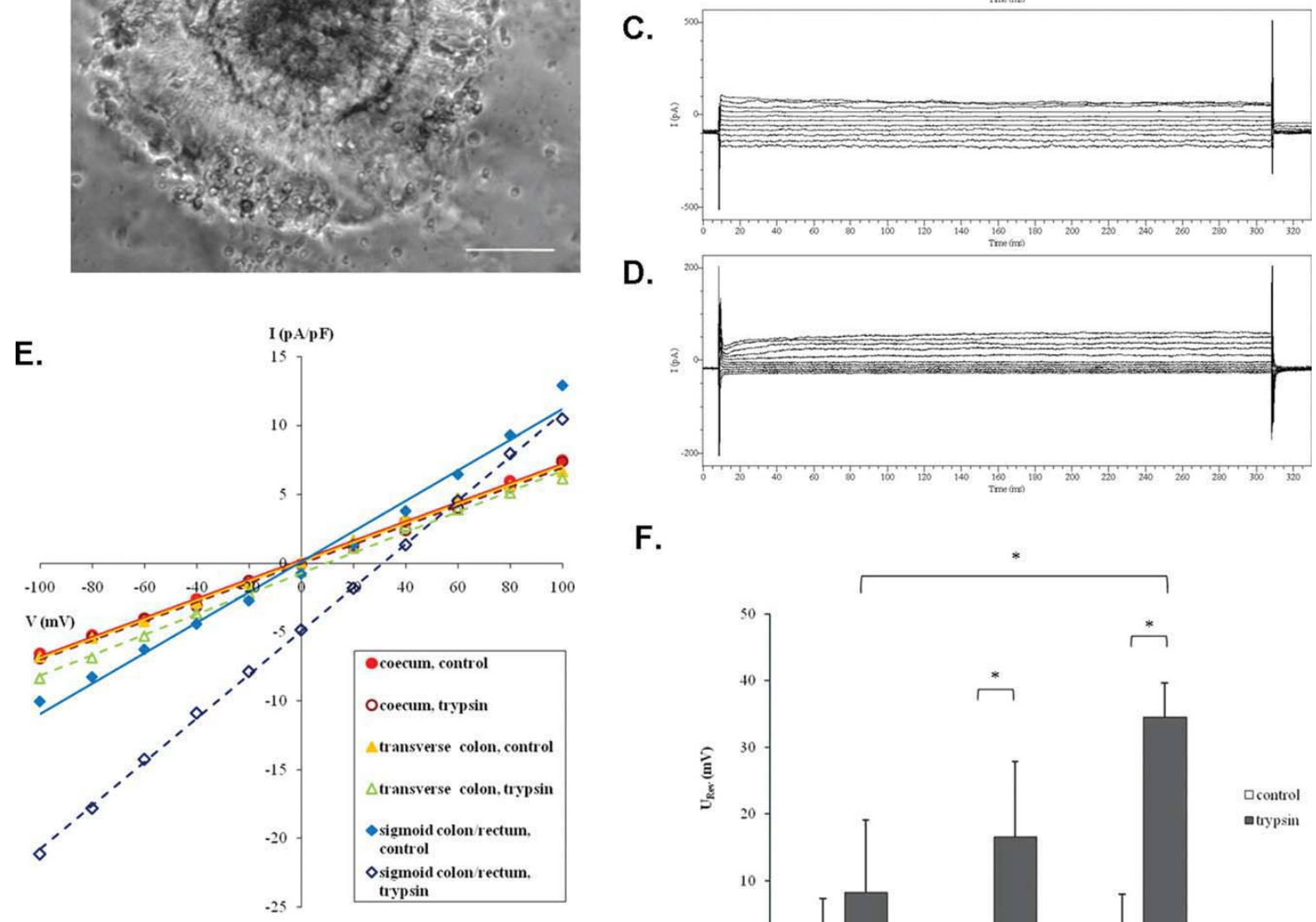

D.

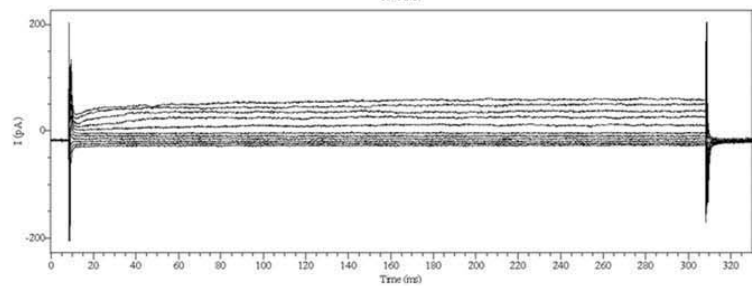

F.

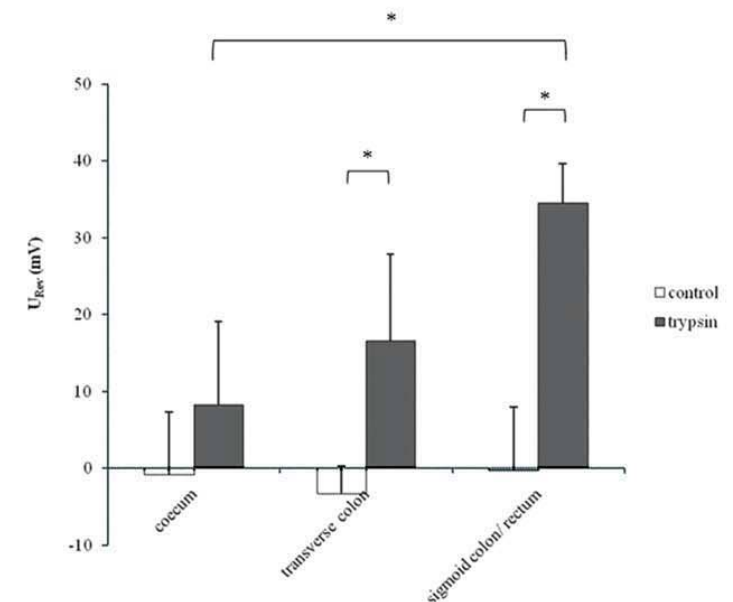

FIGURE 4. Differences in the functional $\mathrm{Na}^{+}$channel activity along the large intestine. (A) Phase contrast image of a control rectum-derived crypt adhered to a Matrigel-coated coverglass. Scale bar $=100 \mu \mathrm{m}$. (B) Representative whole-cell current recording measured on control rectum-derived colonic crypts. (C) Exposure to trypsin caused an increase in inward currents. (D) Inward currents were rapidly suppressed when $\mathrm{Na}^{+}$was replaced with NMDG in the extracellular solution. (E) Average I/V plots obtained in cells derived from cecum $(n=12)$, transverse colon $(n=12)$, and sigmoid colon/rectum $(n=13)$ isolated from five control individuals in each location. Trypsin significantly activated the $\mathrm{Na}^{+}$channel activity in control sigmoid colon/rectum samples. (F) Trypsin caused a significant shift of the reversal potentials towards more positive values in cells derived from transverse and sigmoid colon/rectum samples of control individuals. Note that trypsin-induced changes in reversal potentials were significantly larger in sigmoid colon or rectum derived cells than in cecum. Data represent mean \pm SEM ( $\left.{ }^{*} P<0.05\right) . n=12-13$ colonic crypts isolated from five patients. [Color figure can be viewed in the online issue, which is available at wileyonlinelibrary.com.]

technique in the presence of $\mathrm{HCO}_{3}^{-}$ions. $\mathrm{Cl}^{-}$removal from the standard $\mathrm{HCO}_{3}^{-} / \mathrm{CO}_{2}$ solution caused a marked alkalization in colonic crypts suggesting active anion exchange. Notably, the alkalization was significantly higher in the surface versus the middle and the base of the crypts (Fig. 5A), suggesting that it may be predominantly caused 
TABLE 3. Whole cell current recordings in samples isolated from coecum, transverse colon, and sigmoid colon/rectum of control individuals, prior and after trypsin administration. Currents are expressed as current densities (pA/pF), negative values represent inward currents. Data represent mean \pm SE $\left({ }^{*} p<0.05\right)$. Number of cells is shown in parentheses.

\begin{tabular}{|c|c|c|}
\hline & $\begin{array}{l}\text { coecum (12) basal } \\
\text { ENaC activities }\end{array}$ & $\begin{array}{l}\text { coecum }(12) \\
\text { trypsin-induced } \\
\text { ENaC activities }\end{array}$ \\
\hline$-100 \mathrm{mV}$ & $-6,57 \pm 4,44$ & $-6,94 \pm 4,14$ \\
\hline$-80 \mathrm{mV}$ & $-5,23 \pm 3,70$ & $-5,42 \pm 3,22$ \\
\hline$-60 \mathrm{mV}$ & $-3,96 \pm 2,93$ & $-4,04 \pm 2,33$ \\
\hline$-40 \mathrm{mV}$ & $-2,58 \pm 2,17$ & $-3,14 \pm 2,19$ \\
\hline$-20 \mathrm{mV}$ & $-1,40 \pm 1,46$ & $-1,27 \pm 0,37$ \\
\hline $0 \mathrm{mV}$ & $-0,06 \pm 0,96$ & $-0,09 \pm 0,31$ \\
\hline$+20 \mathrm{mV}$ & $1,28 \pm 1,05$ & $1,31 \pm 1,13$ \\
\hline$+40 \mathrm{mV}$ & $3,03 \pm 1,58$ & $2,37 \pm 1,68$ \\
\hline$+60 \mathrm{mV}$ & $4,51 \pm 2,32$ & $4,02 \pm 2,90$ \\
\hline$+80 \mathrm{mV}$ & $5,96 \pm 3,01$ & $5,53 \pm 3,66$ \\
\hline \multirow[t]{2}{*}{$+100 \mathrm{mV}$} & $7,49 \pm 3,60$ & $7,40 \pm 5,15$ \\
\hline & $\begin{array}{l}\text { transverse colon } \\
\text { (12) basal ENaC } \\
\text { activities }\end{array}$ & $\begin{array}{l}\text { transverse colon } \\
\text { (12) trypsin-induced } \\
\text { ENaC activities }\end{array}$ \\
\hline$-100 \mathrm{mV}$ & $-6,83 \pm 5,07$ & $-8,36 \pm 5,74$ \\
\hline$-80 \mathrm{mV}$ & $-5,46 \pm 3,95$ & $-6,87 \pm 4,78$ \\
\hline$-60 \mathrm{mV}$ & $-4,25 \pm 3,02$ & $-5,29 \pm 3,88$ \\
\hline$-40 \mathrm{mV}$ & $-2,87 \pm 2,09$ & $-3,63 \pm 2,97$ \\
\hline$-20 \mathrm{mV}$ & $-1,48 \pm 1,53$ & $-2,16 \pm 2,41$ \\
\hline $0 \mathrm{mV}$ & $0,05 \pm 1,52$ & $-0,61 \pm 2,09$ \\
\hline$+20 \mathrm{mV}$ & $1,67 \pm 2,29$ & $1,10 \pm 2,34$ \\
\hline$+40 \mathrm{mV}$ & $3,33 \pm 3,20$ & $2,71 \pm 2,91$ \\
\hline$+60 \mathrm{mV}$ & $4,73 \pm 3,61$ & $3,90 \pm 3,78$ \\
\hline$+80 \mathrm{mV}$ & $5,65 \pm 4,09$ & $5,12 \pm 4,67$ \\
\hline \multirow[t]{2}{*}{$+100 \mathrm{mV}$} & $6,65 \pm 4,70$ & $6,15 \pm 5,62$ \\
\hline & $\begin{array}{c}\text { signioid colon/rectum } \\
\text { (13) basal ENaC } \\
\text { activities }\end{array}$ & $\begin{array}{l}\text { sigrnoid colon/rectum } \\
\text { (13) trypsin-induced } \\
\text { ENaC activities }\end{array}$ \\
\hline$-100 \mathrm{mV}$ & $-10,03 \pm 6,94$ & $-21,15 \pm 13,02 *$ \\
\hline$-80 \mathrm{mV}$ & $-8,25 \pm 6,16$ & $-17,82 \pm 11,11 *$ \\
\hline$-60 \mathrm{mV}$ & $-6,26 \pm 4,81$ & $-14,26 \pm 8,95^{*}$ \\
\hline$-40 \mathrm{mV}$ & $-4.41 \pm 3 \_79$ & $-10,89 \pm 6,86^{*}$ \\
\hline$-20 \mathrm{mV}$ & $-2,72 \pm 3,08$ & $-7,87 \pm 5,10^{*}$ \\
\hline $0 \mathrm{mV}$ & $-0,76 \pm 2,36$ & $-4,84 \pm 3,39 *$ \\
\hline$+20 \mathrm{mV}$ & $1,39 \pm 2,74$ & $-1,80 \pm 1,76^{*}$ \\
\hline$+40 \mathrm{mV}$ & $3,80 \pm 4,37$ & $1,36 \pm 1,24$ \\
\hline$+60 \mathrm{mV}$ & $6,46 \pm 7,06$ & $4,57 \pm 3,01$ \\
\hline$+80 \mathrm{mV}$ & $9,28 \pm 10,02$ & $8,00 \pm 5,82$ \\
\hline$+100 \mathrm{mV}$ & $12,89 \pm 15,09$ & $10,48 \pm 7,76$ \\
\hline
\end{tabular}

by the surface-located Slc26a3 (DRA). ${ }^{34}$ In contrast to the activities of apical NHE3, AE activity was significantly higher in the distal versus the proximal part of the colon (Fig. 5B). Since the SLC26A3 (DRA) is the dominant anion exchanger on the apical side of colonic epithelial cells, ${ }^{11,36}$ we also tested the expression level of this transporter. RT-PCR experiments showed no significant difference between the mRNA expressions at the distal and proximal parts of the colon (Fig. 5C).

\section{Changes in the Activities of NHE1 and NHE3 in Colonic Crypts of UC Patients}

After the basic characterization of ion transport mechanisms of the normal human colon, we examined the changes of these ion transport mechanisms in patients suffering from UC. Since UC always involves the rectum, and in many cases sigmoidoscopy is enough for a control endoscopy, biopsy samples were collected only from the sigma and rectum. The resting $\mathrm{pH}_{\mathrm{i}}$ of epithelial cells of the crypts isolated from patients with UC did not differ from the controls (Fig. 6A).

The activity of NHE1 in the colonic crypts isolated from the inflamed region of the distal colon was approximately two times higher than in healthy colonic crypts isolated from the same region (Fig. 6B). However, not only the activity, but also the expression of NHE1 was highly elevated. NHE1 was strongly upregulated in UC patients versus controls (Fig. 6D).

The activities of NHE3 significantly decreased in the middle and in the surface of the crypts in UC patients versus controls. As it was predictable, no changes were observed in the base of the colonic crypts (Fig. 6C). Quantitative RTPCR revealed no significant changes in the UC versus the control group, suggesting that the defect of NHE3 activity is functional, rather than due to a downregulation of NHE3 expression (Fig. 6E). The activity of NHE2 showed no significant differences in UC versus controls (data not shown).

\section{Impaired Activity of $\mathrm{ENaC}$ in UC}

Since the effects of trypsin on $\mathrm{ENaC}$ activity were more pronounced in colonic crypts isolated from sigmoid colon/rectum biopsies and the disease always involves this region, we decided to compare $\mathrm{Na}^{+}$channel activity in this part of the large intestine in subjects with and without UC. Contrary to the control cells, in UC colonocytes trypsin did not elicit significant increase in $\mathrm{Na}^{+}$current (Fig. 7A; Table 4). Although we detected a moderate positive shift in reversal potential following administration of trypsin, the difference did not reach the level of significance (Fig. 7B). These data suggest that besides alterations of other ion transport mechanisms and accumulation of local inflammatory mediators, disorders of $\mathrm{Na}^{+}$transport also contribute to the development of diarrhea in UC. 
A.

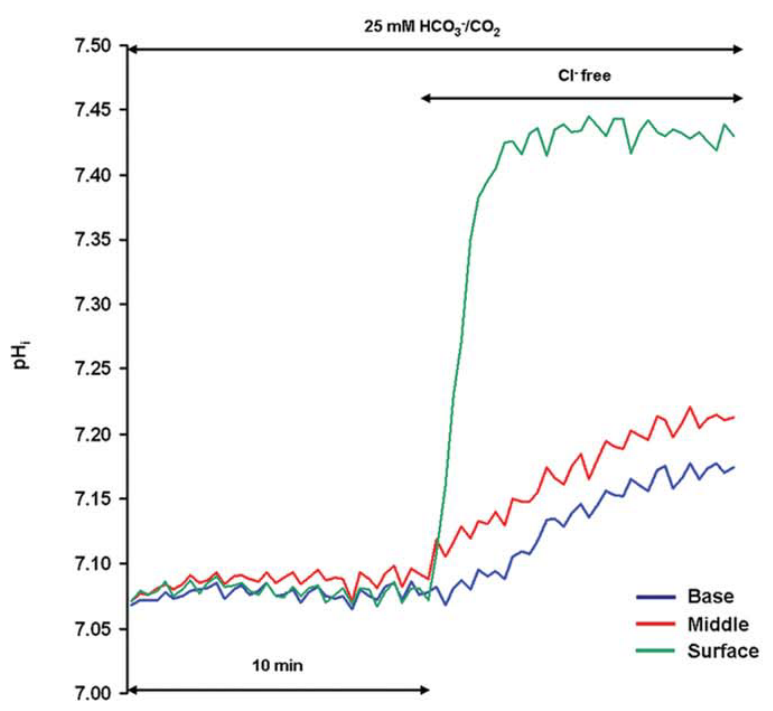

B.

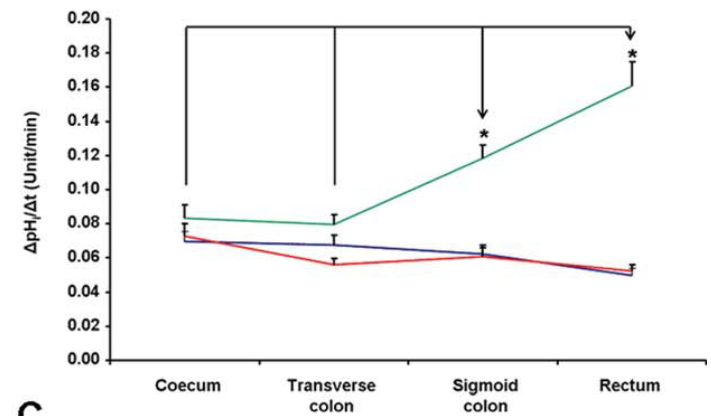

C.

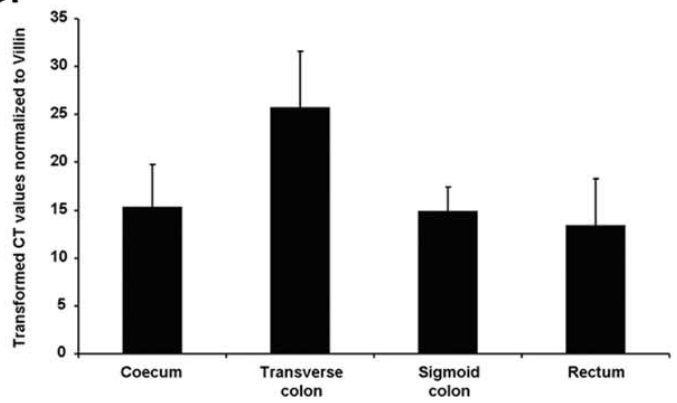

FIGURE 5. $\mathrm{Cl}^{-} / \mathrm{HCO}_{3}^{-}$exchange (AE) activity and DRA expression in control colonic crypts. (A) Representative $\mathrm{pH}_{\mathrm{i}}$ trace of colonic crypts isolated from patients with normal endoscopic findings. Removal of $\mathrm{Cl}^{-}$from the standard $\mathrm{HCO}_{3}^{-} / \mathrm{CO}_{2}$ solution resulted in an alkalization of $\mathrm{pH}_{\mathrm{i}}$. AE activity was the highest in the surface of the crypts. (B) Activity of the $\mathrm{Cl}^{-} / \mathrm{HCO}_{3}^{-}$exchanger in different parts of the colon. Significantly higher AE activity was measured in the distal versus the proximal part of the colon. $n=17-31$ colonic crypts isolated from 4-10 patients. (C) Real-time PCR analysis of DRA mRNA expression in different parts of colon in relation to villin (an epithelial marker). For each region, RNA was isolated from several biopsies of 3-5 controls. Data are presented as means \pm SEM. ${ }^{*}$ Significant difference $(P<0.05)$ between the different parts of the colon. [Color figure can be viewed in the online issue, which is available at wileyonlinelibrary.com.]

\section{Apical Chloride Transport Is Diminished in UC Patients}

On the surface of the crypts, significantly lower $\mathrm{Cl}^{-} /$ $\mathrm{HCO}_{3}^{-}$exchange activity was observed in UC patients versus controls (Fig. 8A). mRNA levels of DRA were reduced by $\sim 50 \%$ in UC patients compared to noninflamed controls (Fig. 8B).

\section{DISCUSSION}

The absorption of water and ions (especially $\mathrm{Na}^{+}$and $\mathrm{Cl}^{-}$) is an important function of colonic epithelial cells. When the cells become unable to maintain normal levels of absorption, different gastrointestinal symptoms such as diarrhea or constipation develop, which in severe forms can be life-threatening. Therefore, understanding the physiology and pathophysiology of absorption in the colon is crucially important. In healthy humans $\approx 1.5 \mathrm{~L}$ of fluid flows into the colon from the small intestine and $90 \%$ of this fluid is absorbed. ${ }^{37}$ The main driving force of this large amount of water reuptake is the $\mathrm{Na}^{+}$absorption from the lumen through the colonic crypts. ${ }^{37}$ In this study we show that the activities of electroneutral (via NHE3) and electrogenic $\mathrm{Na}^{+}$absorption (via ENaC) are in inverse ratio to each other in the proximal and distal colon. The segmental differences of electrogenic $\mathrm{Na}^{+}$absorption have been suggested by Sandle et al. ${ }^{13,38}$ They found that electrogenic $\mathrm{Na}^{+}$transport is higher in the human descending colon versus the ascending colon in vitro. ${ }^{13,39}$ In addition, Sellin and De Soignie ${ }^{39}$ showed that all segments of the human colon actively absorb $\mathrm{Na}^{+}$and $\mathrm{Cl}^{-}$. Although $\mathrm{ENaC}$ was found to be more active in the distal part of the colon, in vivo studies revealed that water and $\mathrm{Na}^{+}$absorption is greater in the proximal versus the distal part of the colon. ${ }^{12,38,41}$ These data predict that electroneutral $\mathrm{Na}^{+}$absorption must be more dominant in the proximal colon. Consistent with recently published data from rodent colon, ${ }^{11}$ we show here that both the activity and the expression of NHE3, but not NHE2, are decreasing from the proximal to distal colon in human. In addition, the activity of NHE3 approximately doubled in the cecum versus the rectum. These results are in accordance with the data obtained in animal models. Aldosterone was found to stimulate intestinal $\mathrm{Na}^{+}$absorption 


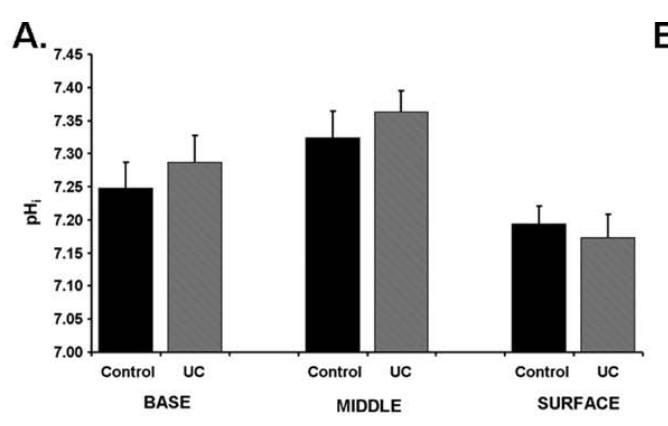

C.

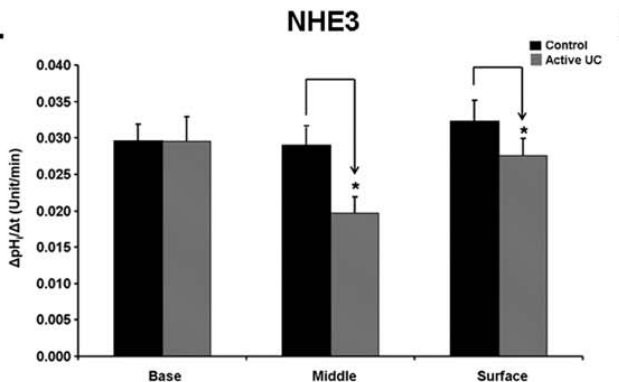

B.

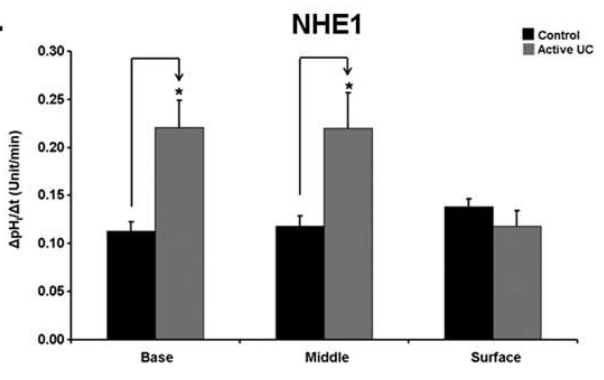

D.

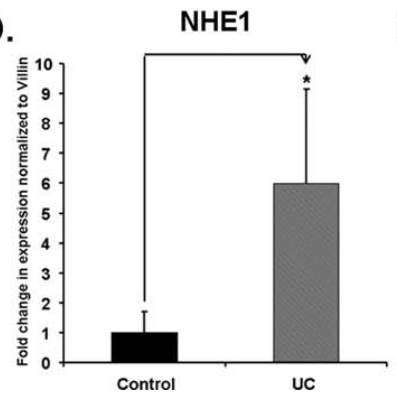

E.

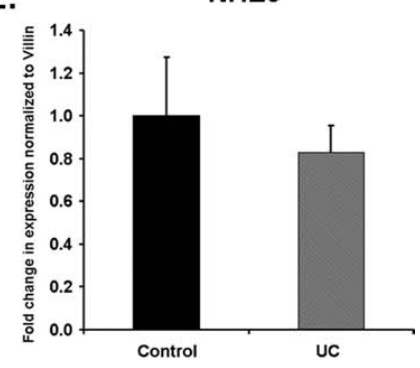

FIGURE 6. Resting $\mathrm{pH}_{\mathrm{i}}$ and changes in the activity and expression of NHE1 and NHE3 in colonic crypts of UC patients. Biopsy samples were collected from the distal part of the colon of the UC patients. Resting $\mathrm{pH}_{\mathrm{i}}$ was determined in UC in the same way as in case of control colonic crypts. (A) No difference was detected in the resting $\mathrm{pH}_{\mathrm{i}}$ between active UC and control colonic crypts. $n=10$ colonic crypts isolated from four patients. (B) The activity of NHE1 isoform was determined both in active UC epithelial cells with the use of 1 and $50 \mathrm{vM}$ HOE-642. Significantly higher NHE1 activity was detected in the base and middle parts of the colonic crypts in active UC compared to the controls. (C) Activity of NHE3 was significantly decreased in active UC throughout the crypt except for the base. $n=18$ colonic crypts isolated from seven patients. Realtime PCRs were performed to determine for (D) NHE1 and (E) NHE3 mRNA expression in biopsies collected from the sigmoid colon in relation to villin expression; results showed a significant and strong increase of NHE1 mRNA expression in UC compared to noninflamed controls, whereas NHE3 mRNA levels were not significantly altered. For RNA isolation, several biopsies from 7 control and 14 UC (mild to moderate inflammation of the sigmoid colon) patients were used. Data are presented as means \pm SEM. * Significant difference $(P<0.05)$ between the different parts of the colon.

and increase NHE3 expression by 3 -fold in the proximal colon but not in the distal colon. ${ }^{42}$ Notably, the expression of NHE2 was unaffected. The prominent role of NHE3 in $\mathrm{Na}^{+}$absorption is suggested by mouse models as well. Diarrhea develops in NHE3-deficient, but not in NHE2-deficient mice. ${ }^{43}$ Furthermore, the loss of NHE2 transporter has no effect on the diarrheal state of NHE3-deficient mice. $^{44}$

Although NHE1 is not involved in the absorption of $\mathrm{Na}^{+}$(it is located in the basolateral membrane), it participates in the $\mathrm{pH}_{\mathrm{i}}$ regulation of colonic epithelial cells. ${ }^{10,45}$ The importance of NHE1 was connected to inflammatory disorders as well; therefore, we extended our study to investigate both the activity and expression of NHE1. ${ }^{2}$ Contrary to NHE3, we could not find segmental differences between the different parts of colon.

Colonic $\mathrm{Cl}^{-} / \mathrm{HCO}_{3}^{-}$exchange also plays an important role in water and $\mathrm{Na}^{+}$absorption from the large intestine. The two main apical anion exchangers in the gastrointestinal tract are the putative anion (PAT1 or SLC26A6) and the downregulated in adenoma DRA or SLC26A3 transporters. ${ }^{29,46}$ Notably, PAT1 is only expressed in the small intestine, whereas DRA has a colon-predominant expression. ${ }^{45,46}$ The prominent role of DRA in the colon is also suggested by the fact that DRA-deficient, but not PAT1-deficient mice display dehydration due to severe diarrhea. ${ }^{47}$ Importantly, mutations of DRA cause congenital diarrhea in humans. ${ }^{48}$ Our experiments demonstrate that $\mathrm{Cl}^{-} / \mathrm{HCO}_{3}^{-}$ exchange is more active in the distal versus the proximal colon. The basolateral anion exchanger 2 (AE2) has been identified in the distal colon both in the surface and crypt cells; however, DRA was localized only to the surface of crypt cells. ${ }^{49,50}$ It is noteworthy that the differences between the $\mathrm{Cl}^{-} / \mathrm{HCO}_{3}^{-}$exchange activities were detected in the surface of the crypts, suggesting alterations of DRA rather than other anion exchangers. This increased $\mathrm{Cl}^{-} /$ $\mathrm{HCO}_{3}^{-}$exchange rate in surface colonocytes was not paralleled by higher DRA mRNA expression levels. Since DRA mRNA expression was standardized to villin expression, which is expressed along the whole crypt length (albeit 


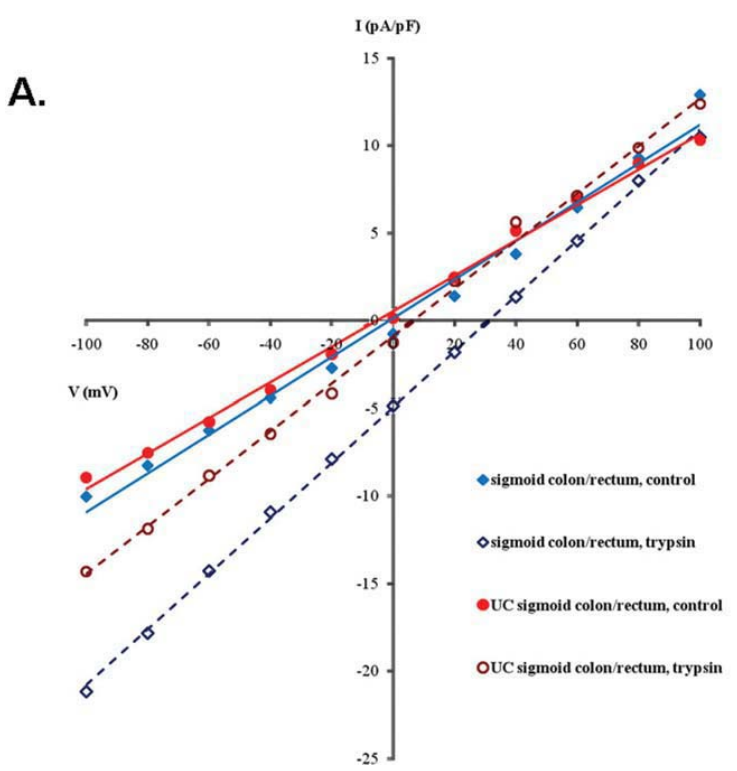

B.

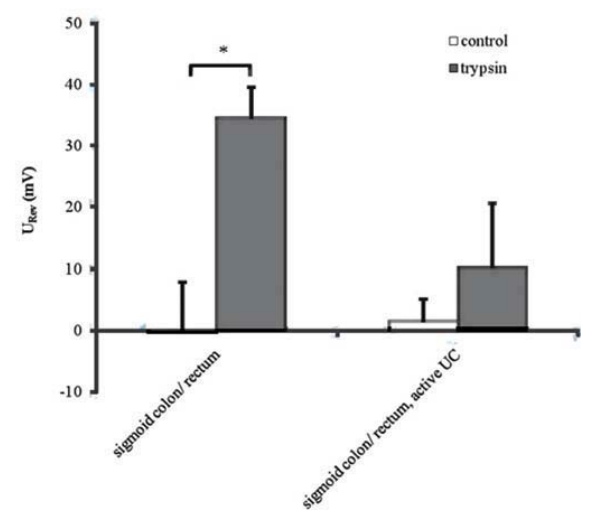

FIGURE 7. Differences in functional $\mathrm{Na}^{+}$channel activity. (A) Average I/V plots obtained in cells derived from sigmoid colon/ rectum ( $n=12)$ of individuals with and without UC $(n=5$, respectively). Trypsin did not activate inward currents in colonic crypts isolated from UC patients. (B) Trypsin caused a significant shift of the reversal potentials towards more positive values in control but not in UC cells. Data are presented as means \pm SEM. ${ }^{*} P<0.05$ significant differences versus the controls. [Color figure can be viewed in the online issue, which is available at wileyonlinelibrary.com.]

more strongly towards to surface), whereas DRA is expressed in a strongly surface-predominant fashion in the human colon, ${ }^{36}$ and since crypt length increases towards the distal colon, such expression studies may fail to reveal a selective increase in surface cell expression.

Following the first, basic physiological part of the study, we investigated the role of the same ion transport mechanisms in UC in which diarrhea is one of the leading symptoms. We found that the expression of NHE1 is strongly upregulated in UC, which is in accordance with elevation of functional activity. This is a very important finding, since experiments in mice revealed that inhibition of NHE1 activity with amiloride strongly decreased the inflammatory processes in vivo in IBD mouse model. ${ }^{2}$ In addition, there is other evidence showing that NHE1 may be involved in the development of UC. NHE1 has been shown to be an important regulator in many types of immune response. ${ }^{51}$ NHE1 promotes TNF- $\alpha$ and IL- 8 production $^{23,52}$ and activation of NHE1 promotes neutrophil migration $^{53}$ and myeloperoxidase activity and release. ${ }^{54}$ The 6-fold elevation in the mRNA expression of NHE1 in UC and the above-described previous observations strongly suggest that inhibition of NHE1 could be a potential therapeutic target.

Next we investigated the two major $\mathrm{Na}^{+}$transport mechanisms (NHE3 and $\mathrm{ENaC}$ ) in patients suffering from active UC. Our results clearly demonstrate that both mech- anisms are functionally damaged. The loss of ENaC function is most probably due to transcriptional alterations. The expression of the ENaC $\beta$ subunit was shown to be downregulated in UC. ${ }^{18}$ In addition, Amasheh et $\mathrm{al}^{55}$ clearly

TABLE 4. Whole cell current measurements in colonic epithelial cells derived from sigmoid colon/rectum of control individuals and patients with UC, prior and after treatment with trypsin. Currents are shown as current densities $(\mathrm{pA} / \mathrm{pF})$. Data represent mean \pm SE $\left(^{*} \mathrm{p}<0.05\right)$. Number of cells is shown in parentheses.

\begin{tabular}{|c|c|c|}
\hline & $\begin{array}{l}\text { UC sigmoid colon/rectum } \\
\text { (12) basal ENaC activities }\end{array}$ & $\begin{array}{c}\text { UC sigmoid colon/rectum } \\
\text { (12) trypsin-induced ENaC } \\
\text { activities }\end{array}$ \\
\hline$-100 \mathrm{mV}$ & $-8,94 \pm 4,35$ & $-14,30 \pm 10,44$ \\
\hline$-80 \mathrm{mV}$ & $-7,54 \pm 3,87$ & $-11,86 \pm 8,67$ \\
\hline$-60 \mathrm{mV}$ & $-5,77 \pm 2,98$ & $-8,84 \pm 6,79$ \\
\hline$-40 \mathrm{mV}$ & $-3,96 \pm 2,20$ & $-6,45 \pm 5,30$ \\
\hline$-20 \mathrm{mV}$ & $-1,92 \pm 1,07$ & $-4,15 \pm 3,24$ \\
\hline $0 \mathrm{mV}$ & $0,15 \pm 0,75$ & $-1,26 \pm 1,89$ \\
\hline$+20 \mathrm{mV}$ & $2,45 \pm 2,07$ & $2,28 \pm 3,69$ \\
\hline$+40 \mathrm{mV}$ & $5,15 \pm 4,34$ & $5,63 \pm 5,16$ \\
\hline$+60 \mathrm{mV}$ & $6,91 \pm 6,35$ & $7,12 \pm 6,59$ \\
\hline$+80 \mathrm{mV}$ & $9,00 \pm 8,20$ & $9,88 \pm 8,79$ \\
\hline$+100 \mathrm{mV}$ & $10,31 \pm 7,55$ & $12,37 \pm 10,42$ \\
\hline
\end{tabular}


A.

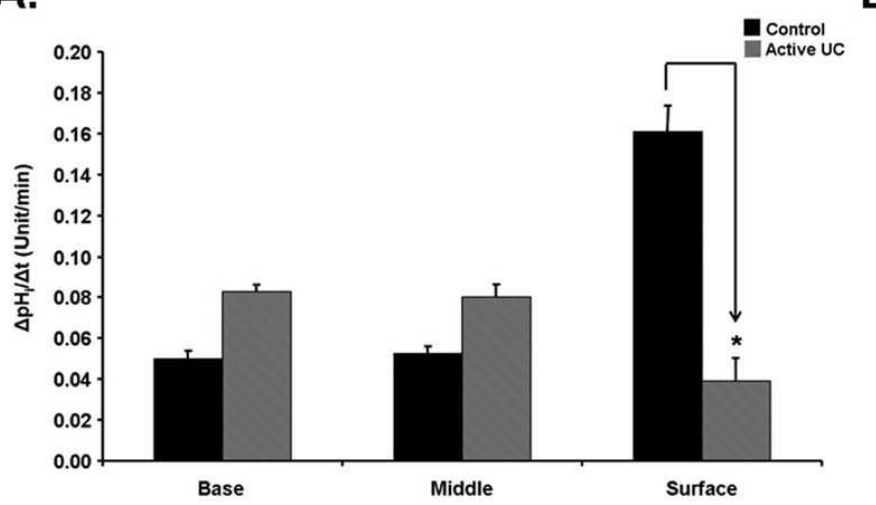

B.

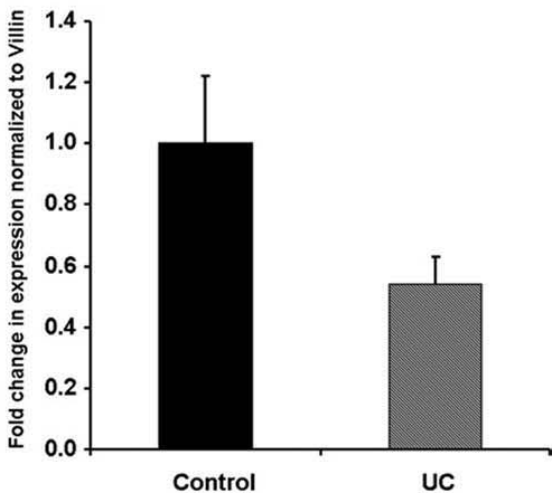

FIGURE 8. The $\mathrm{Cl}^{-} / \mathrm{HCO}_{3}^{-}$exchange activity and DRA expression in UC epithelial cells. (A) The anion exchange activity significantly decreased in the surface of UC colonic crypts. $n=10$ colonic crypts isolated from four patients. (B) Real-time RT-PCRs were performed from the RNA isolated from the biopsies of sigmoid colon for DRA. Results showed a significant decrease of DRA mRNA expression in UC patients compared to controls. ${ }^{*} P<0.05$ significant differences versus the controls. For RNA isolation, several biopsies from 7 control and 14 UC (mild to moderate inflammation of sigmoid colon) patients were used. Data are presented as means \pm SEM.

demonstrated that elevated proinflammatory cytokine levels selectively impair $\beta$ - and $\gamma$-ENaC expression in UC. However, the loss of NHE3 function in UC is less clear. Although Sullivan et $\mathrm{al}^{18}$ demonstrated that the expression of NHE3 is decreased in colitis based on Western analysis of colonic biopsies, we found no such significant differences between control and UC patients when the expression levels of NHE3 were compared to those of a structural brush border membrane protein with similar expression patterns than NHE3. ${ }^{56}$ In addition, NHE3 immunostaining was found to be normal in the brush border membrane of inflamed colonocytes. ${ }^{56}$ Therefore, the molecular mechanism of NHE3 functional damage still remains unsolved, and may be due to changes in the regulatory proteins that ensure NHE3 regulation and membrane retention. ${ }^{57}$

Finally, we provided evidence that both the activity of anion exchange and the expression of the dominant anion exchanger, namely, DRA, are significantly decreased. Downregulated adenoma transporter is dominantly expressed in the surface of the crypts, whereas the basolateral anion exchangers are expressed in all parts of the crypts. ${ }^{50}$ Our experiments on normal crypts showed that the strongest activity of $\mathrm{Cl}^{-} / \mathrm{HCO}_{3}^{-}$exchange occurs on the surface of the crypts. Importantly, anion exchange activity decreased by $\approx 80 \%$ in $\mathrm{UC}$, indicating that $\mathrm{Cl}^{-}$absorption via DRA is seriously damaged. It has also been shown that IL- $1 \beta$ reduces DRA mRNA expression in vitro by inhibiting gene transcription. ${ }^{58}$ Furthermore, highly reactive oxygen metabolites which are known to be involved in the pathogenesis of $\mathrm{UC}^{59}$ inhibit $\mathrm{Cl}^{-} / \mathrm{OH}^{-}$exchange activity in Caco- 2 cells. ${ }^{60}$ These results suggest that gene transcription by proinflammatory cytokines and/or functional changes of
$\mathrm{Cl}^{-}$absorption may play a crucial role in the pathogenesis of diarrhea in colitis.

In conclusion, we have demonstrated in this comprehensive human study that 1) electroneutral (via NHE3) and electrogenic $\mathrm{Na}^{+}$absorption (via ENaC) are in inverse ratio to each other in the proximal and distal colon; 2) the anion exchanger DRA is more active in the distal part of the colon; 3) both sodium and chloride transport is damaged in UC; whereas, 4) NHE1, which has been shown to promote immune response, is strongly upregulated. These results open up new therapeutic targets in UC. Drug development and clinical studies are crucially needed to determine whether selective inhibition of NHE1 and/or stimulation of NHE3, ENaC, and DRA would be beneficial in UC.

\section{ACKNOWLEDGMENTS}

We thank the gastroenterologists and the surgeons for collecting research samples at the University of Szeged and Hannover Medical School, as well as Janina Bonhagen and Brigitte Rausch for technical help. We thank Dr. Jürgen Pünter (Sanofi-Aventis Deutschland $\mathrm{GmbH}$ ) for kindly providing HOE-642.

\section{REFERENCES}

1. Becker JM, Stucchi AF. Treatment of choice for acute severe steroidrefractory ulcerative colitis is colectomy. Inflamm Bowel Dis. 2009;15: 146-149.

2. Németh HZ, Deitch EA, Szabó $\mathrm{C}$, et al. $\mathrm{Na}+/ \mathrm{H}+$ exchanger blockade inhibits enterocyte inflammatory response and protects against colitis. Am J Physiol Gastrointest Liver Physiol. 2002;283: $122-132$.

3. Laubitz D, Larmonier CB, Bai A, et al. Colonic gene expression profile in NHE3-deficient mice: evidence for spontaneous distal 
colitis. Am J Physiol Gastrointest Liver Physiol. 2008;295: G63-G77.

4. Seidler U, Lenzen H, Cinar A, et al. Molecular mechanisms of disturbed electrolyte transport in intestinal inflammation. Ann NY Acad Sci. 2006;1072:262-275.

5. Teleky B, Hamilton G, Cosentini E, et al. Intracellular $\mathrm{pH}$ regulation of human colonic crypts cells. Pflugers Arch. 1994;426: $267-275$.

6. Kunzelmann K, Mall M. Electrolyte transport in the mammalian colon: mechanism and implications for disease. Physiol Rev. 2002;82: 245-289.

7. Musch M, Arvans DL, WU GD, et al. Functional coupling of the downregulated in adenoma Cl-/base exchanger DRA and the apical $\mathrm{Na}+/ \mathrm{H}+$ exchangers NHE2 and NHE3. Am $J$ Physiol Gastrointest Liver Physiol. 2009;296:G202-210.

8. Clauss W, Schäfer H, Horch I, et al. Segmental differences in electrical properties and Na-transport of rabbit cecum, proximal and distal colon in vitro. Pflugers Arch. 1985;403:278-282.

9. Yau WM, Makhlouf GM. Comparison of transport mechanisms in isolated ascending and descending rat colon. Am J Physiol. 1975;228: 191-195.

10. Ikuma M, Kahgarian M, Binder HJ, et al. Differential regulation of NHE isoforms by sodium depletion in proximal and distal segments of rat colon. Am J Physiol Gastrointest Liver Physiol. 1999;276: G539-G549.

11. Talbot C, Lytle C. Segregation of $\mathrm{Na} / \mathrm{H}$ exchanger-3 and $\mathrm{Cl} / \mathrm{HCO} 3$ exchanger SLC26A3 (DRA) in rodent cecum and colon. Am J Physiol. 2010 [Epub ahead of print].

12. Levitan R, Fordtran JS, Burrows BA, et al. Water and salt absorption in the human colon. J Clin Invest. 1962;41: 1754-1759.

13. Sandle GI, Wills NK, Alles W, et al. Electrophysiology of the human colon: evidence of segmental heterogeneity. Gut. 1986;27: 999-1005.

14. Kawamata K, Hayashi H, Suzuki Y. Chloride dependent bicarbonate secretion in the mouse large intestine. Biomed Res. 2006;27: $15-21$.

15. Roediger WE, Lawson MJ, Kwok V, et al. Colonic bicarbonate output as a test of disease activity in ulcerative colitis. J Clin Pathol. 1984; 37:704-707.

16. Schilli R, Breuer RI, Klein F, et al. Comparison of the composition of faecal fluid in Crohn's disease and ulcerative colitis. Gut. 1982;23: 326-332.

17. Weijers HA, Van De Kamer JH. Alteration of intestinal bacterial flora as a cause of diarrhoea. Nutr Abstr Rev. 1965;35:591-604.

18. Sullivan S, Alex P, Dassopoulos T, et al. Downregulation of sodium transporters and NHERF proteins in IBD patients and mouse colitis models: Potential contributors to IBD-associated diarrhea. Inflamm Bowel Dis. 2009;15:261-274.

19. Greig ER, Boot-Handford RP, Mani V, et al. Decreased expression of apical $\mathrm{Na}+$ channels and basolateral $\mathrm{Na}+-\mathrm{K}+$-ATPase in ulcerative colitis. J Pathol. 2004;204:84-92.

20. Civitelli R, Teitelbaum SL, Hruska KA, et al. IL-1 activates the $\mathrm{Na}+/ \mathrm{H}+$ antiport in a murine $\mathrm{T}$ cell. J Immunol. 1989;143: 4000-4008.

21. Vairo G, Royston AK, Hamilton JA. Biochemical events accompanying macrophage activation and the inhibition of colony-stimulating factor-1-induced macrophage proliferation by tumor necrosis factor- $\alpha$, interferon- $\gamma$, and lipopolysaccharide. J Cell Physiol. 1992;151: 630-641.

22. Prpic V, Yu SF, Figueiredo F, et al. Role of $\mathrm{Na}+\mathrm{H}+$ exchange by interferon-gamma in enhanced expression of JE and I-A beta genes. Science. 1989;244:469-471.

23. Orlinska U, Newton RC. Modification of tumor necrosis factor-alpha $(\mathrm{TNF}-\alpha)$ production by the $\mathrm{Na}+$ dependent $\mathrm{HCO} 3$-cotransport in lipopolysaccharide-activated human monocytes. Immunopharmacology. 1995; 30:41-50.

24. Thomas JA, Buchsbaum RN, Zimniak A, et al. Intracellular pH-measurements in Ehrlich ascites tumor cells utilizing spectroscopic probes generated in situ. Biochemistry. 1979;18:2210-2218.
25. Hegyi P, Rakonczay Z Jr, Gray MA, et al. Measurement of intracellular $\mathrm{pH}$ in pancreatic duct cells: a new method for calibrating the fluorescence data. Pancreas. 2004;28:427-434.

26. Bachmann O, Riederer B, Rossmann $\mathrm{H}$, et al. The $\mathrm{Na}+/ \mathrm{H}+$ exchanger isoform 2 is the predominant NHE isoform in murine colonic crypts and its lack causes NHE3 upregulation. Am J Physiol Gastrointest Liver Physiol. 2004;287:G125-133.

27. Cinar A, Chen M, Riederer B, et al. NHE3 inhibition by cAMP and $\mathrm{Ca} 2+$ is abolished in PDZ-domain protein PDZK1-deficient murine enterocytes. $J$ Physiol. 2007;581:1235-1246.

28. Kiela PR, Ghishan FK. Na+-H+ exchange in mammalian digestive tract. In: Johnson LR, ed. Physiology of the Gastrointestinal Tract. Amsterdam: Elsevier Press; 2006:1847-1881.

29. Zachos NC, Tse M, Donowitz M. Molecular physiology of intestinal $\mathrm{Na}+/ \mathrm{H}+$ exchange. Annu Rev Physiol. 2005;67:411-443.

30. Broere N, Chen M, Cinar, et al. Defective jejunal and colonic salt absorption and altered $\mathrm{Na}^{+} / \mathrm{H}^{+}$exchanger 3 (NHE3) activity in NHE regulatory factor 1 (NHERF1) adaptor protein-deficient mice. Pflugers Arch. 2009;457:1079-1091.

31. Scholz W, Albus U, Counillon L, et al. Protective effects of HOE642, a selective sodium-hydrogen exchange subtype 1 inhibitor, on cardiac ischaemia and reperfusion. Cardiovasc Res. 1995;29: $260-268$.

32. Rossier BC. The epithelial sodium channel: activation by membranebound serine proteases. Proc Am Thorac Soc. 2004;1:4-9.

33. Nesterov V, Dahlmann A, Bertog M, et al. Trypsin can activate the epithelial sodium channel $(\mathrm{ENaC})$ in microdissected mouse distal nepron. Am J Physiol Renal Physiol. 2008;295:F1052-F1062.

34. Kleyman TR, Carattino MD, Hughey RP. ENaC at the cutting edge: regulation of epithelial sodium channels by proteases. $J$ Biol Chem. 2009;284:20447-20451.

35. Kellenberger S, Gautschi I, Schild L. Mutations in the epithelial $\mathrm{Na}+$ channel $\mathrm{ENaC}$ outer pore disrupt amiloride block by increasing its dissociation rate. Mol Pharmacol. 2003;64:848-856.

36. Jacob P, Rossmann H, Lamprecht G, et al. Down-regulated in adenoma mediates apical $\mathrm{Cl}-\mathrm{HCO} 3-$ exchange in rabbit, rat, and human duodenum. Gastroenterology. 2002;22:709-724.

37. Binder HJ, Sandle GI. Electrolyte transport in the mammalian colon. In: Johnson LR, ed. Physiology of the Gastrointestinal Tract. New York: Raven Press; 1994:2133-2171.

38. Sandle GI. Salt and water absorption in the human colon: a modern appraisal. Gut. 1998;43:294-299.

39. Sellin JH, De Soignie R. Ion transport in human colon in vitro. Gastroenterology. 1987;93:441-448.

40. Devroede GJ, Phillips SF. Failure of the human rectum to absorb electrolytes and water. Gut. 1970;11:438-442.

41. Devroede GJ, Phillips SF, Code CF, et al. Regional differences in rates of insorption of sodium and water from the human large intestine. Can J Physiol Pharmacol. 1971;49:1023-1029.

42. Cho JH, Musch MW, Bookstein CM, et al. Aldosterone stimulates intestinal $\mathrm{Na}+$ absorption in rats by increasing NHE3 expression of the proximal colon. Am J Physiol. 1998;274: C586-C594.

43. Schultheis PJ, Clarke LL, Meneton P, et al. Renal and intestinal absorptive defects in mice lacking the NHE3 $\mathrm{Na}+/ \mathrm{H}+$ exchanger. Nat Genet. 1998;19:282-285.

44. Ledoussal C, Woo AL, Miller ML, et al. Loss of the NHE2 Na+/H+ exchanger has no apparent effect on diarrheal state of NHE3-deficient mice. Am J Physiol Gastrointest Liver Physiol. 2001;281: G1385-G1396.

45. Hasselblatt $\mathrm{P}$, Warth R, Schulz-Baldes A, et al. pH regulation in isolated in vitro perfused rat colonic crypts. Pflugers Arch. 2000;441: 118-124.

46. Wang Z, Wang T, Petrovic S, et al. Renal and intestinal transport defect in Slc26a6-null mice. Am J Physiol Cell Physiol. 2004;288: C957-C965.

47. Schweinfest CW, Spyropoulos DD, Henderson KW, et al. Slc26a3 (dra)-deficient mice display chloride-losing diarrhea, enhanced colonic proliferation, and distinct up-regulation of ion transporters in the colon. J Biol Chem. 2006;281:37962-37971. 
48. Mäkelä S, Kere J, Holmberg C, et al. SLC26A3 mutations in congenital chloride diarrhea. Hum Mutat. 2002;20:425-438.

49. Ikuma M, Geibel J, Binder HJ, et al. Characterization of $\mathrm{Cl}-\mathrm{HCO} 3$ exchange in basolateral membrane of rat distal colon. Am J Physiol Cell Physiol. 2003;285:C912-C921.

50. Rajendran VM, Binder HJ. Characterization and molecular localization of anion transporters in colonic epithelial cells. Ann N Y Acad Sci. 2000;915:15-29.

51. De Vito P. The sodium/hydrogen exchanger: a possible mediator of immunity. Cell Immunol. 2006;240:69-85.

52. Ohmori Y, Reynolds E, Hamilton TA. Modulation of $\mathrm{Na}+/ \mathrm{K}+$ exchange potentiates lipopolysaccharide-induced gene expression in murine peritoneal macrophages. J Cell Physiol. 1991;148: 96-105.

53. Rosengren S, Henson PM, Worthen GS. Migration associated volume changes in neutrophils facilitate the migratory process in vitro. Am J Physiol Cell Physiol. 1994;267:C1623-C1632.

54. Witko-Sarsat V, Allen RC, Paulais M, et al. Disturbed myeloperoxidase-dependent activity of neutrophils in cystic fibrosis homozygotes and heterozygotes, and its correction by amiloride. J Immunol. 1996;157:2728-2735.
55. Amasheh S, Barmeyer C, Koch CS, et al. Cytokine dependent transcriptional down-regulation of epithelial down-regulation of epithelial sodium channel in ulcerative colitis. Gastroenterology. 2004;126:1711-1720.

56. Yeruva S, Farkas K, Hubricht J, et al. Preserved $\mathrm{Na}+\mathrm{H}+$ exchanger isoform 3 expression and localization, but decreased NHE3 function indicate regulatory sodium transport defect in ulcerative colitis. Inflamm Bowel Dis. 2010;16:1149-1161.

57. He P, Yun CC. Mechanisms of the regulation of the intestinal $\mathrm{Na}+/ \mathrm{H}+$ exchanger NHE3. J Biomed Biotechnol. 2010;2010: 238080.

58. Yang H, Jiang W, Furth EE, et al. Intestinal inflammation reduces expression of DRA, a transporter responsible for congenital chloride diarrhea. Am J Physiol. 1998;275:G1445-1453.

59. McKenzie SJ, Baker MS, Buffinton GD, et al. Evidence of oxidantinduced injury to epithelial cells during inflammatory bowel disease. $J$ Clin Invest. 1996;98:136-141.

60. Saksena S, Gill RK, Tyagi S, et al. Role of Fyn and PI3K in H2O2induced inhibition of apical $\mathrm{Cl}-/ \mathrm{OH}-$ exchange activity in human intestinal epithelial cells. Biochem J. 2008;416:99-108. 
IV. 


\title{
NHE1 activity contributes to migration and is necessary for proliferation of human gastric myofibroblasts
}

\author{
Mátyás Czepán • Zoltán Rakonczay Jr. • Andrea Varró • Islay Steele • Rod Dimaline • \\ Nantaporn Lertkowit • János Lonovics • Andrea Schnúr • György Biczó • \\ Andrea Geisz • György Lázár • Zsolt Simonka • Viktória Venglovecz • \\ Tibor Wittmann • Péter Hegyi
}

Received: 31 March 2011 /Revised: 31 October 2011 /Accepted: 2 November 2011 /Published online: 6 December 2011

(C) Springer-Verlag 2011

\begin{abstract}
Myofibroblasts play central roles in wound healing, deposition of the extracellular matrix and epithelial function. Their functions depend on migration and proliferation within the subepithelial matrix, which results in accelerated cellular metabolism. Upregulated metabolic pathways generate protons which need to be excreted to maintain intracellular $\mathrm{pH}\left(\mathrm{pH}_{\mathrm{i}}\right)$. We isolated human gastric myofibroblasts (HGMs) from surgical specimens of five
\end{abstract}

Specific author contributions György Lázár, Zsolt Simonka, Tibor Wittmann and János Lonovics were involved in patient selection and sample collection; Zoltán Rakonczay Jr., Viktória Venglovecz and Péter Hegyi were involved in tissue culturing and microfluorometric experiments; Andrea Varró, Rod Dimaline, Islay Steele, Nantaporn Lertkowit, Andrea Schnúr, György Biczó and Andrea Geisz performed molecular biology experiments and biological assay experiments. Mátyás Czepán was involved in all of the above mentioned experiments and drafted the manuscript. Péter Hegyi designed and supervised the project, the experiments and the manuscript. Mátyás Czepán spent 3 months in Liverpool as part of the project funded by the NIH and NIHR.

M. Czepán · Z. Rakonczay Jr. J. Lonovics $\cdot$ A. Schnúr $\cdot$

G. Biczó $\cdot$ A. Geisz $\cdot$ T. Wittmann $\cdot$ P. Hegyi $(\triangle)$

First Department of Medicine, University of Szeged, 6720 Korányi fasor 8-10,

Szeged, Hungary

e-mail: hegyi.peter@med.u-szeged.hu

G. Lázár · Z. Simonka

Department of Surgery, University of Szeged,

Szeged, Hungary

V. Venglovecz

Department of Pharmacology and Pharmacotherapy,

University of Szeged,

Szeged, Hungary

A. Varró $\cdot$ I. Steele $\cdot$ R. Dimaline $\cdot$ N. Lertkowit

Department of Physiology, University of Liverpool,

Liverpool, UK patients. Then we characterized, for the first time, the expression and functional activities of the $\mathrm{Na}^{+} / \mathrm{H}^{+}$exchanger (NHE) isoforms 1, 2 and 3, and the functional activities of the $\mathrm{Na}^{+} / \mathrm{HCO}_{3}{ }^{-}$cotransporter (NBC) and the anion exchanger (AE) in cultured HGMs using microfluorimetry, immunocytochemistry, reverse transcription polymerase chain reaction and immunoblot analysis. We showed that NHE1-3, NBC and AE activities are present in HGMs and that NHE1 is the most active of the NHEs. In scratch wound assays we also demonstrated (using the selective NHE inhibitor HOE-642) that carbachol and insulin like growth factor II (IGF-II) partly stimulate migration of HGMs in a NHE1-dependent manner. EdU incorporation assays revealed that IGF-II induces proliferation of HGMs which is inhibited by HOE-642. The results indicate that NHE1 is necessary for IGF-II-induced proliferation response of HGMs. Overall, we have characterized the $\mathrm{pH}_{\mathrm{i}}$ regulatory mechanisms of HGMs. In addition, we demonstrated that NHE1 activity contributes to both IGF-II- and carbachol-stimulated migration and that it is obligatory for IGF-II-induced proliferation of HGMs.

Keywords Fibroblast $\cdot \mathrm{Na}^{+} / \mathrm{H}^{+}$exchange $\cdot$ Gastrointestinal tract $\cdot$ Human
Abbreviations
AE
Anion exchanger
AMV
Avian myeloblastosis virus
AMV-RT
Avian myeloblastosis virus reverse transcriptase
BCECF-AM 2,7-Biscarboxyethyl-5(6)-
DAG Diacyl-glicerol
DAPI 4,6-Diamidino-2-phenylindole
DMEM Dulbecco's Modified Eagle's Medium 


\begin{tabular}{|c|c|}
\hline DMSO & Dimethyl sulfoxide \\
\hline dNTP & Deoxyribonucleotide-triphosphate \\
\hline EDTA & Ethylenediamine tetra-acetic acid \\
\hline EdU & 5-Ethynyl-2-deoxyuridine \\
\hline ER & Endoplasmic reticulum \\
\hline FITC & Fluorescein isothiocyanate \\
\hline GAPDH & $\begin{array}{l}\text { Glyceraldehyde 3-phosphate } \\
\text { dehydrogenase }\end{array}$ \\
\hline $\mathrm{H}_{2}$ DIDS & $\begin{array}{l}\text { 4,4'-Diisothiocyanatodihydrostilbene-2, } \\
\text { 2'-disulfonic acid }\end{array}$ \\
\hline $\mathrm{HaCaT}$ cells & $\begin{array}{l}\text { Human adult low calcium temperature } \\
\text { keratinocytes }\end{array}$ \\
\hline HEPES & $\begin{array}{l}\text { (4-(2-Hydroxyethyl)-1-piperazine- } \\
\text { ethanesulfonic acid }\end{array}$ \\
\hline HGM & Human gastric myofibroblast \\
\hline HOE-642 & $\begin{array}{l}\text { 4-Isopropyl-3-methylsulphonylbenzoyl- } \\
\text { guanidin methanesulphonate also known } \\
\text { as cariporide }\end{array}$ \\
\hline IGF-II & Insulin like growth factor II \\
\hline $\mathrm{IP}_{3}$ & Inositol 1,4,5-trisphosphate \\
\hline$J\left(\mathrm{~B}^{-}\right)$ & Base flux \\
\hline NBC & $\mathrm{Na}^{+} / \mathrm{HCO}_{3}{ }^{-}$cotransporter \\
\hline $\mathrm{NF}-\kappa \mathrm{B}$ & Nuclear factor kappa B \\
\hline NHE & $\mathrm{Na}^{+} / \mathrm{H}^{+}$exchanger \\
\hline NMDG & N-metil D-glucamine \\
\hline PBS & Phosphate buffered saline \\
\hline $\mathrm{pH}_{\mathrm{i}}$ & Intracellular $\mathrm{pH}$ \\
\hline $\mathrm{PIP}_{2}$ & Phosphatidylinositol 4,5-bisphosphate \\
\hline $\mathrm{PKC}$ & Protein kinase $\mathrm{C}$ \\
\hline PLC & Phospholipase C \\
\hline PP & Proton pump \\
\hline RPMI & Roswell Park Memorial Institute \\
\hline RT & Room temperature \\
\hline RT-PCR & $\begin{array}{l}\text { Reverse transcription polymerase } \\
\text { chain reaction }\end{array}$ \\
\hline SEM & Standard error of mean \\
\hline SMA & Smooth muscle actin \\
\hline SR & Sarcoplasmic reticulum \\
\hline
\end{tabular}

\section{Introduction}

Myofibroblasts, also known as activated fibroblasts, are dynamic, spindle-like cells sharing the functional characteristics of both fibrocytes and smooth muscle cells [24]. They are crucial for the production of extracellular matrix and for morphogenesis [42]; moreover, they take part in inflammatory processes related to tissue repair and in the chronic inflammation-adenoma-carcinoma sequence by secreting a broad spectrum of cytokines thereby altering the microenvironment around epithelial cells [23, 41]. To accomplish their functions, myofibroblasts migrate and proliferate in the subepithelial compartment, generating acidic metabolites and consequently protons in the cytosol [21]. Protons are removed from cells mainly by acid/base transporters located on the plasma membrane [7], thus maintaining isoionic intracellular conditions.

Although many authors have investigated the regulation of acid/base transporters and their role in migration and proliferation of epithelial cells [16, 31, 39, 45] or fibroblasts $[10,11,48,57]$, no information is available concerning the effects of acid/base transporter activities on migration and proliferation of gastric myofibroblasts.

One of the main proton extrusion mechanisms is sodium/ hydrogen exchange through the $\mathrm{Na}^{+} / \mathrm{H}^{+}$exchangers (NHEs), which are members of a transporter family comprising of ten isoforms [32, 44]. It has been demonstrated that NHE1 functions not only as a cation exchanger, but also as a modulator of intracellular signalling thereby regulating motility in different animal species including mouse [53], rat [14], dog [30], guinea pig [57] and human cells including leukocytes [49], melanoma cells [55] and hepatoma cells [67]. NHE1 activity was found to be necessary for proliferation of brain-derived pericytes [25], fibroblasts [26], lymphocytes [60] and vascular smooth muscle cells [65]. Furthermore, inhibition of NHE1 activity significantly reduces proliferation rates in vascular smooth muscle cells [65].

It has been demonstrated that gastric epithelial cells secrete matrix metalloproteinase-7 which cleaves myofibroblast-produced insulin-like growth factor binding protein-5 thereby releasing insulin-like growth factor-II (IGF-II). IGF-II acts as a potent stimulant of both epithelial and myofibroblast proliferation [36]. The muscarinic acetylcholine receptor type 3 (M3) agonist carbachol has been shown to increase NHE activity in rabbit parietal cells [3] and in guinea pig pancreatic ductal epithelial cells [59]. Many inhibitors of NHE activity have been described as a consequence of intensive research on amiloride derivatives to develop isoform-specific NHE inhibitors for use in cardiovascular care. 4-Isopropyl-3-methylsulphonylbenzoylguanidin methanesulphonate (HOE-642), also known as cariporide, is one of the most effective compounds, which can dose-dependently inhibit specific NHE isoforms [47].

The aim of this study was to characterize the acid/base transporters of human gastric myofibroblasts (HGMs), focusing on the possible roles of NHE1 in cell migration and proliferation.

\section{Materials and methods}

Chemicals and solutions

Chemicals and solutions used for cell culture were purchased from Sigma-Aldrich (Budapest, Hungary). All reagents for 
immunocytochemistry, unless indicated otherwise, were purchased from Jackson ImmunoResearch Laboratories (West Grove, PA, USA). Chemicals and reagents for polymerase chain reaction (PCR), unless indicated otherwise, were obtained from Promega (Southampton, UK). All primers were purchased from Eurogentec (Southampton, UK).

HOE-642 (cariporide) was kindly donated by SanofiAventis (Frankfurt, Germany). 2,7-Biscarboxyethyl-5(6)carboxyfluorescein-acetoxymethylester (BCECF-AM) and HOE-642 were dissolved in dimethyl sulfoxide. The composition of solutions used for the measurements of intracellular $\mathrm{pH}\left(\mathrm{pH}_{\mathrm{i}}\right)$ is given in Table 1. 4-(2-Hydroxyethyl)-1-piperazineethanesulfonic acid (HEPES) solutions were titrated to $\mathrm{pH} 7.4$ at $37^{\circ} \mathrm{C}$ using either $\mathrm{NaOH}$ or $\mathrm{HCl}$. $\mathrm{HCO}_{3}{ }^{-}$-buffered solutions were gassed with $95 \% \mathrm{O}_{2}$ and $5 \% \mathrm{CO}_{2}$ at $37^{\circ} \mathrm{C}$.

Ethics

The study was approved by the Ethics Committee of the University of Szeged, Hungary. All surgical patients gave informed consent.

\section{Patients, isolation and culture of HGMs}

Tissue specimens from patients undergoing gastric tumour resection in the Department of Surgery, University of Szeged, Hungary were obtained intraoperatively at least 3-4 cm away from the tumour and were transported immediately to the laboratory in ice-cold media for culturing $(n=3)$. Two other specimens from multiple organ cadaver donors were
Table 2 Patients' details

\begin{tabular}{llll}
\hline Patient no. & Gender & Age & Diagnosis \\
\hline 1 & Female & 71 & Gastric cancer \\
2 & Male & 76 & Gastric cancer \\
3 & Male & 66 & Gastric cancer \\
4 & Female & 42 & Subarachnoidal haemorrhage \\
5 & Male & 49 & Traumatic head injury \\
\hline
\end{tabular}

obtained similarly. Patient details can be found in Table 2 . Histopathology confirmed that all specimens were normal gastric tissue samples. The isolation of HGMs was performed using a previously described method [27]. Briefly, the specimens were washed and chopped into very small pieces and were then bathed in a shaking water bath at $37^{\circ} \mathrm{C}$ for $15 \mathrm{~min}$ with $1 \mathrm{mM}$ dithiothreitol. After washing, the specimens were incubated for $30 \mathrm{~min}$ at $37^{\circ} \mathrm{C}$ with $1 \mathrm{mM}$ ethylenediamine tetra-acetic acid (EDTA) four times. Specimens were cultured for 1-2 weeks in Roswell Park Memorial Institute (RPMI) medium supplemented with $10 \%$ fetal bovine serum, $1 \%$ penicillin-streptomycin and $2 \%$ antibiotic-antimycotic solution. After the cells became confluent, they were trypsinized with $0.25 \%$ trypsin-EDTA and were transferred into Dulbecco's Modified Eagle's Medium (DMEM) with $4 \mathrm{mM} \mathrm{L-}$ glutamine containing $10 \%$ fetal bovine serum, $1 \%$ amino acid solution, $1 \%$ penicillin-streptomycin and $2 \%$ antibioticantimycotic solution. The medium was replaced every $48 \mathrm{~h}$ and the cells were passaged after reaching confluency up to

Table 1 Composition of solutions. Values are in millimolar concentrations

\begin{tabular}{|c|c|c|c|c|c|c|c|c|c|c|c|c|c|}
\hline & HEPES & $\mathrm{HCO}_{3}^{-}$ & $\begin{array}{l}\mathrm{NH}_{4} \mathrm{Cl} \\
\mathrm{HEPES}\end{array}$ & $\begin{array}{l}\mathrm{NH}_{4} \mathrm{Cl} \\
\mathrm{HCO}_{3}^{-}\end{array}$ & $\begin{array}{l}\mathrm{Cl}^{-} \text {-free } \\
\text { HEPES }\end{array}$ & $\begin{array}{l}\mathrm{Cl}^{-} \text {-free } \\
\mathrm{HCO}_{3}^{-}\end{array}$ & $\begin{array}{l}\mathrm{Cl}^{-} \text {-free } \\
\mathrm{NH}_{4} \mathrm{Cl} / \\
\mathrm{HEPES}\end{array}$ & $\begin{array}{l}\mathrm{Cl}^{-} \text {-free } \\
\mathrm{NH}_{4} \mathrm{Cl} / \\
\mathrm{HCO}_{3}{ }^{-}\end{array}$ & $\begin{array}{l}\mathrm{Na}^{+} \text {-free } \\
\text { HEPES }\end{array}$ & $\begin{array}{l}\mathrm{Na}^{+} \text {-free } \\
\mathrm{HCO}_{3}^{-}\end{array}$ & $\begin{array}{l}\mathrm{Na}^{+} \text {-free } \\
\mathrm{NH}_{4} \mathrm{Cl} / \\
\mathrm{HEPES}\end{array}$ & $\begin{array}{l}\mathrm{Na}^{+} \text {-free } \\
\mathrm{NH}_{4} \mathrm{Cl} / \\
\mathrm{HCO}_{3}{ }^{-}\end{array}$ & $\begin{array}{l}\text { High K } \mathrm{K}^{+} \\
\text {HEPES }\end{array}$ \\
\hline $\mathrm{NaCl}$ & 130 & 115 & 110 & 95 & & & & & & & & & 5 \\
\hline $\mathrm{KCl}$ & 5 & 5 & 5 & 5 & & & & & 5 & 5 & 5 & 5 & 130 \\
\hline Na-HEPES & 10 & 25 & 10 & & & & & & & & & & 10 \\
\hline $\mathrm{CaCl}_{2}$ & 1 & 1 & 1 & 1 & & & & & 1 & 1 & 1 & 1 & 1 \\
\hline $\mathrm{MgCl}_{2}$ & 1 & 1 & 1 & 1 & & & & & 1 & 1 & 1 & 1 & 1 \\
\hline Glucose & 10 & 10 & 10 & 10 & 10 & 10 & 10 & 10 & 10 & 10 & 10 & 10 & 10 \\
\hline $\mathrm{NH}_{4} \mathrm{Cl}$ & & & 20 & 20 & & & & & & & 20 & 20 & \\
\hline $\mathrm{NaHCO}_{3}$ & & & & & & 25 & & 25 & & & & & \\
\hline HEPES & & & & & 10 & & 10 & & 10 & & 10 & & \\
\hline Na-gluconate & & & & & 140 & 115 & 120 & 95 & & & & & \\
\hline $\mathrm{K}_{2}$-sulfate & & & & & 2.5 & 2.5 & 2.5 & 2.5 & & & & & \\
\hline Ca-gluconate & & & & & 6 & 6 & 6 & 6 & & & & & \\
\hline Mg-gluconate & & & & & 1 & 1 & 1 & 1 & & & & & \\
\hline $\mathrm{NH}_{4}$-sulfate & & & & & & 20 & & 20 & & & & & \\
\hline NMDG & & & & & & & & & 140 & 115 & 120 & 95 & \\
\hline Atropine & & & & & & & & & & 0.01 & 0.01 & 0.01 & \\
\hline Choline- $\mathrm{HCO}_{3}$ & & & & & & & & & & 25 & 25 & 25 & \\
\hline
\end{tabular}


passage 10 . Cell cultures were continually incubated at $37^{\circ} \mathrm{C}$ in a mixture of $5 \% \mathrm{CO}_{2}$ and $95 \%$ air.

\section{Immunocytochemistry}

Twelve thousand HGMs were seeded onto chamber slides and were allowed to adhere overnight. Cells were fixed using 4\% paraformaldehyde for $30 \mathrm{~min}$ and were washed twice with phosphate buffered saline (PBS, Invitrogen, Paisley, UK). Permeabilization was performed by incubation with a filtered, PBS-based solution containing $0.2 \%$ Triton X-100 and $0.3 \%$ protease-free bovine serum albumin for $30 \mathrm{~min}$. Cells were then incubated with $10 \%$ donkey serum in PBS for $30 \mathrm{~min}$. After washing twice with PBS, primary antibodies were added to the chambers and the slides were incubated in moist atmosphere at $4^{\circ} \mathrm{C}$, overnight. The following primary antibodies were used: anti- $\alpha$-smooth muscle actin ( $\alpha$-SMA) antibody raised in guinea pig (1:400), anti-vimentin antibody raised in mouse (1:400), anticytokeratin antibody raised in mouse (1:400), anti-desmin antibody raised in mouse (1:400, all four antibodies from Dako, Denmark) and anti-NHE1, -NHE2 and -NHE3 antibodies raised in goat (1:50, purchased from Santa Cruz Biotechnology, Santa Cruz, CA, USA). Primary antibodies were removed by a sequence of washes for 10 min each with $0.14,0.5$ and $0.14 \mathrm{M} \mathrm{NaCl}$ dissolved in PBS, respectively. Slides were then incubated with secondary antibodies for $60 \mathrm{~min}$ in dark and moist conditions. The following secondary antibodies were used: fluorescein isothiocyanate (FITC)-conjugated anti-guinea pig secondary antibody [1:400, diluted in $10 \mathrm{mM}$ HEPES, $\mathrm{pH}$ 7.5], Texas Red- and FITC-conjugated anti-mouse antibody (1:400) and FITC-conjugated anti-goat secondary antibody (1:400). After hybridization, slides were washed three times with PBS and were covered with 4,6-diamidino-2-phenylindole (DAPI) containing Vectashield mounting medium (Vector Laboratories, Peterborough, UK), then cover slipped.

\section{Intracellular $\mathrm{pH}$ measurement}

One hundred thousand HGMs were seeded onto 24-mmdiameter round glass coverslips in full media. They were allowed to recover for $24 \mathrm{~h}$ before experiments. Coverslips were then transferred into a perfusion chamber and mounted on an inverted microscope (Olympus, Budapest, Hungary). Cells were bathed in HEPES solution at $37^{\circ} \mathrm{C}$ and were loaded with $2 \mu \mathrm{M}$ pH-sensitive fluorescent dye BCECF-AM (Invitrogen, Paisley, UK) for 20 to $30 \mathrm{~min}$. Thereafter, myofibroblasts were continuously perfused with solutions at a rate of 5 to $6 \mathrm{ml} / \mathrm{min}$ and $\mathrm{pH}_{\mathrm{i}}$ was measured by using an imaging system (CellR; Olympus, Budapest, Hungary). Cells were excited at wavelengths of $490 \mathrm{~nm}$ and $440 \mathrm{~nm}$, and the 490/440 fluorescence emission ratio was measured at $535 \mathrm{~nm}$. One $\mathrm{pH}_{\mathrm{i}}$ measurement was recorded per second.

In situ calibration of the fluorescence signal was performed using the high $\mathrm{K}^{+}$-nigericin technique as previously described $[22,58]$. The $\mathrm{pH}$ of high $\mathrm{K}^{+}$-HEPES solution supplemented with $10 \mu \mathrm{M}$ nigericin was set to 6.8 or 7.4 at $37^{\circ} \mathrm{C}$, then cells loaded with BCECF were superfused by these solutions and the 490/440 fluorescence ratio was recorded. Multiple-point calibrations, i.e. sequential BCECF $\mathrm{pH}$ measurements (with high $\mathrm{K}^{+}$-HEPES-nigericin solutions ranging $\mathrm{pH}$ from 6.2 by 0.4 step to 8.2 ) were performed to confirm data accuracy. Linear projections were made from the steady-state fluorescence $\mathrm{pH}$ data during high $\mathrm{K}^{+}$-nigericin superfusion with known $\mathrm{pH}$. Adaptation of projections to the resting fluorescence data of unknown $\mathrm{pH}_{\mathrm{i}}$ in standard HEPES solution results in accurate resting $\mathrm{pH}_{\mathrm{i}}$.

In order to characterize the acid/base transporters, we used ion-withdrawal technique, and ammonium pulse technique in HEPES- and $\mathrm{HCO}_{3}{ }^{-} / \mathrm{CO}_{2}$-buffered solutions. Initial rates (first 30-60 s) of recovery from acidosis were calculated by linear regression.

Determination of buffering capacity and calculation of base fluxes

The intrinsic buffering capacity $\left(\beta_{\mathrm{i}}\right)$ of HGMs was estimated by the $\mathrm{NH}_{4}{ }^{+}$pre-pulse technique [62]. $\beta_{\mathrm{i}}$ refers to the ability of intrinsic cellular components (excluding the bicarbonate buffer system) to buffer changes of $\mathrm{pH}_{\mathrm{i}}$. Briefly, HGMs were exposed to various concentrations of $\mathrm{NH}_{4} \mathrm{Cl}$ while $\mathrm{Na}^{+}$and $\mathrm{HCO}_{3}{ }^{-}$were omitted from the solution to block the $\mathrm{Na}^{+}-$ dependent $\mathrm{pH}$ regulatory mechanisms. $\beta_{\mathrm{i}}$ was estimated by the Henderson-Hasselbalch equation. The total buffering capacity $\left(\beta_{\text {total }}\right)$ was calculated as $\beta_{\text {total }}=\beta_{\mathrm{i}}+\beta_{\mathrm{HCO}^{2}}{ }^{-}=\beta_{\mathrm{i}}+$ $2.3 \times\left[\mathrm{HCO}_{3}{ }^{-}\right]_{\mathrm{i}}$, where $\beta_{\mathrm{HCO}_{3}}{ }^{-}$is the buffering capacity of the $\mathrm{HCO}_{3}{ }^{-} / \mathrm{CO}_{2}$ system and $\left[\mathrm{HCO}_{3}\right]_{\mathrm{i}}$ is the intracellular concentration of $\mathrm{HCO}_{3}{ }^{-}$. Transmembrane base flux $\left[J\left(\mathrm{~B}^{-}\right)\right]$was calculated by using the equation $J\left(\mathrm{~B}^{-}\right)=\mathrm{dpH} / \mathrm{dt} \times \beta_{\text {total }}$. The $\beta_{\text {total }}$ value used in the calculation of $J\left(\mathrm{~B}^{-}\right)$was obtained from Fig. $2 \mathrm{~b}$ by using the $\mathrm{pH}_{\mathrm{i}}$ value at the start of the 30-s period over which $\mathrm{dpH} / \mathrm{dt}$ was measured.

\section{Reverse transcription polymerase chain reaction}

RNA was isolated from myofibroblast cultures using a Qiagen RNEasy Mini Kit (Qiagen House, Crawly, UK) according to the manufacturer's instructions; human kidney RNA was isolated from whole tissue from surgical specimens utilizing TRIzol reagent. RNA was reverse transcribed to cDNA and RNA/primer annealing was performed with $0.5 \mu \mathrm{g}$ oligo-dT primer at $65^{\circ} \mathrm{C}$ for $5 \mathrm{~min}$. After cooling, samples were reverse transcribed in a final reaction volume of $30 \mu \mathrm{l}$ containing the annealed RNA/primer set, 5× AMV (avian 
myeloblastosis virus) buffer, $1.25 \mathrm{mM}$ dNTP (deoxyribonucleotide-triphosphates) mix, 20 unit RNAse inhibitor and 15 unit AMV-RT (AMV-reverse transcriptase). Reactions were incubated at $42^{\circ} \mathrm{C}$ for $1 \mathrm{~h}$; enzymes were inactivated at $85^{\circ} \mathrm{C}$ for 5 min. cDNA $(1 \mu \mathrm{l})$ was used as template for each PCR in a final volume of $25 \mu \mathrm{l}$, containing $10 \times$ master mix Taq-buffer, $10 \mathrm{nM}$ dNTPs, 2.5 unit Taq-polymerase and $1 \mu \mathrm{M}$ NHE primer sets. The sequence of NHE primers is given in Table 3. PCR settings were as follows: denaturation at $95^{\circ} \mathrm{C}$ for $15 \mathrm{~s}$, annealing at $60^{\circ} \mathrm{C}$ for $15 \mathrm{~s}$, extension at $72^{\circ} \mathrm{C}$ for $45 \mathrm{~s}, 30$ cycles. PCR products and DNA HyperLadderPlus (BioLine, Taunton, USA) were run on a $0.8 \%$ agarose gel containing $0.005 \%$ ethidium bromide in Tris-buffered EDTA solution at $80 \mathrm{~V}$, then the gel was illuminated in a BioRad UV (ultraviolet) chamber and photographs were taken.

Immunoblot analysis

Confluent cells $(3,000,000$ cells at least) were washed with PBS after removing the media and were then incubated with $100 \mathrm{mM}$ EDTA for $15 \mathrm{~min}$. After centrifugation $(500 \times \mathrm{g}, 8 \mathrm{~min})$, the supernatant was gently removed and was lysed with RIPA (radio-immuno precipitation assay) buffer supplemented with $1 \%$ protease inhibitor cocktail (Calbiochem-Merck Chemicals, Darmstadt, Germany). Samples were vortexed and frozen in liquid nitrogen for a few seconds then centrifuged at $11,000 \times g$ for $10 \mathrm{~min}$ at $4^{\circ} \mathrm{C}$. The protein concentrations of supernatants containing whole cell protein lysates were determined by using Bradford's reagent. Samples were heat treated at $30^{\circ} \mathrm{C}$ for $30 \mathrm{~min}$ and $100 \mu \mathrm{g}$ protein was electrophoresed on $8 \%$ sodium dodecylsulfate-polyacrylamide gels according to the method of Laemmli using a Hoefer Mighty Small II instrument (Harvard Bioscience Inc., Massachusetts, USA). After separation, proteins were blotted to matching-sized nitrocellulose membrane for $60 \mathrm{~min}$ at $100 \mathrm{~V}$. Membranes were blocked in 5\% nonfat dry milk for $1 \mathrm{~h}$ and were incubated with primary antibodies (1:100 for NHE) overnight at $4{ }^{\circ} \mathrm{C}$ on a rocker. The same NHE primary antibodies were used as for immunocytochemistry. Primary

Table 3 NHE primer sequences

\begin{tabular}{ll}
\hline Primer name & Sequence $\left(5^{\prime}-3^{\prime}\right)$ \\
\hline NHE1 forward & CCT-CTC-TGG-GTG-GAG-AAG-CT \\
NHE1 reverse & CCC-AGG-AAC-GAC-ACA-GAA-AG \\
NHE2 forward & CCA-TGG-AAC-CAC-TGG-GCA-AC \\
NHE2 reverse & TGC-AGG-GGG-AGA-CTT-CTC-AT \\
NHE3 forward & TCC-AAG-TCG-ACC-AAG-CTG-GG \\
NHE3 reverse & AAG-GCC-TCG-TCC-GGA-GAA-AA \\
\hline
\end{tabular}

antibodies were removed by washing with TBST for $3 \times$ 10 min. HRP-conjugated secondary antibodies (Dako, Denmark) were applied for $60 \mathrm{~min}$ at RT on a rocker. After $3 \times 10 \mathrm{~min}$ TBST wash, the immunoreactive protein was visualized by enhanced chemiluminescence. Remaining antibodies were removed by washing with TBST, then anti-glyceraldehyde 3-phosphate dehydrogenase antibody (Dako, Denmark) was added to the membrane for $60 \mathrm{~min}$ at RT. Secondary antibody $(1: 10,000)$ was also applied for $60 \mathrm{~min}$ at RT then signals were recorded as described earlier.

\section{Migration assays}

HGMs (125,000 cells) were seeded onto six-well plates and allowed to adhere overnight in full media. On the following day, the confluent monolayer was gently scratched using a P2 tip. Only the wells containing even-sided and sharp-edged wounds were used for experiments. After gentle washing for three times with serum-free media, wounds were measured and photographed under inverted light microscope. Reagents were then added to the wells in serum-free media in all of the experiments and plates were incubated in $\mathrm{CO}_{2}$ incubator at $37^{\circ} \mathrm{C}$ for $24 \mathrm{~h}$. Migration was evaluated by counting the cells in the same area of the wound after 12 and $24 \mathrm{~h}$ as reported earlier [43].

\section{Proliferation assays}

Myofibroblasts $(50,000$ cells $)$ were seeded onto cover glasses. After overnight incubation, HGMs were synchronized by incubation for $30 \mathrm{~h}$ in serum-free media. Thereafter, $10 \mu \mathrm{M}$ 5-ethynyl-2-deoxyuridine (EdU; Alexa Fluor 488 Imaging Kit, Invitrogen, Oregon, USA; for further details, see reference [50]) was added to the cells for overnight incubation with or without treatment. After incubation, the manufacturer's protocol was applied to fix and permeabilize the cells and to detect EdU incorporation. We used DAPI to detect nuclear staining. The proliferation rate was calculated by normalizing the number of EdU positive cells to the DAPI-stained cells in 10 fields at $20 \mathrm{x}$ magnification.

\section{Statistical analysis}

Values are expressed as means \pm standard error of mean (SEM). Statistical analyses were performed using nonparametric Kruskal-Wallis tests with post-hoc Wilcoxon tests for pairwise comparisons and Bonferroni correction to test post-hoc significance. $p<0.05$ was accepted as significant. $n$ numbers are given as follows: $n=$ number of patients/number of independent experiments per patient. 


\section{Results}

Identification of myofibroblasts

Cells showed positive staining for $\alpha$-SMA and vimentin but not for cytokeratin and desmin, which are characteristics of myofibroblasts (Fig. 1). The purity of the HGM cell cultures was $\sim 100 \%$. As positive controls for cytokeratin and desmin antibodies, we used CAPAN-1 (human pancreatic adenocarcinoma cell line) cells and cultured human high grade pancreatic neuroendocrine carcinoma cells, respectively. In both cases, appropriate localisation was demonstrated (Fig. 1).
Determination of the resting $\mathrm{pH}_{\mathrm{i}}$ of $\mathrm{HGMs}$

The multiple-point calibration technique utilizing high $\mathrm{K}^{+}$-HEPES/nigericin solution was used to determine the resting $\mathrm{pH}_{\mathrm{i}}$ of HGMs. Our experiments showed that the resting $\mathrm{pH}_{\mathrm{i}}$ of HGMs in HEPES solution was $7.09 \pm 0.02$ (Fig. 2).

Characterization of the acid/base transporters of HGMs

Next we tried to identify the functionally active acid/base transporters expressed on the plasma membrane of HGMs. $\mathrm{Na}^{+}$withdrawal from the standard HEPES solution

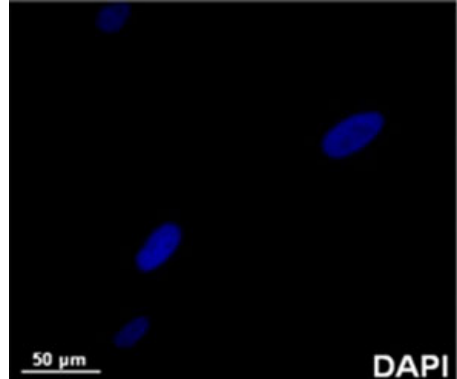

$$
\underline{50 \mu m}
$$

DAP

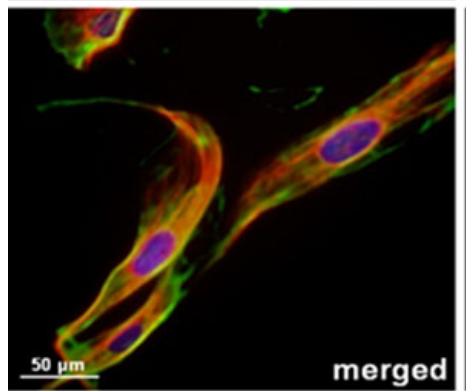

merged
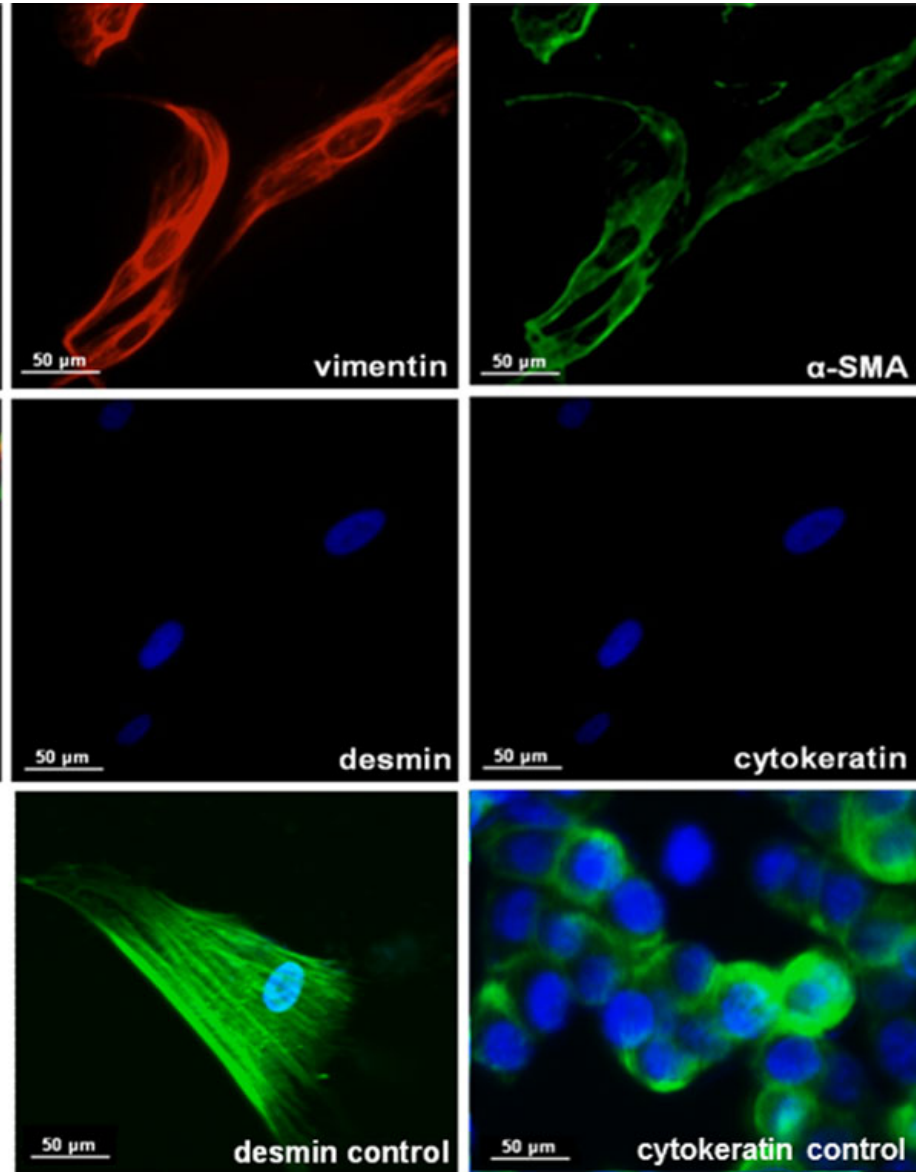

Fig. 1 Immunocytochemical identification of cell cultures. Cells isolated from human gastric samples were grown on chamber slides and were subjected to immunocytochemical analysis of vimentin and $\alpha$-smooth muscle actin ( $\alpha$-SMA) expression as specific markers of myofibroblasts. Cytokeratin and desmin antibodies were used for detecting epithelial and muscle cells, respectively. Nuclei were counterstained with DAPI (blue). Vimentin (red) and $\alpha$-SMA (green) verified the presence of myofibroblasts, whereas no epithelial or smooth muscle cells were detected $(n=5 / 1-2)$. Control stainings were performed to test the desmin and cytokeratin antibodies. Cultured cancer cells (from human high grade pancreatic neuroendocrine carcinoma) were used as positive controls for desmin (green staining, $n=1$ ). To test the cytokeratin antibody, control staining was performed on CAPAN-1 (human pancreatic adenocarcinoma cell line) cells. Green staining shows cytokeratin; blue staining shows DAPI $(n=1)$ 
Fig. 2 The resting $\mathrm{pH}_{\mathrm{i}}$ of gastric myofibroblasts and measurement of buffering capacity. A Human gastric myofibroblasts (HGMs, 100,000) were seeded onto cover glass to form monolayers. Cells were allowed to recover for $24 \mathrm{~h}$. a Phase contrast image of myofibroblasts is shown. Four to seven cells as regions of interests (ROIs) were marked. b Thermaladjusted image is shown to demonstrate homogenous BCECF dye distribution. Color coding shows the $\mathrm{pH}_{\mathrm{i}} ; \mathbf{c} 490$ and d $440 \mathrm{~nm}$ fluorescent images are also shown. e Cells were excited at wavelengths of 490 and $440 \mathrm{~nm}$ after loading the cells with the $\mathrm{pH}$-sensitive fluorescent dye $2 \mu \mathrm{M}$ BCECF-AM, and the 490:440 fluorescence emission ratio was measured at $535 \mathrm{~nm}$. Cells were exposed to continuous perfusion with nigericin/high $\mathrm{K}^{+}$-HEPES solutions of $\mathrm{pH} 6.80$ and 7.40 . The resting $\mathrm{pH}_{\mathrm{i}}$ was calculated by multiple-point calibration $(n=5 / 5-6)$. The figure shows a representative calibration curve; the mean resting $\mathrm{pH}_{\mathrm{i}}$ in standard HEPES solution was $7.09 \pm 0.02$. B The buffering capacity of HGMs was determined by exposing the cells to various concentrations of $\mathrm{NH}_{4} \mathrm{Cl}$ while $\mathrm{Na}^{+}$and $\mathrm{HCO}_{3}{ }^{-}$were omitted from the solution to block $\mathrm{Na}^{+}$-dependent $\mathrm{pH}$ regulatory mechanisms. The intrinsic buffering capacity $\left(\beta_{\mathrm{i}}\right)$ at different $\mathrm{pH}_{\mathrm{i}}$ (black circle, $n=85$ ) was estimated by the Henderson-Hasselbalch equation. Regression analysis was performed using the curve-fitting protocol in Excel. The total buffering capacity ( $\left.\beta_{\text {total }}\right)$ was calculated as $\beta_{\text {total }}$ $=\beta_{\mathrm{i}}+\beta_{\mathrm{HCO}_{3}}{ }^{-}=\beta_{\mathrm{i}}+2.3 \times$ $\left[\mathrm{HCO}_{3}{ }^{-}\right]_{\mathrm{i}}$, where $\mathrm{BHCO}_{3}{ }^{-}$is the buffering capacity of the $\mathrm{HCO}_{3}{ }^{-} / \mathrm{CO}_{2}$ system and $\left[\mathrm{HCO}_{3}\right]_{\mathrm{i}}$ is the intracellular concentration of $\mathrm{HCO}_{3}{ }^{-}$
A

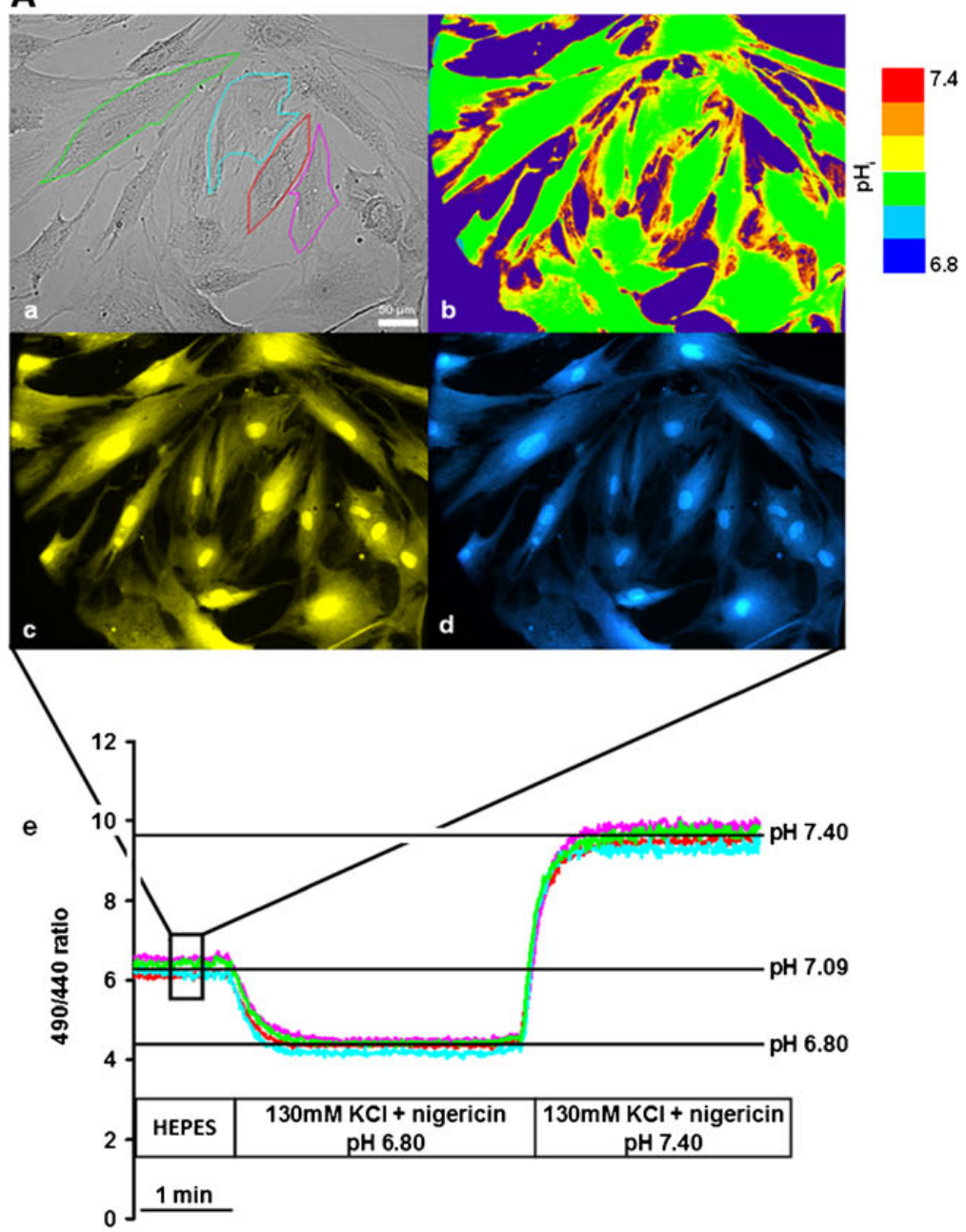

B

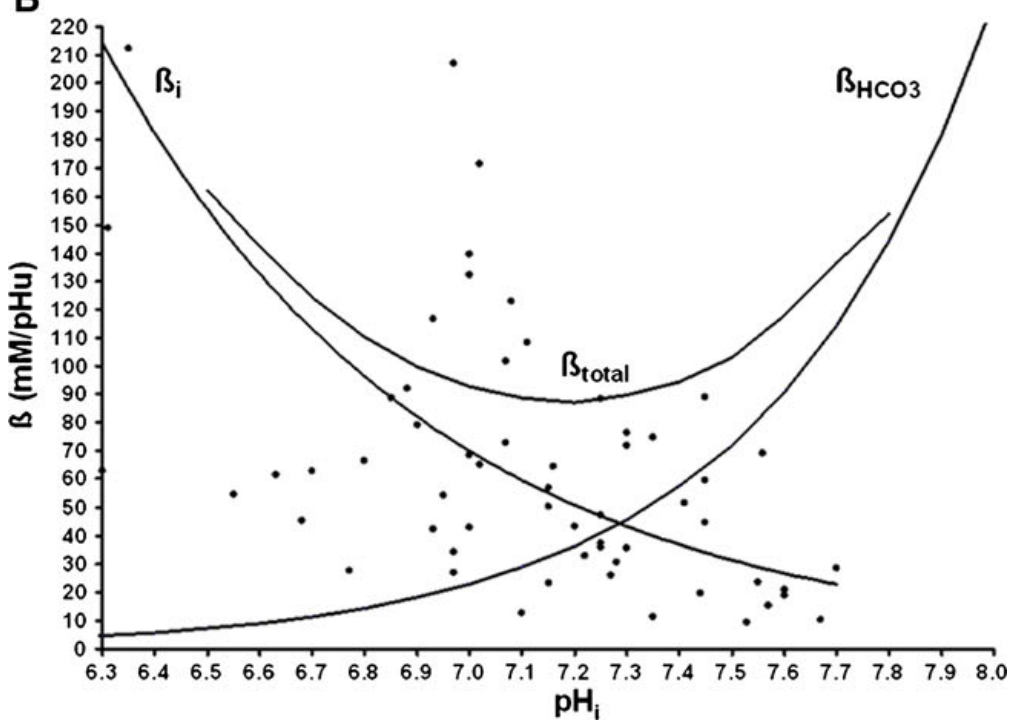


caused strong reversible acidification suggesting the presence of an active $\mathrm{Na}^{+}$-dependent $\mathrm{H}^{+}$efflux mechanism (Fig. 3a).

Switching the standard HEPES solution to standard $\mathrm{HCO}_{3}{ }^{-} / \mathrm{CO}_{2}$ solution caused rapid intracellular acidification, most probably due to $\mathrm{CO}_{2}$ diffusion into the cells. Thereafter, a small $\mathrm{pH}_{\mathrm{i}}$ recovery was observed suggesting a $\mathrm{HCO}_{3}{ }^{-}$ influx and/or $\mathrm{H}^{+}$efflux mechanism (Fig. 3b). In order to determine the $\mathrm{Na}^{+}$dependency of this $\mathrm{HCO}_{3}{ }^{-}$influx $/ \mathrm{H}^{+}$ efflux mechanism, the same experiment was performed in $\mathrm{Na}^{+}$-free conditions (Fig. 3c). Since no recovery was found in the presence of $\mathrm{HCO}_{3}{ }^{-} / \mathrm{CO}_{2}$ in $\mathrm{Na}^{+}$-free solution, we can assume that the $\mathrm{HCO}_{3}{ }^{-}$influx $/ \mathrm{H}^{+}$efflux mechanism in HGMs is $\mathrm{Na}^{+}$-dependent. These results indicate that HGMs express functionally active NHE and/or NBC.

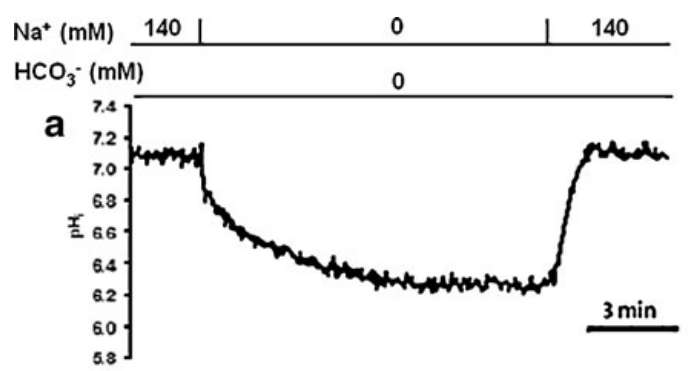

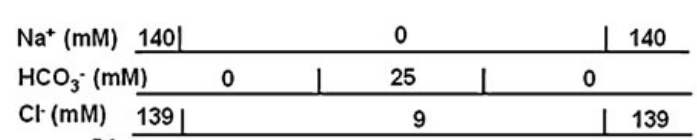

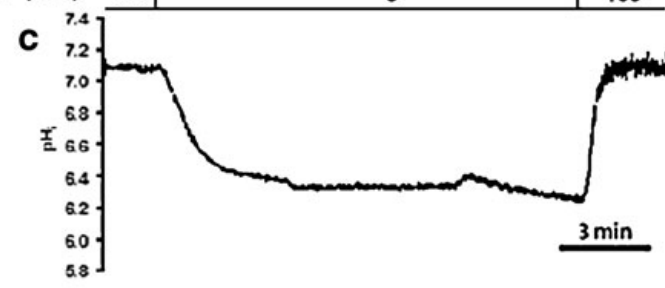

Next we tested whether HGMs contain functionally active anion exchangers (AE). $\mathrm{Cl}^{-}$removal from the standard $\mathrm{HCO}_{3}{ }^{-} / \mathrm{CO}_{2}$ solution caused reversible alkalization suggesting the presence of a $\mathrm{Cl}^{-}$-dependent $\mathrm{HCO}_{3}{ }^{-}$efflux mechanism (Fig. 3d). Importantly, omitting $\mathrm{HCO}_{3}^{-}$from the extracellular solution in combination with $\mathrm{Cl}^{-}$removal resulted in no significant change in $\mathrm{pH}_{\mathrm{i}}$ (Fig. 3e). This indicates that HGMs express functionally active AE.

To confirm these findings, the activities of acid/base transporters were also investigated by the ammonium pulse technique. Exposure of $\mathrm{HGMs}$ to $20 \mathrm{mM} \mathrm{NH}_{4} \mathrm{Cl}$ induced an immediate rise in $\mathrm{pH}_{\mathrm{i}}$ due to the rapid entry of the lipophilic base, $\mathrm{NH}_{3}$, into the cells, which binds intracellular protons generating $\mathrm{NH}_{4}^{+}$and causing alkalization. The recovery from this alkali load is promoted by AEs in the
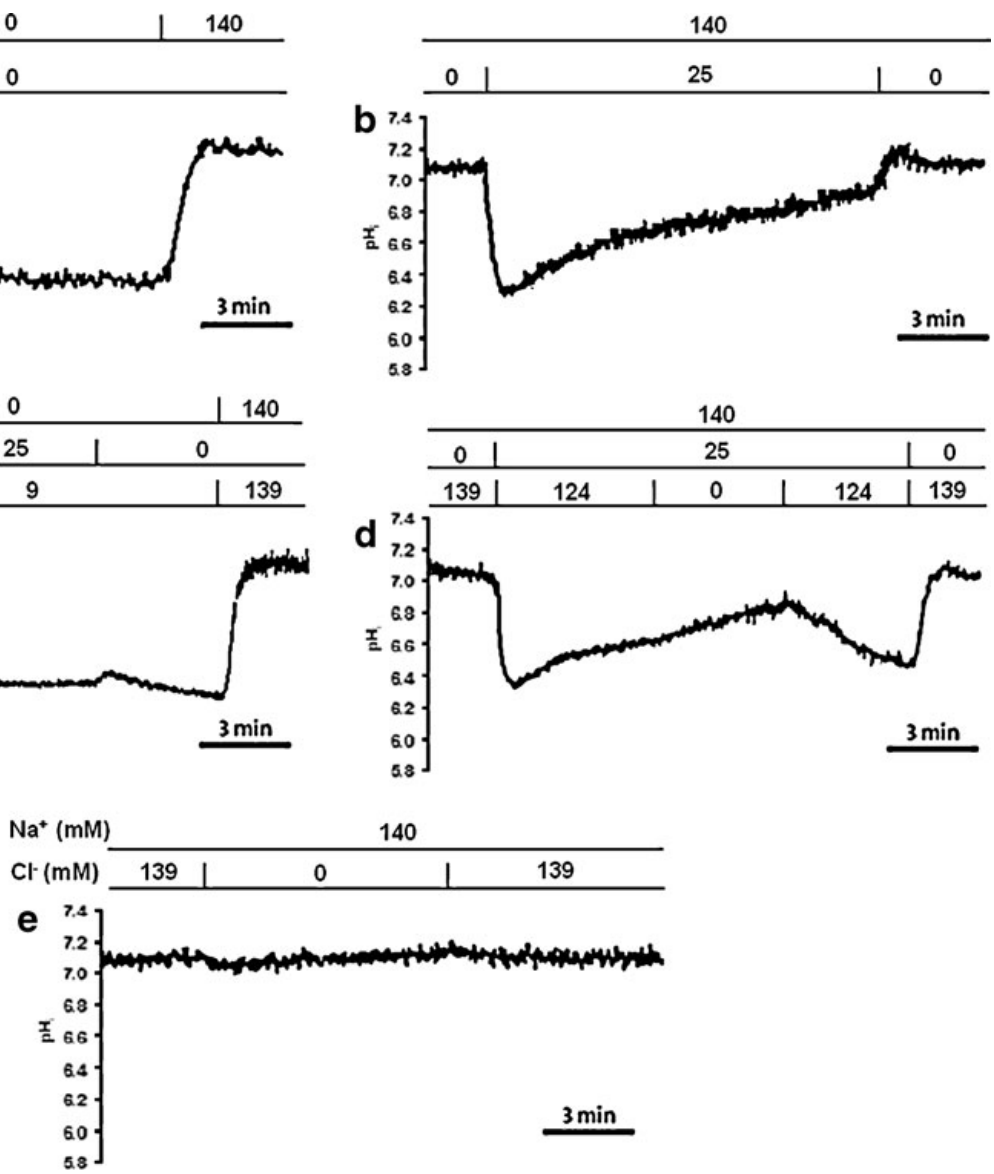

Fig. $3 \mathrm{Na}^{+}$-dependent $\mathrm{HCO}_{3}{ }^{-}$influx and $\mathrm{Cl}^{-}$-dependent $\mathrm{HCO}_{3}{ }^{-}$ efflux mechanisms are present in HGMs. Representative $\mathrm{pH}_{\mathrm{i}}$ curves of HGMs are shown. a The sudden removal of extracellular $\mathrm{Na}^{+}$from the standard HEPES solution caused rapid acidification, which was reversed by the re-addition of the ion. $\mathbf{b}$ Administration of $\mathrm{HCO}_{3}^{-}$ $\mathrm{CO}_{2}$-buffered solution after standard HEPES solution caused acidification of $\mathrm{pH}_{\mathrm{i}}$ followed by alkalization $\left(\mathrm{HCO}_{3}{ }^{-}\right.$influx). c Switching from $\mathrm{Na}^{+}$-free HEPES solution to $\mathrm{Na}^{+}$-free $\mathrm{HCO}_{3}{ }^{-} / \mathrm{CO}_{2}$-buffered solution caused acidification, but no $\mathrm{pH}_{\mathrm{i}}$ recovery was seen. d In $\mathrm{HCO}_{3}{ }^{-} / \mathrm{CO}_{2}$-buffered solution, $\mathrm{Cl}^{-}$removal resulted in alkalization of $\mathrm{pH}_{\mathrm{i}}$ followed by a complete recovery after re-addition of $\mathrm{Cl}^{-}$. e $\mathrm{Cl}^{-}$ removal from the standard HEPES solution did not alter significantly the $\mathrm{pH}_{\mathrm{i}}$, and it reached again the resting value before re-addition of $\mathrm{Cl}^{-}(n=5 / 5-6)$ 
presence of $\mathrm{HCO}_{3}{ }^{-}$and $\mathrm{Cl}^{-}$in the extracellular solution. In support of this, the recovery from alkali load was much steeper in the presence of $\mathrm{HCO}_{3}{ }^{-} / \mathrm{CO}_{2}$ (Fig. 4c, d) compared with the absence (Fig. $4 \mathrm{a}, \mathrm{b}$ ) of $\mathrm{HCO}_{3}{ }^{-} / \mathrm{CO}_{2}$. It is worth mentioning that the slow uptake of $\mathrm{NH}_{4}{ }^{+}$is also a prerequisite for the acid loading. After the removal of $\mathrm{NH}_{4} \mathrm{Cl}, \mathrm{NH}_{3}$ diffuses out of the cell, therefore facilitating the dissociation of intracellular $\mathrm{NH}_{4}{ }^{+}$to $\mathrm{H}^{+}$and $\mathrm{NH}_{3}$, which rapidly decreases $\mathrm{pH}_{\mathrm{i}}$. Thereafter, the $\mathrm{pH}_{\mathrm{i}}$ starts to recover after this acidification owing to activation of $\mathrm{pH}_{\mathrm{i}}$ regulatory mechanisms namely the NHE, NBC and proton pumps (PP; Fig. 4c). In the absence of extracellular $\mathrm{HCO}_{3}{ }^{-}$and in the presence of $\mathrm{Na}^{+}$, the recovery from acidosis reflects the activity of NHE and PP (Fig. 4a). However, the lack of recovery in the absence of $\mathrm{Na}^{+}$excludes functionally active $\mathrm{PP}$ in HGMs (Fig. 4b). The addition of $\mathrm{HCO}_{3}{ }^{-}$to the extracellular solution strongly increases the $\mathrm{pH}_{\mathrm{i}}$ recovery from acidosis (Fig. 4c). Since there is no $\mathrm{pH}_{\mathrm{i}}$ recovery from acidosis in $\mathrm{Na}^{+}$- and $\mathrm{HCO}_{3}{ }^{-}$-free solution (Fig. 4d), it is assumed that the $\mathrm{HCO}_{3}{ }^{-}$influx mechanism is most probably accomplished by the $\mathrm{Na}^{+}$-dependent $\mathrm{NBC}$. Therefore, we tested the effects of the NBC inhibitor $\mathrm{H}_{2}$ DIDS in $0.5 \mathrm{mM}$ concentration and the NHE1 and NHE2 inhibitor HOE-642 at $50 \mu \mathrm{M}$ on the recovery rates during and following an acid load in $\mathrm{HCO}_{3}{ }^{-} / \mathrm{CO}_{2}$-buffered solution (Fig. 4). We calculated $J\left(\mathrm{~B}^{-}\right)$from these and from the above experiments (Fig. 4) and found that NBC inhibition greatly reduced $\mathrm{pH}_{\mathrm{i}}$ recovery after acid load a
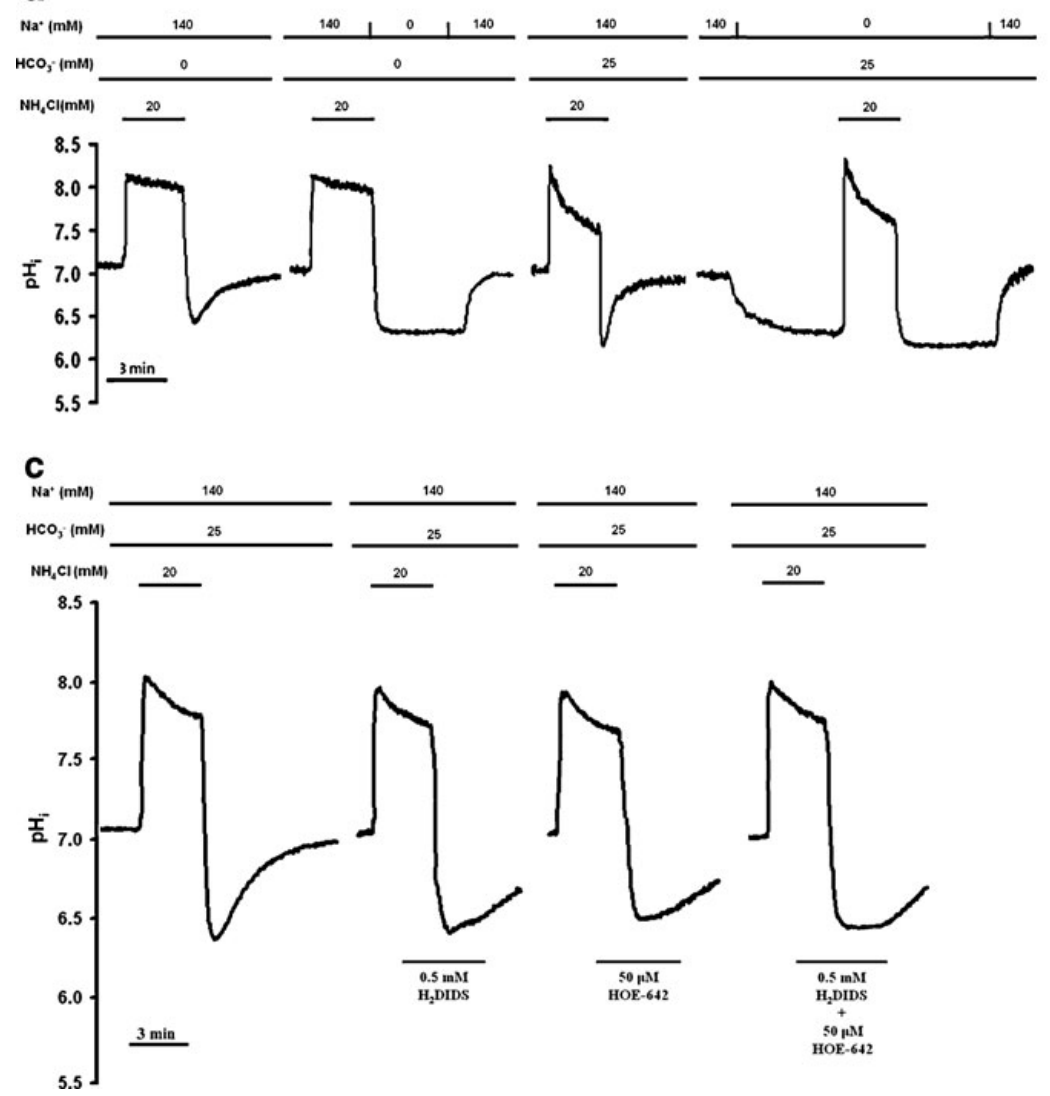

Fig. $4 \mathrm{Na}^{+}$-dependent $\mathrm{H}^{+}$efflux and $\mathrm{Na}^{+}$-dependent $\mathrm{HCO}_{3}{ }^{-}$influx were detected in HGMs a Representative $\mathrm{pH}_{\mathrm{i}}$ curves of HGMs are shown. Cells were exposed to $20 \mathrm{mM} \mathrm{NH}_{4} \mathrm{Cl}$ pulse in HEPESbuffered solution for $3 \mathrm{~min}$. After the acid load, recovery of $\mathrm{pH}_{\mathrm{i}}$ could be observed. However, the administration of $\mathrm{Na}^{+}$-free HEPES solution after the ammonium pulse inhibited $\mathrm{pH}_{\mathrm{i}}$ recovery after the acid load. The same technique was applied in $\mathrm{HCO}_{3}{ }^{-} / \mathrm{CO}_{2}$-buffered solution. Note that the initial phase of the $\mathrm{pH}_{\mathrm{i}}$ recovery during the ammonium pulse is quicker than in HEPES solution and the recovery phase after the acid load is much steeper. Also in $\mathrm{Na}^{+}$-free $\mathrm{HCO}_{3}{ }^{-} / \mathrm{CO}_{2}$-buffered solution, no recovery could be seen after the ammonium pulse. b The bar chart

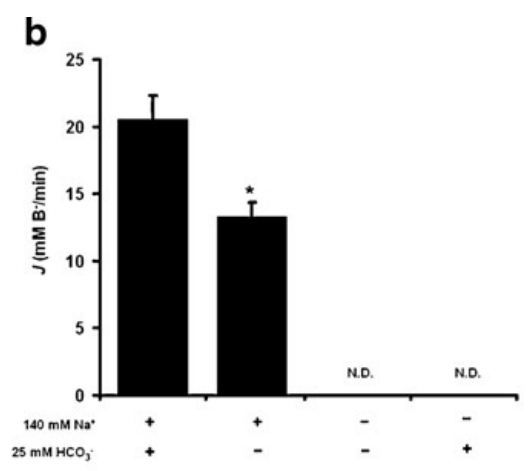

d

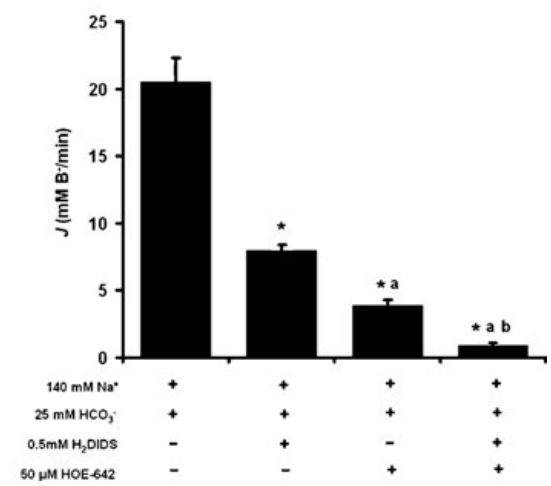

shows the summary data of base fluxes after recoveries from acid load. Values are shown as means \pm SEM $(n=5 / 10-12) .{ }^{*} p<0.05$ vs. $25 \mathrm{mM}$ $\mathrm{HCO}_{3}{ }^{-}$. c Inhibition of $\mathrm{Na}^{+} / \mathrm{HCO}_{3}{ }^{-}$co-transporter (NBC) with $0.5 \mathrm{mM}$ $\mathrm{H}_{2}$ DIDS and/or inhibition of NHE1-2 with $50 \mu \mathrm{M}$ HOE-642 during acid load in $\mathrm{HCO}_{3}{ }^{-} / \mathrm{CO}_{2}$-buffered solution is shown. $\mathbf{d}$ The rates of recovery from acid load were determined and base fluxes were calculated from the experiments shown above. Absolute values are displayed for comparison $(n=5 / 1-2)$; values are shown as means \pm SEM. ${ }^{*} p<0.05$ vs. $140 \mathrm{mM}$ $\mathrm{Na}^{+}, 25 \mathrm{mM} \mathrm{HCO}_{3}^{-} ; \mathbf{a} p<0.05$ vs. $25 \mathrm{mM} \mathrm{HCO}_{3}^{-}+0.5 \mathrm{mM} \mathrm{H}_{2}$ DIDS; b $p<0.05$ vs. $25 \mathrm{mM} \mathrm{HCO}_{3}{ }^{-}+50 \mu \mathrm{M}$ HOE- 642 
(20.54 \pm 1.76 vs. $\left.7.99 \pm 0.39 \mathrm{mM} \mathrm{B}^{-} / \mathrm{min}\right)$ revealing high transporter activity. $50 \mu \mathrm{M}$ HOE-642 further decreased the recovery rate from acidosis $(7.99 \pm 0.39$ vs. $3.91 \pm 0.41 \mathrm{mM}$ $\mathrm{B}^{-} / \mathrm{min}$ ) indicating high NHE1 and NHE2 activities. Simultaneous administration of the two inhibitors resulted in very slow recovery $\left(0.98 \pm 0.09 \mathrm{mM} \mathrm{B}^{-} / \mathrm{min}\right)$. Without $\mathrm{HCO}_{3}{ }^{-} / \mathrm{CO}_{2}$ buffering in standard HEPES solution, cells showed much slower recovery than with bicarbonate buffering ( $13.36 \pm 0.41$ vs. $\left.20.54 \pm 1.76 \mathrm{mM} \mathrm{B}^{-} / \mathrm{min}\right)$. As seen on Fig. 4b, d, eliminating $\mathrm{Na}^{+}$from the extracellular solution inhibited the cells to recover from an acid load in both $\mathrm{HCO}_{3}{ }^{-} / \mathrm{CO}_{2}$-buffered solution and in standard HEPES solution.

Next, we focused our attention on characterizing the NHE isoforms expressed on the plasma membrane of HGMs. The HGMs were acid-loaded by exposure to a 3-min pulse of $20 \mathrm{mM} \mathrm{NH}_{4} \mathrm{Cl}$ in HEPES solution followed by a 5-min exposure to $\mathrm{Na}^{+}$-free HEPES solution (Fig. 5a). Since neither $\mathrm{Na}^{+}$nor $\mathrm{HCO}_{3}^{-}$was present in the extracellular solution, acid/base transporters were inhibited and the $\mathrm{pH}_{\mathrm{i}}$ was adjusted to a stable acidic level. NHE activity was induced by the re-addition of extracellular $\mathrm{Na}^{+}$and the activity of NHEs was determined by measuring the initial rates of $\mathrm{pH}_{\mathrm{i}}$ recovery over the first $60 \mathrm{~s}$ (60 data points). The activities of the different NHE isoforms were determined by using the isoform selective NHE inhibitor HOE-642 (cariporide). At $1 \mu \mathrm{M}$ HOE642 inhibits NHE1 whereas at $50 \mu \mathrm{M}$ it inhibits both NHE1 and NHE2, but not NHE3 [69].

Our data indicate that NHE1 is responsible for about $85 \%$ of the $\mathrm{Na}^{+} / \mathrm{H}^{+}$exchange activity, whereas NHE2 activity is around $10 \%$ and the remaining NHE activity is approximately 5\% (Fig. 5b). Of course, we cannot exclude the possibility of the involvement of other NHEs. However, even if they were expressed, they would only have marginal influence on $\mathrm{H}^{+}$efflux.

mRNA and protein expression of NHE1-3 in HGMs

Based on results of the functional measurements, we investigated the presence of NHE transporters at the mRNA and protein levels. Reverse transcription polymerase chain reaction confirmed the expression of NHE1, NHE2 and NHE3 (Fig. 5c). We also analysed the expression of NHE isoforms in HGMs by Western blot. We found that NHE1 is present in HGMs, but we were unable to show NHE2 and NHE3 expression. Positive controls (human kidney) confirmed that the antibodies used for these studies were fit for purpose (Fig. 5d). We speculate that NHE2 and NHE3 protein abundance is low in our lysates so below the limit of detection. Using immunocytochemistry, we demonstrated NHE1-3 localisation to the plasma membrane of HGMs (Fig. 5e).
IGF-II and carbachol increases NHE activity

We then investigated the effects of IGF-II and carbachol on the activities of NHEs. Importantly, both IGF-II and carbachol dose-dependently stimulated NHE activity. Carbachol concentrations were tested in range of $1-1,000 \mu \mathrm{M}$. Carbachol $(10 \mu \mathrm{M}) \mathrm{had}$ the greatest effect on NHE activity. $100 \mathrm{ng} / \mathrm{ml}$ IGF-II was more effective than $10 \mathrm{ng} / \mathrm{ml}$ in increasing NHE activity (Fig. 6).

Migration of HGMs is stimulated by carbachol and IGF-II

Next, we investigated the effects of carbachol and IGF-II on cell migration and the role of NHE1 in migration of HGMs using scratch wound assay. We found that both $100 \mathrm{ng} / \mathrm{ml}$ IGF-II and $10 \mu \mathrm{M}$ carbachol stimulate the migration of HGMs (Fig. 7). Inhibition of NHE1 by HOE-642 had no effect on unstimulated cell migration, but it significantly inhibited both carbachol- and IGF-II-stimulated migration (by $29 \pm 7 \%$ and $33 \pm 8 \%$, respectively).

IGF-II increases proliferation in an NHE1-dependent manner

Finally, we tested the effects of HOE-642, IGF-II and carbachol on HGM proliferation. EdU incorporation assays showed that $100 \mathrm{ng} / \mathrm{ml}$ IGF-II increased cell proliferation over two-fold. Carbachol and/or HOE-642 did not affect proliferation. However, NHE1 inhibition by $1 \mu \mathrm{M}$ HOE-642 completely blocked the stimulatory effect of IGF-II on cell proliferation (Fig. 8).

\section{Discussion}

In this study, we have characterized the $\mathrm{pH}_{\mathrm{i}}$ regulatory mechanisms of HGMs for the first time. The data demonstrate that NHE1 activity contributes to IGF-II- and carbacholstimulated migration and that it is obligatory for IGF-IIinduced proliferation of HGMs.

The resting $\mathrm{pH}_{\mathrm{i}}$ of HGMs, $7.09 \pm 0.02$, is similar to that in fibroblasts [12, 28, 46] and smooth muscle cells [64]. Myofibroblasts displayed three main acid/base transporters, namely $\mathrm{NBC}, \mathrm{AE}$ and NHE. These are also the main mechanisms regulating $\mathrm{pH}_{\mathrm{i}}$ in fibroblasts $[2,12,29]$ and in smooth muscle cells [15]. Thus, AE decreases, whereas, NBC and NHE increase $\mathrm{pH}_{\mathrm{i}} . J\left(\mathrm{~B}^{-}\right)$calculations revealed high NBC and high NHE activities which are the main transporters aiding recovery from an acid load in HGMs. In the present study we chose to focus on the roles of NHEs.

Carbachol $(10 \mu \mathrm{M})$ strongly stimulated NHE activity of HGMs. It has been shown that carbachol also increases NHE (and AE) activity in lacrimal gland epithelia [59] and in rabbit 
parietal cells [3]. In the latter study, carbachol strongly increased NHE activity and its effect was completely blocked by $1 \mu \mathrm{M}$ HOE-642 suggesting the involvement of NHE1.
Atropine or intracellular $\mathrm{Ca}^{2+}$ chelation inhibited the activation of NHE indicating a typical muscarinic receptor effect with a $\mathrm{Ca}^{2+}$-dependent signalling pathway $[4,59]$. In the
Fig. 5 Identification of NHE isoforms. a Representative $\mathrm{pH}_{\mathrm{i}}$ curves of HGMs are shown.

Cells were loaded with acid by using the ammonium pulse technique. After $\mathrm{Na}^{+}$

withdrawal, the isoformselective NHE inhibitor HOE-642 was administered in $1 \mu \mathrm{M}$ (inhibits NHE1) or $50 \mu \mathrm{M}$ (inhibits NHE1 and NHE2) concentration, together with re-addition of $\mathrm{Na}^{+}$. The initial rates of the $\mathrm{pH}_{\mathrm{i}}$ recovery during HOE-642 administration were calculated by linear regression analysis to determine the activity of NHE isoforms.

b The bar chart demonstrates that NHE1 is responsible for 83 $\pm 5 \%$, NHE2 for $11 \pm 1 \%$ and other isoforms for $4.5 \pm 0.8 \%$ of all $\mathrm{Na}^{+} / \mathrm{H}^{+}$exchange activity. Data are shown as means \pm SEM $(n=5 / 5-6)$. c Reverse transcription PCR confirmed the expression of NHE1-3 isoforms $(n=3 / 6-7)$. Expected PCR product sizes are as follows: NHE1, 341 bp; NHE2, 407 bp; NHE3, 299 bp. In water blind, we used water as template. d Immunoblot analysis showing different NHE isoforms in HGMs and human kidney controls. Protein sizes are as follows: NHE1, $95 \mathrm{kDa}$; NHE2, $85 \mathrm{kDa}$; NHE3, $75 \mathrm{kDa}$;

GAPDH, $36 \mathrm{kDa}(n=4-5 / 3-10)$.

e NHE1, NHE2 and NHE3

were identified by immunocyto-

chemistry in the plasma

membrane of HGMs. Nuclei

were counterstained with DAPI

(blue staining). No specific

staining was detected when the primary antibody was omitted $(n=3 / 1-2)$

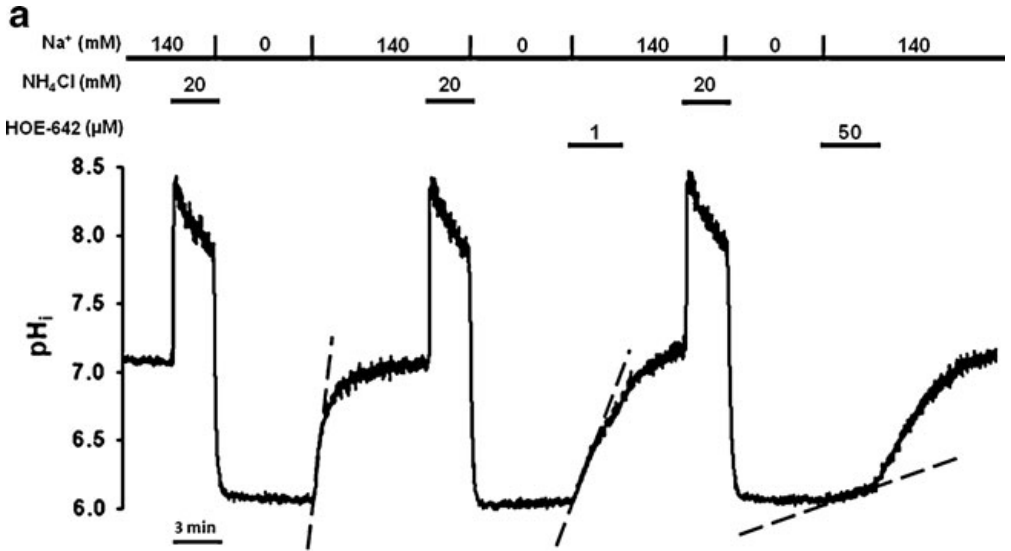

b

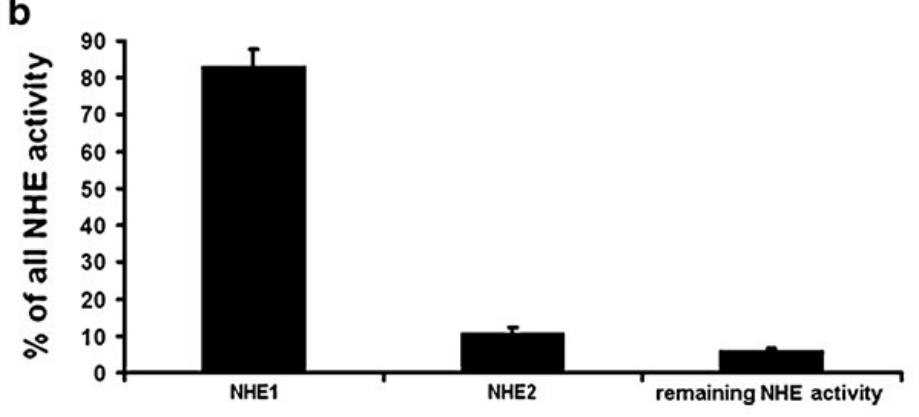

C

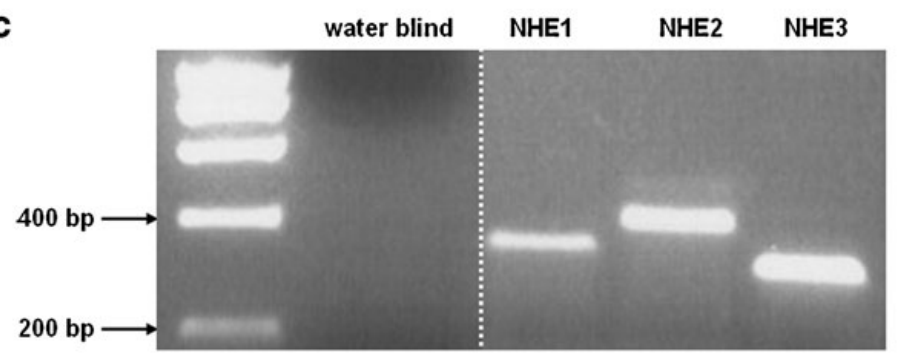

d

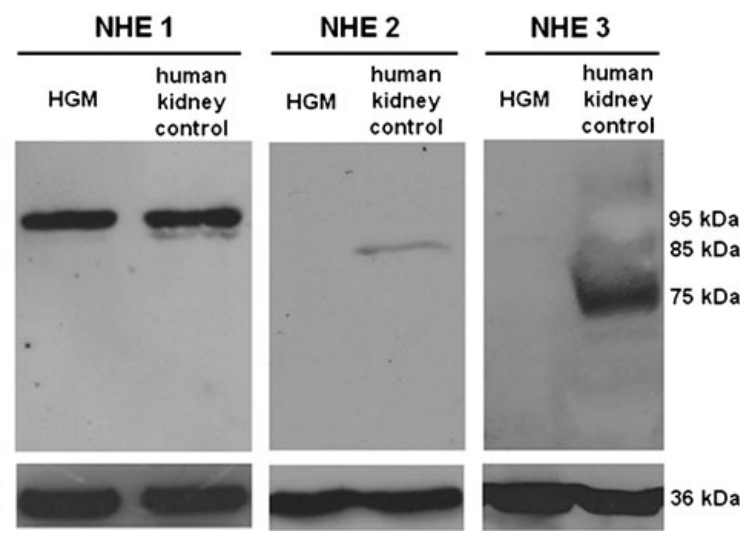



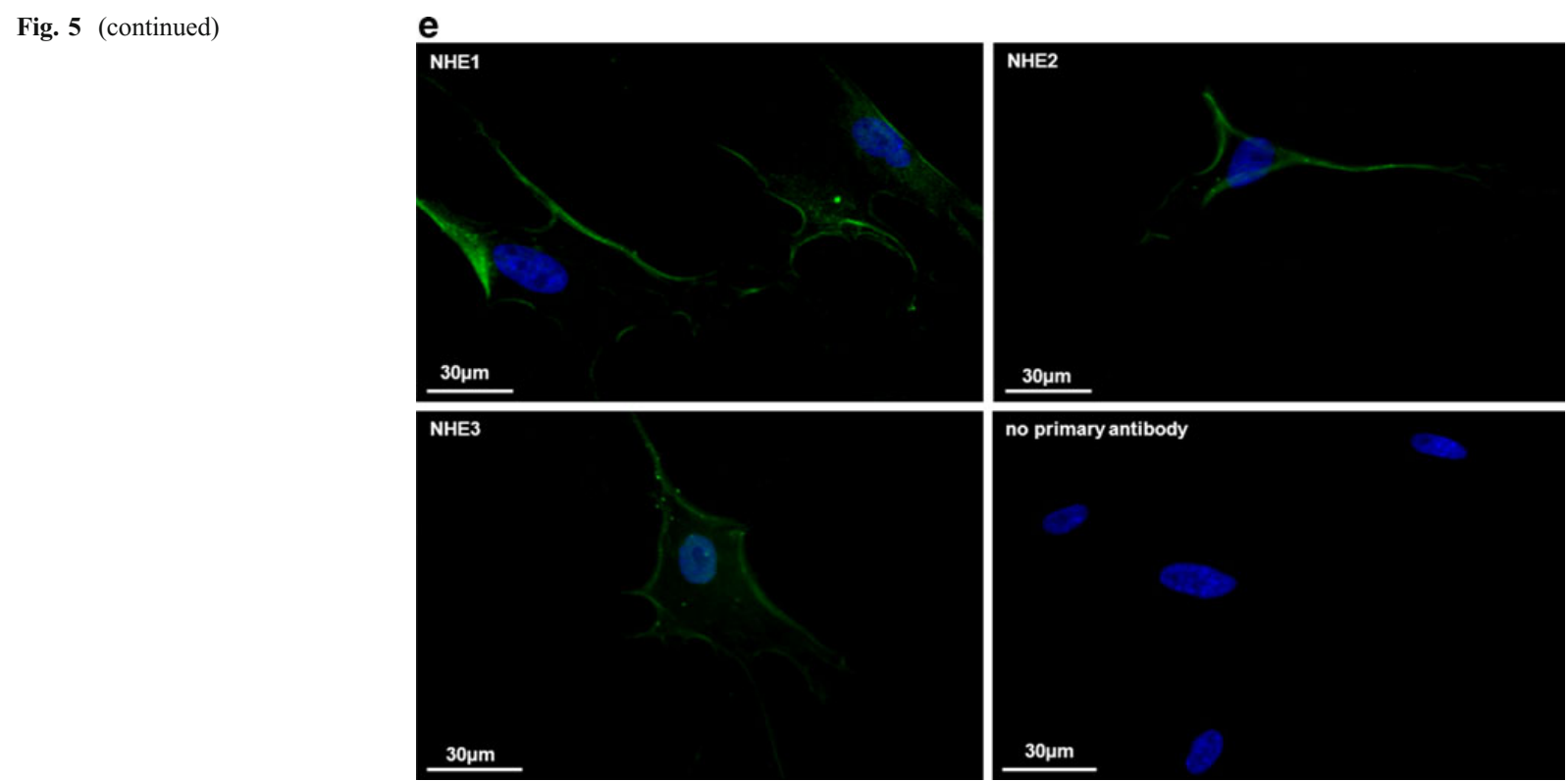

a

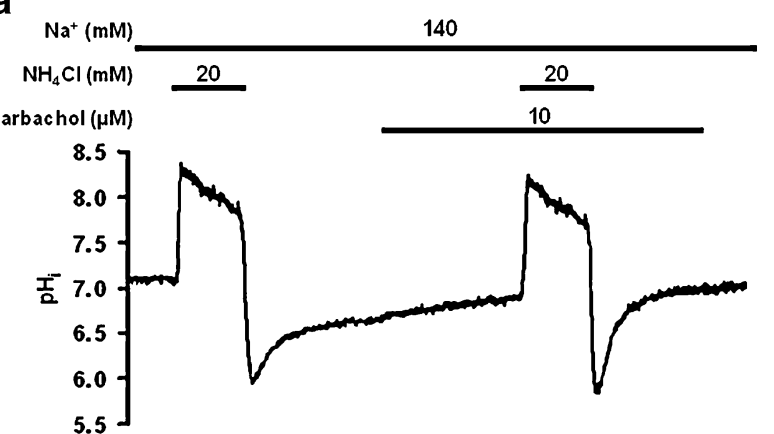

b

$\mathrm{Na}^{+}(\mathrm{mM})$

140

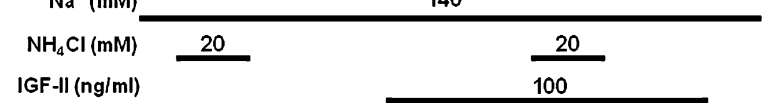

IGF-II (ng/ml)

100
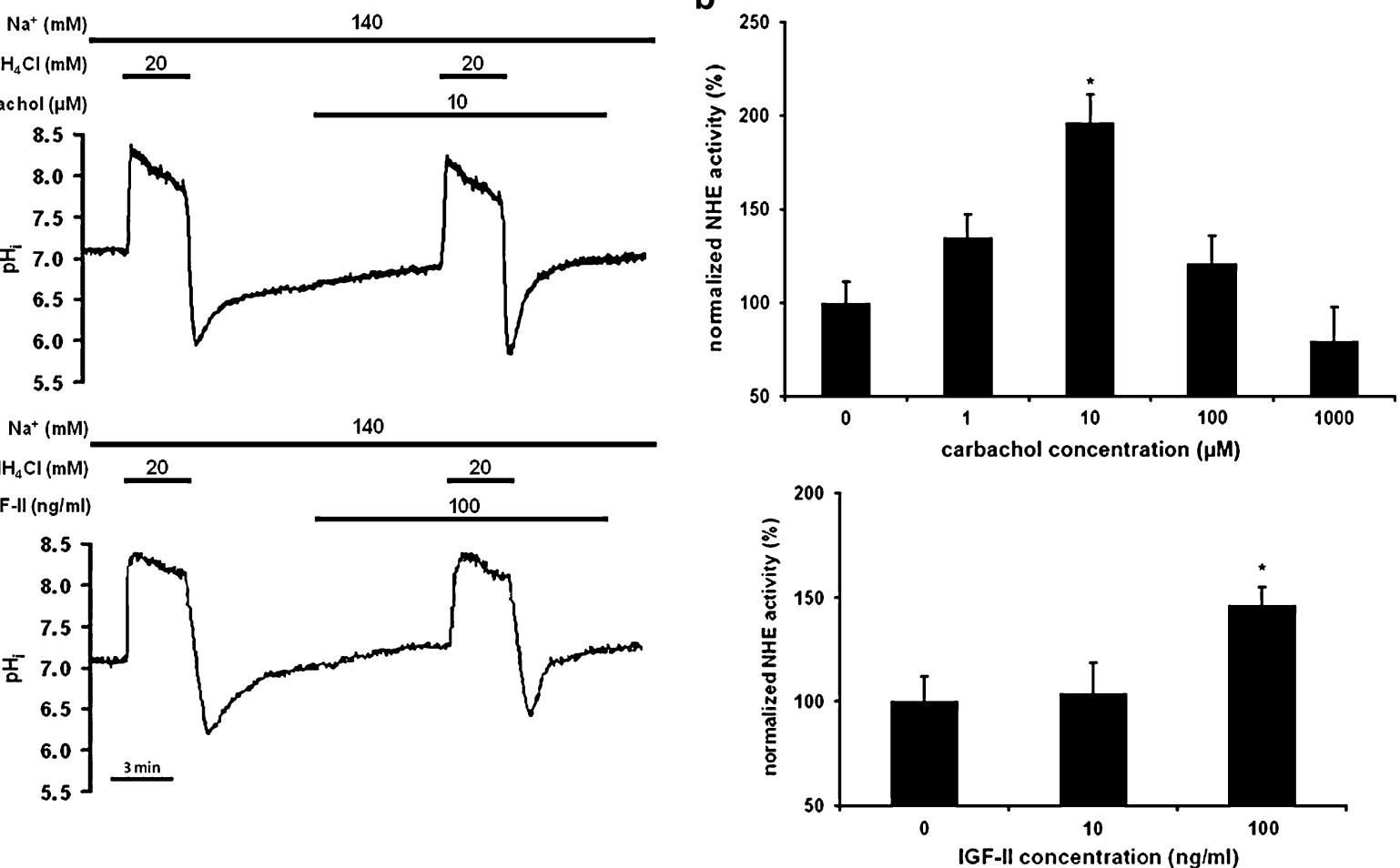

Fig. 6 The effects of carbachol and IGF-II on NHE activity. a Representative $\mathrm{pH}_{\mathrm{i}}$ curves of HGMs are shown. We tested different carbachol and IGF-II concentrations on NHE activity using the ammonium pulse technique. The figure shows the effects of $10 \mu \mathrm{M}$ carbachol and $100 \mathrm{ng} / \mathrm{ml}$ IGF-II treatment. Note that the changes in the rates of $\mathrm{pH}_{\mathrm{i}}$ recovery from acidosis during treatment are much

higher compared with the recovery rates without IGF-II or carbachol treatment. b The bar diagram shows the summary data obtained from the above mentioned experiments. Administration of $10 \mu \mathrm{M}$ carbachol and $100 \mathrm{ng} / \mathrm{ml}$ IGF-II significantly increased NHE activity. Values are normalized to the basal NHE activity. Data are shown as means \pm SEM $(n=5 / 5-6) .{ }^{*} p<0.05$ vs. $0 \mu \mathrm{M}$ or $0 \mathrm{ng} / \mathrm{ml}$ 
a

O hours

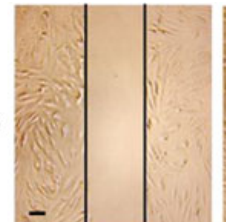

12 hours

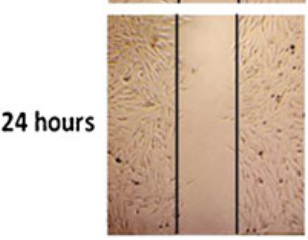

no treatment
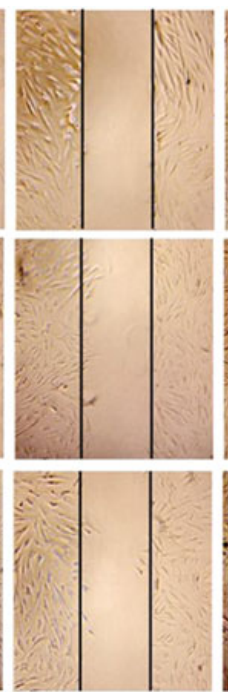

$1 \mu \mathrm{M} \mathrm{HOE}-642$
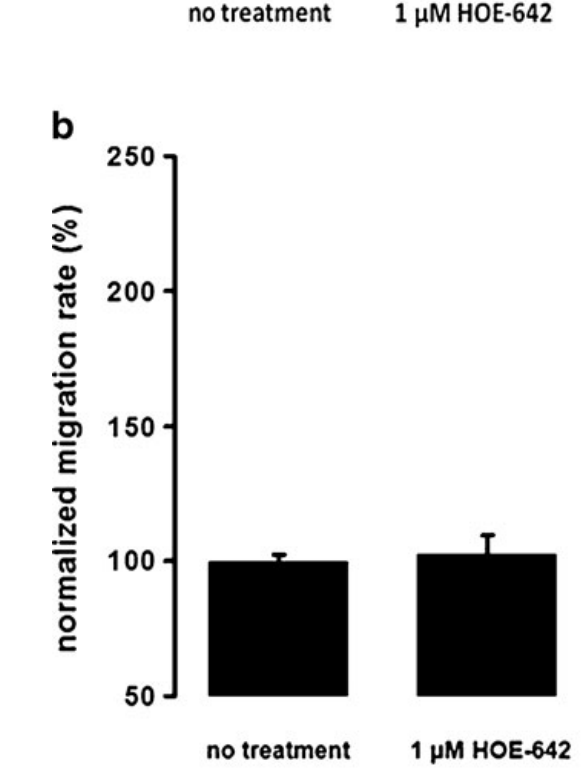

$100 \mathrm{ng} / \mathrm{ml}$ IGF-II
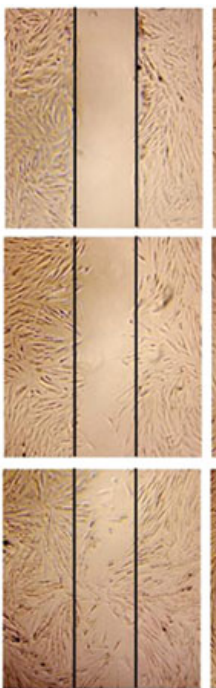

\section{0}

and

$1 \mu \mathrm{M} \mathrm{HOE}-642$
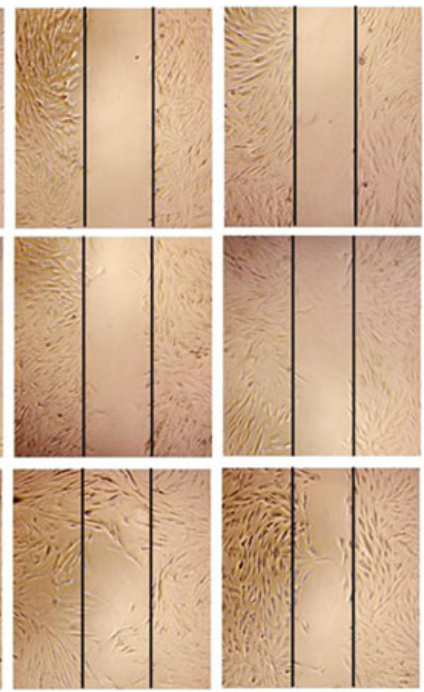

$10 \mu \mathrm{M}$ carbachol

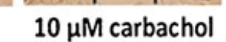

and

$1 \mu \mathrm{M} \mathrm{HOE}-642$

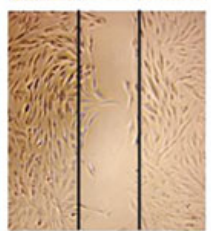

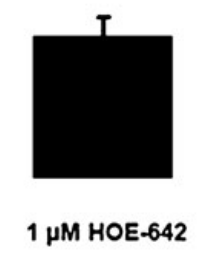
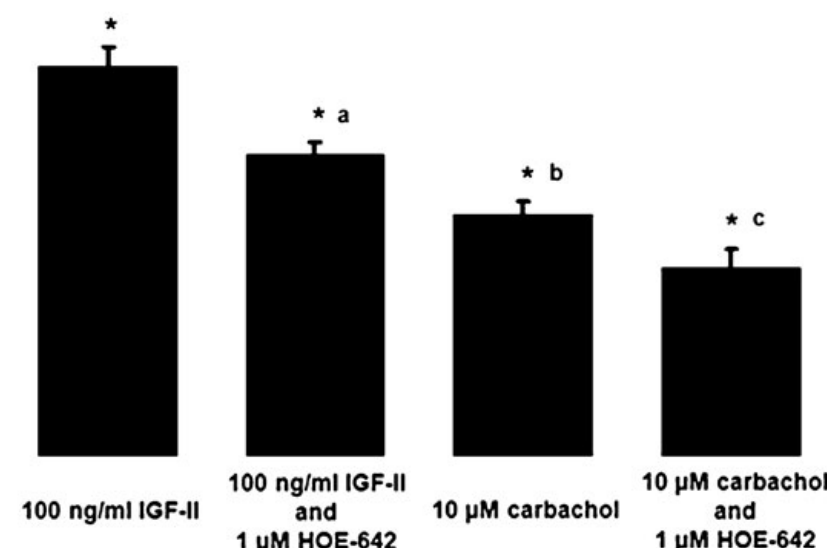

Fig. 7 Carbachol and IGF-II treatment increased migration rates of HGMs in a NHE1-dependent manner. a HGMs $(100,000)$ were cultured in six-well plates. After reaching confluency, the monolayer was wounded by a P2 tip along an oriented line in the middle of the well and detached cells were removed by washing with serum-free media. Only wounds with sharp and even edges were used for experiments. Reagents were added to the wells in serum-free media and the plate was incubated for $24 \mathrm{~h}$ at $37^{\circ} \mathrm{C}, 5 \% \mathrm{CO}_{2}$. Images were

latter publications, the authors suggested that $\mathrm{Ca}^{2+}$-dependent stimulation causes a selective activation of NHE1, whereas cAMP-dependent stimulation with forskolin-activated NHE1, NHE2 and more strongly NHE4. In $\mathrm{HCO}_{3}{ }^{-}$-containing solution, $\mathrm{pH}_{\mathrm{i}}$ did not change indicating that activation of NHE and AE is primarily volume regulatory mechanisms,

taken at 0,12 and $24 \mathrm{~h}$ from representative areas. Cells were treated with or without $10 \mu \mathrm{M}$ carbachol or $100 \mathrm{ng} / \mathrm{ml} \mathrm{IGF-II,} \mathrm{and/or} 1 \mu \mathrm{M}$ HOE-642 and cells which migrated into the wound were counted at 12 and $24 \mathrm{~h}$. The scale bar on the first picture represents $100 \mu \mathrm{m}$. b The bar chart shows the migration rates normalized to the basal rate at $24 \mathrm{~h}$. Values are shown as means \pm SEM, $n=5 / 1-3 ;{ }^{*} p<0.05$ vs. no treatment, $a p<0.05$ vs $100 \mathrm{ng} / \mathrm{ml}$ IGF-II, $b p<0.05$ vs $100 \mathrm{ng} / \mathrm{ml}$ IGF-II and $1 \mu \mathrm{M}$ HOE-642, $c p<0.05$ vs $10 \mu \mathrm{M}$ carbachol

and they speculated that the physiological significance of secretagogue-induced NHE activity may be related to volume and not to $\mathrm{pH}_{\mathrm{i}}$ regulation during acid secretion of rabbit parietal cells [3].

IGF-II, which has been shown to stimulate migration and proliferation of many cell types including myofibroblasts 
a
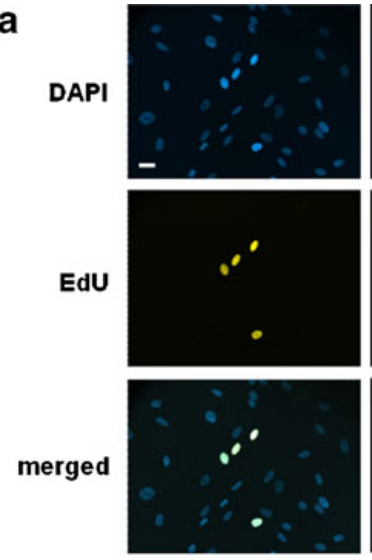

no treatment
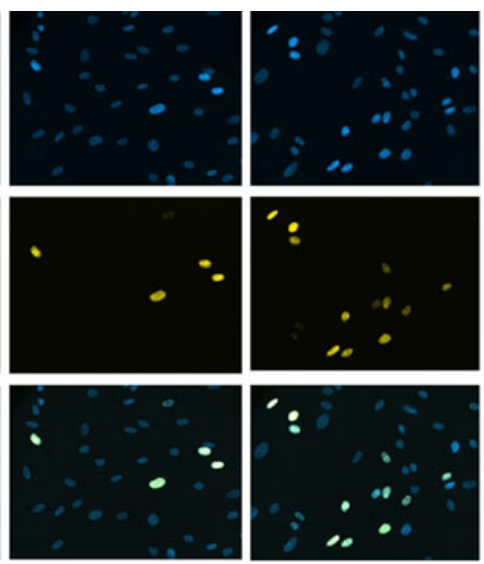

$1 \mu \mathrm{M} \mathrm{HOE-642}$

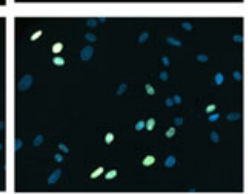

$100 \mathrm{ng} / \mathrm{ml} \mathrm{IGF-II}$
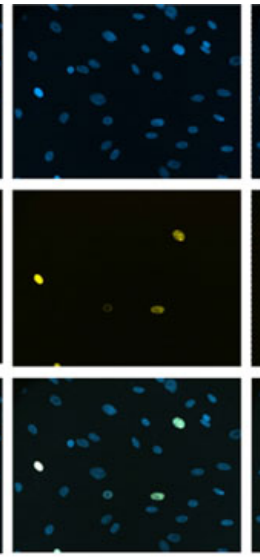

$100 \mathrm{ng} / \mathrm{ml}$ IGF-II

and

$1 \mu \mathrm{M}$ HOE-642
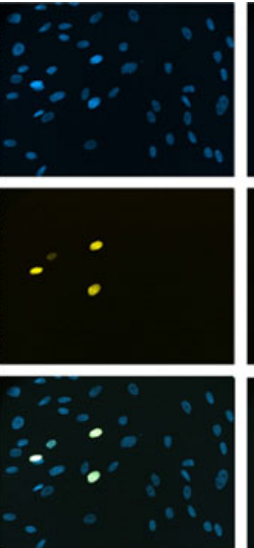

$10 \mu \mathrm{M}$ carbachol
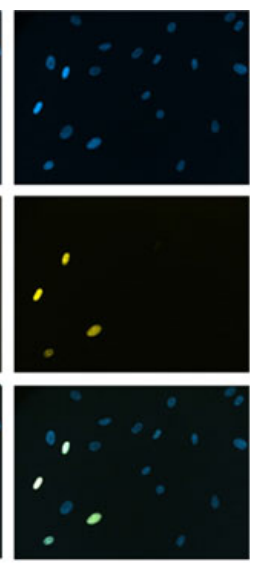

$10 \mu \mathrm{M}$ carbachol and $1 \mu$ M HOE-642

b
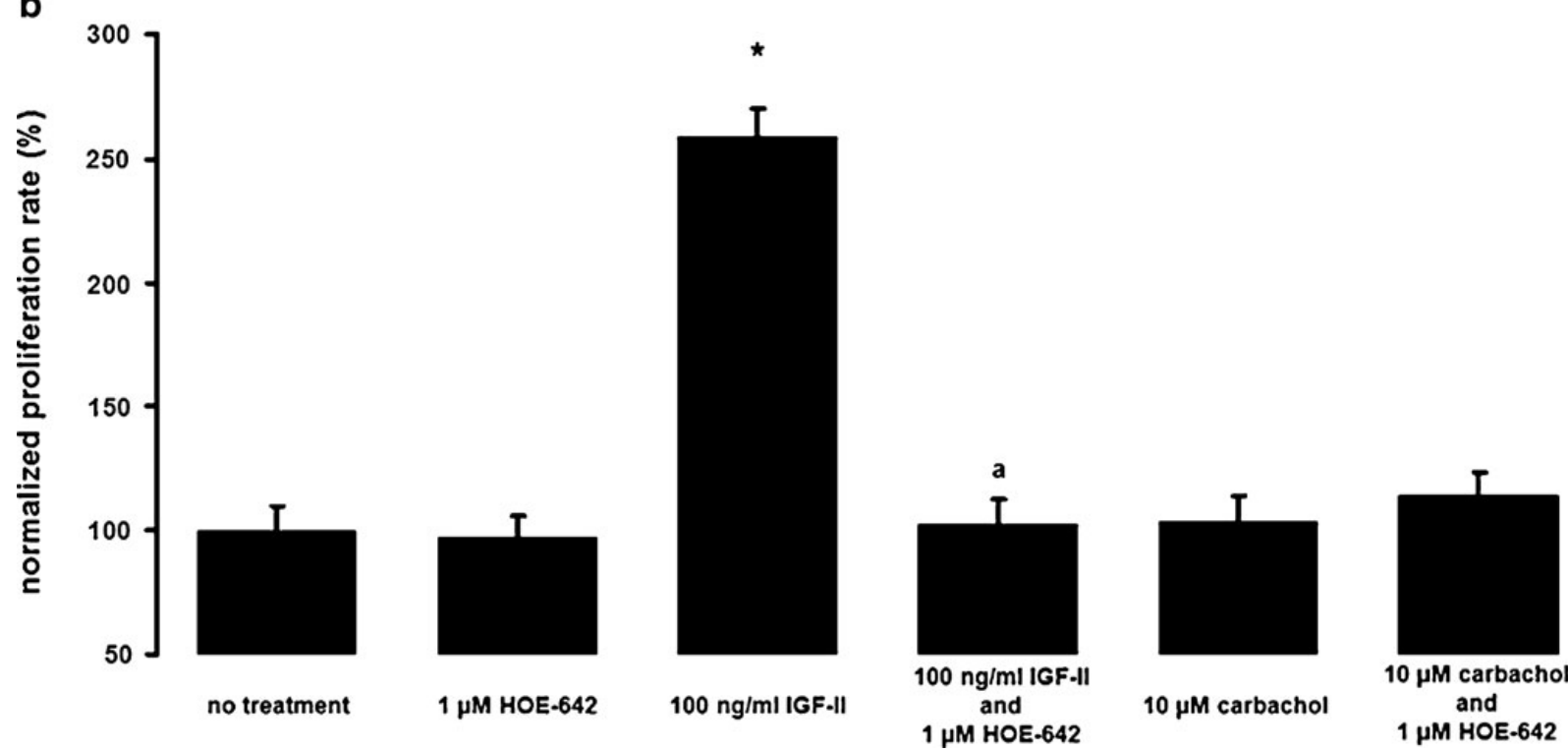

$10 \mu \mathrm{M}$ carbachol

$10 \mu \mathrm{M}$ carbachol and $1 \mu \mathrm{M}$ HOE-642

Fig. 8 IGF-II stimulates the proliferation of HGMs in a NHE1dependent manner. a Representative images showing EdU localisation after treatment with $1 \mu \mathrm{M}$ HOE-642, $100 \mathrm{ng} / \mathrm{ml}$ IGF-II and/or $10 \mu \mathrm{M}$ carbachol compared to control. HOE-642 $(1 \mu \mathrm{M})$ did not affect proliferation either on its own, or in a combination with $10 \mu \mathrm{M}$ carbachol. IGF-II $(100 \mathrm{ng} / \mathrm{ml})$ increased the rate of proliferation. Furthermore, the

inhibition of NHE1 suppressed the IGF-II stimulatory response. Nuclei were counterstained with DAPI (blue staining). The scale bar on the first picture represents $50 \mu \mathrm{m}$. b The bar chart shows the proliferation rates of $a$ normalized to the basal proliferation rate; ${ }^{*} p<0.05, a p<0.05$ vs $100 \mathrm{ng} / \mathrm{ml}$ IGF-II $(n=5 / 1-2)$

[36, 52], also stimulated NHE activity. It is known that IGF-II exerts its effects through the tyrosine kinase receptor IGF-IR and it is also well known that NHE1 is mainly regulated by phosphorylation. Meima et al. reported that IGF-IR activates Ser/Thr kinases in the Akt signalling pathway and increases myofibroblast migration, growth and NHE activity by phosphorylating intracellular NHE regulatory domains thus enhancing transporter activity [37]. The distal region of the cytoplasmic tail of NHE corresponding to

amino acids $700-815$, is enriched in serine and threonin residues that are phosphorylated by different protein kinases in response to hormones and/or growth factors [51]. It has also been suggested that Ser/Thr kinases not only stimulate NHE1 activity, but also increase NHE1 promoter transcription [5]. ERK1/2 regulates gene expression via the MAPK cascade [40] after NHE1 phosphorylation/activation through p $90^{\mathrm{RSK}}$ (a downstream substrate of ERK1/2) [56]. p $90^{\mathrm{RSK}}$ directly phosphorylates NHE1 at position 703(Ser) in vascular

\section{望 Springer}


smooth muscle cells after growth hormone treatment and the exchanger activity was found to be increased [56]. Another important factor in the regulation of NHE is protein 14-3-3, which binds to position 703(Ser) after its phosphorylation and limits dephosphorylation by protein phosphatases [33]. Additional Ser/Thr phosphorylation sites have been recently identified in the ERK pathway, but their importance must be confirmed [35].

Our experiments demonstrate that reagents increasing NHE activity also increase HGM migration and proliferation, so the question arises whether in turn NHE inhibition may inhibit cell migration and proliferation. The effects of parasympathomimetics on cell migration are conflicting, though they are thought to stimulate NHE activity in general. In HaCaT cells, carbachol did not alter single random cell locomotion compared to non-treated cultures [38]. Epidermal keratinocytes showed enhanced migration after long-term muscarinic stimulation with acetylcholine in an agarose gel outgrowth system [18], whereas carbachol treatment arrested wound healing in epidermal keratinocytes [9]. Besides the differences between species and tissues, it seems that various muscarinic receptors can mediate different migration responses even in the same cell [63]. Our experiments clearly showed that $10 \mu \mathrm{M}$ carbachol stimulated migration of HGMs, at least partly in a NHE1-dependent manner, but higher or lower doses had no further effect on migration (data not shown). It is known that protein kinase $\mathrm{C}$ (PKC) might mediate $\mathrm{M} 3$ receptor signals causing PLC to cleave membrane phospholipids. PIP2 is cleaved into diacyl glycerol and IP3 which is released into the cytosol and binds to IP3 receptors localised at the ER (or SR) causing consequent increase of the cytosolic calcium concentration and a cascade of activity including locomotion of contractile cells [1]. M3 receptors, through PLC, may also activate PI3K/Akt cascade. In the context of gastric cancer, it is worth mentioning that apoptosis can be suppressed through the PI3K/Akt/mTOR pathway allowing vigorous proliferation and better survival [68]. PKC modulates gene regulation via NF- $\mathrm{KB}$ and by joining Raf/ MAPK cascade. It has been shown recently that PKC may phosphorylate the potent activation transcription factor-2, which controls c-Jun-mediated activation of transcription [66]. The observed increase in migration in our studies suggests, however, a permissive or supporting role of NHE1 in enabling migratory mechanisms to take effect in response to bioactive compounds. Others have found that not only NHE1 activity, but also intact NHE1 protein structure is required for locomotion, since mutations/modifications of protein structure or inhibition of the exchanger activity also inhibits migration [30]. Notably, NHE1 is a scaffoldingorganizing protein functioning as a transmembrane signal transducer for various agents modulating cell volume, cell migration and growth through NHE1 activity [27]. Muscarinic agonists have also been shown to evoke differential effects on proliferation depending on the type of the muscarinic receptor [63]. We found that the M3 agonist carbachol does not induce proliferation of HGMs.

IGF-II stimulates the proliferation of many cell types, including myofibroblasts $[19,36]$. NHE1 may act as an organizer of different cell growth inducing signals through modulation of transporter activity via receptor tyrosine kinases and joint pathways. Denker et al. reported that NHE1 protein contains an intracellular esrin/radixin/moesin (ERM) motif close to the plasma membrane, which anchors the protein to the subcortical actin filament network and serves as a host to actin polymerization [14]. In a wound healing assay, migration was impaired when mutations disrupted the ERM site. Not only ERM site mutations, but also mutations of the transporter sequence (resulting in diminished NHE1 activity), impair de-adhesion resulting in failure to retract lamellipodia. Besides this membrane anchoring, NHE1 is important in regulating cell volume and local $\mathrm{pH}$ at changing membrane sites of a moving cell; it is known that in fibroblasts NHE1 is most abundant at the rear and front pole of a spatially polarized migrating cell [14].

We showed that inhibition of NHE1 blocks migration and proliferation of HGMs. Since stromal cells play an important role in cancer initiation and progression $[6,13$, 31 , our results may have both physiological and therapeutic relevance. It is well documented that proliferation is reduced by NHE1 inhibition in human cancer cells [20, 49]. However, it is also possible that intracellular alkalization simply promotes or permits proliferative responses, because as the $\mathrm{pH}_{\mathrm{i}}$ becomes more alkaline, cellular metabolism becomes more rapid mainly due to the more effective energy producing mechanisms [20]. For example, in tumour cells, acid/base conditions are of particular importance, because cancer cells share an aberrant intracellular alkalization facilitating their malignant behavior, whereas the microenvironment becomes more acidic [8]. Nevertheless, as mentioned before, NHE1 is highly regulated by phosphorylation and Akt kinases that phosphorylate NHE1 increasing its activity also stimulate proliferation at the same time [17, 34, 54].

In conclusion, we have demonstrated that HGMs express functionally active NHE, NBC and AE transporters which regulate $\mathrm{pH}_{\mathrm{i}}$. Furthermore, we have shown that NHE1 contributes to IGF-II- and carbachol-stimulated migration, and that it is obligatory for IGF-II-induced proliferation.

Acknowledgements We would like to thank Graham Dockray, professor at the Department of Physiology, University of Liverpool (Liverpool, UK) for his kind help and supervision of the molecular biology experiments. We would also like to thank Drs. László Tiszlavicz and István Balázs Németh, pathologists at the Department of Pathology, University of Szeged (Szeged, Hungary) for their continuous technical support and accurate histological evaluations of our gastric tissue specimens. Cariporide was a generous gift from Sanofi-Aventis, 
(Frankfurt, Germany). Our funding sources were Hungarian Scientific Research Fund K76844, K73141, National Development Agency (TÁMOP) 4.2.1.B-09/1/KONV, 4.2.2-08/1/2008-0002 and 4.2.2-08/1/ 2008-0013, Hungarian Academy of Sciences BO/00334/08/5 and BO/ 00174/10/5, NIH PHS398/2590 and NIHR L115931.

Conflict of interest statement The authors hereby declare that there is no conflict of interest to disclose.

\section{References}

1. Alberts B, Alexander J, Julian L, Martin R, Keith R, Peter W (2002) Molecular Biology of the Cell, 4th edn. Garland Science, New York, US

2. Alexandratou E, Dido Y, Panagiotis H, Dimitris K, Spyros L (2002) Human fibroblast alterations induced by low power laser irradiation at the single cell level using confocal microscopy. Photochem Photobiol Sci 8:547-552

3. Bachmann O, Sonnentag T, Siegel WK, Lamprecht G, Weichert A, Gregor M, Seidler U (1998) Different acid secretagogues activate different $\mathrm{Na}+\mathrm{H}+$ exchanger isoforms in rabbit parietal cells. Am J Physiol 275:G1085-G1093

4. Bachmann O, Reichelt D, Tuo B, Manns MP, Seidler U (2006) Carbachol increases $\mathrm{Na}+-\mathrm{HCO} 3-$ cotransport activity in murine colonic crypts in a M3-, Ca2+/calmodulin-, and PKC-dependent manner. Am J Physiol Gastrointest Liver Physiol 291:G650-G657

5. Besson P, Fernandez-Rachubinski F, Yang W, Fliegel L (1998) Regulation of $\mathrm{Na}+/ \mathrm{H}+$ exchanger gene expression: mitogenic stimulation increases NHE1 promoter activity. Am J Physiol 274: C831-C839

6. Bhowmick NA, Neilson EG, Moses HL (2004) Stromal fibroblasts in cancer initiation and progression. Nature 432:332-337

7. Cala PM, Anderson SE, Cragoe EJ (1988) Na/H exchangedependent cell volume and $\mathrm{pH}$ regulation and disturbances. Comp Biochem Physiol 90:551-555

8. Cardone RA, Casavola V, Reshkin SJ (2005) The role of disturbed $\mathrm{pH}$ dynamics and the $\mathrm{Na}+\mathrm{H}+$ exchanger in metastasis. Nat Rev Cancer 5:786-795

9. Chernyavsky AI, Arredondo J, Wess J, Karlsson E, Grando SA (2004) Novel signaling pathways mediating reciprocal control of keratinocyte migration and wound epithelialization through M3 and M4 muscarinic receptors. J Cell Biol 166:261-272

10. Chung MK, Kim HC (2002) Volume-activated chloride currents from human fibroblasts: blockade by nimodipine. Gen Physiol Biophys 21:85-101

11. Damkier HH, Aalkjaer A, Praetorius J (2010) Na+-dependent HCO3- import by the slc4a10 gene product involves Cl- export. J Biol Chem 285:26998-27007

12. Davies JE, Ng LL, Kofoed-Enevoldsen A, Li LK, Earle KA, Trevisan R, Viberti G (1992) Intracellular $\mathrm{pH}$ and $\mathrm{Na}+\mathrm{H}+$ antiport activity of cultured skin fibroblasts from diabetics. Kidney Int 42:1184-1190

13. De Wever O, Demetter P, Mareel M, Bracke M (2008) Stromal myofibroblasts are drivers of invasive cancer growth. Int J Cancer 123:2229-2238

14. Denker SP, Barber DL (2002) Cell migration requires both ion translocation and cytoskeletal anchoring by the $\mathrm{Na}-\mathrm{H}$ exchanger NHE1. J Cell Biol 159:1087-1096

15. Duquette RA, Wray S (2001) pH regulation and buffering power in gastric smooth muscle. Eur J Physiol 442:459-466

16. Gleeson D (1992) Acid-base transport systems in gastrointestinal epithelia. Gut 33:1134-1145

17. Goss GG, Woodside M, Wakabayashi S, Pouyssegur J, Waddell T, Downey GP, Grinstein S (1994) ATP dependence of NHE-1, the ubiquitous isoform of the $\mathrm{Na}+/ \mathrm{H}+$ antiporter. Analysis of phosphorylation and subcellular localization. J Biol Chem 269:8741-8748

18. Grando SA, Crosby AM, Zelickson BD, Dahl MW (1999) Agarose gel keratinocyte outgrowth system as a model of skin re-epithelization: requirement of endogenous acetylcholine for outgrowth initiation. J Invest Dermatol 101:804-810

19. Grotendorst GR, Rahmanie H, Duncan MR (2004) Combinatorial signaling pathways determine fibroblast proliferation and myofibroblast differentiation. FASEB 18:469-479

20. Harguindey S, Orive G, Pedraz JL, Paradiso A, Reshkin SJ (2005) The role of $\mathrm{pH}$ dynamics and the $\mathrm{Na}+/ \mathrm{H}+$ antiporter in the etiopathogenesis and treatment of cancer. Two faces of the same coin-one single nature. Biochim Biophys Acta 1756:1-24

21. Hayashi H, Aharonovitz O, Alexander RT, Touret N, Furuya W, Orlowski J, Grinstein S (2008) $\mathrm{Na}+/ \mathrm{H}+$ exchange and $\mathrm{pH}$ regulation in the control of neutrophil hemokinesis and chemotaxis. Am J Physiol Cell Physiol 294:C526-C534

22. Hegyi P, Rakonczay Z, Gray MA, Argent BE (2004) Measurement of intracellular $\mathrm{pH}$ in pancreatic duct cells: a new method for calibrating the fluorescence data. Pancreas 28:427-434

23. Hinz B (2010) The myofibroblast: paradigm for a mechanically active cell. J Biom 43:146-155

24. Hinz B, Phan SH, Thannickal VJ, Galli A, Bochaton-Piallat M-L, Gabbiani G (2007) The myofibroblast: one function, multiple origins. Am J Pathol 170:1807-1816

25. Iida M, Nakamura N, Kamouchi M, Kitazono K, Kuroda J, Matsuo R, Hagiwara N, Ishikawa E, Ooboshi H, Ibayashi S (2008) Role of NHE1 in calcium signaling and cell proliferation in human CNS pericytes. Am J Physiol Heart Circ Physiol 294: H1700-H1707

26. Kapus A, Grinstein S, Wasan S, Kandasamy R, Orlowski J (1994) Functional characterization of three isoforms of the $\mathrm{Na}+/ \mathrm{H}+$ exchanger stably expressed in Chinese hamster ovary cells. ATP dependence, osmotic sensitivity, and role in cell proliferation. J Biol Chem 269:23544-23552

27. Koliakos G, Paletas K, Kaloyianni M (2008) NHE-1: a molecular target for signalling and cell matrix interactions. Connect Tissue Res 49:157-161

28. L'Allemain G, Paris S, Pouysségur J (1984) Growth factor action and intracellular $\mathrm{pH}$ regulation in fibroblasts. Evidence for a major role of the $\mathrm{Na}+/ \mathrm{H}+$ antiport. J Biol Chem 259:5809-5815

29. L'Allemain G, Paris S, Pouysségur J (1985) Role of a Na+-dependent $\mathrm{Cl}-\mathrm{HCO} 3$ - exchange in regulation of intracellular $\mathrm{pH}$ in fibroblasts. $\mathrm{J}$ Biol Chem 260:4877-4883

30. Lagana A, Vadnais J, Le PU, Nguyen TN, Laprade R, Nabi IR, Noël J (2000) Regulation of the formation of tumor cell pseudopodia by the $\mathrm{Na}(+) / \mathrm{H}(+)$ exchanger NHE1. J Cell Sci 113:3649-3662

31. LaPointe MS, Batlle DC (1994) $\mathrm{Na}+\mathrm{H}+$ exchange and vascular smooth muscle proliferation. Am J Med Sci 307:S9-S16

32. Lee SH, Kim T, Park E-S, Yang S, Jeong D, Choi Y, Rho J (2008) NHE10, an osteoclast-specific member of the $\mathrm{Na}+\mathrm{H}+$ exchanger family, regulates osteoclast differentiation and survival. Biochem Biophys Res Commun 369:320-326

33. Lehoux S, Ji A, Florian JA, Berk BC (2001) 14-3-3 Binding to $\mathrm{Na}+/ \mathrm{H}+$ exchanger isoform-1 is associated with serum-dependent activation of $\mathrm{Na}+/ \mathrm{H}+$ exchange. J Biol Chem 276:15794-15800

34. Luo J, Sun D (2007) Physiology and pathophysiology of $\mathrm{Na}(+) / \mathrm{H}(+)$ exchange isoform 1 in the central nervous system. Curr Neurovasc Res 4:205-215

35. Malo ME, Fliegel L (2006) Physiological role and regulation of the $\mathrm{Na}+/ \mathrm{H}+$ exchanger. Can J Physiol Pharmacol 84:1081-1095

36. McCaig C, Duval C, Hemers E, Steele I, Pritchard DM, Przemeck S, Dimaline R, Ahmed S, Bodger K, Kerrigan DD, Wang TC, Dockray GJ, Varro A (2006) The role of matrix metalloproteinase-7 
in redefining the gastric microenvironment in response to Helicobacter pylori. Gastroenterology 130:1754-1763

37. Meima ME, Webb BA, Witkowska HE, Barber DL (2009) The sodium-hydrogen exchanger NHE1 is an Akt substrate necessary for actin filament reorganization by growth factors. J Biol Chem 284:26666-26675

38. Metzger M, Just L, Boss A, Drews U (2005) Identification and functional characterization of the muscarinic receptor M3 in the human keratinocyte cell line HaCaT. Cells Tissues Organs 180:96-105

39. Moolenaar WH, Tsien RY, van der Saag PV, de Laat SW (1983) $\mathrm{Na}+/ \mathrm{H}+$ exchange and cytoplasmic $\mathrm{pH}$ in the action of growth factors in human fibroblasts. Nature 304:645-648

40. Moor AN, Fliegel L (1999) Protein kinase-mediated regulation of the $\mathrm{Na}(+) / \mathrm{H}(+)$ exchanger in the rat myocardium by mitogenactivated protein kinase-dependent pathways. J Biol Chem 274:22985-22992

41. Mutoh H, Sashikawa M, Hayakawa H, Sugano K (2010) Monocyte chemoattractant protein-1 is generated via TGF-beta by myofibroblasts in gastric intestinal metaplasia and carcinoma without H. pylori infection. Cancer Sci 101:1783-1789

42. Nakayama H, Enzan H, Miyazaki E, Toi M (2002) Alpha smooth muscle actin positive stromal cells in gastric carcinoma. J Clin Pathol 55:741-744

43. Noble A, Towne C, Chopin L, Leavesley D, Upton Z (2003) Insulin-like growth factor-II bound to vitronectin enhances MCF-7 breast cancer cell migration. Endocrinology 144:2417-2424

44. Orlowski J, Grinstein S (2004) Diversity of the mammalian sodium/ proton exchanger SLC9 gene family. Eur J Physiol 447:549-565

45. Pedersen SF (2006) The $\mathrm{Na}+\mathrm{H}+$ exchanger NHE1 in stressinduced signal transduction: implications for cell proliferation and cell death. Eur J Physiol 452:249-259

46. Perona R, Portillo F, Giraldez F, Serrano R (1990) Transformation and $\mathrm{pH}$ homeostasis of fibroblasts expressing yeast $\mathrm{H}(+)$-ATPase containing site-directed mutations. Mol Cell Biol 10:4110-4115

47. Radhakrishnan J, Kolarova JD, Ayoub IM, Gazmuri RJ (2011) AVE4454B-a novel sodium-hydrogen exchanger isoform-1 inhibitor-compared less effective than cariporide for resuscitation from cardiac arrest. J Lab Clin Med 157:71-80

48. Rentsch ML, Ossum CG, Hoffmann EK, Pedersen SF (2007) Roles of $\mathrm{Na}+/ \mathrm{H}+$ exchange in regulation of $\mathrm{p} 38$ mitogen-activated protein kinase activity and cell death after chemical anoxia in NIH3T3 fibroblasts. Eur J Physiol 454:649-662

49. Ritter M, Fuerst J, Wöll E, Chwatal S, Gschwentner M, Lang F, Deetjen P, Paulmichl M (2001) $\mathrm{Na}(+) / \mathrm{H}(+)$ exchangers: linking osmotic dysequilibrium to modified cell function. Cell Physiol Biochem 11:1-18

50. Salic A, Mitchison TJ (2008) A chemical method for fast and sensitive detection of DNA synthesis in vivo. Proc Natl Acad Sci 105:2415-2420

51. Sardet C, Fafournoux P, Pouysségur J (1991) Alpha-thrombin, epidermal growth factor, and okadaic acid activate the $\mathrm{Na}+\mathrm{H}+$ exchanger, NHE-1, by phosphorylating a set of common sites. J Biol Chem 266:19166-19171

52. Schmid C (1995) Insulin-like growth factors. Cell Biol Int 19:445-457

53. Schneider L, Stock C-M, Dieterich P, Jensen BH, Pedersen LB, Satir P, Schwab A, Christensen ST, Pedersen SF (2009) The Na+/H+ exchanger NHE1 is required for directional migration stimulated via PDGFR-alpha in the primary cilium. J Cell Biol 185:163-176

54. Slepkov ER, Rainey JK, Sykes BD, Fliegel L (2007) Structural and functional analysis of the $\mathrm{Na}+/ \mathrm{H}+$ exchanger. Biochem $\mathrm{J}$ 401:623-633
55. Stock C, Gassner B, Hauck CR, Arnold H, Mally S, Eble JA, Dieterich P, Schwab A (2005) Migration of human melanoma cells depends on extracellular $\mathrm{pH}$ and $\mathrm{Na}+/ \mathrm{H}+$ exchange. $\mathrm{J}$ Physiol 567:225-238

56. Takahashi E, Abe J, Gallis B, Aebersold R, Spring DJ, Krebs EG, Berk BC (1990) p90(RSK) is a serum-stimulated $\mathrm{Na}+\mathrm{H}+$ exchanger isoform-1 kinase. Regulatory phosphorylation of serine 703 of $\mathrm{Na}+/ \mathrm{H}+$ exchanger isoform-1. J Biol Chem 274:2020620214

57. Taves J, Rastedt D, Canine J, Mork D, Wallert MA, Provost JJ (2008) Sodium hydrogen exchanger and phospholipase D are required for alpha1-adrenergic receptor stimulation of metalloproteinase-9 and cellular invasion in CCL39 fibroblasts. Arch Biochem Biophys 477:60-66

58. Thomas JA, Buchsbaum RN, Zimniak A, Racker E (1979) Intracellular $\mathrm{pH}$ measurements in Ehrlich ascites tumor cells utilizing spectroscopic probes generated in situ. Biochemistry 18:2210-2218

59. Tóth-Molnár E, Venglovecz V, Ózsvári B, Rakonczay Z, Varró A, Papp JG, Tóth A, Lonovics J, Takács T, Ignáth I, Iványi B, Hegyi P (2007) New experimental method to study acid/base transporters and their regulation in lacrimal gland ductal epithelia. Investig Ophthalmol Vis Sci 48:3746-3755

60. Vereninov AA, Vassilieva IO, Yurinskaya VE, Matveev VV, Glushankova LN, Lang F, Matskevitch JA (2001) Differential transcription of ion transporters, NHE1, ATP1B1, NKCC1 in human peripheral blood lymphocytes activated to proliferation. Int J Exp Cell Physiol Biochem Pharmacol 11:19-26

61. Watanabe M, Hirano T, Asano G (1995) Roles of myofibroblasts in the stroma of human gastric carcinoma. Nippon Geka Gakkai Zasshi 96:10-18

62. Weintraub WH, Machen TE (1989) $\mathrm{pH}$ regulation in hepatoma cells: roles for $\mathrm{Na}-\mathrm{H}$ exchange, $\mathrm{Cl}-\mathrm{HCO} 3$ exchange, and $\mathrm{Na}-\mathrm{HCO} 3$ cotransport. Am J Physiol 257:G317-G327

63. Wessler I, Kirkpatrick CJ (2008) Acetylcholine beyond neurons: the non-neuronal cholinergic system in humans. Br J Pharmacol 154:1558-1571

64. Wray S (1988) Smooth muscle intracellular pH: measurement, regulation, and function. Am J Physiol Cell Physiol 254: C213-C225

65. Wu S, Song T, Zhou S, Liu Y, Chen G, Huang N, Liu L (2008) Involvement of $\mathrm{Na}+/ \mathrm{H}+$ exchanger 1 in advanced glycation end products-induced proliferation of vascular smooth muscle cell. Biochem Biophys Res Commun 375:384-389

66. Yamasaki T, Takahashi A, Pan J, Yamaguchi N, Yokoyama KK (2009) Phosphorylation of activation transcription factor-2 at serine 121 by protein kinase $\mathrm{C}$ controls c-Jun-mediated activation of transcription. J Biol Chem 284:8567-8581

67. Yang X, Wang D, Dong W, Song Z, Dou K (2011) Suppression of $\mathrm{Na}(+) / \mathrm{H}(+)$ exchanger 1 by RNA interference or amiloride inhibits human hepatoma cell line SMMC-7721 cell invasion. Med Oncol 28:385-390

68. Yap TA, Garrett MD, Walton MI, Raynaud F, de Bono JS, Workman P (2008) Targeting the PI3K-AKT-mTOR pathway: progress, pitfalls, and promises. Curr Opin Pharmacol 8:393412

69. Yeruva S, Farkas K, Hubricht J, Rode K, Riederer B, Bachmann O, Cinar A, Rakonczay Z, Molnár T, Nagy F, Wedemayer J, Manns M, Raddatz D, Musch MW, Chang EB, Hegyi P, Seidler U (2010) Preserved $\mathrm{Na}(+) / \mathrm{H}(+)$ exchanger isoform 3 expression and localization, but decreased NHE3 function indicate regulatory sodium transport defect in ulcerative colitis. Inflamm Bow Dis 16:1149-1161 


\section{A humán kationos tripszinogén és mutációinak szerepe pancreatitisben}

\section{Tézis kivonat}

\section{BEVEZETÉS}

A pancreatitis a hasnyálmirigy gyulladásos megbetegedése, kialakulásának hátterében a pancreasban kórosan megnövekedett tripszinaktivitása áll. A korai tripszin aktiválódás ellen többek között a pancreas vezeték sejtek által termelt, bikarbonátban gazdag, alkalikus folyadék folyamatos szekréciója véd. A folyadék folyamatos termelése biztosítja a zimogének vékonybélbe jutását. A szekréció csökkenése az emésztőenzimek kijutási időtartamának megnövekedése mellett az intraduktális $\mathrm{pH}$ savanyodását eredményezi. Ez felveti annak lehetőségét, hogy az intraduktális pH csökkenése szerepet játszik a betegség kialakulásában.

A hasnyálmirigy-gyulladás örökletes formája a herediter pancreatitis, dominánsan öröklődő autoszomális betegség, hátterében a legtöbb esetben a kationos tripszinogént kódoló szerin proteáz 1 (PRSS1) gén pontmutációi állnak. Az a felismerés, hogy a PRSS1 mutációk betegséget okoznak, igazolta a tripszin pancreatitisben betöltött kulcsfontosságú szerepét. A betegekben előforduló gyakoribb PRSS1 mutációk (p.R122H, p.N29I) megváltoztatják a fehérje biokémiai tulajdonságait oly módon, hogy fokozzák a spontán tripszin képződést (autoaktivációt). Mindezt az autoaktiváció és lebontás kimotipszin C (CTRC) általi szabályozásának a megváltoztatása révén érik el. A mutáció a tripszinogén fehérje hibás feltekeredését és emiatt a sejtből történő csökkent szekrécióját is okozhatja. A hibás feltekeredésből fakadó endoplazmatikus retikulum (ER) stressz a tripszin aktivitástól független mechanizmussal okozhat betegséget. A betegséget okozó PRSS1 mutációk mellett számos ritkábban előforduló pontmutációt is leírtak idiopátiás pancreatitises betegekben. Ezen ritka mutációk szerepe a betegség kialakulásában nem bizonyított, de sok szerző szerint feltételezhető a betegséget okozó mutációk analógiájára. 


\section{CÉLKITÜZÉSEK}

Kísérleteinkben célul tüztük ki a pH változás hatásának vizsgálatát a kationos tripszinogén autoaktivációjára. Célunk volt továbbá idiopátiás sporadikus pancreatitises betegekben talált 13 ritka tripszinogén variáns biokémiai jellemzése és sejtes szekréciójának vizsgálata, illetve a variánsok betegség okozó szerepének megállapítása a kapott eredmények alapján.

\section{ANYAGOK ÉS MÓDSZEREK}

\section{PRSS1 génvariánsok elkészítése}

A humán PRSS1 és CTRC kódoló DNS-ét tartalmazó pcDNA3.1(-) eukarióta és pTrapT7 prokarióta expressziós plazmidok a laboratóriumban rendelkezésre álltak. APRSS1 génvariánsokat PCR-mutagenezissel állítottuk elő. A mutagenezis sikerességét minden esetben DNSszekvenálással ellenőriztük.

\section{Az emésztő proenzimek termelése és tiszítása}

A vad típusú és mutáns humán kationos tripszinogén fehérjét aminopeptidáz P-hiányos $E$. coli törzsben (LG-3) termeltettük. A zárványtestekben felhalmozódott fehérjét ultrahang kezelés segítségével izoláltuk, melyet in vitro renaturálás követett. CTRC előállítása humán embrionális vese sejtek (HEK 293T) tranziens transzfekciója segítségével történt.

A vad típusú és mutáns tripszinogéneket ekotin- míg a CTRC-t nikkel affinitás kromatográfia segítségével tisztítottuk meg. A fehérje preparátumok koncentrációit a $280 \mathrm{~nm}$-en mért fényelnyelésből számítottuk ki a fehérje moláris extinkciós koefficiensének felhasználásával.

\section{A proteázok aktivitásának meghatározása}

$\mathrm{Az}$ enzimaktivitást szintetikus peptid szubsztráton mértük. A proteolitikus hasítás eredményeképpen sárga p-nitroanilin keletkezett, amelynek felszaporodását spektrofotométer segítségével követtük. 


\section{A tripszinogén variánsoksejtes szekréciójának vizsgálata}

A szekréciós kísérletekhez HEK293T sejtvonalat használtunk. A sejtek transzfekciója után 48 órával vizsgáltuk a tápfolyadékba kiválasztott tripszinogén mennyiségét. A termelt fehérje mennyiség megállapításához enzim aktivitás mérést, poliakrilamid-gélelektroforézist, valamint Western blot technikákat alkalmaztunk.

\section{EREDMÉNYEK}

\section{Vizsgáltuk a humán kationos tripszinogén autoaktivációjának pH-függését}

1. Kimutattuk, hogy a pH 8,5-ről 7-re csökkenésével a humán kationos tripszinogén autoaktivációjának sebessége fokozódik, azonban a pH további csökkenésével (7-röl 6-ra) csak kis eltérés volt megfigyelhetö.

\section{Funkcionálisan jellemeztünk idiopátiás pancreatitises betegben talált 13 humán kationos tripszin variánst}

1. A 13 mutációból csak 1 (p.D100H) variáns mutatott fokozott autoaktivációt, amely hasonlított a betegséget okozó mutációk fenotípusához. Ezt a variáns azonban csökkent szekréció is jellemezte, így a növekedett intrapancreatikus tripszin aktivitás nem valószínüsíthető.

2. Érdekes módon, öt tripszinogén mutáns (p.P36R, p.G83E,p.I88N, p.V123M) kimotripszin $\mathrm{C}$ általi gyorsabb lebomlást tanúsított, ami ellentétben áll a patogén mutációk fenotipusával.

3. A szekréciós vizsgálatok azt mutatták, hogy két variánsnak a kiválasztása (p.I88N, p.K170E) növekedett, ezzel szemben ötnek nagyobb (p.D100H, p.C139F), illetve kisebb (p.K92N, p.S124F, p.G208A) mértékben csökkent a vad típushoz képest. Mivel a p.I88N variáns lebomlása fokozott volt, az emelkedett tripszin aktivitás ebben az esetben sem valószínü.

4. Három mutáns (p.Q98K, p.T137M, p.S181G), nem mutatott eltérést a vad típushoz képest. 


\section{KÖVETKEZTETÉSEK}

Munkánk során kimutattuk, hogy a humán kationos tripszinogén autoaktivációja $\mathrm{pH}$ függő, a pH savanyodásával az autoaktiváció sebessége fokozódik. Ez arra enged következtetni, hogy a csökkent folyadék szekrécióval járó intraduktális pH esése elősegíti a korai tripszin aktivációt és ezáltal hozzájárul a pancreatitis kialakulásához.

A sporadikus krónikus pancreatitises betegekben talált ritka PRSS1 variánsok nem mutatták a klasszikus betegséget okozó fenotípust, viszont a gyors degradáció, illetve csökkent szekréció gyakran megfigyelhető volt. A szekréciós defektussal rendelkező variánsok (p.D100H, p.C139F) patogenitása a következményes ER stressz miatt, a fokozott szekréciót mutató variánsé (p.K170E) pedig az emelkedett tripszinaktivitás miatt valószínűsíthető. 